Multi-stakeholder promotion of civic participation: assessing the Open Government Partnership's influence on national policy

Christopher Wilson

Doctoral Thesis submitted for the degree of PhD

Department of Media and Communication,

Faculty of Humanities, University of Oslo

March, 2019 


\section{Summary}

Global multi-stakeholder initiatives (MSIs) leverage collaboration between government and civil society to improve public sector governance in participating countries. Noting the prominence of public governance MSIs in international policy discourse, and the lack of longterm data against which to assess their impact, this doctoral research proposes three alternative strategies for evaluating their effectiveness and influence. Defining the causal mechanisms through which MSIs aim to influence national policy allows testing of effectiveness prior to long-term outcomes. Measuring effects in adjacent policy areas allows for a more nuanced assessment of MSIs' institutional influence. Lastly, more rigorous quality metrics can be applied to the norms promoted by MSIs, in order to evaluate their potential impact.

These strategies are applied in multi-method analysis of the Open Government Partnership's (OGP) promotion of civic participation to member countries. Causal mechanisms related to argumentation and policy learning are demonstrated to drive OGP's policy influence, and OGP is found to have a modest institutional effect on countries' public governance outside of OGP-specific policy fora, including the informal institutionalization of policy. OGP's effect is most pronounced in countries that already enjoy strong traditions for civic participation, and in regard to more progressive norms related to collaborative decision-making. The application of quality metrics suggests, however, that if adopted, the norms and policies promoted in an OGP context are not likely to contribute to the OGP's end goal of more responsive and accountable governance.

This analysis validates the three evaluation strategies proposed above and adds nuance to current discourse on MSI effectiveness. After presenting the full scope of research, this cover chapter closes with implications for MSI advocacy strategies and theories of global norm promotion. 


\section{Prefatory note}

This dissertation follows the Norwegian standard format for article-based doctoral theses. As noted by the University of Oslo, Faculty of Humanities:

The thesis can consist of one continuous work or several smaller works. A thesis based on several smaller works shall normally consist of at least 3 works, as well as a summary/introductory article.

(https://www.hf.uio.no/english/research/phd/thesis-evaluation/guidelines/article-based-theses.html)

This dissertation is based on four articles that have been submitted or published in peerreviewed journals. It is structured according the University guidelines for article-based theses, and consists of two parts:

- Part I consists of a cover chapter, describing the full breadth of the research, and presenting holistic analysis, including a summary presentation of each journal article.

- Part II consists of the four articles on which this dissertation is based, presented in full. 


\section{Acknowledgements}

Dissertations are hard and there's lots of people to thank. Let's start with the academics.

$\varnothing$ yvind Ihlen asked all the hard questions, over and over and over, forcing me to internalize the annoying rigor that defines good academic work, instead of simply talking about it. Dan Honig does a great job of demonstrating how academic work can make the world a better place, and how to manage institutions to make it so. Mary Francoli and Jonathan Fox provided critical comments and insights early and late in the game. Danny Lämmerhirt and Iris Beau Segers saved the day with reliability testing.

Thanks too to the Beeck Center and Office of the Provost at Georgetown University, for giving me an institutional home for the two years I was in DC. Thanks especially to Sonal Shah for helping me to distinguish between what's feasible and what's meaningful when researching American politics, even though that work it never made it into this dissertation.

This research would not have been possible without the interest and practical support of the OGP. Thanks to the OGP Support Unit and IRM for letting me peak so often beneath the hood. Thanks especially to Abhinav Bahl and Joe Foti for regularly sensechecking my ramblings, speculations, and findings.

Most importantly, thanks to Holly and Mathea for consistently forcing fun, and for pretending that my descriptions of this dissertation were interesting and comprehensible. Thanks to Moksie for not biting me during my final writing sprint. 


\section{Contents}

SUMMARY II

PREFATORY NOTE III

ACKNOWLEDGEMENTS

CONTENTS

LIST OF TABLES AND FIGURES IN THE COVER CHAPTER VII

PART I: COVER CHAPTER 1

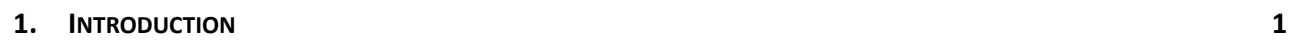

1.1. The RISE OF MULTI-STAKEhOlder INITIATIVES 2

1.1.1. Three Alternative Strategies FOR ASSESSing MSI EFFECTIVENESS AND INFLUENCE 6

1.2. The OPEN GOVERNMENT PARTNERSHIP AND CIVIC PARTICIPATION 9

1.2.1. VARIETIES OF PARTICIPATION
15

1.2.2. ASSESSING THE QUALITY OF CIVIC PARTICIPATION

1.2.3. OPEN GOVERNMENT AND CIVIC PARTICIPATION IN THE CONTEXT OF DIGITAL MEDIA 20

1.2.4. RECONSIDERING OGP'S INFLUENCE AND EFFECTIVENESS IN THE PROMOTION OF CIVIC PARTICIPATION 27

$\begin{array}{lll}\text { 1.3. RESEARCH QUESTIONS } & 31\end{array}$

2. THEORY $\lcm{34}$

2.1. THEORIES OF NORM PROMOTION AND POLICY ADOPTION

2.1.1. THEORETICAL TRADITIONS FROM INTERNATIONAL RELATIONS AND POLICY STUDIES 35

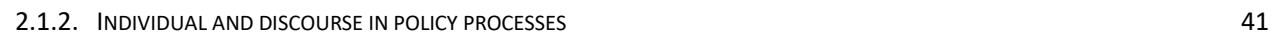

2.1.3. INSTITUTIONALIZATION AND POLICY OUTCOMES

2.2. CAUSAL INTERACTION, OGP, AND E-PARTICIPATION 48

2.3. THE CONTRIBUTIONS OF CIVIC PARTICIPATION TO RESPONSIVE AND ACCOUNTABLE GOVERNMENT 52

2.4. NORMATIVITY, PARTICIPATION, AND TECHNOLOGY 57

3. MethOdS $\quad 59$

$\begin{array}{lr}\text { 3.1. MULTI METHODS RESEARCH DESIGN } & 59\end{array}$

$\begin{array}{ll}\text { 3.2. COMPARATIVE ANALYSIS } & 61\end{array}$

3.3. WITHIN-CASE PROCESS TRACING $\quad 62$

3.4. CASE SELECTION, THEORETICAL DEVELOPMENT, AND EXTERNAL VALIDITY 68 
4.1. MULTI-STAKEHOLDER INITIATIVES, POLICY LEARNING AND INSTITUTIONALIZATION: THE SURPRISING FAILURE OF OPEN GOVERNMENT IN NORWAY

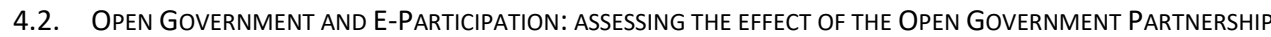
AND NATIONAL POLITICAL FACTORS

4.3. DIGITAL CIVIC INTERACTION: IDENTIFYING, CONCEPTUALIZING AND COMPARING INTERACTIONS BETWEEN GOVERNMENTS AND PUBLICS

4.4. LOOK WHO'S TALKING: ASSESSING CIVIC VOICE AND INTERACTION IN OGP COMMITMENTS 79

5. DISCUSSION AND CONCLUSIONS

5.1. MULTI-STAKEHOLDER MECHANISMS OF INFLUENCE

5.2. ATTRIBUTING THE DIFFUSION OF CIVIC PARTICIPATION NORMS TO OGP 88

5.3. THE QUALITY OF OGP'S CONTRIBUTIONS TO CIVIC PARTICIPATION 92

5.3.1. NORMS PROMOTED $\quad 94$

5.3.2. INTERMEDIATE OUTPUTS 95

5.3.3. POLICY ADOPTION AND INSTITUTIONALIZATION 96

6. CONTRIBUTIONS, LIMITATIONS, AND OPPORTUNITIES FOR FURTHER RESEARCH 98

6.1. THEORETICAL CONTRIBUTIONS 98

$\begin{array}{ll}\text { 6.2. Policy ReleVANCE } & 103\end{array}$

6.1. LIMITATIONS AND AVENUES FOR FURTHER RESEARCH 106

7. Reference list 111

PART II: ARTICLES

ARTICLE 1:

MULTI-STAKEHOLDER POLICY LEARNING AND INSTITUTIONALIZATION: THE SURPRISING FAILURE OF OPEN

$\begin{array}{ll}\text { GOVERNMENT IN NORWAY } & 140\end{array}$

ARTICLE 2:

Open Government AND E-Participation: Assessing the effect of the Open Government PaRTNership ANd NATIONAL POLITICAL FACTORS

ARTICle 3:

DIGITAL CIVIC INTERACTION: IDENTIFYING, CONCEPTUALIZING AND COMPARING INTERACTIONS BETWEEN GOVERNMENTS AND PUBLICS

ARTICLE 4:

LOOK WHo's TALKING: AsSESSING CIVIC VoICE AND INTERACTION IN OGP COMMITMENTS 


\section{List of tables and figures in the cover chapter}

FIGURE 1: BASIC RESULTS CHAIN FOR MSI EFFECTIVENESS AND IMPACT 6

TABLE 1: OFFICIAL PROMOTION OF CIVIC PARTICIPATION NORMS BY OGP, 2011-2018 12

Figure 2: LEVELS IN THE IAP2 SPECTRUM OF PARTICIPATION 18

FIGURE 3: OGP'S RESULTS CHAIN

FIGURE 4: NORMS SOCIALIZATION IN A HUMAN RIGHTS CONTEXT

FIGURE 5: SEQUENCE AND INDEPENDENCE OF CAUSAL MECHANISMS IN THE CONTEXT OF MSIS

TABLE 2: DOCUMENTS AND EVIDENTIARY SOURCES APPLIED TO WITHIN-CASE ANALYSIS

TABLE 3: OVERVIEW OF ARTICLES

FIGURE 6: A FULL THREE-LEVEL MODEL FOR DIGITAL CIVIC INTERACTION

FIGURE 7: ANALYTICAL FRAMEWORK FOR KNOWLEDGE TRANSFER AND POLICY LEARNING 83

TABLE 4: CHANGE IN COUNTRIES' E-PARTICIPATION SCORES FOLLOWING OGP MEMBERSHIP 89 


\section{PART I: Cover Chapter}

\section{Introduction}

Multi-Stakeholder Initiatives (MSIs) are private governance arrangements that combine global policy platforms with national coordination process and arenas for debate, in which representatives of government, civil society, and the private sector collaborate to address policy challenges in participating countries. Global MSIs have become increasingly common in the last two decades (Stern, Kingston, \& Ke, 2015), but enthusiasm in global policy discourse is matched by significant criticism from participants (Asbed, Gordon, \& Hubbell, 2005; Hintz \& Milan, 2014; Miller-Dawkins, 2014), and there is currently no clear evidence that MSIs designed to improve the quality of public governance in participating countries are achieving their objectives (Brockmyer \& Fox, 2015). The Open Government Partnership (OGP) is a prominent example of a public governance MSI, designed to encourage more responsive and accountable government in participating countries. This dissertation examines OGP's influence on civic participation policy, in order to validate three strategies for assessing MSI effectiveness. It is supported by four peer reviewed journal articles, described holistically in this cover chapter.

The cover chapter proceeds as follows. This introduction describes the context and rational for the research, beginning with a description of MSIs and by proposing three alternative strategies for assessing the influence of public governance MSIs on national policy. After describing the rationale for validating these strategies through research on the OGP and civic participation, the remainder of this introduction presents background and previous research on OGP and civic participation. The introduction closes by drawing connections between the three alternative strategies for assessing MSI influence and this dissertation's three research questions.

Following this introduction, section two describes theory applied across the dissertation, with special emphasis on theories of how national governments engage with global norms and the role of individual civil servants and policy makers in facilitating or blocking the policy influence of public governance MSIs. A third section describes the methods employed in various analyses, beginning with a description of the dissertation's over-arching multi-methods research design. After discussing the methods applied to 
comparative and within-case analyses respectively, this section finishes with a close description of case selection methods and their implications for external validity and theory building.

Section four presents an overview and publication status of the four peer reviewed articles through which this research is pursued. Each article is summarized, outlining research objectives, methods, findings, and implications for the dissertation's three research questions. Section five presents and discusses findings related to each of the three research questions presented above, drawing holistic conclusions and suggesting implications. The sixth and final section describes how these findings contribute to developing theory and practice regarding the MSIs' influence on national policy, noting limitations and suggesting avenues for further research. Following a bibliography of works cited in this dissertation's cover chapter, copies of each of the four articles are attached as appendices.

\subsection{The rise of Multi-Stakeholder Initiatives}

Global Multi-Stakeholder Initiatives (MSIs) distinguish themselves from traditional governance partnerships by their emphasis on "discourse, networks and adaptive and flexible decision-making," which balances multiple interests and perspectives in order to leverage "soft power" to achieve policy objectives (Bezanson \& Isenman, 2012, p. 2). The proliferation of MSIs on the global stage has been dramatic, and Stern et al.'s (2015) noncomprehensive review cites a "fourfold increase in these types of efforts between 2000 and 2015 alone" (p. 3). This is most prominent in transnational policy areas such as environmental conservation, labor standards in global supply chains, and global internet governance, where a significant body of research has addressed the implications that MSIs have for the delegation of authority (Institute for Human Rights and Business, 2017; Mena \& Palazzo, 2012), legitimacy (Bäckstrand, 2006; Mena \& Palazzo, 2012; Moog, Spicer, \& Böhm, 2015), and rule setting by non-state actors (Fransen \& Kolk, 2007; Pieth, 2006).

The multi-stakeholder approach has also been significantly leveraged to address policy challenges within national jurisdictions, where MSIs combine global platforms for articulating norms and policies, with national platforms for coordinating their adoption and implementation (Bezanson \& Isenman, 2012, pp. 1-4). Initiatives such as the Open Government Partnership (OGP), the Extractive Industries Transparency Initiative (EITI), the Global Initiative on Fiscal Transparency (GIFT), and the Open Contracting Partnership (OCP), 
for example, aim to improve the quality of public governance within participating countries. Described in Brockmyer \& Fox's (2015) evidence review as "public governance MSIs," these initiatives operate differently than "private sector MSIs, which attempt to supplement weak government capacity to enforce basic social and environmental standards through partnerships between businesses and civil society," most notably through their "focus on information disclosure and participation in the public sector" (p. 7).

Although the details of their organization and activities can differ significantly, public governance MSIs are generally structured around a global policy platform, which is used to simultaneously recruit country members and to promote norms, policies, and standards related to information disclosure and participation in the public sphere. As countries join public governance MSIs, these norms and policies are intended to guide members' implementation and inspire national reforms. Globally, there is broad support for these efforts, but it is not clear the degree to which they have been successful in influencing public governance within member countries, nor the precise ways in which they hope to do so.

Indeed, research on public governance MSIs has not enjoyed the academic attention paid to transnational and private sector MSIs, and has been dominated by evaluations commissioned by, or produced in partnership with practitioner or funder organizations. Brockmyer \& Fox's (2015) report for the Transparency and Accountability Initiative on the evidence base for four prominent public governance MSIs is exemplative, as is Gruzd et al.'s (2018) series of reports for USAID on public governance MSIs in Africa, the University of Washington's Task Force report on MSI standards for financial transparency (Jackson School Task Force, 2012) and the MSI Integrity report on governance structures in the Extractive Industries Transparency Initiative (MSI Integrity, 2015).

These assessments do not explicitly theorize the ways in which public governance MSIs seek to achieve their goals, nor do the initiatives necessarily do so themselves. In tracking the strategies through which public governance MSIs expect "to move through the results chain from inputs, to outputs, to medium and long- term outcomes," Brockmyer \& Fox $(2015$, p. 18) note in fact that some initiatives "remain agnostic about how their efforts might play out on the ground" (p. 19). These initiatives are nonetheless marked by a shared expectation that multi-stakeholder dialogues and communication processes across national and international for a will enable governance reforms (pp. 18, 24, 31, 35, 41). 
In some MSI contexts, these interactions are described as a process through which "organizations put pressure on the government to improve its performance" or "create the outside pressure necessary to push governments toward greater transparency" (Brockmyer \& Fox, 2015, pp. 53, 35). This aligns with the suggestion by while Gruzd et al. (2018) that public governance MSIs have in some countries increased "the avenues, opportunities, and entry points available for citizens to express their voice and influence political processes and outcomes," enabling the successful promotion of policy reforms (p. 2). Descriptions of persuasion and political pressure recall theories of human rights norm promotion and contestation, which rely on mechanisms of contestation and coercion (Finnemore \& Sikkink, 1998; Risse-Kappen \& Sikkink, 1999). This body of scholarship has proven influential, and its theoretical tenets have been applied to a variety of recent advocacy contexts (Acharya, 2004; Ben-Josef Hirsch, 2014; Zimmermann, 2016), but not explicitly to the context of public governance MSIs.

Some MSI theories of change anticipate less confrontational dynamics. A representative of the Construction Sector Transparency Initiative suggests that "perhaps the most important role of the [multi-stakeholder group] is to use 'gentle persuasion' to encourage the government to disclose information," while the Global Initiative on Fiscal Transparency would appear to prioritize coordination over formal rules for participation, and relies on "moral suasion" to influence national policy makers (Brockmyer \& Fox, 2015, pp. $31,41)$. This emphasis on social information sharing and interaction has been echoed in other contexts. Brockmyer \& Fox suggest that global governance theorists would expect MSIs to achieve their goals through information sharing, accessing expertise and building consensus (p. 11), while Honig \& Weaver (2018) find that the Aid Transparency Index shapes government behavior "primarily via the diffusion of professional norms, organizational learning, and peer pressure" (p. 1) and the Open Government Partnership is described as a race to the top incentivized by peer pressure (Elgin-Cossart, Sutton, \& Sachs, 2016, p. 17). While research on international rankings and policy diffusion have explicitly theorized social dynamics of competition, emulation and learning between national governments (Jörgens, 2009; Meseguer, 2005; Towns \& Rumelili, 2017), these frameworks have not been applied to the context of public governance MSIs.

The correspondence of rhetoric surrounding public governance MSIs with theories of influence from international relations and policy studies suggests that social dynamics and 
information exchange between and within countries might drive the influence of public governance MSIs on national policy. This has not been tested, however. Though they have become a prominent vehicle for promoting global norms and policies to national governments, there has been no systematic research effort to assess the ways in which public governance MSIs actually influence national policy, or to theoretically ground popular theories of change that justify their work.

Nor do assessments of public governance MSIs find clear evidence that they are actually achieving such long-term impact (Aaronson, 2011; Brockmyer \& Fox, 2015; ElginCossart et al., 2016; Gruzd et al., 2018; Guerzovich \& Moses, 2016). This may be due to the relatively short amount of time that most public governance MSIs have been active (C. Corrigan, 2014; Elgin-Cossart et al., 2016; Gruzd et al., 2018; Haufler, 2010). As Brockmyer \& Fox (2015) note:

the evidence collected to date suggests that these initiatives are still operating within the early stages of their proposed results frameworks. While public governance MSIs have made some notable progress promoting information disclosure and participation, there is little evidence thus far that these reforms have been effective at improving government accountability or achieving broader social, economic, and/or environmental impacts (p. 7).

It should be noted that "impact" is in this sense understood as the final stage in a sequential and cumulative results chain, which begins with inputs to MSI implementation, then moves through MSI outputs, outcomes, and impacts, as portrayed in Figure 1. 
Figure 1: Basic results chain for MSI effectiveness and impact, adapted from (Brockmyer \& Fox, 2015, p. 18)

\begin{tabular}{|c|c|c|c|}
\hline A: Inputs & B: Outputs & C: Outcomes & D: Impacts \\
\hline $\begin{array}{l}\text { MSI legitimacy, } \\
\text { process and } \\
\text { structure. }\end{array}$ & $\begin{array}{l}\text { Measures of } \\
\text { institutional } \\
\text { effectiveness, } \\
\text { rules, } \\
\text { commitments } \\
\text { and activities } \\
\text { undertaken to } \\
\text { comply with MSI } \\
\text { membership. }\end{array}$ & $\begin{array}{l}\text { Changes to } \\
\text { government } \\
\text { policy or } \\
\text { practice, what } \\
\text { Brockmyer \& } \\
\text { Fox term } \\
\text { "effectiveness" } \\
\text { (2015, pp. 17- } \\
18) .\end{array}$ & $\begin{array}{l}\text { Changes in the } \\
\text { broader socio- } \\
\text { economic } \\
\text { issues targeted } \\
\text { by the MSI. }\end{array}$ \\
\hline
\end{tabular}

The results chain is cumulative in the sense that evaluations aim to attribute late stage results to results from previous stages in the chain. This has the effect of narrowing the scope of analysis to outputs and outcomes that are explicitly anticipated in earlier results stages. For example, if a MSI's primary issue focus fighting corruption in public service delivery, the decreased levels of corruption would only count as "impacts" in this results chain to the extent that they could be attributed to outcomes, such as changes to reporting regulations, in turn attributable to outputs, such as MSI commitments, and inputs, such as participation rules and coordination processes. If early stage results (such as the participation rules imposed by MSIs or the institutional process of participating in MSI fora) influence government policy or practice outside of MSI-specific policy processes, and contribute somehow to lowering levels of corruption in public service delivery, that would not be captured in this results chain.

\subsubsection{Three alternative strategies for assessing MSI effectiveness and influence} Accepting the claim that "it is simply too soon to expect meaningful evaluations of [MSI] effectiveness or impact" (Brockmyer \& Fox, 2015, p. 66), this dissertation seeks to assess the effectiveness and influence of public governance MSIs in the absence of such evidence, and proposes three strategies with which to do so.

Firstly, by elaborating and clarifying the causal mechanisms through which public governance MSIs influence national governments and contribute to long-term impacts, it is possible to determine whether those mechanisms are active in specific MSI processes, and 
by extension, whether public governance MSIs are "on track" to achieve their objectives. A casual mechanisms is here understood as "the pathway or process by which an effect is produced or a purpose is accomplished" (Gerring, 2008, p. 178), and is further defined in section 2.1 .

Secondly, MSIs operate within the context of a broad diffusion of public governance norms, which may be attributed to multiple of actors and influences. Expanding analysis beyond MS-specific policy fora and results chains can help to determine if public governance MSIs are influencing national policy beyond outcomes explicitly linked to MSI processes.

Lastly, assessing the democratic value of specific norms and policies promoted by public governance MSIs can indicate the likelihood that their adoption will contribute to long-term impacts in national public governance.

To test these strategies, this dissertation assesses how the Open Government Partnership (OGP) promotes norms of civic participation, and the influence that this has had on the policy and governance contexts of participating countries. While there are significant differences between public governance MSIs, the OGP is a useful research object for at least two reasons.

Firstly, OGP's prominence provides a wealth of data with which to test alternative assessment strategies. OGP's position in international policy discourse has been described as the culmination of more than twenty years of policy discourse regarding government technology and collaboration (Kassen, 2014), and the initiative has been quite successful in rebranding norms of democratic governance as open government (Lucke \& Große, 2014). The vigorous advocacy and policy discourse surrounding OGP has produced a wealth of reports, discussions, and advocacy materials produced by government and civil society organizations. This represents a rich data source for testing the influence and effectiveness of MSIs more generally.

Secondly, OGP's broad scope and highly voluntary nature provide a productive environment in which to assess MSI influence, absent the hard compliance systems associated with other models of public sector governance or global norm promotion. Unlike multilateral legal or quasi-legal regimes such as the EU or human rights treaty regimes, public governance MSIs rely entirely on the voluntary implementation of governments. For most public governance MSIs, this involves voluntary subscription to a set of shared 
standards against which country implementation of MSIs can be designed and evaluated. OGP takes this one step further by mandating national governments to determine the content of their national action plans and the substantive criteria against which their implementation will be evaluated (Brockmyer \& Fox, 2015, p. 34). In this sense, OGP exaggerates the defining quality of public governance MSIs. An emphasis on national processes through which norms of open government are debated and interpreted provide a rich data source for assessing the influence of MSI advocacy on national policy.

Selecting OGP as the research object for this dissertation also contributes to an emergent, but still modest body of research, despite the initiative's prominence and increased research attention to "open government" as a more general concept (Wirtz \& Birkmeyer, 2015; World Bank Group, 2016). As with public governance MSIs more generally, research on OGP is dominated by the so-called "grey literature" produced by think tanks or advocacy organizations, often coordinated or contracted by funder organizations ${ }^{1}$ or the OGP secretariat (Falla, 2018; Foti, 2014, 2016; Khan \& Foti, 2015; Whitt, 2015)² and the cohort of national researchers responsible for conducting the initiative's independent reviews of government implementation. ${ }^{3}$ Peer reviewed research on the initiative is less common, with the exception of a recent special issue (Francoli \& Höchtl, 2017), and is marked by an emphasis on national case studies across disparate journals and disciplines (Cañares, 2016; Faria \& Rehbein, 2016; Fraundorfer, 2017; Piotrowski, 2017), or analyses in which OGP is a peripheral focus (Davies \& Bawa, 2012; Gonzalez-Zapata \& Heeks, 2014; Luna-reyes \& Harrison, 2016; Peixoto, 2013; Sandoval-Almazan \& Gil-Garcia, 2015; Yu \& Robinson, 2012).

Lastly, it is worth noting the rationale for studying civic participation norms promoted in an OGP context. Civic participation occupies a privileged position in OGP's ethos, and is

\footnotetext{
${ }^{1}$ For example, note the Open Data Research Network and Symposium (http://opendataresearch.org/, accessed 14 November 2018), the Global Research Network on Opening Governance (https://www.macfound.org/networks/research-network-opening-governance/, accessed 14 November 2018), the Making All Voices Count research grants (http://www. makingallvoicescount.org/research/, accessed 14 November 2018), the Research Consortium on the Impact of Open Government (http://www.worldbank.org/en/topic/governance/brief/launch-of-research-consortium-on-the-impact-ofopen-government-processes, accessed 5 March 2019).

${ }^{2}$ See also OGP's Multi-donor Trust Fund research strategy (https://www.opengovpartnership.org/ogp-trustfund/research-on-impact-and-effectiveness-of-open-government, accessed 14 November 2018).

${ }^{3}$ See OGP's Independent Reporting Mechanism, https://www.opengovpartnership.org/about/independentreporting-mechanism, accessed 16 October 2018.
} 
uniquely prominent both in the initiative's architecture and implementation, as will be discussed in section 1.2.3. This emphasis may also be read in the initiative's vision statement, where civic participation features both a component of the initiative's end goal, and an instrument towards that end, through dialogue with civil society.

OGP's vision is that more governments become sustainably more transparent, more accountable, and more responsive to their own citizens, with the ultimate goal of improving the quality of public policies and services, as well as the level and scope of public participation. This will require a shift in norms and culture to ensure open and honest dialogue between governments and civil society (Open Government Partnership, 2014b, p. 8).

The centrality of civic participation in an OGP context is complemented by its centrality to other MSIs' theories of change (Brockmyer \& Fox, 2015, p. 7), and the prominence of participatory rhetoric in global policy discourse more generally (Nabatchi, Sancino, \& Sicilia, 2017). These factors provide a rich landscape from which to draw data on the promotion of civic participation norms, and strengthen OGP's position as a proxy for understanding the dynamics of MSI norm promotion more generally.

The remainder of this introduction describes those dynamics in greater detail, presenting background and prior research on the OGP and civic participation, before presenting three research questions, each of which is associated with one of the assessment strategies presented above.

\subsection{The Open Government Partnership and civic participation}

Launched by eight founding countries in 2011, the Open Government Partnership (OGP) is dedicated to helping governments "become sustainably more transparent, more accountable, and more responsive to their own citizens" (Open government Partnership, 2011). To do so it positions itself as "an international platform to connect, empower and encourage domestic reformers committed to transforming government and society through openness" (Open Government Partnership, 2014b, p. 8), and uses this platform to recruit member countries and secure high-level political commitment to open government values. These values include access to information, civic participation, public accountability, and technology and innovation for openness and accountability, and are articulated in the Open 
Declaration, which governments endorse upon joining the OGP (Open Government Partnership, 2011). These four "core values" form the basis of all OGP activities and implementation (Open Government Partnership, 2015b).

Upon joining the OGP, member countries also commit to a developing national action plans for open government in collaboration with national civil society organizations. This domestic policy process is intended to open up political space for national reformers, which can draw on the international legitimacy of the OGP in negotiating the content and scope of national action plans (Open Government Partnership, 2014b, p. 4). To support this process, the OGP secretariat conducts and facilitates a variety of global networking, knowledge production, and training activities, disseminating a variety of norms and policy examples, aligned with the four core values of open government, and intended to provide inspiration and guidance for the development of national action plans.

The OGP has developed significantly in the eight years since its founding. The initiative's secretariat has grown from a staff of three to over 60, and its membership from 8 to 70 governments, with increases in operating budget and international prominence to match (Open Government Partnership, 2016b). This growth has also been accompanied by institutional developments and changes to the ways in which OGP engages with member governments. There have been several revisions to the OGP's articles of governance, iterative developments in the procedures for providing country support, and multiple elaborations of the guidelines and methodologies for the OGP's Independent Reporting Mechanism (IRM), which coordinates national researchers responsible for conducting evaluations of OGP implementation in each country. These developments suggest an increasing institutionalization of interactions between the OGP secretariat and OGP members, with implications for how OGP is conceptualized and operationalized within government institutions.

A similar development can be traced in the OGP's promotion of civic participation. Though the OGP's constitutive Articles of Governance only loosely define civic participation as government efforts to "mobilize citizens" (Open Government Partnership, 2015b, p. 18), participation was firmly and deliberately embedded in the OGP's organizational architecture in hopes of facilitating meaningful implementation (Goldstein \& Weinstein, 2012). This is most widely commented in regard to the civil society's equal footing with government on 
OGP's executive steering committee, which has been credited with facilitating domestic engagement (T. Corrigan \& Gruzd, 2018, p. 3) and defining responses to instances of members "acting inconsistently with open government values" (Elgin-Cossart et al., 2016, p. 8).

OGP's operational understanding of civic participation has also developed significantly from the original articulation of policies and processes through which governments "mobilize citizens to engage in public debate, provide input, and make contributions that lead to more responsive, innovative and effective governance" (Open Government Partnership, 2015b, p. 18). In regard to the creation of national action plans, this development this can be read in the increasingly participatory rhetoric with which the OGP encourages governments to pursue "active engagement" (Open Government Partnership, 2014a), "collaboration" (Velasco-Sánchez, 2016), and "co-creation" (Open Government Partnership, 2017a), according to more elaborate and specific guidelines and recommended procedures. Simultaneously, there has been a proliferation of case studies, webinars and other communications promoting civic participation activities that might be included as government commitments in national action plans, such as participatory budgeting or citizen participation in legislative activities. The official communications through which OGP has promoted civic participation norms and policies to member countries between 2011 and 2018 is presented below, in Table $1 .^{4}$

\footnotetext{
${ }^{4}$ Overviews of materials and events referenced in Table 1 were accessed on 10 March 2019 at the following websites. OGP webinars: https://www.opengovpartnership.org/resources/ogp-webinars; OGP steering committee meetings (full steering committee meetings only):

https://www.opengovpartnership.org/about/ogp-steering-committee/meetings-minutes-and-communications; activities at the OGP Global Summits: https://drive.google.com/drive/folders/OB471ujVfgLNMTFZkbkFvUVFOcUk, https://ogpsummit2015.sched.com/, and https://ogpsummit2018.sched.com/ (website for Paris Summit no longer active, Summit schedule on file with author; OGP guidance notes:

https://www.opengovpartnership.org/resources/government-legislature. Documents detailing training materials and secretariat communications with national points of contact on file with author.
} 
TABLE 1: OFFICIAL PROMOTION OF CIVIC PARTICIPATION NORMS BY OGP, 2011-2018

\begin{tabular}{|c|c|}
\hline \multirow[t]{2}{*}{2011} & $\begin{array}{l}\text { Open Declaration asserts civic participation and tech for accountability as "core } \\
\text { principles." }\end{array}$ \\
\hline & $\begin{array}{l}\text { Power of Open event at OGP's formal launch includes a "How-to Alley" where } \\
\text { participants were encouraged to "circulate freely among different } 30-35 \text { stations" } \\
\text { where experts present case studies and best practices regarding "Expert } \\
\text { presentations on "10 key open government challenges," including: "open rule-making } \\
\text { and policy making processes" and "citizen partners in local service delivery } \\
\text { monitoring." }\end{array}$ \\
\hline \multirow[t]{2}{*}{2012} & $\begin{array}{l}\text { Adoption of OGP's Articles of Governance, which reiterate the core principles } \\
\text { contained in the Open Declaration. }\end{array}$ \\
\hline & $\begin{array}{l}\text { Webinars are conducted on Public Participation, ICT for Citizen Engagement, Citizens' } \\
\text { Budget, and Grievance Redress Mechanisms. }\end{array}$ \\
\hline \multirow[t]{3}{*}{2013} & $\begin{array}{l}\text { Bilateral calls and emails with national points of contact emphasize the importance } \\
\text { consultative action plan processes. }\end{array}$ \\
\hline & $\begin{array}{l}\text { Webinars and trainings conducted on Codes of Practice for Public Consultations, E- } \\
\text { petitions, Citizen Engagement in Law Making, and Strengthening the Demand and Use } \\
\text { of Open Data Initiatives }\end{array}$ \\
\hline & $\begin{array}{l}\text { OGP Global Summit includes workshops and seminars on Broadening Civil Society } \\
\text { Engagement, Institutionalizing Public Participation in Policy-making, Participation and } \\
\text { Collaboration in the Arts, and Citizen Engagement by Audit Institutions }\end{array}$ \\
\hline \multirow[t]{3}{*}{2014} & Dedicated country-support staff begins bilateral outreach to national focal points. \\
\hline & $\begin{array}{l}\text { Webinars and trainings conducted on Citizen Engagement with Supreme Audit } \\
\text { Institutions, Digital Platforms for Processing Freedom of Information requests, and } \\
\text { Public Participation in Budget Making }\end{array}$ \\
\hline & $\begin{array}{l}\text { Guidance Note on National OGP Dialogues provides bullet point suggestions on the } 7 \\
\text { "guidelines for public consultation on country commitments" outlined in the OGP } \\
\text { Articles of Governance (availability of process and timeline, adequate notice, } \\
\text { awareness raising, multiple channels, breadth of consultation, documentation and } \\
\text { feedback, and consultation during implementation). }\end{array}$ \\
\hline \multirow[t]{3}{*}{2015} & $\begin{array}{l}\text { Publication of the Values Guidance Note elaborates appropriate objectives for action } \\
\text { plan commitments related to civic participation and technology }\end{array}$ \\
\hline & $\begin{array}{l}\text { Guidance Notes on action plan development and government self-assessments } \\
\text { reiterate the values of civic participation and technology for accountability, without } \\
\text { elaborating detailed guidance on their interpretation. }\end{array}$ \\
\hline & $\begin{array}{l}\text { Global Summit in Mexico includes workshops and seminars on Permanent } \\
\text { Consultation Forums, Radical Experiments in Citizen Engagement at the City Level, }\end{array}$ \\
\hline
\end{tabular}




\begin{tabular}{|c|c|}
\hline & $\begin{array}{l}\text { Collaboration in Fiscal Transparency Portals, and benchmarking participation through } \\
\text { comparative indices. }\end{array}$ \\
\hline & $\begin{array}{l}\text { Steering Committee articulates alignment of OGP norms for civic participation with } \\
\text { the goals and targets in the } 2030 \text { Agenda for Sustainable Development. }\end{array}$ \\
\hline 2016 & $\begin{array}{l}\text { Global Summit in Paris included workshops on e-consultations, participatory justice } \\
\text { initiatives, strategies for community policy-making, constitutional crowdsourcing, } \\
\text { inclusion in e-participation, and collaborative approaches to public services. }\end{array}$ \\
\hline & $\begin{array}{l}\text { Webinars conducted on citizen engagement in e-rulemaking and the state of civic } \\
\text { participation in Latin America. }\end{array}$ \\
\hline & $\begin{array}{l}\text { Steering Committee meetings included opening remarks emphasizing the need for } \\
\text { "protection and enhancement of civic space, deeper co-creation and civic } \\
\text { participation" and discussion of civil society participation as a condition for } \\
\text { preventing Turkey's categorization as "inactive". }\end{array}$ \\
\hline 2017 & $\begin{array}{l}\text { Participation \& Co-creation Standards provides specific guidance on how include } \\
\text { citizen and civil society participation and co-creation in the processes of developing } \\
\text { and monitoring national action plans, including "basic requirements" and "advanced } \\
\text { steps," and explicitly encouraging "co-ownership and joint decision making." }\end{array}$ \\
\hline & $\begin{array}{l}\text { Steering Committee meetings moved to have components of the co-creation and } \\
\text { participation standards are integrated into OGP membership criteria, adopted IAP2 } \\
\text { thresholds for national consultations to be included in protocols for placing OGP } \\
\text { countries "under review", cited participation as an area of concern in reviewing the } \\
\text { implementation of OGP by Montenegro and Azerbaijan, proposed "triggers" related } \\
\text { to civic participation for identifying "countries of concern", and proposed specific } \\
\text { membership criteria amendments related to citizen participation. }\end{array}$ \\
\hline 2018 & $\begin{array}{l}\text { Global Summit in Tblisi included workshops on designing multi-stakeholder forums, } \\
\text { designing participatory budgeting, civil society approaches to monitoring civic space, } \\
\text { participatory law making, strategies for participatory decision making, public dialogue } \\
\text { case studies, co-creation processes as a tool to build trust, using ICT in civic } \\
\text { participation, defending civic space, and deliberative approaches to policy problems } \\
\text { and decision-making. }\end{array}$ \\
\hline & $\begin{array}{l}\text { Webinars conducted on engaging marginalized communities, and to introduce the } \\
\text { participation and co-creation standards. }\end{array}$ \\
\hline & $\begin{array}{l}\text { Steering Committee meetings described new support and guidance on direct citizen } \\
\text { engagement and participation, reiterated the value of civic participation (in } \\
\text { statements by new OGP co-chairs and the Feminist Open Government Initiative), } \\
\text { highlighted upcoming OGP trust fund research on the impact of public participation, } \\
\text { and proposed a rapid response mechanism in response several conditions, including } \\
\text { limits on civic participation in participating countries. }\end{array}$ \\
\hline
\end{tabular}


It can be useful to distinguish the rich variety with which OGP promotes civic participation along three vectors:

i. the specificity of norms,

ii. whether norms are promoted globally or directly to national governments, and

iii. whether civic participation is anticipated in the consultative process for developing national action plans, or as an activity described in those action plans (corresponding to the input and output stages of the results chain in Figure 1).

Firstly, OGP requires participating countries to endorse the abstract norms of civic participation as one of four "core principles of open government" described in the Open Government Declaration (Open Government Partnership, 2011). These principles are consistently referenced throughout OGP's engagement with countries, but are never precisely defined or prescribed in country-specific contexts. Instead, and in the interest of allowing national governments to themselves determine the most appropriate modalities for civic participation, abstract principles are complemented by a wide variety of case studies, trainings and guidelines, providing a wealth of inspirational material for governments, without specifically prescribing what civic participation ought to look like in any given country. This approach can be traced to the decision to design OGP as a "big tent" initiative, whereby the ambiguity and adaptability of open government norms is hoped to support the initiative's recruiting efforts (Goldstein \& Weinstein, 2012).

Secondly, and in keeping with the above distinction, the vast majority of OGP's norm promotion occurs at the global register, through open events, trainings, and publications that are in principle accessible to any interested parties. Open government norms and policies are promoted directly to member governments primarily in the context of evaluations by the OGP's Independent Reporting Mechanism (IRM) and through the "country support" function that has been increasingly institutionalized within the OGP secretariat since 2014.

Lastly, the rhetoric of civic participation is present throughout OGP policy and promotional material, but is most prominently promoted in regard to the process of developing national action plans. Though IRM researchers categorize action plan commitments according to OGP values, including civic participation, there are no clear 
guidelines for developing or evaluating civic participation activities. The processes through which those commitments are determined and articulated, on the other hand, feature prominently in OGP's promotion of civic participation, most notably in the Participation \& Co-Creation Standards released in 2017 (Open Government Partnership, 2017a), as will be discussed in section 1.2.2.

\subsubsection{Varieties of participation}

Despite the variety of ways in which governments are encouraged to pursue civic participation, this core value is only loosely defined in the OGP context. It is tempting to distinguish OGP's articulation of civic participation from more widely used concepts, such as citizen engagement, political participation, and democratic participation. A clear differentiation with these concepts would likely be difficult, given the tendency towards "conceptual confusion" and "concept stretching" in their use (Ekman \& Amnå, 2012, pp. 283-284). In regard to participation alone, semantic inconsistencies in have led several scholars to avoid these distinctions and focus instead on substantive scope (see for example K. Yang, 2012, p. 449).

It is, however, worth briefly considering the most prominent associations with each of the concept's two constitutive terms. The term civic immediately recalls civic engagement, and might thus be understood as distinct from political or democratic. Ekman and Amnå's (2012) review suggests, for example, that the civic in civic engagement is used by many scholars to designate a civil sphere that is characterized by actions independent of government apparatus (such as voluntary and community activities), and which is distinct from actions taken in the political sphere, such as voting or membership in political parties (p. 285). This distinction appears directly at odds with civic in OGP's understanding of civic participation, however, which is predicated upon government coordinated activities and initiatives. The foundational Open Government Declaration, for examples, proclaims government support for civic participation, described as government-led activities which "mobilize citizens to engage in public debate, provide input, and make contributions that lead to more responsive, innovative and effective governance" (Open Government Partnership, 2015b, p. 18). This understanding is reiterated in the OGP's Articles of Governance, where it is exemplified with engagement in government processes, such as "policy formulation," "decision making," "public feedback," and the "monitoring and 
evaluation of government activities" (Open Government Partnership, 2011, p. 21), all implying actions within an explicitly political sphere.

Similarly, the term participation recalls common distinctions between participation and engagement. These differences are often conceptualized along a continuum of activity, whereby participation implies more deliberate and active political action (such as participation in protest or elections) and engagement implies more passive activities (such as joining trade unions or consuming political information), sometimes described as latent participation, and understood to subsequently facilitate and condition more active participation (Dahlgren, 2016; Ekman \& Amnå, 2012; van Deth, 2016). This distinction also fails to hold in the OGP context. The OGP's Values Guidance Note, for example, explicitly references freedoms of "association including trade union laws or NGO laws" in describing civic participation (Open Government Partnership, 2015a, p. 2), and the notion of engagement with open government data as a preliminary stage of civic participation is prominent research on civic engagement in an open government context (Cañares, 2016; Gurumurthy, Bharthur, \& Chami, 2017; José María Marín, 2016; Liden, 2016; Peixoto, Fall, \& Sjoberg, 2016).

Civic participation in an open government context should thus be understood broadly, without strict exclusion to particular types of democratic, political or civic activities, but categorically tied to government action. Because OGP is implemented primarily by governments developing and implementing national action plans, all reference to civic participation is inevitably bound up in some action taken by government, whether by directly creating fora and processes for participation, or indirectly by creating space for such activity, through changes to regulatory contexts. This breadth frustrates efforts to determine how and when civic participation might contribute to the OGP's objective of more responsive and accountable government, and may be part of the reason why OGP does not more systematically evaluate civic participation activities pursued by member countries, as is discussed in the following sub-section.

\subsubsection{Assessing the quality of civic participation}

OGP uses two types of measures for assessing civic participation. Firstly, international comparative metrics are used to determine whether countries are eligible to join the initiative (Open Government Partnership, 2015b, pp. 15-16), or to assess "overall progress 
of OGP countries in key areas around OGP values" (Foti, 2016, p. 27). These include the Voice and Accountability dimension of the World Bank's World Governance Indicators, which aggregates 61 indicators from 32 data sources to present perceptions of electoral effectiveness, freedoms of expression and association, and a free media (Kaufmann, Kraay, \& Mastruzzi, 2011; "Voice and Accountability Methodology Description," n.d.), ${ }^{5}$ and the Economist Intelligence Unit's Democracy Index, which measures political participation according to the protection of civil liberties in law, as well as public interest and willingness to participating in formal political processes and protests (The Economist Intelligence Unit, 2019, pp. 51-60). ${ }^{6}$ These measures indicate the degree to which national regulatory and political contexts facilitate civic participation, rather than the quality of civic participation processes or initiatives per se.

Secondly, researchers for OGP's Independent Reporting Mechanism (IRM) are instructed to review the participatory quality of action plan development processes according to six criteria (prior availability of timeline and process, adequacy of advance notice, awareness-raising, online consultations, in-person consultations, and publication of a summary of comments), ${ }^{7}$ and to categorize of action plan development according to the IAP2 Spectrum of participation, whose five levels of participation are defined by objectives and organizer commitments to participants, as presented in Figure 2.

\footnotetext{
${ }^{5}$ See also http://info.worldbank.org/governance/wgi/\#doc-intro, accessed 10 March 2019.

${ }^{6}$ See also https://www.eiu.com/topic/democracy-index, accessed 10 March 2019.

${ }^{7}$ With the exception of "advance notice", which also notes the number of days of advance notice, these are binary determinations noting whether or not the criteria were implemented (though the criterion of timeline availability also distinguishes whether timelines were made available "online" or on "other channels"). See details in the OGP Data Explorer, available at https://www.opengovpartnership.org/about/independentreporting-mechanism/ogp-data, accessed 10 March 2019.
} 
Figure 2: Levels in the IAP2 Spectrum of Participation (adapted from International Association for Public Participation, 2016)

\begin{tabular}{|c|c|c|c|c|}
\hline INFORM & CONSULT & INVOLVE & COLLABORATE & EMPOWER \\
\hline $\begin{array}{l}\text { To provide the } \\
\text { public with } \\
\text { balanced and } \\
\text { objective } \\
\text { information to } \\
\text { assist them in } \\
\text { understanding } \\
\text { the problem, } \\
\text { alternatives, } \\
\text { opportunities } \\
\text { and/or } \\
\text { solutions. }\end{array}$ & $\begin{array}{l}\text { To obtain public } \\
\text { feedback on } \\
\text { analysis, } \\
\text { alternatives } \\
\text { and/or } \\
\text { decisions. }\end{array}$ & $\begin{array}{l}\text { To work directly } \\
\text { with the public } \\
\text { throughout the } \\
\text { process to } \\
\text { ensure that } \\
\text { public concerns } \\
\text { and aspirations } \\
\text { are consistently } \\
\text { understood and } \\
\text { considered. }\end{array}$ & $\begin{array}{l}\text { To partner with } \\
\text { the public in } \\
\text { each aspect of } \\
\text { the decision } \\
\text { including the } \\
\text { development of } \\
\text { alternatives and } \\
\text { the } \\
\text { identification of } \\
\text { the preferred } \\
\text { solution. }\end{array}$ & $\begin{array}{l}\text { To place final } \\
\text { decision making } \\
\text { in the hands of } \\
\text { the public. }\end{array}$ \\
\hline $\begin{array}{l}\text { We will keep } \\
\text { you informed. }\end{array}$ & $\begin{array}{l}\text { We will keep } \\
\text { you informed, } \\
\text { listen to and } \\
\text { acknowledge } \\
\text { concerns and } \\
\text { aspirations, and } \\
\text { provide } \\
\text { feedback on } \\
\text { how public } \\
\text { input influenced } \\
\text { the decision. }\end{array}$ & \begin{tabular}{|l|} 
We will work \\
with you to \\
ensure that your \\
concerns and \\
aspirations are \\
directly \\
reflected in the \\
alternatives \\
developed and \\
provide \\
feedback on \\
how public \\
input influenced \\
the decision.
\end{tabular} & $\begin{array}{l}\text { We will look to } \\
\text { you for advice } \\
\text { and innovation } \\
\text { in formulating } \\
\text { solutions and } \\
\text { incorporate } \\
\text { your advice and } \\
\text { recommendatio } \\
\text { ns into the } \\
\text { decisions to the } \\
\text { maximum } \\
\text { extent possible. }\end{array}$ & $\begin{array}{l}\text { We will } \\
\text { implement what } \\
\text { you decide. }\end{array}$ \\
\hline
\end{tabular}

The IAP2 Spectrum is one of several categorical frameworks, including the OECD's conceptualization of citizen engagement (OECD, 2001) and the three stages of participation composing the UN's E-participation framework (United Nations Department of Economic and Social Affairs, 2016), which can collectively be traced back to Arnstein's (1969) seminal ladder of participation. The IAP2 is a popular adaptation of this model, and has been applied 
to a variety of individual participatory processes, ${ }^{8}$ as well as comparative analysis (Nelimarkka et al., 2014). Though Spectrum does not provide metrics or empirical indicators for categorizing specific participatory processes, and is not intended to be used as an evaluation framework, categories from the Spectrum nevertheless feature in OGP country reports and comparative analysis (Foti, 2016; OGP Independent Reporting Mechanism, 2017; Open Government Partnership, 2017a; Steibel, Alves, \& Konopacki, 2017; Whitt, 2015). The IAP2 Spectrum can be read as the primary measure by which the IRM evaluates the quality of civic participation in OGP implementation.

Notably, the IAP2 Spectrum is not used to the evaluate the quality of civic participation in the individual commitments and activities that are described in government action plans. Indeed, there is no specific evaluation framework for assessing civic participation in national action plans. Instead, IRM researchers code individual commitments according to whether they are relevant to OGP's core values. ${ }^{9}$ Commitments coded as relevant to the value of civic participation are then assessed according to the same evaluation framework as all other commitments, categorized according to four levels of ambition and five degrees of whether they "made a difference" (worsened, did not change, marginal, major, outstanding), all according to contextual analysis by individual researchers in each country.

In summary, comparative indicators for national regulatory contexts for civic participation are used to determine OGP membership and assess member countries progress. The IAP2 Spectrum is used to categorize the participatory quality of national consultations and co-creation processes, and individual commitments in action plans are coded as either being relevant to the value of civic participation, or not. This represents the full extent to which OGP systematically assesses the quality of civic participation. There are, however, a variety of metrics and frameworks for assessing the quality of specific processes

\footnotetext{
${ }^{8}$ A curated list of applications is available at the IAP2 website, https://www.iap2.org/page/cva, accessed 9 March 2019.

${ }^{9}$ Guidance for this determination is sparse. The OGP Values Guidance Note, for example, suggests that civic participation initiatives targeting public participation should be open to all citizens and include the right to be heard, and discourages assumptions about how civic participation will be increased by access to information, decentralization, or inter-agency cooperation initiatives, but its 260 words of guidance provide only examples, and are far from comprehensive (Open Government Partnership, 2015a, p. 2).
} 
and policies for civic participation. Some of these will be discussed in section 2.2, when considering theories of how civic participation contributes to responsive and accountable government.

For now, it is important only to note that no metrics are used to assess whether participatory processes in the OGP context contribute to OGP's end goal of more responsive and accountable government. This is particularly problematic given deep-seated concerns that countries might embrace the norms and ideals of civic participation accompanying MSI membership "in order increase their international reputation" and "to avoid more difficult and potentially transformative openness and transparency efforts" (Verhulst \& Young, 2017, p. 38). This concern has been raised in regard to specific cases of OGP implementation (Guerzovich \& Moses, 2016, p. 12; Whitt, 2015, pp. 1-2), and some have gone so far as to argue that "countries have used OGP as a smokescreen to distract from on-going corruption, lacking transparency, and government secrecy" (Fraundorfer, 2017, p. 611).

In this context, the metrics applied to civic participation by the OGP IRM are insufficient. They provide useful information, for example demonstrating that action plan consultations have become more open over time (Foti, 2016), that only a quarter of civic participation commitments in Latin American action plans had potentially transformative impact $(25 \%)$ or were completed within the action plan time frame (28\%) (Whitt, 2015, p. 2), and that civic participation is absent from "almost 9 in 10 commitments that aim to fight corruption" (Steibel et al., 2017, p. 11). IAP2 categories and comparative regulatory indicators fail, however, to provide insight on the degree to which the participation norms and policies that are promoted and adopted in an OGP context will actually contribute to promoting responsive and accountable government. As such, and in regard to civic participation at least, these measures fail to assuage fears that OGP action plans constitute mere box checking exercises or smoke screens, allowing governments to deflect demands for meaningful participation and reform.

\subsubsection{Open government and civic participation in the context of digital media} To understand civic participation in an OGP context also requires considering the rise and dissemination of new information and communications technologies. OGP was founded at a time when access to internet and mobile technologies had been on a steady and dramatic 
rise for years. This trend has persisted, ${ }^{10}$ and been marked by a proliferation of innovative approaches to technologically-facilitated citizen-state interaction. In 2009, the European Commission described a surge of citizen engagement in policy making driven by access to ICTs (Millard et al., 2009, p. 4), which the UN 2016 Survey on E-Government characterized as a continually "growing positive trend in the relationship between people and governments [driven by the] vast networking opportunities opened up by new media channels" (United Nations Department of Economic and Social Affairs, 2016, p. 51).

The proliferation of digitally-mediated participation is also notable for its variety. The Civic Tech Field Guide ${ }^{11}$ has catalogued 242 instances of civic technology, categorized according to 60 different tactics for leveraging technology in civic action, while the online catalogue Participedia ${ }^{12}$ documents hundreds of methodologies for participatory governance processes that are facilitated by digital media, and categorizes them according to multiple characteristics, including the types of actors they involve, the types interaction they facilitate and the degree of issue complexity to which they are best suited.

These developments have fueled wide and steady speculation about how digital media might reshape the relationship between governments and their constituents. Several scholars have also noted the fundamental implications that technology poses to the information structures and ecosystems within which participation is actualized, (Dahlberg, 2011; Fung, Russon Gilman, \& Shkabatur, 2013; Hale, John, Margetts, \& Yasseri, 2018; Janssen \& Helbig, 2015; Zuckerman, 2014), and how excitement surrounding these developments have catalyzed government interest in participatory models, both online and off (Freeman \& Quirke, 2013; Smith, 2009; Vogt \& Haas, 2015; Wagner, Vogt, \& Kabst, 2016). Stepwise recommendations on the expansion of e-services and government modernization have thus been complemented by ambitious and speculative visions of government 2.0 (Linders, 2012), wiki government (Noveck, 2009), and cyber democracy (Ferber, Foltz, \&

\footnotetext{
${ }^{10}$ Data on global media penetration from 2011 to 2016 (latest data available) retrieved from the World Bank's Data Bank (https://databank.worldbank.org/) on 2 March 2019 show that "Individuals using the Internet (\% of population)" increased from 31,1 to 45,8 globally and from 13,0 to 29,9 in low and middle income countries, while the number of "Mobile cellular subscriptions per 100 people" increased from 77,4 to 95,7 globally and from 83,7 to 100,7 in low and middle income countries.

${ }^{11}$ See https://civictech.guide/, accessed 3 March 2019.

${ }^{12}$ See http://participedia.net/en/about, accessed 3 March 2019.
} 
Pugliese, 2007), often driven by enthusiasm, or even "breathless exuberance" on the part of governments (Harrison, 2013).

It is in this context that the emergence of open government and OGP are best understood. The conceptual ambiguity between technological solutions to open data and the political foundations of open government have been widely commented (Peixoto, 2013; Yu \& Robinson, 2012), and were deliberately harnessed in OGP's "big tent" design, in an effort to increase the initiative's salience and boost recruitment (Goldstein \& Weinstein, 2012). This effort has been largely successful, and OGP has come to dominate global policy discourse surrounding the use of digital media and technology in government (Harrison, 2013; Kassen, 2014), even as technology has become central to the way in which open government is conceptualized by practitioners (Gonzalez-Zapata \& Heeks, 2014), researchers and commentators (Wirtz \& Birkmeyer, 2015).

This has resulted in an interesting dichotomy regarding technology and participation in an OGP context. On the one hand, OGP's promotion of civic participation has deliberately and explicitly avoided the hype surrounding digital technologies. Guidance on the collaborative development of national action plans, for example, has consistently emphasizes the importance of appropriate combinations of online and offline consultative activities in individual country contexts (Open Government Partnership, 2017a). On the other hand, technology and digital media remain deeply embedded in the way that civic participation is referenced and conceptualized in an OGP context. The Open Government Guide, for example, offers recommendations, guides, standards, and case studies for using digital tools to engage with the public as an "intermediate step" towards achieving more open government (Transparency and Accountability Initiative, 2013) and Whitt's (2015) analysis of civic participation in Latin American action plans associates the use of technology with transformative impact (Whitt, 2015, p. 13). In this sense, the "unstoppable momentum of rapid advances in communications technology" described in OGP's promotional and strategic material provides an important context for understanding the rise and the influence of open government (Open Government Partnership, 2014b, p. 9). Doing so requires a brief review of those advances, as well as the factors that have been suggested to drive their diffusion.

The most comprehensive effort to track advances in technology and participation is provided by the UN's biannual e-government survey, which assesses the degree to which 
governments have adopted e-participation policies or practices, understood as "the process of engaging citizens through ICTs in policy, decision- making, and service design and delivery so as to make it participatory, inclusive, and deliberative,"(UN E-Government Survey 2018: Gearing E-Government to support transformation towards sustainable and resilient societies, 2018, p. 112). The UN has argued that e-participation tends to advance in stages, first by countries providing information online, then engaging in digitally facilitated consultations, and finally by finding novel technological tools and strategies to include citizens in participatory decision-making and policy-making (United Nations Department of Economic and Social Affairs, 2016, p. 55), and has found marked increases in country implementation of all three stages during the period that OGP has been active.

The 2016 Survey noted, for example, that "with growing access to social media, an increasing number of countries now proactively use networking opportunities to engage with people and evolve towards participatory decision-making," and found that the number of countries that consult citizens online regarding key policy issues had doubled since 2012 (United Nations Department of Economic and Social Affairs, 2016, pp. 3, 66). The diffusion of online consultations continued in the following years, quite dramatically in some regions. In Africa, for example, online consultations went from being non-existent in 2016, to becoming available in all but two countries by the time of the 2018 E-Government Survey (UN EGovernment Survey 2018: Gearing E-Government to support transformation towards sustainable and resilient societies, 2018, p. 120). This comes directly on the heels of OGP hosting its first two African regional summits in 2015 and 2016, convening eight African governments for a South-South learning event with the World Bank, and appointing South Africa as the initiative's co-chair.

No research has explored the relationship the global diffusion of e-participation and growth of OGP activity and membership, but three relationships could be described to explain their correspondence. The first explanation is that the same factors are driving the diffusion of e-government and the rapid expansion of OGP. This explanation is supported by researchers who see the OGP as an expression of broader change in the norms and technologies of governance. Harrison (2013), for example, argues that the rise and prominence of OGP signifies a broader cultural move towards "government 2.0", in which "social media enable[s] governments to invite citizens, as democratic watchdogs and 
collaborators as well as creative do-it-yourself forces, into the administration of government" (p. 396).

There is no clear evidence base against which to evaluate the validity of this explanation. While research on other public governance MSIs has documented that membership is motivated by both social incentives and instrumental behavior (David-Barrett \& Okamura, 2016), no comparative analysis has assessed the factors driving OGP membership. The best evidence is represented by a handful of case studies that loosely attribute membership decisions to international factors, including international diplomacy (Gerson \& Nieto, 2016; Schneider, 2015) or pressure from multilateral and donor organizations (Arias, Gomez, Rivera, \& Fernandez, 2016; Francoli, Ostling, \& Steibel, 2015; Montero \& Taxell, 2015; Schneider, 2015). Absence of evidence is not evidence of absence, however, and it is entirely plausible that national factors considered in e-participation literature, including national demand, the alignment of political structures, and technological infrastructure, also play a driving role in regard to OGP membership.

Research on the factors driving e-participation is much more extensive, but inconclusive. Norris (2001, cited in Katz \& Halpern, 2013) has prominently argued that "the spread of Internet use plays the single most significant predicator of national e-government adoption" (11). Comparative analysis by Krishnan \& Teo (2009) supports this view, but also demonstrates that the effect of "information infrastructure" is significantly moderated by "governance factors" including political stability, government effectiveness and rule of law. National factors also feature prominently in the framework promoted by Wirtz \& Birkmeyer (2015), who emphasize the importance of complementary legal frameworks in driving the adoption of open government. Åström et al.'s (2012) analysis goes so far as to differentiate between democratic and non-democratic countries, and finds "economic globalization to be the strongest predictor of e-participation initiatives in non-democratic countries" (142). Other analyses have emphasized institutional cultures and characteristics, particularly at the sub-national level (Chatfield \& Reddick, 2016; Jun \& Weare, 2011; T.-M. Yang \& Wu, 2016)

Public demand for online interaction has also been highlighted. The most recent UN E-Government Survey argues that e-participation is driven more by citizen demand and activism than by access to resources or technologies (United Nations Department of Economic and Social Affairs, 2016, p. 3) and (Yavuz \& Welch's (2014) survey of city websites finds that more participatory functionality is associated with higher degrees of offline 
participation in governance processes. This emphasis on public demand aligns with the analytical framework asserted by (Katz \& Halpern, 2013, p. 11) and Rose, Flak, \& Sæb $\varnothing$ (2018)'s stakeholder theory, which attributes civil society and citizen groups with the capacity to increase the urgency and salience of engagement values in the design and implementation of open government activities. Other studies complicate this by distinguishing between degrees of interactivity and their respective drivers. Comparative analysis by Krishnan et al. (2017) suggests that government willingness to publish information and consult publics online is positively associated with e-government maturity, but that willingness to engage in collaborative e-decision-making is negatively associated. Lee, Chang, Berry, Lee, \& Berry (2017) make similar distinctions in their global data set, and find evidence suggesting that while social mechanisms of competition and learning drive the diffusion of e-government, these drivers are not associated with the diffusion of more participatory e-democracy, which requires normative and citizen pressure from below.

No research has directly attributed the diffusion of e-participation to the advocacy of international actors, though attention to international policy intermediaries in the study of policy diffusion suggests they may well play a role (Stone, 2012). Similarly, e-participation drivers such as technological diffusion, national governance context, and citizen demand may well also play a role in driving countries to join OGP. This quite simply has not been tested.

A second explanation for the relationship between these two phenomena is that the global diffusion of e-participation is contributing to the growth of OGP, insofar as OGP provides a platform for consolidating and promoting the e-participation activities that countries that are already implementing. This view aligns with Kassen's (2014) instrumental understanding of OGP, as a mechanism whose position in global discourse enables participating countries to consolidate and advance e-participation and e-government activities, "by harmonizing them with a single internationally approved conception, which in turn will lead to the promotion of civic engagement globally" (p. 55). This view is supported by several OGP case studies that describe national action plan processes that fail to initiate new policy and reform initiatives, and instead curate pre-existing policy initiatives (Arias et al., 2016, p. 20; Fraundorfer, 2017, pp. 617-620; Montero, 2015b, p. 6; Montero \& Taxell, 2015, p. 28). An internal synthesis of OGP-related research produced by the OGP secretariat notes that: 
joining OGP may represent a way for a country to 'get credit' from potential donors, investors, or trading partners. Indeed, scholars of international relations have noted that in many cases, countries make international commitments that align with their interests, adopting behavior they would have chosen anyway (Downs, Rocke, and Barsoom, 1996; Von Stein, 2005) (Hasan, 2016, p. 3).

By this logic, whatever countries' motivation to join OGP, doing so is easier if they have already adopted e-participation policies and activities, because it lowers the adaptation cost implied by creating new activities for national action plans.

Finally, the third explanation for the relationship between OGP growth and the diffusion of e-participation is that OGP actually contributes to the global diffusion of civic participation facilitated by digital technology, in line with the initiative's mandate. This would align with arguments that OGP has catalyzed a shift in global policy discourse, (Kassen, 2014), and has the power to shape global norms (Elgin-Cossart et al., 2016, pp. 819).

There are at least three pathways through which OGP might be contributing to the diffusion of e-participation. Firstly, member countries might design and adopt new eparticipation initiatives as part of the action plan development process. The case studies and internal syntheses referenced above suggest that this is not obviously the case. According to the second pathway, OGP may be contributing to the diffusion of e-participation among non-member countries by virtue of its position in global discourse.

The existence of the partnership has the potential to spur a race to the top among nonmember governments as well, either by shaping global norms on transparency or by encouraging nonmember countries to become members and make the necessary reforms to meet the eligibility criteria. (Elgin-Cossart et al., 2016, p. 26).

The third pathway may be identified in the socialization of participation norms, as described in OGP strategy documents. By positioning itself as a "common platform" for disparate reform initiatives and government institutions (Open Government Partnership, 2014b, pp. 16-19), OGP contributes to the institutionalization of norms outside of the consultations and action plan commitments that constitute the OGP results chains, contributing to ancillary policy outcomes, such as the adoption and implementation of e- 
participation. This is the focus of this dissertation's second research question, and the second assessment strategy proposed in section 1.1.1.

In summary, the emergence of an open government agenda and the growth of OGP should be understood within the context of widespread enthusiasm for technology and the rapid diffusion of e-participation. The causal relationship between OGP's growth and the diffusion of digital tools and techniques for participation remains unclear, however. Both phenomena may be influenced by a similar collection of causal factors. The diffusion of eparticipation may also be driving countries to join OGP by lowering the adaptation costs. OGP may, in turn, be contributing to the diffusion of e-participation, either by encouraging countries to pursue e-participation activities in their action plans, by shaping the global norms that influence non-members, or by socializing participation norms in member countries.

This dissertation will explore the third pathway of the third explanation, testing whether OGP exerts a causal effect on the diffusion of e-participation, in line with the second assessment strategy presented in section 1.1.1. The most likely explanation for the parallel growth of OGP and the diffusion of e-participation is some combination of these relationships, however. Section 2.2 considers this potential in greater detail, and proposes the theoretical foundations for their interaction.

\subsubsection{Reconsidering OGP's influence and effectiveness in the promotion of civic} participation

This introduction has adopted a broad lens in order to capture the variety of ways in which OGP promotes civic participation norms and policies and the complicated normative context in which that occurs. Doing so suggests that ambiguity surrounding civic participation has been strategically leveraged by OGP in order to secure government support and participation. High level political endorsement in turn opens political space for domestic policy dialogue and the development of national action plans, and facilitates the continued promotion of civic participation norms through the dissemination of consultation guidelines, case studies, webinars, and trainings. Extended exposure to civic participation norms, and importantly, exposure to actual civic participation during action plan development, is hoped 
to socialize participation norms within government institutions. As articulated in an early theory of change:

As norms shift and governments become more comfortable with transparency, governments will begin introducing more opportunities for dialogue and become more receptive to civil society input and participation (Open Government Partnership, 2014b, p. 16).

This description of socialization aligns nicely with causal mechanisms that were associated with public governance MSIs above, but lacks detail, and has not been directly addressed by the emergent body of research on OGP, which is primarily oriented towards the content of action plan commitments (Berliner, 2015; Francoli \& Clarke, 2014; Herrero, 2015; Petrie, 2015a; Schwegmann, 2013; Steibel et al., 2017) and the processes through with action plans are developed (T. Corrigan \& Gruzd, 2018; Francoli et al., 2015; Guerzovich \& Moses, 2016; Montero, 2015b, 2015a; Montero \& Taxell, 2015).

This emphasis can be characterized as an emphasis on the inputs stage in OGP's results chain, displayed in Figure 3 , and has been explained by the fact that OGP is a relatively young initiative, and that it is too soon to seek evidence of long-term impact (Brockmyer \& Fox, 2015, p. 38; Elgin-Cossart et al., 2016, p. 3; Foti, 2014, pp. 9-10). According to this logic, outcomes and impacts haven't happened yet, which explains the dominance of compliance studies in OGP research (Brockmyer \& Fox, 2015, p. 38; Gruzd et al., 2018, p. 3). 
Figure 3: OGP's results chain (adapted from Foti, 2014: 2)

\begin{tabular}{|c|c|c|c|}
\hline $\begin{array}{l}\text { Inputs: } \\
\text { Domestic: National } \\
\text { action planning and } \\
\text { implementation. } \\
\text { International: } \\
\text { Connecting, } \\
\text { empowering, and } \\
\text { supporting domestic } \\
\text { reformers. }\end{array}$ & $\begin{array}{l}\text { Outputs } \\
\text { Domestic: } \\
\text { Concrete, } \\
\text { ambitious, and } \\
\text { relevant national } \\
\text { action plan } \\
\text { commitments are } \\
\text { implemented. } \\
\text { International: } \\
\text { Domestic } \\
\text { reformers are } \\
\text { connected, } \\
\text { empowered, and } \\
\text { have adequate } \\
\text { support. }\end{array}$ & $\begin{array}{l}\text { Outcomes } \\
\text { OGP } \\
\text { governments } \\
\text { become more } \\
\text { accountable and } \\
\text { responsive by } \\
\text { making policy } \\
\text { processes more } \\
\text { open }\end{array}$ & $\begin{array}{l}\text { Impacts } \\
\text { As a } \\
\text { consequence of } \\
\text { more open } \\
\text { government, } \\
\text { public services } \\
\text { are delivered } \\
\text { more efficiently, } \\
\text { public resources } \\
\text { are managed } \\
\text { more wisely, and } \\
\text { people are safer. }\end{array}$ \\
\hline & actıvity & & \\
\hline
\end{tabular}

As with the generalized results chain for public governance MSIs presented in Figure 1 , the OGP results chain follows a logic of sequenced attribution that is cumulative and specific. A technical paper from the OGP IRM suggests that the ability to attribute impacts to OGP decreases as one moves along the chain, "due to the inherent time lag between commitment implementation and impact, as well as other intervening causes" (Foti, 2014, p. 9). This is represented by the slope at the bottom of Figure 3 , suggesting that attribution of impacts would be difficult, even if the research community were willing to wait for applicable evidence.

This presumed reliance on long-term evidence to assess OGP may be spurious, however, and has fueled rampant speculation about whether and how OGP might contribute to improvements in national governance. While some commentators suggest that OGP is most impactful in countries "that lean towards more authoritarian characteristics" (Turianskyi, Corrigan, Chisiza, \& Benkenstein, 2018, p. 18), others argue that government 
transparency will only lead to government accountability in countries that enjoy participatory institutions and a free press (Peixoto, 2013). This has in turn driven debate about revisions to OGP's eligibility criteria (Open Government Partnership, 2017b, pp. 4042 ), and suggestions that low eligibility criteria might actually contribute to dynamics of "open washing," whereby reform processes are "coopted and used to bolster the international legitimacy of regimes that remain fundamentally closed and undemocratic" (Brockmyer \& Fox, 2015, p. 11; see also Elgin-Cossart et al., 2016, p. 28; Guerzovich \& Moses, 2016, p. 12). More critical scholars suggest that open washing is widespread, also in established democracies and founding countries, which "use the OGP as a smokescreen to distract from on-going corruption, lacking transparency, and government secrecy" (Fraundorfer, 2017, p. 611).

Evaluating these assertions requires rigorous research beyond compliance studies and narrow attribution within the OGP results chain. To contribute to that endeavor, this dissertation accepts the absence of evidence for long-term impacts, but proposes three alternative strategies for assessing the influence and effectiveness of OGP's promotion of civic participation.

This introduction has provided the background against which to develop and test those strategies. It began by noting a lack clarity regarding how public governance MSIs might influence the national policy and practice of member countries, and the theoretical relevance of social dynamics including persuasion, argumentation, emulation and learning. This provides a starting point for defining theoretically grounded causal mechanisms for MSI influence, and testing whether those mechanisms are present prior to the manifestation of long-term impacts. This introduction then presented background information on OGP's promotion of civic participation, including the policy context of e-government and eparticipation in which OGP operates, and questioned the relationship between the growth of the OGP and the diffusion of e-participation globally. This allows the scope of analysis to be widened to include outcomes external to the OGP results chain, in this instance, eparticipation outcomes. Lastly, this introduction highlighted the conceptual ambiguity surrounding civic participation norms and policies in an OGP context. Doing so noted a lack of measures for assessing whether those norms and policies, if successfully promoted and adopted, can be expected to contribute to OGP's objective of more responsive and accountable government in member countries. 
Collectively, these strategies contribute to the emerging body of research on public governance MSIs beyond compliance studies and MSI-specific results chains, while adding nuance to the current discourse on MSI effectiveness and OGP impact. They also directly inform the articulation of this dissertation's three research questions.

\subsection{Research questions}

This dissertation applies three research questions with which to develop and validate alternative strategies for assessing the influence and effectiveness of public governance MSIs.

RQ1: How do voluntary multi-stakeholder initiatives like the OGP influence the national policy of member countries?

RQ2: To what degree is the global diffusion of civic participation norms attributable to OGP?

RQ3: To what degree can the participation norms promoted and adopted in an OGP context be expected to contribute to responsive and accountable government?

These research questions are presented briefly below. Each question is contextualized and main findings are presented, together with comments on how findings relate to the other research questions.

\section{i. How do voluntary multi-stakeholder initiatives like the OGP influence the national policy of member countries?}

The assessment literature and theories of change associated with public governance MSIs seem to imply that initiatives' influence on national governments is exercised through mechanisms of persuasion and argumentation, which are most clearly articulated by social constructivist scholars describing international norm entrepreneurship in international relations. The highly voluntary nature of public governance MSIs are significantly different from the compliance frameworks of human rights norms, however, and OGP's theory of change emphasizes processes of socialization that are distinct from mechanisms of persuasion. This analysis thus turns to policy studies for alternative explanatory frameworks, and explores the feasibility of mechanisms of influence that are related to emulation and learning. These mechanisms are tested through process tracing OGP's promotion of civic 
participation in Norway, which is identified as a deviant and data rich case appropriate for theory building, as discussed in section 3.4.

This research question is primarily oriented towards the assessment strategy of defining causal mechanisms and testing for whether they are active prior to the manifestation of long-term impacts. It also helps to explain the findings of the two subsequent research questions.

\section{ii. To what degree is the global diffusion of civic participation norms attributable to OGP?}

Analysis related to this dissertation's first research questions demonstrated how OGP's "platform to consolidate disparate reform initiatives" (Open Government Partnership, $2014 b$, p. 19) can influence individual civil servants who participate in the consultative processes attached to domestic implementation, and who may then bring OGP norms back to their institutional contexts and continue processes of norm socialization.

To assess whether this phenomenon is common among OGP member countries, causal analysis explores the relationship between OGP membership and countries' implementation of e-participation. There are distinct differences between the civic participation norms promoted by OGP and the concept of e-participation. The prominence of technology in OGP discourse, the broad diffusion of e-participation during OGP's growth, and the close association of e-participation with open government in global policy discourse nevertheless suggest that e-participation might be a suitable object expanding the scope of analysis of OGP effectiveness. Doing so would validate the second assessment strategy presented in section 1.1.1, suggesting knock on effects of OGP membership and norm promotion. This is pursued through analysis of e-participation data for all countries, using data from the UN E-Participation Index 2003-2018, where OGP membership is a treatment variable. OLS regressions and data tables are used to identify correlations and determine causality. Bootstrapping and regressions are further applied to test for the role and influence of national factors such as the salience and structural alignment of participation norms in countries.

This research question is primarily oriented towards the assessment strategy of expanding the scope of attributable outcomes. It also provides empirical evidence in support of the theoretical framework and causal mechanisms articulated in the first research question. The distinction between OGP's effect on e-participation in general, and the more specific indicator of collaborative e-decision-making also informs this dissertation's final 
third research question, regarding the contributions of OGP norms to responsive and accountable governance.

\section{iii. To what degree can the participation norms promoted and adopted in an OGP context be} expected to contribute to responsive and accountable government?

Even if OGP is successful in institutionalizing civic participation in governments and contributing to the diffusion of participatory policy outside of OGP-specific policy fora, it is not certain that this influence will contribute to OGP's end goal of more responsive and accountable governance in member countries. The quality of governance outcomes associated with OGP's influence depends significantly on the democratic quality of civic participation norms and policies promoted and adopted in an OGP context, and ultimately on the national political and cultural contexts in which those norms are adopted and implemented. It is not feasible to assess the contextualization of civic participation in all OGP member countries. Instead, this research question aims to test the degree to which civic participation norms and policies will likely contribute to the OGP's end goals of more responsive and accountable government, according to a conceptual categorization of those norms and policies. To do so, this analysis reviews design characteristics and quality metrics from the literature on e-participation, open government, civic voice, accountability studies, and political communication. These metrics are then applied to the norms promoted by the OGP to national governments, the activities described in the national action plans of member countries, and the policy outcomes identified in within-case analysis.

This research question is primarily oriented towards the assessment strategy of applying rigorous quality metrics to MSI norms. The review of relevant literature also provides support and conceptualization to the choice of e-participation for an appropriate research object for this dissertation's second research question. 


\section{Theory}

This section presents theory on which this dissertation is based. Emphasis is given to theoretical frameworks for understanding global norm promotion and adoption in national policy contexts, in support of the effort to define theoretically grounded mechanisms for MSI policy influence, as described in this dissertation's first research question. Section 2.1 presents that theory by first sketching theoretical frameworks for global norm diffusion and policy translation, then describing the rational for drawing on those traditions collectively, and theorizing the roles of individuals and institutions in the promotion and adoption of global norms.

Following this, section 2.2 demonstrates how this theoretical framework accommodates the interaction of causal mechanisms, demonstrated by a review of the relationship between OGP and e-participation. Section 2.3 presents theory on the contribution of civic participation to responsive and accountable government, in support of this dissertation's third research question. This section closes by addressing the normative position of the research in regard to civic participation and technology.

\subsection{Theories of norm promotion and policy adoption}

This research is oriented towards understanding the influence of public governance MSIs on national policy contexts, and the causal mechanisms through which that influence is exercised. Causal processes can be loosely understood as the links between inputs and outputs, as "the pathway or process by which an effect is produced or a purpose is accomplished" (Gerring, 2008, p. 178). This dissertation further understands causal mechanisms as distinct from intervening variables, insofar as they do not produce outcomes independently, but do so through their interaction with contextual factors, and are in this sense "portable" and identifiable across contexts (Falleti \& Lynch, 2009).

This section begins by identifying theories of global norm promotion and its effects national policy. The two most prominent and well-developed theoretical frameworks for this dynamic can be found in the body of international relations scholarship considering human rights promotion after the end of the Cold War, and various branches of policy studies considering processes of policy diffusion, transfer, translation, and learning across international and national contexts. Neither of these bodies of research directly address 
public governance MSIs, nor are the norms and policies they study synonymous with those promoted by the OGP or considered in this research. They nevertheless provide the most immediately applicable theoretical foundations for defining causal mechanisms through which public governance MSIs exert their policy influence, as will be presented below.

\subsubsection{Theoretical traditions from international relations and policy studies}

The end of the cold war prompted several decades of social constructivist theory development by international relations (IR) scholars seeking to understand the influence of international norms and norm entrepreneurship on countries' democratic practice. Much early work centered on human rights adoption and compliance (Risse-Kappen \& Sikkink, 1999) and emphasized the role of transnational actors in promoting international norms (Finnemore, 1993; Finnemore \& Sikkink, 1998), while a second generation of scholarship emphasized dynamics of norm diffusion associated with the European Union (Linden, 2002; Schimmelfennig, 2000). This strain of theory is broad and somewhat dated, but has enjoyed a modest resurgence in recent human rights scholarship (Acharya, 2004; Nielsen \& Simmons, 2015; Terman \& Voeten, 2017; Zimmermann, 2016). This resurgence has highlighted three general mechanisms according to which international norms are expected cross borders and be adopted by national governments, including hegemonic and coercive mechanisms whereby countries are compelled to adopt global norms, transnational socialization mechanisms, in which national and transnational actors effectively argue and persuade national policy makers, and elite preference mechanisms, where national decision makers adopt global norms in the pursuit of their own interests (Zimmermann, 2016, pp. 94-104).

Of these three, mechanisms of compliance are not clearly relevant to the voluntary character of public governance MSIs examined here. Though self-interest has been shown to drive MSI membership, as a means of strengthening countries international reputation and position (Brockmyer \& Fox, 2015, p. 11; David-Barrett \& Okamura, 2016), this dynamic has not been shown to drive policy adoption subsequent to joining public governance MSIs, and is not clearly referenced in the theories of change presented in section 1.1. This dissertation's attention to international relations theory relies primarily on frameworks for understanding transnational socialization mechanisms related to argumentation and persuasion. 
IR scholars have advanced a number of theories about how socialization occurs, many of which emphasize social pressure and information flow between countries (Dobbin, Simmons, \& Garret, 2007; Finnemore \& Sikkink, 1998; Simmons, 2009). Relatively little research has attended to the theorizing the ways in which domestic factors shape the reception and adoption of global norms, despite a widespread recognition that "international norms must always work their influence through the filter of domestic structures and domestic norms, which can produce important variations in compliance and interpretation of these norms" (Finnemore \& Sikkink, 1998, p. 893).

The influence of domestic structure and domestic norms for the adoption of global norms is widely acknowledged in IR scholarship (Cortell \& Davis, 2002), even if it is only exceptionally traced in domestic processes (Cortell \& Davis, 2005). More regularly, IR scholarship operationalizes the influence of domestic factors according to a "logic of appropriateness" exercised by national political elites, who determine whether global norms are adopted (March \& Olsen, 2011; Müller, 2004; Nielsen \& Simmons, 2015). According to this view, political elites are the "gatekeepers" who determine the political appropriateness of global norms, and whether they are institutionalized and empowered in national contexts (Checkel, 1997, p. 576). While a handful of studies have explored these dynamics in specific country contexts (Acharya, 2004; Cortell \& Davis, 2005; Niemann \& Schillinger, 2017; Zimmermann, 2016), the majority of scholarship on global norm promotion has emphasized interactions between governments (Steinberg, 2003; Terman \& Voeten, 2017; Towns \& Rumelili, 2017), and little attention has been given to defining the domestic mechanisms through which global norms are adopted into national policy.

The most detailed attention to domestic processes is likely found in Risse's (1999) conceptualization of how human rights socialization. This work distinguishes between socialization mechanisms marked by political pressure and bargaining, by institutional habitualization, and by argumentation and dialogue, and Risse suggests that all three are "necessary for the successful internalization of international norms into domestic practices" (Risse, 1999, p. 530). Risse suggests an important sequence to these processes, whereby habitualization is conditioned on the successful prior operation of the other two mechanisms, as presented in Figure 4. 
Figure 4: Norms socialization in a human rights context. Adapted from (Risse-Kappen \& Sikkink, 1999)

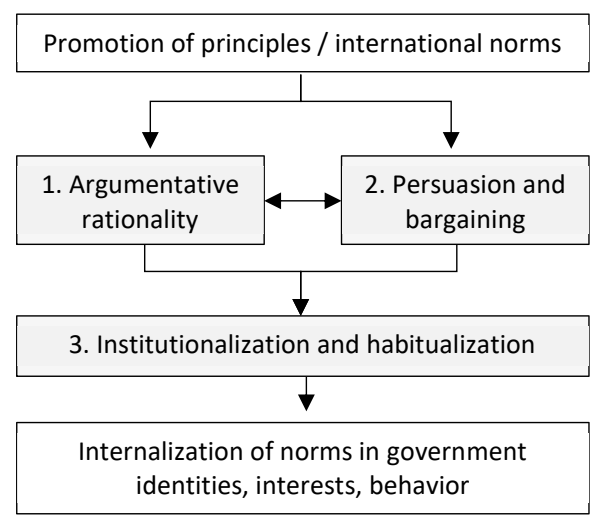

At first glance, each of these three mechanisms is relevant to the context of public governance MSIs, and OGP in particular, whose theory of change explicitly anticipates habitualization, and whose implementation has been marked by highly contentious debate and political pressure (T. Corrigan \& Gruzd, 2018; Guerzovich \& Moses, 2016; Schneider, 2015). OGP's deliberate use of international legitimacy to facilitate collaboration, dialogue, and coordination between stakeholders in action plan development resonates strongly with Risse's understanding of "argumentative rationality," where participants in a discourse "act as if material pressures, political power, and hierarchies were absent" (p. 553). Much as the OGP requires collaborative action plan development in order to place national civil society organizations on equal deliberative footing with government, Risse notes that argumentative rationality favors weaker groups, and is enabled in a human rights context by the social pressure of international peers, where otherwise resistant government actors are pressured to make tactical and symbolic concessions to global norms (pp. 539-542). This resonates strongly with the notion that OGP will "create a space in which high-level political leadership commits to reform, midlevel reformers are empowered, and civil society actively participates" (Guerzovich \& Moses, 2016, p. 3).

Risse provides the most detailed articulation from IR scholarship of how global norms are received and adopted in national contexts. The relevance of this theoretical framework should be treated with caution, however, given the highly contentious context in which it is developed. The antagonistic and often combative nature character of government 
engagement with global norms in Risse's framework contrasts starkly with the voluntary character of public governance MSIs (Risse-Kappen \& Sikkink, 1999) ${ }^{13}$, which may lend itself to less confrontational mechanisms of norm socialization.

A burgeoning body of scholarship on policy transfer and translation might help to fill this gap. Policy translation studies stem directly from research on policy diffusion, which explores the ways in which governmental policies are diffused across political entities in international or subnational environments, according to the communicative understanding of diffusion advanced by Everett Rogers (2003). This body of work draws significantly on a social constructivist approach to norm diffusion (Dobbin et al., 2007), and has proposed a number of comparable social mechanisms according to which government policies are distributed within the international arena, including learning, emulation, competition and coercion (Dobbin et al., 2007; Jörgens, 2009; Meseguer, 2005). Of these, the coercive mechanism has strong corollaries in the IR literature focused on human rights compliance (Dixon, 2017; Zimmermann, 2016), while competition has primarily studied in regard to the diffusion of economic and trade policies (Dobbin et al., 2007). The mechanisms of learning and emulation resonate strongly with the ways in which public governance MSIs aim to leverage social incentives and peer pressure to facilitate a "race to the top," but have not been assessed in the context of public governance policy or norm promotion by MSIs.

Policy diffusion studies have traditionally been oriented towards intra-governmental social dynamics, but have increasingly focused on policy adoption processes within countries. This is broadly denoted by the analytical and rhetorical shift away from diffusion and towards policy transfer, which emphasizes the communication of policy from "sender" to "borrower" governments (Dolowitz \& Marsh, 2000; Evans \& Davies, 1999; James \& Lodge, 2003; Obinger, Schmitt, \& Starke, 2013; Park, Wilding, \& Chung, 2014; Stone, 2004). Attention to these dynamics has highlighted instances in which transfer was distorted or incomplete, emphasizing the domestic political and communicative dynamics that inhibit successful policy transfer (Park, Lee, \& Wilding, 2016; Stein, Michel, Glasze, \& Putz, 2015), a

\footnotetext{
${ }^{13}$ Antagonistic resistance to the imposition of global norms is perhaps the defining characteristics of the nine case studies in which Risse's conceptual framework is validated (Kenya, Uganda, South Africa, Tunisia, Morocco, Indonesia, the Philippines, Chile, Guatemala, and Eastern Europe).
} 
research orientation later characterized as policy translation (Johnson \& Hagström, 2005; Stone, 2012).

The policy translation framework pays close attention to the discursive processes that shape and adapt global policies to national contexts. Though the voluntary nature of public governance MSI has been central to framing this analysis, the processes through which MSI norms are defined and implemented can be contentious and highly political (Halloran, 2015). The translation perspective provides a useful tool for assessing national policy debates in which competing national interests are mobilized to contest the appropriate meanings and understandings of global norms and policy (Park et al., 2014; Stone, 2004, 2016). As described in Johnson \& Hagström's (2005) study of policy translation in Sweden,

the translation process can be compared to a battlefield where groups with competing and irreconcilable perceptions of reality vied for supremacy. Since none of these groups managed to gain the upper hand, the process took on a life of its own. In such a struggle the political skills of the various actors often tend to play an important role (p. 343).

This description recalls social constructivist attention to how the appropriateness of global norms are debated in national contexts (Checkel, 1997; Müller, 2004; Niemann \& Schillinger, 2017), as well as recent scholarship on the translation and localization of norms (Zimmermann, 2016; Zwingel, 2012), and suggests that insights from each field might contribute to better understanding the ways in which national contextual factors influence the uptake of global norms by national actors.

Before looking more closely at the specific insights from IR theories of norm promotion and theory on policy translation, it is worth considering the challenges and advantages that might follow from integrating these two strains of theory. The most immediate objection to bridging these two branches of scholarship is that they study different things, most notably regarding degrees of specificity. Norms are generally considered to be abstract principles that guide behavior and expectations, which may or may not be codified in law or policy, and whose breadth allows for "a lot of acceptable options for 'appropriate behavior'” (Winston, 2017, p. 2). Policy is generally understood to be more specific and uniquely identifiable across jurisdictional contexts, which provides analytical 
clarity, and also organizes scholars of policy diffusion thematically around issues such as social welfare policy (Obinger et al., 2013) or specific EU directives (Vukasovic \& Huisman, 2017).

This distinction is contestable, however. Norms are regularly presented with high degrees of specificity, particularly in the context of international behavior. International law is itself often defined as a set of "specific legal norms" (Brunnée \& Toope, 2010), and recent international relations scholarship has noted that social norms can entail absolute standards for state behavior (Towns \& Rumelili, 2017), while O'Mahoney (2014) has proposed that norms are defined by tension between specific understandings of their application. Policy diffusion researchers have meanwhile emphasized the ambiguity inherent in structured policy, describing the abstraction operationalized by specific policy regimes (Hansen, 2016), and noted that many diffusion initiatives advance policy agendas that "consist of a shared set of objectives, rather than a set of identifiable tools or techniques" (Common, 2013, p. 14).

This observation justifies drawing on both areas of study in order to better understand how domestic factors influence the national adoption of global norms. Doing so builds on the social constructivist foundations shared by both, and employs the kind of "analytical eclecticism" advocated by Katzenstein \& Okawara (2001) as an appropriate method for "understanding inherently complex social and political processes," by drawing systematically on the insights of multiple, and potentially competing analytical paradigms ( $p$. 167).

It is also worth noting that norm promotion by OGP is particularly well suited to analysis along a spectrum of "soft norms" and "hard policies." OGP's theory of change can be read to deliberately equivocate between the high level political endorsement of abstract norms and the pursuit of ambitious reforms and specific policy in national action plan processes (Goldstein \& Weinstein, 2012), as discussed in section 1.2. Any insights regarding the effects of OGP norm specificity on processes of adoption and the influence of national factors are likely to be relevant to the study of both policy translation and norm entrepreneurship, and may provide further opportunities for bridging the two.

This analysis thus follows Katzenstein \& Okawara's (2001) assertion that analytical eclecticism makes the complex interplay of norms, power, and interests more intelligible by drawing selectively on different analytical paradigms. The remainder of this subsection 
explores insights from these two strains of theory in greater detail, and suggests how they might inform a theory of influence for public governance MSIs, before briefly reviewing the theory relevant to this dissertation's other two research questions.

\subsubsection{Individual and discourse in policy processes}

This dissertation aims to define theoretically-grounded causal mechanisms that drive MSI's national policy influence, and to do so in a way that is sensitive to the inherent complexity of policy change. This implies moving beyond categorical reference to the importance of national factors, exemplified by attention to the normative alignment of political structures in IR scholarship (Cortell \& Davis, 2002) and the path dependency of national institutions in policy transfer studies (Park et al., 2016). Theorizing causal mechanisms in this context requires direct theorization of policy change processes at multiple levels. As Kay \& Baker (2015) note

Mechanisms underpinning policy change [...] operate at the micro (individual behavior), meso (the actions of policy communities or networks), and macro (institutional or social systems that structure political interaction) levels. All three levels can be important in determining or constituting a given policy process $(p 9)$.

Acknowledging that scholarship on norm promotion and policy translation provide useful theoretical foundations for macro-level analysis, and that OGP offers a rich set of operational data on meso-level interactions, this dissertation is theoretically anchored to analysis at the micro level of individuals. This approach allows analysis to draw on theoretical insights regarding the "gatekeepers" of norm adoption (Checkel, 1997), while expanding that analysis beyond political elites, to acknowledge the ways that other actors within government institutions frame and construct policy ideas in line with their interests and objectives (Erikson, 2015; Johnson \& Hagström, 2005).

In practical terms, this entails anticipating that civil servants and policy-makers will be exposed to OGP norms through a variety of discursive structures. These might include national action plan consultations, peripheral debates on national policy, international exchanges with peers from other countries or the OGP secretariat, or internal processes within government institutions who have been called to participate in the OGP domestic policy mechanism. Individuals interact with norms and policy ideas in these different 
discourses in complicated ways, negotiating the content and relevance of OGP norms even as their own strategic positions may be shaped and defined by how those norms are framed and asserted by others (Erikson, 2015).

Importantly, this will occur differently within different discursive structures, as a function of the actors and incentives at play (Leipold \& Winkel, 2017). Persuasive argumentation and political pressure on national elites in domestic discourse may most closely resemble frame contestation (Boscarino, 2016), translation processes marked by irreconcilable interpretations of policy (Johnson \& Hagström, 2005: 376-383) or the spheres of influence framework when national advocates coordinate with international counterparts (Steinberg, 2003). The salience of OGP norms in international discourse might be affected by the varying degrees of interaction and reciprocity between promoters and receivers of policy (Park et al., 2016, 2014) or social incentives mobilized by treating national civil society actors as "proxies" for international advocacy movements (Sanders, 2016). Institutional engagement with OGP norms and processes may trigger dynamics of competition and comparison within or across institutions (Ben-Aaron, Denny, Desmarais, \& Wallach, 2016; Berliner \& Erlich, 2015; Jun \& Weare, 2011), prompt changes to the internal narratives and cultures by which institutions are defined (Chadwick, 2011; Schmidthuber, Antons, \& Hilgers, 2015; Wirtz, Piehler, Thomas, \& Daiser, 2016), or highlight incoherence between institutional and public facing policies related to open government (Savard, Villeneuve, \& Caron, 2013).

Some individuals may participate in more of these processes than others. Of particular interest are individuals that participate in multiple discursive structures, and transport norms and policy frames between them. The concept of "go-betweens" has been adopted in policy diffusion literature to refer to actors that facilitate diffusion by sharing information across macro and micro policy jurisdictions (Graham, Shipan, \& Volden, 2013). In their study of policy diffusion in US courts, Douglas, Raudla, \& Hartley (2015) distinguish between "top down" go-betweens that exert pressure to facilitate coercive mechanisms in a federated policy environment, and "epistemic" go-betweens that "help to 'transport' the policy across jurisdictional lines" (p. 489). While epistemic go-betweens in this read are primarily understood as organizations, such as trade organizations that organize conferences and publish educational materials, the emphasis on how such actors facilitate learning as a diffusion mechanism may be relevant to the interaction of policy makers and civil servants across multiple discursive structures in an MSI context (pp. 491-492). 
Individuals might also function as policy entrepreneurs. Policy entrepreneurs have been studied in a wide variety of advocacy and policy processes, but are traditionally understood as individual actors that "seek to initiate dynamic policy change" by "identifying problems, networking in policy circles, shaping the terms of policy debates, and building coalitions" (Mintrom, 1997, p. 739). As such, policy entrepreneurs are defined by the ways in which they deliberately pursue specific policy outcomes in the discursive structures where MSI norms and policies are debated and shaped. Douglass et al. note that epistemic gobetweens may also be policy entrepreneurs when they not only "transport" policy across multiple jurisdictions, but also "seek to initiate dynamic policy change by winning support for ideas" within their home institutions (Douglas et al., 2015, p. 489).

By tracing how individuals from multiple government agencies engage with multiple discursive structures as policy entrepreneurs and epistemic go-betweens, this analysis aims to thresh out the complex ways in which MSI influence is manifest in complex policy environments. It does so from a social constructivist perspective that expects individuals to "engage in the construction of ideas and discourses at the same time as their room for maneuver is affected by such constructions" (Erikson, 2015, p. 452), and cognizant of the fact that different discursive structures are likely to emphasize individuals' national, institutional or personal context to varying degrees (the macro, meso and micro, as Kay \& Baker would have it).

This approach responds to Falleti \& Lynch's (2009) observation that "specifying the analytically relevant aspects of the context within which a causal mechanism plays out is an integral yet widely ignored part of building valid causal explanations (pp. 1161-1162). A close look at the interaction of causal mechanisms and context also suggests that the logic of appropriateness applied by social constructivist theorists to explain state behavior is likely insufficient in this regard. Individuals can certainly be expected apply a logic of appropriateness when engaging with OGP norms in the discursive structures described above. The complex interplay of incentives and institutions also implies other logics, however, especially in the context of contentious policy debate.

Ben-Josef Hirsch's (2014) study of ideational change and norm emergence provides a useful categorization. Ben-Josef Hirsch proposes three types of logics, which he describes as "changes in the rational and moral reasoning and argumentation that frame the practice 
that is associated with an emerging norm are likely to make this practice congruent with more contexts" (pp. 812). These changes to the content of a norm include:

changes in the ideas associated with the goals expected to be attained by the application of the norm ('logic of consequences'), with its morality ('logic of appropriateness'), and with its relations with similar or alternative practices ('specification') (pp. 812).

While both IR and policy translation theorists have emphasized a logic of appropriateness in domestic debates about global norms, this framework opens for the operation of other logics that may be equally important.

The interaction of multiple logics with the influence of national, institutional or personal contexts presents a messy ideational process for any one individual, and mapping the potential variations of such processes is beyond the scope of this dissertation. It is important to acknowledge the multiple levels and logics of influence and ideation, however, while identifying detailed and theoretically-grounded causal mechanisms for MSI influence. While not strictly ethnographic, this approach aligns with Prince's (2012) call for attention to how different groups of individuals drive the ideas and discourses underpinning policy transfer, while satisfying Falleti \& Lynch (2009) call to specify the most analytically relevant aspects of context in causal analysis (pp. 1161-1162).

\subsubsection{Institutionalization and policy outcomes}

The policy influence of MSIs must inevitably be manifest at the level of institutions. In keeping with OGP rhetoric regarding the "socialization" of participation norms in government institutions over time, however, this dissertation does not treat changes to formal policy changes as the only possible evidence of OGP's influence. Instead, this dissertation posits a continuum between formal policy outcomes that might be represented by changes to legislation or administrative rules, and informal policy outcomes, which might be represented by changes to cultures or practices within institutions.

At the "soft" end of this continuum is a phenomenon often described as institutional culture change, indicated by uniform or widespread changes in behavior. Erikson (2015) suggests that "informal institutionalization manifests, for example, when many or the majority of all actors adapt their behavior to a certain policy frame, in either a positive or a 
negative way" (pp. 457-458). While practitioners have sometimes expected this type of change to result from the institution of open government regulations, institutional culture has demonstrated a remarkable resilience in the face of open government policy (Goëta \& Davies, 2016; Wirtz et al., 2016). Indeed, Villeneuve's (2014) study of Swiss transparency legislation finds a relationship between institutional independence and the effects of legislation on institutional culture, noting that the "greater the latitude an organisation has in terms of its management the greater the shirking of ATI obligation" (p. 561).

Other theorists have suggested that changes to institutional cultures are a precondition for formal policy outcomes. Checkel (1997) describes the "empowerment" of global norms in national contexts, defined by early stages of policy making related to the "politics of adoption" and agenda setting (pp. 476). Stone (2012) distinguishes between the "hard" transfer of policy from the "soft transfer" of policy knowledge, which provides "the intellectual matter that underpins policies" (p. 494). Studies on the implementation of open government and civic participation policy have also noted the importance of government culture as an enabling factor (Freeman \& Quirke, 2013; Wirtz et al., 2016; T.-M. Yang \& Wu, 2016) and Pasquier \& Villeneuve (2007) cite "hierarchic, introverted and risk-averse" culture as a key reason that bureaucracies resist opening to the public (p. 157).

When considering how norms move along this continuum of policy outcomes from informal to formal institutionalization, several of the causal mechanisms described above might be relevant. Björnehed \& Erikson (2018) describe a "ladder of institutionalization" (whereby policy ideas are introduced into policy agendas, gain the support and acknowledgement, and are formally institutionalized) that recalls Checkel's notion of empowerment, but offers little detail on the roles and interactions of individuals in that process (p. 113). Similarly, Risse-Kappen et al's (1999) notion of habitualization following from bargaining and argumentation is clearly relevant, but is not detailed enough to describe how individuals contribute to these processes, or to trace the influence of global norms within government institutions.

A more detailed framework can be found in Heikkila \& Gerlak's (2013) conceptual approach to collective policy learning, which describes the processes through which individuals access policy information and share the products of their learning to support collective learning within institutions, leading to "changes in collective behaviors or actions," 
as well as "formalized rules or sets of institutional arrangements and policies" (pp. 491-492). Heikkila \& Gerlak's model resonates strongly with the theoretical alignment of this dissertation, especially in providing an explanatory link between the norms and policy information promoted by MSIs, the discursive engagement of individuals, and the policy outcomes manifest in institutions. According to their framework, processes of individual learning are marked by three phases of knowledge acquisition: acquisition, translation and dissemination, which can be mapped onto MSI processes. Acquisition of information can be considered synonymous with exposure to MSI norm promotion, when that promotion includes information about policy. Translation refers to the process by which individuals interpret and assess what they learn about global norms. This process determines whether individuals then proceed to the third stage of dissemination, where they share the products of their policy learning with others, within and across institutions. This can initiate the same cycle for other individuals, contributing to group learning dynamics, the production of collective learning products, and policy outcomes.

This suggests the combination of MSI knowledge transfer and policy learning as a mechanism through which public governance MSIs exert their national influence. Developing and validating an analytical framework for this processes is the main focus of Article 1 . The resulting model is presented in detail and its implications discussed in section 5.1. Here it is worth briefly considering the sequential relationship between policy learning processes the IR theoretical processes of socialization.

In the framework advanced by Risse-Kappen \& Sikkink (Risse-Kappen \& Sikkink, 1999), mechanisms of persuasion and argumentation are only successful when followed by mechanisms of institutional habitualization. This can be read as a function of the antagonistic character of human rights socialization in Risse's cases, whereby governments actively resist the imposition of global norms. This antagonism may not be manifest in the context of voluntary public governance MSIs, where argumentative rationality may alone be sufficient to produce policy outcomes. Indeed, in light of the discursive theory presented above, mechanisms of argumentative rationality and strategic bargaining would operate in the multiple discursive structures through which individual policy makers and civil servants are exposed to MSI norms, and may lead directly to formal policy outcomes through the outputs of national action plans. These discursive structures would also be the starting point 
for processes of collective policy learning, which are initiated when individuals access policy knowledge (in this case, the norms promoted by MSIs), and extend into processes of institutional socialization, independent of the mechanisms of argumentation and bargaining.

This suggests a sequential logic to the mechanisms of persuasion and learning in the context of public governance MSIs, but that these mechanisms may also operate in parallel, as displayed in Figure 5.

Figure 5: Sequence and independence of causal mechanisms in the context of public governance MSIs

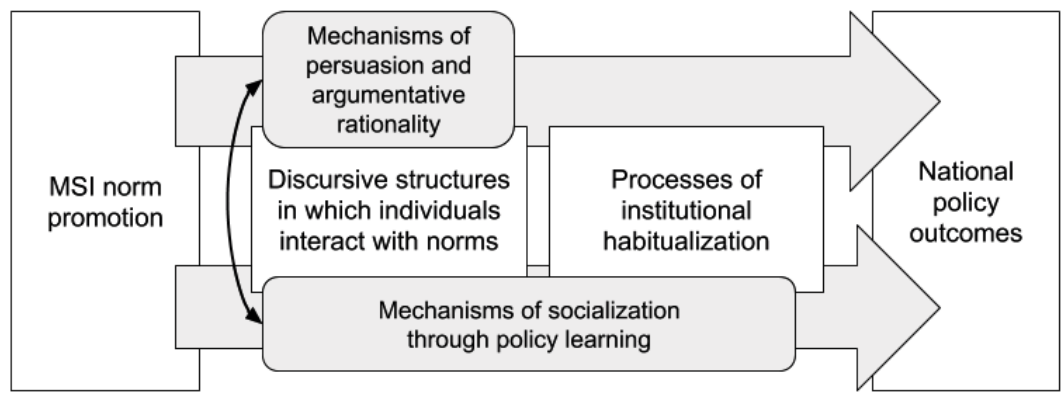

In summary, this section has so far presented IR norms scholarship and policy studies research on diffusion and translation as the two strains of research most theoretically relevant to this research. A cursory review of these literatures suggested that IR theoretical mechanisms of persuasion, bargaining, and argumentation, and policy studies theoretical mechanisms of emulation and learning, might be relevant for understanding the national policy influence of public governance MSIs.

Applying the logic of analytical eclecticism to integrate insights from each of these bodies of work suggests a close attention to how individual civil servants and policy makers interact with discursive structures in the context of MSI norm promotion. In particular, this suggests close attention to the ways in which individuals assess MSI norms, sensitive to national, institutional and personal context (Kay \& Baker, 2015), and varying logics of appropriateness, consequences, and specification (Ben-Josef Hirsch, 2014).

It was suggested that this engagement with MSI norms shapes the degree to which individuals facilitate the national adoption of norms, by endorsing and advancing norms and policy frames across discursive structures. Of particular note are instances in which 
individuals might function as gatekeepers, blocking or facilitating the dissemination of norms and policy frames (Checkel, 1997), or as epistemic go-betweens and policy entrepreneurs, who (sometimes deliberately) transport norm content and policy frames between multiple discursive structures. A close look at these roles highlighted the potential for MSI norm promotion to lead to variety of policy outcomes, spanning informal outcomes of institutional culture change and formal outcomes of policy adoption.

Theorizing individual discursive action as the link between MSI norm promotion and national policy outcomes highlights two causal mechanisms that might underpin the national policy influence of public governance MSIs. The mechanism of persuasive argumentation is drawn from theories of human rights socialization, is expected to operate in the discursive structures generated by MSI norm promotion, and may lead directly to hard policy outcomes. The mechanism of knowledge transfer and policy learning is drawn from theories of policy diffusion and policy change, and describes a sequence beginning with MSI norm promotion, through individual engagement in discursive structures, to informal institutionalization of norms and the eventual production of formal policy outcomes. These insights are used to develop an analytical framework with which to explain knowledge transfer and policy learning in Article 1. This framework is in turn used to posit theoretic propositions for developing a predictive theory of MSI influence, as will be discussed in detail in section 5.1 .

\subsection{Causal interaction, OGP, and e-participation}

Causal mechanisms interact with the contexts in which they manifest. As Falleti \& Lynch (2009) note:

...causal mechanisms are distinct from both inputs and outputs; they are portable and so may operate in different contexts. But depending on the nature and attributes of those contexts, the same causal mechanism could result in different outcomes ( $p$. 1161).

The ways in which mechanisms and contexts interact can be complex, especially in policy change processes, where Kay \& Baker (2015) recommend careful application of a process tracing methodology to the "dense web of relationships connecting states, companies, civil society organizations, and individuals as a policymaking system as well as 
analysis of their mutual influences," in order to account for the "antecedent, exogenous, complementary, and unobserved variables" that constitute policy context (pp. 2, 8).

While there has been significant theorization of inter-variable interaction and interactions between causal mechanisms and context, however, little attention has been paid to the potential for interaction between causal mechanisms as they are understood here. Layall (2015) notes that "settings marked by multiple [causal] mechanisms that interact in complex ways to produce a given effect" are particularly challenging for policy makers and impact evaluations (p. 206), but does not explore the ways in which these interactions might be theorized or measured. Indeed, causal theorists make regular reference to the existence of multiple causal mechanisms in a given context, and consistently warn about the analytical dangers of "equifinality (many different paths to the same outcome), and multifinality (many different outcomes from the same value of an independent variable depending on context)" (Bennett \& Elman, 2006, p. 251), but the mechanisms through which causal mechanisms might interact remain untheorized.

A detailed theorization of that dynamic is not pursued here. This analysis is nonetheless sensitive to the potential interaction of multiple causal mechanisms underpinning MSIs' policy influence. This sensitivity is enabled by a theoretical and analytical focus on individuals' engagement with discursive structures, and particularly with regard to the detailed theorization of multiple logics through which individuals assess global norms, and the multiple levels of influence to which these processes are subjected.

The degree of detail pursued here is somewhat arbitrary; one could differentiate infinitely between different layers and aspects of policy context. Institutional context, for example, considered here as one level of contextual influence in line with Kay \& Baker's distinctions between macro, meso, and micro levels of policy, could be broken down further, to acknowledge the multiple layers within institutions and the potential for tension and conflict between them (Falleti \& Lynch, 2009, p. 1156; see also Savard et al., 2013 for discussion in the context of open government). The approach adopted here, nonetheless, significantly extends the degree of granularity with which global norm adoption has been theorized, and can account for instances of interaction between causal mechanisms with a corresponding degree of detail.

This can be demonstrated with a brief review of the causal relationships proposed in section 1.2.3 to explain the parallel growth of OGP and the diffusion of e-participation. As 
discussed in that section, e-participation diffusion might contribute to country decisions to join OGP by lowering the costs of joining, insofar as the activities to be included in action plans are already initiated. This dynamic can also be influenced by social forces associated with enthusiasm for e-participation, as described in IR theories of norm diffusion.

Finnemore \& Sikkink's (1998) influential work on the lifecycle of global norms describes three sequential stages (pp. 895-905). The first stage of "norm emergence" is characterized by international advocacy efforts, norm building, and the increased acceptance of global norms by states in the international community. A "tipping point" is reach when norm entrepreneurs "have persuaded a critical mass of states to become norm leaders and adopt new norms" (p. 901). This introduces the second stage of "norm cascade," which is characterized by "pressure for conformity, desire to enhance international legitimation, and the desire of state leaders to enhance their self-esteem" (p. 895). The final stage of "internalization" describes an international environment in which "norms acquire a taken-for-granted quality and are no longer a matter of broad public debate" (p. 895).

Dynamics of conformity and esteem during norm cascades are particularly compelling in the current context, insofar as countries can be expected to seek "'social proof' - states comply with norms to demonstrate that they have adapted to the social environment-that they 'belong'” (see also Bucher \& Jasper, 2017; Finnemore \& Sikkink, 1998, p. 903). In an international policy discourse marked by enthusiasm for technology and participation, OGP membership provides a powerful signaling tool with which countries can indicate that they too practice "government 2.0". Importantly, the logic of norm cascades suggests that increasing social pressure to conform increases as norms adoption spreads. Analogously, increased diffusion of e-participation could be expected to increase the social pressure to signal belonging through international membership in initiatives like the OGP. In this context, the lowered "cost" of joining OGP becomes particular salient. Research on the ratification of human rights treaties has noted that governments ratify treaties because ratification allows states to make a costless expression of support for the principles treaties contain. Those who ratify reap "rewards for positions rather than for effects" [...] Because human rights agreements are not effectively monitored, "the expressive benefits that countries gain from the act of joining the treaty will be enjoyed...regardless of whether they actually comply 
with the treaty's requirements" (Nielsen \& Simmons, 2015, p. 3, citing Hathaway, 2002).

While compliance is not a relevant cost in the OGP context, the adaptation cost of designing and implementing new policies for national action plans might be, in line with the "cost hypothesis" that EU directives are best implemented when they are a "good fit" with existing policy and regulatory frameworks in member countries (Dunia, 1997). ${ }^{14}$ This validates concerns that countries are using OGP to "get credit" for things they would have done anyway or are already doing (Hasan, 2016, p. 3), but also suggests that the diffusion of e-participation might be driving membership, by increasing the number of things that countries are already doing.

This read adds depth and complexity to the material incentives for OGP membership suggested in OGP case studies (presented in in section 1.2.3). Expectations of increased investment and cooperation may underpin OGP's growth, and have been demonstrated to drive membership in the Extractive Industries Transparency Initiative (David-Barrett \& Okamura, 2016) and human rights treaty ratification (Nielsen \& Simmons, 2015). International relations scholars note, however, that countries regularly take policy action simply to "look good" in the international community, independent of any material incentives (Erickson, 2014, p. 182).

A close read of theories of norm cascades and international signaling suggests that in the context of increasing diffusion of e-participation and enthusiasm for government 2.0, OGP provides an easy way to do so. This in turn might interact with mechanisms of persuasion, argumentation, and policy learning that are at play in domestic contexts. Specifically, these dynamics can influence individuals' assessment of global norms in relation to national context and according to logics of morality, consequences and specification. This opens theoretical space for assessing not only interactions, but potential conflicts between causal mechanisms.

Section 1.2 .3 suggested two apparently contrary explanations, noting that OGP growth may be causing e-participation, or e-participation diffusion may be causing OGP

\footnotetext{
${ }^{14}$ Though subsequent research has largely debunked "goodness of fit" as an indicator of implementation in the EU context (Gerven, Vanhercke, \& Gürocak, 2014; Mastenbroek \& Kaeding, 2006), the idea of adaptation costs remains relevant to speculating on the drivers of OGP membership.
} 
growth. Attention to individual interactions with multiple discursive structures and causal mechanisms allows a theorization of how both might be true. Importantly, this operationalizes Falleti \& Lynch's argument the results of causal mechanisms depend entirely on contextual details within which causal mechanism operate (2009, p. 1151). A civil servant might, for example, find that a global norm is antithetical to the mandate of the institution in which she works, but that publically endorsing that norm can be advantageous for a country's international position. This implies an assessment of the norm according to multiple logics and contextual influences, which can be traced to mechanisms of argumentation, persuasion, policy learning, or even conformity. Mechanisms in this instance can produce the contextual factors which influence the outcomes of other causal factors.

The theoretical framework developed here situates the interaction of causal mechanisms in individual assessments regarding the appropriateness of global norms, which influences their outcomes. Whether the civil servant described above decides to strategically promote the global norm in her institution depends entirely on how she is exposed to different causal mechanisms, and how she experiences their influence. By this logic, the theoretical exposition of gatekeepers, norm entrepreneurs, and go-betweens is hoped not only to add analytical rigor by explicitly identifying the most analytically relevant aspects of the context at study (Falleti \& Lynch, 2009, p. 1167). Explicitly theorizing the ways in which they transport norms content and policy frames between discursive structures is hoped to also allow for a more detailed recognition of how causal mechanisms might interact.

\subsection{The contributions of civic participation to responsive and accountable government}

The idea of including members of the public in policy-making and policy processes has long been a source of enthusiasm, and widely hoped to improve the quality of democratic governance (Rowe \& Frewer, 2005). Scholarship on the matter has been more critical, noting that the devil is in the details. It is not only a question of which "tools and techniques [can be applied] for increasing public involvement in public decisions", but "rethinking the underlying roles of, and relationships between, administrators and citizens" (King, Feltey, \& O’Neill Susel, 1998, p. 317). 
The dangers of magical participatory thinking have been confirmed in several administrative contexts (Bryer, 2011; Mizrahi, Vigoda-Gadot, \& Cohen, 2009; Scott \& Thomas, 2017), and some research has documented participatory processes that have little or no effect on policy outcomes (Irvin \& Stansbury, 2004). Field experiments conducted in the context of international development have, moreover, shown that increased levels of participation can in some instances actually have adverse effects on the quality of governance (Khwaja, 2004; Sexton, n.d.).

Agreement on the specific factors that contribute to meaningful and efficient participation has been elusive, however, at least in part due to a proliferation of novel mechanisms for civic participation. Already at the turn of the century, Rowe \& Frewer (2000) complained that there was "little comprehensive or systematic consideration of these matters in the academic literature, and hence whether any particular application of a particular method may be considered successful usually remains undetermined" (p. 10). Notably, Rowe \& Frewer's observation was made without reference to digital media. ${ }^{15}$ The application of technology towards public participation has radically accelerated the diversity of tools and techniques to include everything from government wikis, to social media, to mobile apps for participatory mapping, and interactive voice response technology. It is hard to overstate the complexity this adds to what Fung calls "the multiplex conditions of modern governance" (Fung, 2006, p. 66).

Fung's response to this complexity is notable (2006). His Democracy Cube operationalizes a meta-level design approach to participatory processes, arguing that while public participation is most valuable for its potential to deficits of legitimacy, justice and effectiveness in existing governance mechanisms, not all participatory processes do so equally or comprehensively. "There is no canonical form of direct participation in modern democratic governance; modes of contemporary participation are, and should be, legion" ( $p$. 66). The logic here is that some participatory mechanisms will primarily address legitimacy deficits, others deficits of justice and so on. This necessitates design frameworks that acknowledge and compare how different architectural characteristics of participatory processes contribute to different aspects of democracy.

\footnotetext{
${ }^{15}$ Rowe \& Frewer typologize eight of the "most formalized public participation methods," including referenda, public hearings, citizen juries, and focus groups (Rowe \& Frewer, 2000, pp. 8-9)
} 
Fung proposes the spatial model of a Democracy Cube with which to make such distinctions, identifying three architectural characteristics with which to evaluate participation's contribution to legitimacy, justice and effectiveness. These characteristics are inclusivity, interactivity, and influence, which Fung describes as "who participates, how participants communicate with one another and make decisions together, and how discussions are linked with policy or public action" (p.66). Following the logic that "no single participatory design is suited to serving all [democratic] values simultaneously; particular designs are suited to specific objectives" (Fung, 2006, p. 74), it follows that a distinct set of design characteristics would attend to values of responsive and accountable governance.

A review of literature on contemporary participatory mechanisms highlights a structural approach to the communicative dynamics that Fung describes as inclusivity and interactivity. This is especially prominent in conceptual frameworks grappling with the affordances and disintermediation digital media can offer to public participation. Frameworks have attended to the directionality of communication (Ferber et al., 2007; Mergel, 2013; Welch \& Fulla, 2005; Zhou, Su, Wang, Hu, \& Zhang, 2013), the number and type of participants (Ferber et al., 2007; Haro-de-Rosario, Saez-Martin, \& del Carmen CabaPerez, 2016; McMillan, 2002), or whether communications and contributions to participatory processes are publically visible (Ferber et al., 2007; Peixoto \& Fox, 2016a). Other theorists emphasize the institutionalization and timing of government responses in participatory initiatives (Freeman \& Quirke, 2013), the back-and-forth quality "responsive dialogue" in cyber politics (McMillan, 2002; Yavuz \& Welch, 2014), or the automation of feedback mechanisms in government accountability programs (Gigler \& Bailur, 2014; McGee \& Edwards, 2016; Peixoto \& Fox, 2016a; Sjoberg, Mellon, \& Peixoto, 2015). Unsurprisingly, this suggests that sustained communication is an important meta-level design consideration for participatory processes that aim to contribute to responsive and accountable government.

This emphasis on communication and interaction aligns well with the "relational and communicative core of accountability" (Bovens, Shillemans, \& Goodin, 2014, p. 4). Government accountability is at bottom a transactional concept, implying that accountable actors share information and are judged by a corresponding party (Mabillard \& Zumofen, 2016). Accountability in a government must combine a relational and interactive dynamic with specific systems of control, however. "...limiting accountability to a simple function of 
answer- ability (the capacity of the administration to give an answer) without providing for sanctions in case of reprehensible behaviour may diminish the controlling power of accounting agencies" (Schedler, 1999, cited in Mabillard \& Zumofen, 2016, p. 7).

The exercise of control is an organizing principle for several conceptions of government accountability (Bovens, 2007; Fox, 2007; Lindberg, 2013), and the notion of "controlling power" in Schedler's articulation recalls the link to decision-making authority in Fung's cube. This has been articulated by deliberative theorists as the "coupling" of public deliberation with political elites. Scholars of participation in international development discuss this dynamic in candid terms of "power" when considering the political and contextual factors that can obstruct meaningful interaction between publics and government institutions (Gaventa, 2004). As Cornwall \& Coelho (2007) argue, "simply creating spaces does little to rid them of the dispositions participants may bring into them" (p.12).

Attention to the contextual manifestation of power relationships and control is also prominent in "bottom up" and ad hoc evaluation frameworks for evaluating novel forms of participation (see, for example Peixoto et al., 2016), and features in typologies like the IAP2 which distinguish categorically between types of participation (see also the categorical distinctions between consultation and collaborative problem solving in Loureiro, Cassim, Darko, And, \& Salome, 2016). This suggests control as a second meta-level design consideration for civic participation in the context of government responsiveness and accountability.

When considering interaction and control in the context of government responsiveness and accountability, it is worth noting that in the majority of evaluation and assessment frameworks referenced above, outcomes of government response and accountability are most readily considered as specific instances. Grossly oversimplified, they aim to discern the characteristics necessary such that any participatory process $X$ will lead to government response or instance of accountability $Y$ (note how "outcomes of interest" are framed in Peixoto \& Fox, 2016a). It would be a mistake, however, to understand the relationship between civic participation and accountable government as a one-off affair in the context of OGP. As noted in Carolan's review of evidence on open data, transparency and accountability, meaningful government accountability in an open government context 
requires "functioning response systems" and institutions responsible for enforcing accountability norms (Carolan, 2016, p. 6).

Thus, while civic participation processes can contribute to producing specific government or instances of government being called to account, they may also contribute to cultivating a practice and culture of accountability and responsiveness within government institutions. This notion of accountability is distinct from transactional and results-based accountability, though the two can sometimes align (Piotrowski, 2007, p. 108).

The responsiveness and accountability pursued in an OGP context is socialized and institutionalized, not episodic or transactional. OGP's theory of change hopes to achieve this objective through repeated instances of participation and civic interaction.

Each of [the] stages of the OGP process presents an opportunity and obligation for governments to engage with civil society and citizens. The action planning cycle is designed to become a virtuous cycle leading to ever more ambitious reforms, greater citizen engagement, and more faithful implementation of policies. [...] As norms shift and governments become more comfortable with transparency, governments will begin introducing more opportunities for dialogue and become more receptive to civil society input and participation (Open Government Partnership, 2014b, p. 16).

There has been little research conducted to determine whether the socialization process anticipated by OGP will actually bear fruit, though several studies have suggested that open government and citizen engagement practices interact with institutional and political cultures in complicated ways (Bertot, Jaeger, \& Grimes, 2010; Chadwick, 2011; Goëta \& Davies, 2016). Lemieux, Trapnell, Worker, \& Excell's (2015) analysis of Right to Information Regimes by is notable for its attention to the specific effects of implementing Right to Information legislation, including "third-degree outcomes [which] include the institutionalization of information access (disclosure as business-as-usual) and its impact on broad development outcomes" (p. 77).

Notably, this study did not document any such outcomes, and analysis of comparable legislation in the Swiss context found no evidence that it contributed to broad cultural changes in government institutions (Villeneuve, 2014). If this is due to lack of socialization mechanisms such as those suggested in section 2.1, the evaluation frameworks and literature described here suggest that specific participatory processes might pursue this 
through the systematization of sustained interaction, complemented by explicit design attention to dynamics of power in participation.

In summary, this subsection built on Fung's observation that specific characteristics of participatory processes contribute to different democratic values. Review of literature on government accountability and literature on participation suggests that meta-level design considerations related to interaction and control might be most closely associated with government responsiveness and accountability outcomes. Notably, this review also suggested the potential importance of systematizing these design considerations, consistent with mechanisms of socialization discussed at the beginning of this section. These observations provide a basis for developing quality metrics for civic participation, described in section 5.3 .

\subsection{Normativity, participation, and technology}

The discourse surrounding OGP often assumes that more civic participation is necessarily a good thing. A significant body of research suggests that this is not categorically the case however, as is described in section 2.3. Grönlund (2009) notes comparable presumptions in the study and practice of e-participation, including the assumption that "direct democracy is the ideal value for eParticipation [and] that increased sophistication in technology use leads to increased sophistication of participation" (p. 13). There is little evidence that technology is improving the quality of participation or that e-participation is significantly improving the quality of democratic governance in any systematic way, however, and several scholars have noted a bias towards success in the design and sampling strategies of e-participation research (Damnjanović, 2019; Geissel \& Newton, 2012; Spada \& Ryan, 2017).

As discussed in section 1.1.3, this enthusiasm for digital approaches to improving democratic governance can also be discerned in the discourse surrounding OGP, and the prominence of technological solutions in action plans have led researchers to quip that if the initiative "had a penny for every mention of the establishment of a website, the Partnership would fund itself" (Bahl, 2012).

As with the normative presumptions surround civic participation more generally, assumptions regarding the utility or appropriateness of technological approaches to 
participation may not be sound. Over-attention to technology in civic participation can distract from more traditional and more meaningful methods of facilitating participation offline (Damnjanović, 2019; Guerzovich \& Moses, 2016; Montero \& Taxell, 2015), and the enthusiasm for digital is sometimes deliberately used to distract from the absence of more traditional participatory mechanisms (Åström et al., 2012, p. 148; Jeff Gulati, Williams, \& Yates, 2014, p. 530). Over-emphasis on digital can also exacerbate inequalities in representation and access to government (Rumbul, 2015), facilitate political disengagement, and discredit other forms of civic feedback and participation (Mcgee, Anderson, Hudson, \& Feruglio, 2018, p. 10). The OGP secretariat appears to be thoughtfully attuned to these dangers, and has repeatedly warned against confusing open government with e-government and technology with transparency (Foti, 2014, p. 19, 2016, p. 22). Guidance on consultative processes consistently urges appropriate combinations of online and offline consultative mechanisms (Open Government Partnership, 2017a).

Technological enthusiasm nevertheless persists in government engagement with OGP. Indeed, as Harrison (2013) suggests, it is precisely this enthusiasm which differentiates open government discourse from previous policy agendas related to e-government and participation:

...this time, the wave of democratic enthusiasm is coming from inside the government itself. The payoff is an unprecedented array of solicitations and government programs for citizen empowerment; to register ideas and opinions, contribute to policy and decision making, and improve their lives and government itself through new forms of engagement with Government 2.0 (p. 398).

This dissertation makes an effort to identify instances of normative bias in regard to participation and the use of technology, clearly marking such instances as they arise in discourse, research, norm promotion, and practice. It does not, however, offer a thorough critique of these biases, nor thoroughly resist them.

This research is primarily interested in methodological strategies for assessing the influence of MSI norm promotion, and does not take a clear normative position on the norms under study. This may in some instances be read as subscribing to the same normative biases described above. By clearly identifying and articulating biases, however, this research hopes to provide additional tools for testing normative assumptions about the 
effects of participation and technology. This is particularly relevant in regard to this dissertation's third research question, which explores the degree to which civic participation norms are likely to contribute to responsive and accountable government.

\section{Methods}

This section presents the methods, measures, and data sources used in the dissertation. It begins a presentation in section 3.1 of the rationale, risks and advantages of using an adaptive, multi-methods research design. The following two sub-sections describe the specific methods and data applied in comparative and case study research, respectively. This includes consideration of validity and reliability, and special attention to the implications of my role as a national Research for the OGP IRM in the dissertation's single case study. Section 3.4 closes by discussing the process of case selection in detail, and the implications it has for external validity of this dissertation's findings.

\subsection{Multi methods research design}

This dissertation employs both quantitative and qualitative methods to support an argument spanning large $\mathrm{n}$-comparative analysis, within-case analysis, and conceptual development. Quantitative analysis is conducted on the relationship between OGP membership and measures of countries' e-participation policy $(n=193)$, as well as the coded content of OGP commitments in in countries' national action plans $(n=494)$. This contributes to balancing out scholarship on the OGP, which has to-date been dominated by individual case studies (Brockmyer \& Fox, 2015, p. 38). Qualitative analysis was conducted for a single country case, and integration of the two methods responds to calls from scholars of policy diffusion to deploy more creative research designs with an emphasis on the roles and functions of individual actors (Maggetti \& Gilardi, 2016; Prince, 2012).

The analytical advantages of multi-method research designs are widely acknowledged, particularly regarding their potential for analytical triangulation and precision (Gallagher, 2013; Meissner, Creswell, Klassen, Plano, \& Smith, 2011; Thurmond, 2001; Yin, 2009). In order to strengthen construct validity and the validity of findings, this approach also emphasizes the use of multiple data sources and convergent lines of inquiry (Gawel \& Bernsen, 2011, p. 17; Michener, 2015, p. 192; Yin, 2009, pp. 103-123). This includes content 
analysis of OGP action plans, comparative data on national policies, and the document and interview analysis derived from case-based research, which will be presented in detail below.

To generalize grossly, quantitative methods that are well-suited to identifying causal patterns across country cases, while qualitative methods that are well-suited to understanding the causal mechanisms that underpin those patterns. Combining these methods and their comparative advantages strengthens this dissertation's approach to case selection, as discussed in detail at the end of this section. Here it is worth noting that case selection in this research is best considered sequentially, whereby the two large scale quantitative studies reveal patterns of causal influence across large sets of countries, identifying typical cases, extreme cases, deviant and influential cases (Seawright \& Gerring, 2008). Deviant cases are particularly useful for the development of theoretical premises, and several are identified in comparative analysis, including Norway. Norway is also classified as a data rich case, and selected for within-case analysis of causal mechanisms in line with case selection methods recommended by George \& Bennett (2005, pp. 19-21, 75) and Seawright \& Gerring (2008, pp. 302-303), as will be discussed in section 3.4.

It should also be noted that the multi-methods design employed here allowed for an iterative design process that was much more circuitous than the sequence of case selection described above. Indeed, research on the Norwegian case was initiated several years before other analyses, adapting hypotheses and research design in light of findings from that case as well as other analyses. This processes, which Yin calls adaptive research design (2009, pp. 65-67), is closely analogous to the "soaking and poking" phase in process tracing, whereby a researcher "immerses oneself in the details of the case and tries out proto-hypotheses that may either quickly prove to be dead ends or become plausible and worthy of more rigorous testing (Bennett \& Checkel, 2014, p. 18).

This process involved several analytical pivots and adjustments to research design during the course of this dissertation. Such an approach necessarily introduces methodological risks, including the opportunity for bias or the risk that equivocation between measures and concepts associated with different methods will weaken the rigor of the research design (Yin, 2009, p. 65). These are non-trivial considerations for this dissertation, whose research object is of such an ambiguous character that norms of participation are assigned multiple definitions across multiple data sets, and which includes 
participant observations methods in the study's single case study. Analytical steps have been taken to mitigate these risks, and are described in section 3.3.

\subsection{Comparative analysis}

Two comparative analyses were conducted to assess the influence of OGP on civic participation in participating counties. Firstly, member countries' OGP action plans were reviewed for expressed intention to facilitate civic participation through government commitments. This analysis relied on commitment data released by the OGP IRM, covering action plans produced by OGP members between 2012 and 2015, and updated in December 2016 on the OGP website ${ }^{16}$. The full data set consisted of 2,015 commitments contained in 100 action plans from 61 participating countries. 494 commitments were filtered for relevance and subjected to content analysis. Content analysis applied the quality metrics developed in this dissertation's Article 3, and also coded commitments according to whether they made explicit reference to the use of technology or digital media.

In order to guard against bias or error in coding and content analysis, a "peer checking" method (Vaismoradi, Turunen, \& Bondas, 2013) was applied to twenty percent of coded entries, ensuring coder reliability and validity. Descriptive statistical analysis was then applied to the coded data for government commitments, in order to assess whether participation in OGP had produced explicit intentions to engage in civic participation within OGP policy fora.

It is worth noting that this analysis did not aim to measure causal effects. Only countries participating in OGP were assessed. Descriptive statistics suggested insights into the nature of commitments produced in OGP policy processes, but did not assert or attempt to identify a causal relationship between OGP norm promotion and national policy outcomes. Indeed, this analysis demonstrated a significant lack of government commitments to civic participation, representing a lack of policy outcomes for which a causal influence might have been asserted.

The second comparative analysis in this dissertation had a much broader scope of analysis in regard to countries, time periods and dependent variables. This analysis was

\footnotetext{
${ }^{16}$ See https://www.opengovpartnership.org/about/independent-reporting-mechanism/ogp-data, accessed 8 March 2019.
} 
oriented towards this dissertation's second research question and the assessment strategy of expanding the scope of attributable outcomes beyond the OGP results chain presented in Figure 3. To do so, causal analysis was applied to data on OGP membership and eparticipation, wherein OGP membership functioned as a treatment, and a full sample of countries were assessed $(n=193)$. In order to rigorously ascertain the causal direction of any statistical correlations, analysis covered a wider timespan than the four years of action plans described above, assessing the relationship between OGP membership and countries' eparticipation performance since the OGP's founding in 2011. Data on OGP membership was drawn from the OGP website. ${ }^{17}$ Comparative data on countries' scores on the UN's Eparticipation Index (EPI) were pulled from pdf copies of the UN E-Government Survey publications from 2003-2018, including a sub-indicator score for collaborative e-decisionmaking. The resulting data set included 193 countries, of whom 73 were OGP members at some point of time covered in the analysis. This analysis used statistical regressions to test for a causal relationship between OGP membership and the adoption of e-participation and collaborative e-decision-making, as recorded in the EPI.

Additionally, causal analysis of OGP's effect on e-participation assessed the role of national factors that might be expected to influence the adoption of civic participation norms. Values for these indicators were downloaded from publicly available data sources maintained by the World Bank, Freedom House and freedominfo.org. Moderation tests were applied using the PROCESS macro for SPSS (Hayes, 2013), and OLS regressions with an interaction term were used to test for mediation effects of the same variables. R-squared values and T-tests were used to assess the validity of findings from all statistical analyses.

\subsection{Within-case process tracing}

The comparative analyses described above suggest causal effects, but do not identify the mechanisms through which those effects are exercised. In order to identify and describe these mechanisms, process tracing methodology is applied to the deviant and data rich case of OGP in Norway. Case selection methods are described in detail in section 3.4. This subsection describes evidentiary sources included in within-case analysis and the rationale

\footnotetext{
${ }^{17}$ See https://www.opengovpartnership.org/about/independent-reporting-mechanism/ogp-data, accessed 8 March 2019.
} 
for using a process tracing methodology for that analysis, before discussing the risks associated with that method, and challenges relating to my role as a practitioner in that OGP case. The sub-section closes by describing the set of steps taken to mitigate risks of bias, equifinality and multifinality in analysis.

As described below in section 3.4, Norway was selected for within-case research partly due to its data rich character. As one of the founding members of the OGP, Norwegian civil servants began discussing the initiative with other founding countries nearly two full years prior to the OGP's formal launch, providing a rich body of experience and documentation on how civic participation and open government norms were disseminated and received. This analysis thus includes Norwegian institutional engagement with OGP and civic participation norms beginning with initial planning conversations in early 2010, through the completion of the implementation period of Norway's second national action plan in 2015.

Analysis focuses on the uptake of civic participation norms in 8 government agencies, ${ }^{18}$ and includes multiple evidentiary sources, which are presented in detail below. Some of this evidence predates formal data collection for this dissertation, and was obtained through my role as the national researcher responsible for evaluation of Norway's first two national action plans coordinated by the OGP Independent Reporting Mechanism (IRM). This dissertation's analysis is inevitably informed by that experience, presenting a number of methodological and analytical challenges, which will be discussed below. It is here worth noting that this process predated this doctoral research design and data collection, and has been conceptualized as ex post facto participant observation in order to identify and mitigate biases. Analysis thus includes evidence from the IRM process, including notes from my participation in public events, as well as interviews and correspondence with

\footnotetext{
${ }^{18}$ Section for ICTs, Modernization and Innovation in the Ministry of Local Government and Modernization (KMD, previously FAD), Various divisions in the Norwegian Ministry of Foreign Affairs (MFA), Agency for Public Management and eGovernment (DIFI), Department of Civil Society and the Voluntary Sector in Ministry of Government Administration, Reform and Church Affairs (KUD), Legislation Department in the Ministry of Justice, Directorate of Health in the Ministry of Health and Care Services, Department for Economic and Administrative Affairs in Ministry of Petroleum \& Energy, and the Department of Consumer Affairs and Equality in the Ministry of Children and Equality.
} 
government representatives. Consent was secured retroactively from individuals whose correspondence and interview data was included in this analysis. ${ }^{19}$

Formal data collection for this dissertation included twenty-seven in-depth and semistructured interviews, lasting approximately one hour and conducted between March and September 2018, either in person or over phone or VOIP. Interviews were recorded then transcribed, translated, and subjected to categorical and axial coding (Bryman, 2015, pp. 574-589). Documents secured through formal data collection included official and internal documents related to the OGP process, as well as reports and correspondence from civil society counterparts. An overview of evidentiary sources from the Norwegian case is presented in Table 2.

Table 2: Documents and evidentiary sources applied to within-case analysis

\begin{tabular}{|c|c|}
\hline Data sources & Details \\
\hline $\begin{array}{l}\text { Websites and } \\
\text { administrative } \\
\text { documents }\end{array}$ & $\begin{array}{l}\text { Multiple sources associated with national OGP coordination and } \\
\text { commitment implementation in } 8 \text { Norwegian agencies }\end{array}$ \\
\hline $\begin{array}{l}\text { OGP documents } \\
\text { related to Norway's } \\
\text { first two national } \\
\text { action plans }\end{array}$ & $\begin{array}{l}-2 \text { National Action Plans } \\
-4 \text { Formal assessments by the OGP IRM } \\
-2 \text { Self-assessment reports by the Norwegian government and } 22 \\
\text { individual agency self-assessment reports }\end{array}$ \\
\hline $\begin{array}{l}\text { Semi structured } \\
\text { interviews* } \\
\text { (March } 2017-\text { Sept } \\
\text { 2018) }\end{array}$ & $\begin{array}{l}\text {-With agency focal points for commitments in national action plans } \\
(12) \\
\text {-With individuals responsible for coordinating national } \\
\text { participation in OGP (8) } \\
\text {-With civil society stakeholders and counterparts (9) }\end{array}$ \\
\hline $\begin{array}{l}\text { Personal } \\
\text { documentation from } \\
\text { the IRM process, 2012- } \\
2015\end{array}$ & $\begin{array}{l}\text {-Notes from over } 50 \text { informal interviews with government and civil } \\
\text { society representatives between May } 2013 \text { and September } 2015 \\
\text {-Notes from } 3 \text { sector-specific public consultations conducted in } \\
\text { May } 2013\end{array}$ \\
\hline
\end{tabular}

\footnotetext{
${ }^{19}$ Note that my role as IRM researcher is not clearly stated in Article 1, in order to preserve anonymity for the peer review process. Instead, that article notes that "the author [... participated in policy debate and IRM evaluations of OGP in Norway while working as [redacted to preserve anonymity]." An explanation and suggested footnote have been supplied to the journal editor.
} 
-Notes from public consultations and information meeting held the Norwegian agency responsible for OGP coordination (KMD)

*= 27 interviews were conducted, but two interviewees occupied dual roles, resulting in a total of 29 interviews indicated in the column to the right.

Use of a process tracing methodology in this analysis responds directly to calls for deeper qualitative study of norm adoption and policy diffusion (Cortell \& Davis, 2005; Douglas et al., 2015). The utility of process tracing has been demonstrated for several dynamics embedded in the current research effort, including the role of ideas in policy processes (Jacobs, 2014), the uptake of collaborative policy initiatives in government institutions (Ulibarri, 2015), and the influence of national factors on global norm adoption (Cortell \& Davis, 2005). Kay \& Baker (2015) provide a detailed assessment of the contributions that rigorous process tracing methods can make to policy studies, and stress the approach's "methodological advantages in building and testing theories of policy change over time, notably in supporting a theoretical pluralism that gives answers to the problem of complexity in policy studies" (2).

Ironically, this complexity also plays to a common weakness in the application of process tracing, and the dangers of failing to account for occurrences of equifinality (when multiple causal mechanisms contribute to the same outcome) or multifinality (when multiple outcomes are generated by a single causal mechanism) in particular (Bennett, 2002; Mahoney \& Goerts, 2006). The risks of overlooking such dynamics are greater with increased complexity in causal environments, and are particularly salient in policy-making processes, where

understanding change in terms of only one or two causal variables will, in many cases, likely underestimate causal complexity. There may not be just a few but many variables, and the relationships between them may be independent-dependent but also potentially interdependent as well as temporally dynamic (Kay \& Baker, 2015).

The complexity inherent to studying processes of policy change is exacerbated for this research contextually, ontologically, and in regard to the bias that accompanies interviews conducted in normative contexts. Contextually, introducing the international and 
transnational dynamics of MSI norm promotion further muddies the already muddy waters of policy analysis, increasing the chances that analysis will fail to account for equifinality and multifinality in the "performative and constantly interpretative and experimental process" through which international policy intermediaries facilitate the adoption of norms and policy by national policy makers (Stone, 2012, p. 493).

Ontologically, the effort to generate theoretical premises and propositions about the influence of norms will always struggle to account for the ways in which normative processes are influenced by cultural factors which cannot be exhaustively identified. The influence of culture is as slippery as it is ubiquitous, and as Cortell \& Davis (2002) note, the imprecise nature of norms and culture make it impossible for deductive reasoning to exclude the possibility that alternate and previously unidentified mechanisms and contributing factors might also be active and sufficient to produce outcomes of interest (p. 85). Lastly, and in regard to bias, interviews with government representatives and documents produced by government organizations can be expected to advance a particular narrative regarding government performance and the influence of OGP, and cannot be treated as objective representations in the context of causal process tracing.

This final point is the most widely treated methodological challenge to a rigorous process tracing methodology, and is exacerbated in the current case by my previous role as the national researcher for OGP'S IRM. As the IRM researcher for Norway, I led the evaluation of two national action plans, beginning in 2012 and concluding in 2016, one year prior to the design of this dissertation's research strategy and preliminary data collection for this doctoral thesis. My role as IRM research thus predates, but inevitably influences this research design and analysis. The remainder of this sub-section discusses how this complicates the methodological challenges of equifinality and multifinality, and steps taken to mitigate those risks.

IRM evaluations and doctoral research on the Norwegian OGP case can be clearly distinguished on a timeline, but overlap significantly in terms of people and data. The IRM processes, for example, included interviews with over 50 government officials responsible for the design and implementation of specific OGP commitments, several of which were interviewed again as part of the formal data collection process. Reports and documents of the IRM process feed directly into process tracing analysis, including notes taken while acting as an IRM researcher, and contribute to the Norwegian case's character as a data rich case. 
Previous experience and personal familiarity with the people and institutions surrounding Norwegian OGP processes introduces a meaningful risk of analytical bias in process tracing, however, including socio-cultural bias and confirmation bias in particular (Schwartz, 1955, pp. 352-353). To mitigate these risks, data from the IRM process was incorporated into doctoral research design as ex-post facto participation observation. Appropriate methodological safeguards were combined from the literature on participant observations (Becker, 1958; Drury \& Stott, 2001; Roulston \& Shelton, 2015) and the literature on process tracing (Bennett \& Checkel, 2014; Bennett \& Elman, 2006; Collier, 2011b; Gawel \& Bernsen, 2011; Mahoney \& Goerts, 2006) to establish three strategies for managing risks to construct validity and the potential for spurious analysis.

Firstly, evidence for particular causal mechanisms or influences on OGP norm adoption derived from interviews and documents were queried against multiple evidentiary sources (including administrative, interview and participant observational sources) (Kay \& Baker, 2015, pp. 13-14; Yin, 2009, pp. 118-120). When support for findings was confirmed through data triangulation, hypotheses were subjected to Bayesian-inspired evidentiary tests, to explicitly update prior expectations in light of new evidence, and to test the uniqueness and certainty of evidence in order to evaluate its inferential power (Bennett \& Checkel, 2014, pp. 16-7, 24-25). Findings and hypotheses were deemed valid after these two steps were validated with stakeholders in Norway and in the OGP IRM, and continually evaluated through an iterative and deductive process as new findings and evidence came to light.

Secondly, this approach was designed to maximize evaluation of alternative explanations, a technique that dominates five of the ten best practices recommended for process tracing by Bennet \& Checkel (Bennett \& Checkel, 2014, pp. 17-31). Evidence is collected from multiple stakeholder perspectives (government, civil society, OGP and evaluator) for each agency and causal process under study in order to identify as many potential explanations as possible. Theoretical attention to the complex intersection of macro, meso and micro levels of policy processes (Kay \& Baker, 2015, p. 8) also informs data collection and interview processes, encouraging the articulation and identification of mechanisms that might not align with dominant interpretations or those anticipated by the discourse surrounding OGP. Comparison of causal processes across eight distinct 
government agencies and policy outcomes adds the potential for dissonance and contrast in comparing and evaluating alternative explanations.

Thirdly, this analysis distinguishes between categories of causal process observations (Collier, 2011a), prioritizing those that highlight independent variation between the causal force of norms and ideas, and the force associated with material or structural policy mechanisms. Put simply, explanations that highlight the causal force of an idea are more compelling if the material rules, regulations and incentives that are in place would alone have led to a different result. This might be exemplified by causal explanations that account for changes to directives or institutional procedures, independent of changes to personal beliefs and actions of government actors regarding civic participation, and where that distinction emphasizes the contributions of one dynamic independent of the other. Emphasis on such contrasting observations helps to identify and address collinearity between normative mechanisms and the material or structural mechanisms of institutions and procedures which may embody or communicate those norms (Jacobs, 2014, pp. 46-47).

\subsection{Case selection, theoretical development, and external validity} Causal analysis in Article 2 suggests that OGP's influence on civic participation in member countries is significantly moderated by national contextual factors, but noted several outliers to this general correlation, and particularly regarding the relationship between freedom of information legislation and e-participation, hereafter described as deviant cases. Norway, USA and other northern European countries are prominent among these outliers. As founding OGP countries, Norway and USA can also be considered data rich countries, by virtue of the documentation available on civil servants' exposure to OGP norms and discourses across a broad swath of institutional contexts, beginning two years prior to the launch of the initiative.

Norway is doubly relevant as both a deviant and data rich case in this regard. In terms of data availability, my role as IRM researcher in Norway (discussed in section 3.4) allows access to a wide range of data on OGP norm promotion. In regard to deviance, Norway is a surprising exception to the presumed correlation between strong democratic performance and strong OGP implementation, and has been described as representing a "race to the bottom" in OGP performance (Petrie, 2015b). Norway is selected for within-case analysis on this basis, the implications of which are discussed below. 
The Norwegian case's deviant and data rich character is particularly advantageous for identifying and characterizing causal mechanisms, and developing theoretical premises for those mechanisms which can then be tested and expanded in order to develop middle range theory with predictive capacity (A. Bennett \& Checkel, 2015: 269-272; Falleti, 2006; Kay \& Baker, 2015). This implies a "building block" approach to theoretical development, in which individual and contrasting case studies are used develop and test theoretical premises, which in turn help to develop the scope conditions for middle range theory on specific types of cases. According to this process, within case analysis is used to identify "subtypes or the causal processes that apply to a subtype of cases," collectively contributing to "the cumulative refinement of contingent generalizations on the conductions under which particular causal paths occur, and fills out the cells or types of a more comprehensive theory" (George \& Bennett, 2005, p. 112). The deviant and data rich character makes Norway a useful first case for developing the theoretical propositions that can be subsequently tested against a broader set of contrasting cases.

This dissertation should accordingly be understood as the first step toward building a theory of MSI policy influence, which has important implications for considering the external validity of findings. Most obviously, this dissertation's reliance on a single case study suggests that findings cannot be applied to other cases. This is particularly true given the case's deviant character, and the distinct character of the Norwegian context, including the highly developed nature of democratic institutions and Norway's role as a founding member of OGP, which are not shared by the majority of countries to whom MSIs promote norms of public governance. The findings from within-case research in the Norwegian context cannot and should not be categorically applied to a wider population of cases. ${ }^{20}$

Any consideration of this dissertation's external validity must be based on the distinction between analytical generalization derived from theoretical claims about causal relationships, and statistical generalization derived from numerical assessments about the representivity of a case to a population (Yin, 2009, pp. 40-65). The analytical generalizability

\footnotetext{
${ }^{20}$ This would likely be the case for most single cases in the broader population of OGP members, where political, economic, geographic, and cultural factors vary infinitely, and OGP norms are always uniquely defined and adopted according to country context. Indeed, there may be no "representative" case of OGP participation. OGP's interpretive and voluntary character exaggerates the "hardy and perennial dilemma of comparative public policy scholarship" where "it is not possible to make comparative case comparisons or when comparative cases are imperfectly matched so controlling is not feasible" (Kay \& Baker, 2015, p. 6).
} 
to which this research aspires is part and parcel with the project of theory building described above. The use of theory-guided process tracing "offers a way forward [when it is not possible to make comparative case comparisons] by supporting causal inference from within-case research designs by supporting robust theoretically plural explanations of policy change" (Kay \& Baker, 2015, p. 6). This provides a basis for theory building around the policy influence of public governance MSIs, while adding nuance and complexity to the policy discourse surrounding their evaluation and design. 


\section{Summary of Analyses}

This dissertation is based on peer-reviewed journal articles. The breadth and scope of this dissertation's research questions required four separate analysis and articles, which are presented in Table 3, together with their publication status and substantive focus. These four articles are interlinked both methodologically and analytically, in an effort to holistically address the three research questions presented in section 1.3.

Most notably, Articles 1 and 2 are mutually informative, though they are individually associated with distinct research questions and assessment strategies. Article 2 provides empirical evidence in support of Article 1's theoretical and explanatory analysis of the causal mechanisms underpinning MSI influence (RQ1), for example, while Article 1 explains the mechanism responsible for attributing e-participation diffusion to OGP in Article 2 (RQ2). In a similar vein, Article 4 applies and validates the quality metrics developed in Article 3 (RQ3), while also providing evidence in support of arguments levied in Articles 1 and 2. Methodologically, large-n quantitative analysis in Article 2 is used to support case selection for Article 1's within case analysis.

The remainder of this section presents each of these analyses in turn, highlighting justification, methods, findings, and relationships to other articles. 
Table 3: Overview of articles

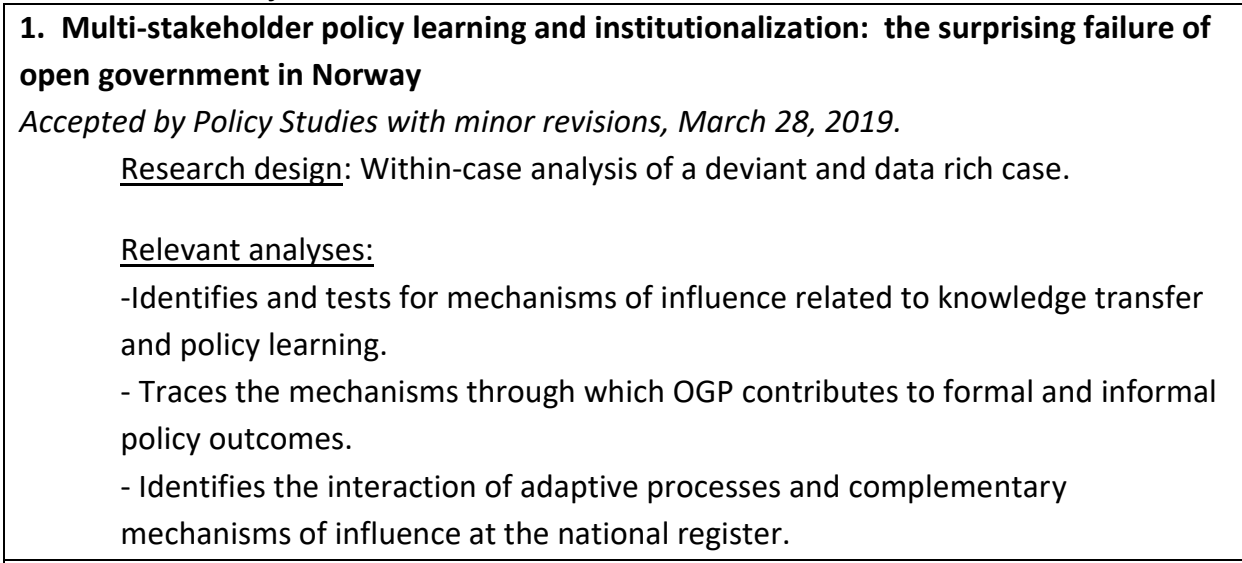

2. Open Government and E-Participation: assessing the effect of the Open Government Partnership and national political factors

Revisions submitted to Government Information Quarterly Jan 18, 2019.

Research design: Comparative analysis of e-participation in OGP participating and non-participating countries ( $n=193)$.

Relevant analyses:

-Assesses whether OGP contributes to the institutionalization of e-participation and collaborative e-decision-making.

-Tests the influence of national contextual factors on OGP's influence.

\section{Digital Civic Interaction: Identifying, conceptualizing and comparing interactions} between governments and publics

Submitted to International Journal of Communication, December 12, 2018.

Research design: Conceptual development.

Relevant analyses:

-Draws quality metrics for civic participation from a selection of relevant literatures.

- Emphasizes the importance of interaction for civic participation in an open government context.

4. Look Who's Talking: Assessing Civic Voice and Interaction in OGP Commitments

Published in eJournal of eDemocracy and Open Government special issue on Dec. 2017

Research design: Comparative analysis of action plan commitments by OGP participating countries $(n=61)$.

Relevant analyses:

- Evaluates the contributions of civic participation and civic voice in OGP action plans, according to the quality metrics described in Article 3. 


\subsection{Multi-stakeholder initiatives, policy learning and institutionalization:}

\section{the surprising failure of open government in Norway}

This article assesses the policy outcomes that resulted from OGP's promotion of civic participation in Norway, with a specific focus on participation enabled by digital media. This analysis identifies the causal mechanisms linking OGP to specific policy outcomes in eight government agencies.

To do so, this article first situates Norway as a data rich case, and as deviant in regard to the presumed correlation of democratic governance and OGP implementation. ${ }^{21}$ The article then conceptualizes a continuum for policy outcomes that might result from OGP norm adoption, distinguishing between formal and informal institutionalization of norms. An analytical framework for assessing the policy outcomes of OGP's norm promotion is then developed, drawing on the OGP's own theory of change, as well as theoretical frameworks from policy studies and norms research in international relations. A process tracing methodology is applied to determine what Norwegian policy outcomes can be associated with OGP's promotion of civic participation, the causal mechanisms through which that influence can be explained, and the analytical and theoretical implications of those findings.

Analysis of the Norwegian OGP case draws on administrative, interview and observational data collected over a 6-year period, and assesses processes and outcomes associated with 8 distinct Norwegian institutions. Iterative application of deductive and inductive analytical methods identify 3 formal and 3 informal policy outcomes associated with participation in OGP. In all three instances of informal policy outcomes, knowledge transfer from OGP and subsequent policy learning cycles demonstrate significant explanatory power. In one of these instances, these mechanisms continued to build on informal policy outcomes and led to a formal policy outcome. Regarding other instances of formal policy outcomes, mechanisms of argumentation and persuasion were identified in one instance, and no causal mechanism was evident in the other.

\footnotetext{
${ }^{21}$ Analysis of the relationship between OGP membership, freedom of participation and e-participation pursued in Article 2 (section 5.2) is not referenced in this article. Nor does this article discuss Norway's deviant character in regard to that analysis, though it is methodologically relevant for considering this dissertation as a whole.
} 
Causal analysis emphasized the important role that individual civil servants and policy makers play in gatekeeping or facilitating processes of policy learning in response to the promotion of norms by international actors like the OGP, and the institutionalization of policy outcomes by extension. In particular, this emphasized the variety of ways in which global norm promotion can be blocked and OGP's aspirations towards national institutionalization thwarted. Analysis suggests that the norms promoted by MSIs like the OGP might have greater salience and potential impact on national policy when they are framed and promoted according to institutional and individual logics, and particularly when those framings anticipate distinctions between logics of morality, consequences, and specification.

Theoretically, this analysis validates the explanatory power of an analytical framework in which global norm promoters like the OGP influence national policy through a combination of knowledge transfer and policy learning. Doing so fills a notable gap in policy studies, and provides an analytical foundation for bridging several other fields of study. This analysis also generates two specific theoretical propositions, regarding the importance of "fit" between global norms and national context, and the importance of policy frames that emphasize logics of consequence and specification. The article closes by sketching a research agenda in which those propositions can be tested, in order to a develop middle-range theory capable of predicting the influence of public governance MSIs like the OGP.

In summary, this article demonstrates the explanatory power of knowledge transfer and policy learning as a causal mechanism underpinning OGP's policy influence. It also demonstrates a continuum of policy outcomes that might result from MSI norm promotion, and highlights the important and complicated role of individuals in gatekeeping and shaping these processes.

Status: Submitted to Policy Studies, October 22, 2018, awaiting response.

\subsection{Open Government and E-Participation: assessing the effect of the Open Government Partnership and national political factors} This article assesses whether membership in OGP has an effect on countries' e-participation practice, and the influence of national contextual factors on that relationship. 
To do so, this article notes OGP expectations regarding how sustained interaction between governments and civil society will change norms and culture within government over time, and conceptualizes how this might result in outcomes external to OGP action plans. The article then compares data on OGP membership with data from the UN EParticipation Index (EPI) from 2012 through 2018. OLS regressions are run on the 2018 eparticipation scores of 193 countries, in which OGP membership in 2014 is treated as a treatment variable $(n=65)$, and shown to have a significant statistical correlation with eparticipation scores. This correlation is weaker but more statistically significant for the more interactive variable of collaborative e-decision-making. Data tables were constructed to compare the e-participation scores of OGP members in the periods before and after joining OGP (data covering 2008-2018 was available for 58 OGP member countries). This analysis suggests that the correlation is in fact causal, and that OGP membership has a modest but statistically significant causal effect on e-participation in member countries.

Regressions were also run to test whether national factors related to civic participation exert a moderating force on OGP's e-participation effect, or were mediated by OGP membership and are actually responsible for OGP's effect. Specifically, two types of national factors were assessed in relation to OGP membership in 2014 and e-participation scores in 2018. The alignment of national political and administrative structures was indicated by scores for voice and accountability on the World Governance Indicators for 2014. The national legitimacy of civic participation norms was operationalized through the number of years that countries have had functioning freedom of information legislation, and the average quality of democratic practice over the last quarter century, as assessed by experts in the annual Freedom in the World Report.

When considering the relative predictive power of all variables, the single indicator for national structures demonstrated a much stronger influence on all dependent variables than either legitimacy variable. This was true for OGP membership, both dependent eparticipation variables, and in moderating OGP's effect on both dependent variables. This suggests that the alignment of democratic structures is a more important factor for both eparticipation and OGP membership than aspects of national culture or democratic traditions. Indeed, the legitimacy of participation norms was further complicated by differences in the effects of each variable, and that the number of years with FOIA legislation actually had a negative moderation effect on the relationship OGP and both e-participation variables. 
Removing outliers for the moderating variable (Sweden has had FOIA legislation for nearly 300 years) weakened but did not remove the negative moderation effect, suggesting a complicated relationship between norm legitimacy and the effect on international norm promotion by MSIs like the OGP. Scatter plots for this relationship suggested several outlying cases for quantitative analysis.

On the question of whether OGP is actually exerting an influence, or simply mediating the work of national factors "behind the scenes," regressions revealed significant variation. In particular, the direct effects of all three national factor variables on eparticipation occupy a wide range (.005 - .724). Despite this, OGP's effect on e-participation variables when controlling for mediation effects is considerable, positive, statistically significant, and consistent (ranging between .207 and .237 for e-participation and between .227 and .246 for e-decision-making). This suggests that OGP has a meaningful effect on countries' e-participation performance independent of national factors. OGP's influence is most meaningfully moderated by domestic structures, and banded visualizations suggest that this effect is most pronounced at the upper end of the dependent variable. This implies that that OGP will have a stronger effect on e-participation in countries whose political and institutional structures are already aligned with civic participation norms. Legitimacy of participation norms does not clearly exercise a comparable effect.

In summary, the article suggests that OGP exercises a modest but statistically significant positive influence on countries' e-participation practice, and that this effect is not attributable to national contextual factors. This is effect is, however, most pronounced regarding the promotion of less progressive participation norms, and in countries that already exhibit strong democratic practice.

Status: Revisions submitted to Government Information Quarterly Aug 31, 2018. Awaiting response.

\subsection{Digital Civic Interaction: Identifying, conceptualizing and comparing interactions between governments and publics}

This article proposes a conceptual model for identifying and comparatively assessing instances of civic participation and interaction between government and non-governmental 
actors facilitated by digital media. The emphasis on digital civic interaction is more narrowly focused on digital than this dissertation's attention to civic participation, and addresses a wider universe of universe of cases, beyond OGP-specific norms and policies. While the substantive focus of this article is thus distinct from the rest of the dissertation, the resulting model provides quality metrics for assessing civic participation norms and policies in line with this dissertations' third research question, which are then applied in this Article 4.

This article begins by noting the prominence and variety of digital civic interaction as an empirical phenomenon worldwide. It then asserts a tension between the importance of the phenomena in scholarly commentary, and the lack of theoretical or conceptual attention it has received as a cross-disciplinary phenomenon. This is followed by a sketch of how digital civic interaction has been treated in prominent scholarly disciplines, including political communication studies, political science, public administration studies, e-participation studies, and development and communication studies, noting common trends in research objects and research designs. The article then draws on this literature and communications theoretical understandings of interaction to construct a conceptual model for digital civic interaction that transcends disciplinary boundaries.

Goertz's 3-level model for social science concepts is used to structure the concept (Goertz, 2012). This results in the identification of digital civic interaction as a primary level concept, according to which empirical phenomena can be commonly compared and assessed, and which can be defined according to a non-continuous scale of 6 modes, ranging from the government release of information to the public, to sustained and bi-directional interaction between government institutions and non-government actors (releasing, enabling, receiving, reacting, responding, and dialogue). The concept's secondary level identifies four constitutive components of digital civic interaction, drawn from a broad array of relevant literature, by virtue of their capacity to contribute to responsive and accountable government. These include two-way and inter-referential communication, participant control, governance context, and digitally-enabled interaction, which are considered collectively necessary and sufficient. The third level of the concept identifies empirical indicators for each of the constituent components, and discusses their constitutive and causal inter-relationships. 
The full model is presented in Figure 6 The first three constitutive components at the second level and their corresponding indicators provide quality metrics for assessing the quality of civic participation norms promoted and adopted in the context of public governance MSIs. These metrics are presented in full detail in section 5.3.

Figure 6: A full three-level model for digital civic interaction INDICATOR LEVEL (discernible in either policy or practice) SECONDARY LEVEL BASIC LEVEL

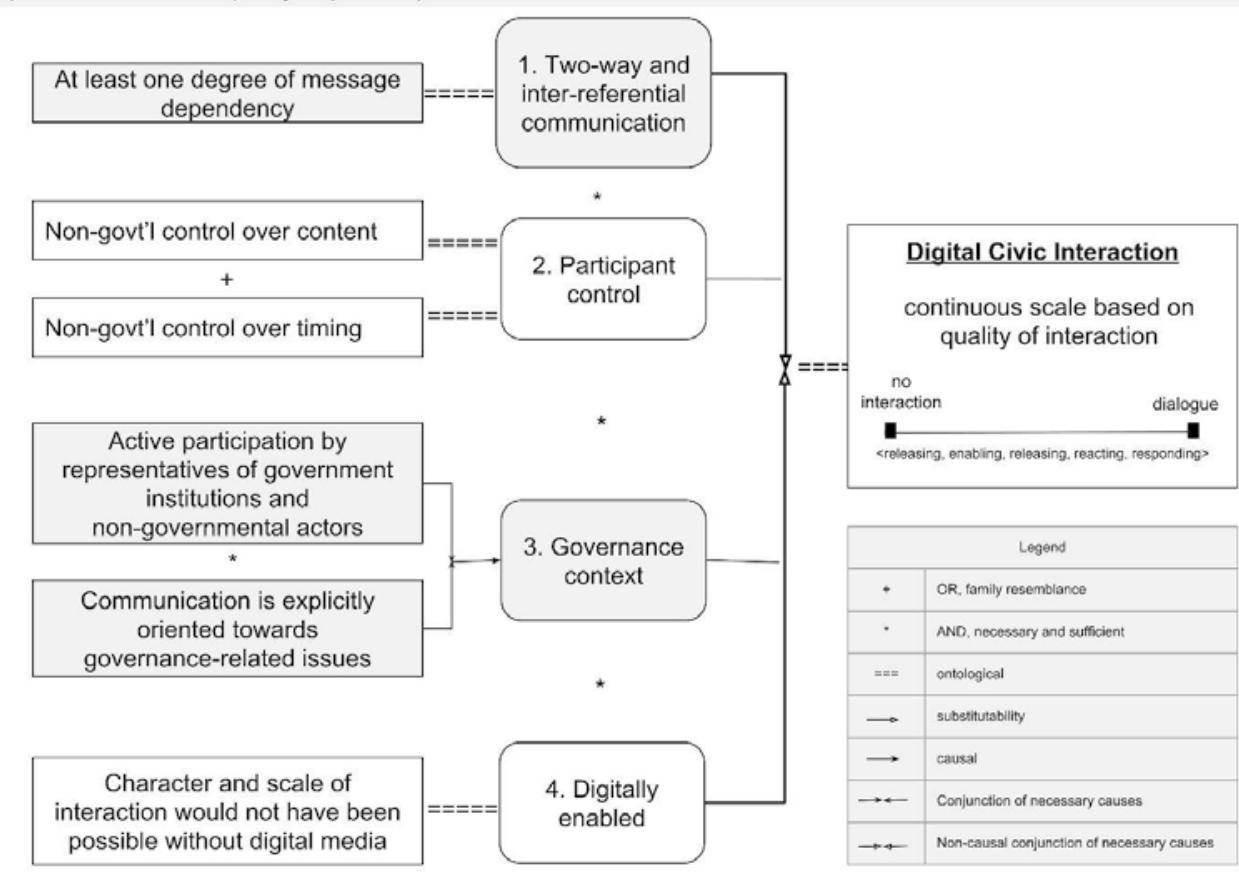

The structured application of Goertz's 3-level model forces explicit theorization of the multiple components embedded within the concept and the relationships between them. The resulting analytical precision is expected to increase the utility of the concept for scholars from different disciplines and the potential for cross-disciplinary collaboration. Analytical distinctions between the causal and ontological nature of components provide specific building blocks for typological theorizing and conducting comparative analysis regarding the effects digital civic interaction has on political communication environments and relationships. The article closes with an argument regarding the particular role to be played by scholars of political communication in advancing this research agenda. 
In summary, this article proposes an operational and theoretically-grounded model for identifying and comparing instances of civic participation and interaction facilitated by digital media, across contexts and disciplines. In doing so it draws on multiple strands of literature relevant to OGP's promotion of civic participation, and proposes conceptual components and empirical indicators for assessing the quality of civic participation norms and policies in the context of open and responsive government. These are applied as quality metrics in Article 4, in support of this dissertation's third research question.

Submitted to International Journal of Communication, December 12, 2018. Awaiting response.

\subsection{Look Who's Talking: Assessing Civic Voice and Interaction in OGP Commitments}

This article assesses the degree to which commitments made by governments in their OGP national action plans pursue meaningful civic participation.

This builds on research by the OGP's International Reporting Mechanism showing that only a minority of national action plan commitments are relevant to civic participation (Foti, 2016, p. 23; see also Steibel et al., 2017; Whitt, 2015). By conducting content analysis on those commitments coded by the IRM as relevant to the value of citizen participation, this article assesses whether outputs in the results chain presented in Figures 1 and 3 represent the adoption of meaningful civic participation norms and policies in the OGP, in line with this dissertation's third research question.

This analysis begins by situating national action plans within the OGP results chain, arguing that commitments in national action plans provide a better indicator of OGP's influence on countries' engagement with civic voice and interaction than the processes through which action plans are developed. The article then draws on the conceptual model for digital civic interaction described in Article 3, in order to establish a framework for assessing the quality of civic participation in the context of responsive and accountable government. This framework is then applied through content analysis of commitments in OGP national action plans, based on data provided by the OGP Independent Reporting 
Mechanism (IRM). The data set used in this analysis was updated by the IRM in December 2017, and includes 2,015 commitments from 100 action plans by 61 participating countries.

After filtering for language and substantive relevance as indicated by IRM coding, 484 commitments were subjected to content analysis. Specifically, commitments were assessed to determine the frequency with which citizen participation implied interaction between government and non-governmental actors, and the degree to which that interaction could be considered a meaningful in the context of responsive and accountable governance.

Content analysis revealed that civic participation in OGP action plans often involves no direct interaction between citizens and governments, and that many commitments are coded as relevant to civic participation by the IRM because they involve the release of information that may be relevant to civic participation, not because they explicitly facilitate, enable, or even anticipate participation. Indeed, only $46 \%$ of those commitments coded by the OGP as relevant to civic participation anticipated any type of interaction between government and non-government actors (comprising $9.6 \%$ of the full data set). Of these, moreover, nearly half (45\%) anticipated passive interaction without specific roles for both government and non-government actors, such as publishing government information online and expecting that it would be accessed by an unspecified non-governmental audience.

This analysis further revealed that, contrary to the broader ethos of the OGP, technology did not play a significant role in facilitating civic participation and interaction. Less than a quarter (24.9\%) of commitments coded as relevant to citizen participation relied on the use of digital technology, and technology was most prominent in participation commitments that were the least interactive.

Commitments were also coded for the quality of proposed interaction, according to metrics for interactivity and participant control, as described in the previous sub-section. Scores for these variables were also quite low, with only 5 of the 484 coded commitments explicitly describing significant degrees of both message dependency and participant control. Close analysis further revealed a predominance of suggestive language in government commitments, which raises questions about the utility of these metrics, and the degree to which the civil servants responsible for drafting these commitments are familiar with relevant norms and policies. 
The article concludes by noting that "outside formal OGP consultation processes, and at least in the early iterations of OGP action plans, the international partnership has not produced significant government intentions towards civic interaction and civic voice" (21).

In summary, this article applies the quality metrics drawn from Article 3 to the content of 61 countries national action plans, and finds that the civic participation norms and policies described in those action plans score poorly according to these metrics. The civic participation activities in national action plans describe only rare and very limited degrees of message dependency and participant control, suggesting that they should not necessarily be expected to make significant contributions to more responsive and accountable government.

Status: Published in the Journal of eDemocracy and Open Government, special issue on "Open Government and the Open Government Partnership (OGP)," December 12, 2017. 


\section{Discussion and conclusions}

This section presents a holistic discussion of findings from each of this dissertation's four analyses, organized according to the research questions presented in section 1.3.

i. How do voluntary multi-stakeholder initiatives like the OGP influence the national policy of member countries?

ii. To what degree is the global diffusion of civic participation norms attributable to OGP?

iii. To what degree can the participation norms promoted and adopted in an OGP context be expected to contribute to responsive and accountable government?

\subsection{Multi-stakeholder mechanisms of influence}

This dissertation's first research question asks how public governance MSIs influence the policy and practice of participating countries, and the theory reviewed in section 2.1 suggested two causal mechanisms through which this might occur, each of which is discussed below.

This dissertation's theoretical emphasis is on defining and validating causal mechanism related knowledge diffusion and policy learning. This is motivated by the voluntary character of public governance MSIs, and expectations that they will succeed in influencing national policy through peer pressure and social incentives, often characterized as a "race to the top" (Elgin-Cossart et al., 2016; Turianskyi \& Chisiza, 2018). In particular, MSI emphasis on knowledge sharing across global networks enables social dynamics of learning and emulation that are widely commented in the literature on international policy diffusion (Dobbin et al., 2007; Maggetti \& Gilardi, 2016), but have not been significantly explored in the context of global norm promotion.

An analytical framework was elaborated in Article 1 to explain how public governance MSIs like the OGP influence national policy through processes of knowledge transfer and policy learning. This framework suggests that the norm promotion of public governance MSIs includes the transfer of knowledge about norms and policies to national actors through a variety of overlapping discourses, closely mirroring what Stone describes as "the 'soft transfer' of broad policy ideas" associated with international NGOs, and which 
often seed processes of policy learning, policy experimentation and "'hard' policy transfer" (Stone, 2012, pp. 494-496). This process of knowledge transfer feeds into individual and collective processes of policy learning that "start with individuals and move up into different levels of subunits of a group" (Heikkila \& Gerlak, 2013, p. 486). This process involves a complex interplay of individual policy makers and civil servants with institutions and multiple discursive structures surrounding MSIs, mapping nicely on what the OGP describes as a "platform [for government reformers] to consolidate disparate reform initiatives under a common framework"(Open Government Partnership, 2014b, p. 19).

Policy learning is one causal mechanism enabled by these processes, and can lead to informal institutionalization of policy norms, indicated by broad changes to beliefs and behavior, and may in some instances lead to formal policy outcomes (Heikkila \& Gerlak, 2013, pp. 491-493). This sequence is depicted in Figure 7.

Figure 7: Analytical framework for knowledge transfer and policy learning

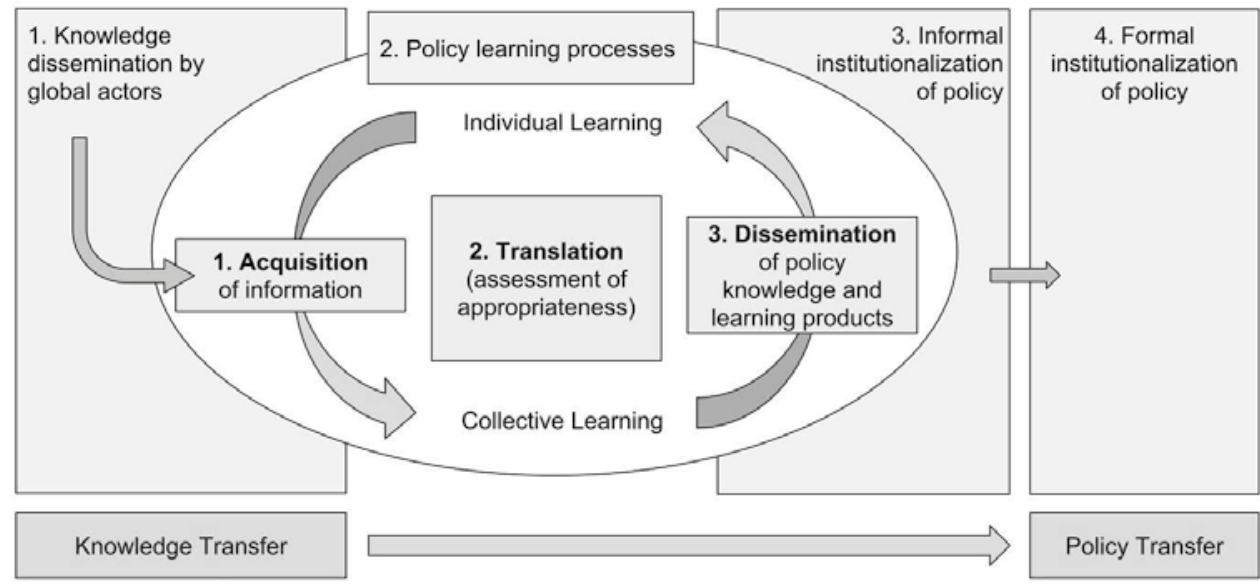

Application of this framework to the Norwegian case validated its explanatory power and emphasized the importance of individuals in that process, in line with calls for greater attention to individual actors in policy processes (Kay \& Baker, 2015; Prince, 2012). In particular, causal progression from norm promotion and knowledge transfer to processes of policy learning relied on individuals assessing the appropriateness of global norms and policies, echoing logics of appropriateness described by IR theorists at the national level (Checkel, 1997), though with greater nuance, as will be discussed below. 
This suggests that individual processes of translation in the policy learning cycle are a key point for determining whether OGP's knowledge dissemination has impacts outside national action plan processes, as individual civil servants and policy makers take those policy learnings and beliefs back with them to other institutional contexts, in much the same way as "epistemic go-betweens" that interact with multiple institutions in a policy diffusion process facilitate diffusion by helping "to transport the policy across jurisdictional lines" (Douglas et al., 2015, p. 489). This understanding of individuals as go-betweens and gatekeepers in policy learning processes roles helps to explain Article 2's findings that OGP is responsible for some portion of the global diffusion of e-participation.

The complex processes of individual translation and assessments of appropriateness in policy learning might also explain the inconsistent moderation effects of domestic legitimacy on OGP promotion of participation norms found in Article 2. In particular, the number of years that countries had Freedom of Information legislation had a negative interaction effect on OGP's influence, and showed Norway to be one of several outliers. Process tracing in the Norwegian case suggests that close alignment of national cultural and structural factors with global norms need not always facilitate the adoption and institutionalization of those norms in national contexts. This challenges the prominence of national political culture and systems in how international relations theorists have conceptualized logics of appropriateness driving the national adoption of global norms (Checkel, 1997; Cortell \& Davis, 2005; March \& Olsen, 2011). Indeed, this analysis revealed that individual assessments of norm appropriateness that were much more complex and nuanced, and respondents articulated a number of factors that influenced their determination of appropriateness, beyond national cultural norms.

Some of these articulations highlighted institutional incentives and consequences. One respondent noted, for example, that any adoption of civic participation norms would in the end be futile, and "over time be overshadowed by the ponderous Norwegian way of doing things" (NO184). Other articulations focused on personal incentives and motivations, and described a "what's in it for me mentality" (NO193) in institutional responses to OGP. Viewed collectively, respondent's assessments of norm appropriateness were influenced by multiple factors across national, institutional and personal contexts, in line with Kay \& Baker's attention to layering causal processes across macro, meso and micro policy contexts (2015, pp. 8-10). Assessments of norm appropriateness also appear to extend well beyond 
the "simple behavioral proposition" that assesses the fit between a norm and an identity or context (March \& Olsen, 2011, p. 479; Müller, 2004). Assessments of appropriateness described by respondents are better categorized according to the three logics of morality, consequences, and specification (relation to comparable policy) that Ben-Josef Hirsch finds to underpin processes of change in the content of norms (2014).

Respondents also demonstrated a significant tension between institutional incentives, personal contexts and national appropriateness in regard to OGP norms, and several respondents described how national level alignment with OGP norms was less important that institutional considerations. Assessing these tensions within the framework of multiple logics and layers of contextual influence suggests that conflict between levels and logics can have a blocking effect, and implies that "gatekeeper" roles are not held exclusively by political elites and policy makers as has been implied by IR theorists (Checkel, 1997), but may also include low level civil servants. This also validates the theoretical assertion that the IR emphasis on a simple alignment of national politics with global norms (Cortell \& Davis, 2002) is not a sufficient measure of norms' appropriateness in MSI advocacy and policy learning processes. In some cases, alignment of national norms and politics with global norms might instances hurt more than they help the adoption and promotion of those norms, if alignment introduces institutional disincentives or inhibits problem recognition among key individuals. In the Norwegian case, strong alignment of national level norms, perceptions regarding institutional consequences, and logics of specification vis-à-vis complementary activities all combined to produce a prominent conviction that Norwegian governance was "already open enough" and that OGP norms for civic participation were redundant. As articulated by one respondent, "why should we be pressured on this, we who are so open?" (NO184).

These dynamics merit further study, but at the very least, they serve as a stark counterpoint to research that assigns definitive influence to national level characteristics. This tendency is most easily discernable in IR scholarship at the turn of the century, which described national politics as the primary "filters" through which global norms must pass to become institutionalized in a national context (Cortell \& Davis, 2002; Finnemore \& Sikkink, 1998). This focus has persisted in the study of policy diffusion, however, and can be traced in the way that path dependency is associated with national institutions and legislation in policy translation (Park et al., 2016). This analysis suggests a need to attend more closely to 
how contextual factors at the subnational level influence the diffusion and adoption of international norms.

Lastly, it should be noted that instances of tension and conflict in individual's assessment of OGP norms enabled the articulation of two theoretical propositions about policy learning and adoption in an MSI context. Section 7.1 presents these propositions within the context of this dissertation's theoretical contributions, and discusses how they can be used to develop a middle-range theory for predicting the influence of public governance MSIs.

In addition to its primary focus on knowledge transfer and policy learning, this thesis also anticipated causal mechanisms of persuasion and argumentation drawn from social constructivist theories of transnational human rights advocacy (Finnemore \& Sikkink, 1998; Risse-Kappen \& Sikkink, 1999). In particular, the mechanisms of strategic bargaining and argumentation described by Risse (1999) recall suggestions that MSIs' global legitimacy will open political space for civil society in domestic policy fora.

High-level support by presidents, prime ministers, or ministry heads creates the political space necessary to innovate and collaborate. Mid-level bureaucrats within the government have the technical expertise and knowledge necessary to carry out reforms. Civil society organizations create the outside pressure necessary to push governments toward greater transparency (Brockmyer \& Fox, 2015, p. 35).

This logic recalls the dynamics of instrumental adaptation and strategic bargaining, which Risse-Kappen et al. suggest often dominate early stages of global norm promotion, and directly leverage international credibility to facilitate argumentation, persuasion, and dialogue (1999, p. 5). "Argumentative rationality" is a distinctive feature of this stage, where international legitimacy and attention enables participants in that discourse, and weaker groups in particular, to "act as if material pressures, political power, and hierarchies were absent" (Risse, 1999, p. 553). This closely mirrors MSIs' own descriptions of domestic policy fora and collaborative implementation enabled by the legitimacy of global norms.

Within-case analysis of the OGP in Norway identified a comparable mechanism at play in at least one agency process. The Ministry of Culture's Department of Civil Society adopted a Declaration of principles for interaction and dialogue with NGOs on the basis of 
extended interaction and negotiation with civil society representatives in Norway. Civil society leaders interviewed within the IRM process in 2015 suggested that the international legitimacy and attention conveyed by OGP were deliberately leveraged by civil society participants in those discussions, and were essential in securing the Declaration (Wilson, 2017, pp. 27-29; additional notes on file with author).

Notably, however, the policy fora and discursive processes associated with this Declaration were not particularly contentious, so while some mechanisms related to persuasion and legitimacy appears to be at work, it is not clear the degree to which "argumentative rationality" was at play, or even necessary. Validating a mechanism for MSI influence that more clearly aligns with Risse's conceptualization might require analysis in a country context marked by greater degrees of contention between civil society and government, in which consultative and discursive processes manifest clearly opposed strategic interpretations of norms (Johnson \& Hagström, 2005) and where the "countervailing force" of civil society is more directly enabled by MSI engagement (Halloran, 2015, p. 4).

It was not possible within the scope of this research to define or validate a detailed causal mechanism related to argumentation and persuasion. Within-case research suggests that this mechanism was at play in the Norwegian case, but was not able to trace it definitively. Similarly, scope constraints prevented a more rigorous evaluation of individual processes of translation and assessment in the case of the Norwegian Declaration of principles, which might have produced a detailed account of interaction between causal mechanisms in a specific MSI policy context. This analysis nevertheless validates the theoretical framework employed, and suggests how it might be used to trace that type of interaction. While falling short of a comprehensive or definitive answer about how public governance MSIs influence national policy, this analysis nevertheless validates the plausibility of one mechanism for exerting that influence. Doing so also responds to Falleti \& Lynch's (2009) call for more detailed contextual analysis, and demonstrates an approach that is theoretically rigorous enough to accommodate the interaction of multiple causal mechanisms underpinning norm promotion and adoption in a complex policy environment.

In summary, this analysis has defined a novel causal mechanism for MSI influence through knowledge dissemination and policy learning, and traced that mechanism in 
qualitative analysis. Doing so demonstrates the viability of the first assessment strategy proposed in section 1.1.1, while also adding nuance and detail to theoretical assumptions about how public governance MSIs influence national policy, particularly regarding the roles of individuals and the potential for a continuum of policy outcomes. Two theoretical propositions were also developed, with which to develop scope conditions for a predictive theory of MSI influence. Lastly, this analysis explains the causal effect of OGP membership on the diffusion of e-participation, and offers an analytical framework with which to explain the peculiar moderating effect that domestic legitimacy has on countries' implementation of OGP and e-participation, which are discussed in the following section.

\subsection{Attributing the diffusion of civic participation norms to OGP}

This dissertation's second research question considers the degree to which the diffusion of civic participation norms is attributable to OGP's norm promotion. This was applied to the relationship between OGP's growth and the diffusion of e-participation, understood as a policy arena external to the OGP results chain, in line with second assessment strategy presented in section 1.1.1.

Section 1.2.3 noted that this is not the only causal relationship that might explain the parallel growth of OGP and diffusion of e-participation. A casual effect might be exerted in the opposite direction, if diffusion of e-participation drives OGP membership, by lowering the adaptation costs of developing new participatory policy and increasing the social salience of identification with "government 2.0". It may also be the case that OGP membership and e-participation diffusion are driven by the same causal factors, as an example of multifinality in policy processes. Lastly, section 1.2.3 noted that if OGP is contributing to the diffusion of e-participation, it might be doing so along three distinct pathways: through action plan commitments, by shaping the global norms that influence non-member countries, or by socialization participation norms across institutions in member countries.

Article 2 in this dissertation tested that third pathway, assessing whether OGP membership affects the uptake of e-participation in member countries, outside of the OGP results chain. Analysis was conducted using data on e-participation in 194 countries between 2003 and 2018. While this data set includes measures of e-participation for OGP non- 
members, it is important to note that the research design only measures OGP's effect on member countries, in keeping with the third pathway described above.

OLS regressions revealed that OGP membership had a modest but significant effect on countries' E-participation Index (EPI) scores. Specifically, OGP member countries perform better than non-OGP countries on the EPI by nearly 30 points, and by just over 30 points on the sub-index for collaborative e-decision-making. To test the directionality of this correlation, data tables were constructed for 62 OGP members, comparing average eparticipation scores on the two surveys before and two surveys after joining OGP. As shown in Table 4, e-participation scores improved for almost all of the 62 countries for which data was available, suggesting that OGP's effect on e-participation is likely causal.

Table 4: Change in countries' e-participation scores following OGP membership

\begin{tabular}{|c|c|c|c|c|c|}
\hline $\begin{array}{l}\text { Average } \\
\text { change }\end{array}$ & $\begin{array}{l}\text { Median } \\
\text { change }\end{array}$ & $\begin{array}{l}\text { Minimum } \\
\text { Change }\end{array}$ & $\begin{array}{c}\text { Maximum } \\
\text { Change }\end{array}$ & $\begin{array}{l}\text { Avg neg } \\
\text { change }\end{array}$ & $\begin{array}{l}\text { Avg pos } \\
\text { change }\end{array}$ \\
\hline \multicolumn{4}{|c|}{ all countries $(n=62)$} & $(n=8)$ & $(n=56)$ \\
\hline 0,051 & 0,048 & $-0,030$ & 0,160 & $-0,018$ & 0,061 \\
\hline
\end{tabular}

Note: all changes are statistically significant at $\mathrm{P}<.001$ according to $T$ test

EPI data does not identify specific policies, so it is impossible to determine whether or not indicators for e-participation reflect policies and activities undertaken in association with OGP action plans. This seems unlikely, however, given that between 2011 and 2015, OGP member countries produced only 105 commitments explicitly leveraging technology to advance civic participation (as described in Article 4). OGP's effect on e-participation in member countries is more likely manifest outside of OGP's results chain and OGP-specific policy fora. This suggests that at least some of the global diffusion of e-participation can be attributed to the OGP. The theoretical framework developed in section 2.1 and validated in the Norwegian context suggests how this might occur. Specifically, individual policy makers and civil servants exposed to OGP's promotion of civic participation norms may function as policy entrepreneurs and epistemic go-betweens (Douglas et al., 2015), deliberately sharing norm content and policy frames in a way which facilitating the diffusion of norms and policies across institutions.

This finding not imply that OGP is solely responsible for the diffusion of eparticipation, of course. It is entirely possible that dynamics of multifinality are at play, 
whereby obscure background variables are driving OGP membership and e-participation in parallel. More obviously, the dynamics described here emphasize the social environment in which national governments operate when they join multilateral initiatives or adopt global policies. OGP norm promotion does not take place in a vacuum, and likely interacts with other normative initiatives and norm entrepreneurs advancing digital government and eparticipation agendas, like the UN and the OECD. Individual policy-makers and civil servants participating in OGP processes are also exposed to these influences, and may well function as go-betweens and policy entrepreneurs in the service of other policy outcomes as well. This analysis suggests that the signaling and identification dynamics outlined by social constructivists (Finnemore \& Sikkink, 1998; Simmons, 2009) may well be active in regard to global policy discourse of open government and "government 2.0". Additional study is required to determine the degree to which this influences country behavior, and how it might interact with the causal influence that OGP has been demonstrated to exert in this analysis. The main contribution of this analysis has been to provide clear evidence for OGP's influence and efficiency outside of the OGP value chain, validating the assessment strategy associated with this dissertation's second research question.

Before closing this section, it is worth noting the differences in OGP's influence on general EPI scores and scores on the sub index of collaborative e-decision-making. Coefficients for OGP's effect on the more progressive metric of e-decision making were consistently about $10 \%$ stronger than OGP's effect on e-participation across analyses ${ }^{22}$. These differences suggest that OGP is responsible for driving the diffusion of more collaborative participatory practices than mere information provision or consultation. According to this read, the open data portals, access to information initiatives, and other "low hanging fruit" that dominate OGP action plans (Foti, 2016; Schwegmann, 2013) are government initiatives that likely would have been advanced independent of the OGP. This type of commitment may represent countries using OGP as "a way for a country to 'get

\footnotetext{
${ }^{22}$ This was the case regarding simple regressions for OGP membership in 2014 and EPI scores in 2018 (0.274 over 0.308$)$, as well as mediation tests controlling for all three variables of domestic legitimacy and structure ( 0.246 over $0.221,0.259$ over 0.237 , and 0.227 over 0.207 ).
} 
credit' [for those activities] from potential donors, investors, or trading partners" (Hasan, 2016, p. 3).

A second distinction should be made regarding the moderation effect of domestic structures exert on OGP influence. Not only is OGP's most significant contribution to eparticipation diffusion to be found in the diffusion of more participatory policies and practices, but OGP has the strongest influence in countries whose domestic structures are already aligned with civic participation norms. It is worth noting that these countries often belong to what has been termed "the first wave of e-participation" (Åström et al., 2012), (often European) countries that the UN E-Participation Index refers to as high performers, that were early leaders in e-information provision and are now leading global progress in implementing e-consultations and collaborative e-decision-making (United Nations Department of Economic and Social Affairs, 2016, pp. 71-73). OGP's most significant impact seems to be on the leaders, rather than the laggards of civic participation, open government and e-participation

Lastly, it should be acknowledged that this analysis has only explored the degree to which OGP can be attributed with the diffusion of e-participation and civic participation norms within participating countries. The prominence of OGP in international policy discourse gives the initiative significant signaling power (Kassen, 2014), and as Elgin-Cossart et al. (2016) have argued, "the power to shape norms not only affects member countries but also lends strength to the global movement for transparency and anti-corruption. Therefore, the partnership may indirectly influence nonmembers as well" (p.12). This effect was not tested in this dissertation.

In summary, though this dissertation found little evidence that OGP is contributing to the diffusion of civic participation norms through explicit OGP processes such as the design and implementation of national action plans, it has demonstrated that a significant portion of e-participation's global diffusion can be attributed to OGP's influence in member countries. This validates the assessment strategy of expanding analysis to include outcomes outside of MSI-specific results chains. 


\subsection{The quality of OGP's contributions to civic participation}

This dissertation's third research question asks to what degree the participation norms and policies promoted and adopted in an OGP context can be expected to contribute OGP's goals of more responsive and accountable government.

Section 1.2.2 described the ways in which civic participation norms are evaluated by the OGP secretariat, most notably through the categorization of action plan development according to the IAP2 spectrum. Section 2.3 presented theories and frameworks for evaluating the democratic quality of public participation and the contribution of civic participation to responsive and accountable government. This review highlighted the importance of meta-level design considerations in line with Fung's argument that different participatory characteristics contribute to different democratic values (2006), and suggested that characteristics related to the systematization of interaction and control might be most relevant for understanding how the "tools and techniques" can restructure the fundamental relationships between citizens and administrators (King et al., 1998, p. 317).

Characteristics of interaction and control were further elaborated in Article 3 of this dissertation, which reviewed how participatory initiatives are treated in literatures of eparticipation, open government, political communication and public administration in order to develop metrics for assessing the contribution of civic participation to responsive and accountable government. Doing so highlighted the importance of sustained citizen-state interaction in a governance context, which was presented as three constitutive components of a broader conceptual model and associated with empirical indicators in Article 3. These components can be considered as meta-level design characteristics associated with outcomes of responsiveness and accountability, and are presented briefly below. ${ }^{23}$

i. Two-way and interferential communication, here referred to as reciprocity, implies that communication between government and non-government actors moves in both directions, or may even be "tri-directional" including a public

\footnotetext{
${ }^{23}$ The conceptual model's fourth conceptual component of digital technology is not categorically relevant to the quality of participation initiatives. Indeed, research suggests that the thoughtful design of digitally facilitated participation initiatives is dramatically more important for their success than the question of whether or not technology is used (Treisman, Kelley, \& Johnston, 2016).
} 
audience (Ferber et al., 2007). Importantly, back and forth communication according to this measure is also cumulative, in the sense that messages from citizens to government (whether questions, complaints or requests) receive a response, and that response explicitly acknowledges the content of that message. This measure thus complements the emphasis on bi-directionality in eparticipation literature (McMillan, 2002; Zhou et al., 2013), with accountability research's attention to the importance of civic voices being heard and accessible to the broader public (Loureiro et al., 2016; Peixoto \& Fox, 2016b).

ii. Participant control implies that the citizens participating in civic participation initiatives have some degree of control over either the content or the timing of their participation. This extends beyond notions of accessibility and availability of participatory mechanisms, by incorporating notions of decision-making power prominent in e-participation literature (Grönlund, 2009). In the context of safeguarding the quality of democratic processes, it is a minimum criteria for avoiding superficial participation (Åström et al., 2012).

iii. Civic participation that is situated in a governance context will enjoy the active representation of government. This implies that the organization of participation is not outsourced to third parties, and that there is institutional "buy-in" and endorsement of participatory processes and outcomes (Liu, 2016; Reddick, 2005). A governance context further implies that participation initiatives are substantively oriented towards relevant governance issues. Explicitly addressing topics and processes that matter to citizens acknowledges the importance of explicitly civic spaces in open government reform (Carolan, 2016, p. 6; Guerzovich \& Moses, 2016, p. 3) and that in the context of government accountability the most meaningful issues and information will be those over which government finds it most difficult to relinquish control.

Together, these measures operationalize characteristics of civic participation that are expected to lead more responsive and accountable government, but which are not incorporated into OGP evaluations and assessments described in section 1.2.2. Article 3 systematized these characteristics and linked them to the operational and empirical indicators presented in Figure 6 (section 4.3, p. 78). Doing so enables qualitative and 
systematic comparison of specific participatory norms and policies across contexts. This approach was validated by applying these metrics to OGP action plan commitments in this dissertation's Article 4.

The remainder of this section considers the application of these metrics to norms and policies promoted and adopted in the OGP context more generally, as documented elsewhere in this dissertation.

Three primary registers will be considered, including

i. the norms promoted directly by OGP and in the discourse surrounding OGP,

ii. the intermediate outputs represented by commitments in national action plans, and

iii. the outcomes represented by formal and informal institutionalization of participation norms by participating governments.

\subsubsection{Norms promoted}

As discussed in section 1.1.2, norm promotion by OGP and in associated discourse can be distinguished according to participation in action plan development and participation in action plan commitments (inputs and outputs in the OGP results chain, respectively). The most prominent and detailed promotion of civic participation norms is found in OGP guidance on developing national action plans. Action plan development would also be the most promising site for socializing norms of civic participation, through repetition and sustained reciprocity in line with the OGP theory of change.

OGP's guidance for developing national action plans is elaborate, and includes a number of recommendations in line Fung's understanding of meta-level design characteristics. Several of these can be associated with the quality metrics proposed above. Formal guidance documents for government Points of Contact give clear instructions towards topical relevance and government input (governance context), and instruct governments to provide feedback (reciprocity) (Open Government Partnership, 2016a). Though there are no clear instructions on providing non-government counterparts with control over collaborative processes (participant control), this is outlined in ample detail in the Practical Handbook for Designing and Managing an OGP Multi-stakeholder Forum, with 
recommendations and examples of the rules and procedures that ought to govern national bodies (Velasco-Sánchez, 2016, p. 2). ${ }^{24}$

OGP guidance to countries on developing civic participation commitments and initiatives is much less explicit, and is articulated exclusively through simple reference to the core values of open government. Elaboration of the principle of civic participation emphasizes the importance "open[ing] up decision-making to all interested members of the public" but does not indicate the importance of a governance context or the dynamics of participant control and reciprocity that indicate interactivity (Open Government Partnership, 2015a, p. 2). These elements can be read into the multiple case studies and trainings disseminated by OGP and described in Table 1, but tend to be presented as descriptive rather than prescriptive.

\subsubsection{Intermediate outputs}

Lack of guidance on developing civic participation commitments may explain the lack of civic voice and interaction in national action plans, and the failure of government commitments to meet the quality metrics proposed above. As discussed in Article 4, commitments to civic participation in OGP national action plans only very rarely anticipate meaningful participation and interaction. Of the 494 commitments deemed relevant to civic participation by the OGP IRM and included in this analysis, only 55 qualified as the most interactive mode of dialogue. Of these, only 3 explicitly described participant control and only 2 explicitly described any degree of reciprocity. This was attributed in part to the general imprecision of language used in government commitments. Indeed, the prominence of unclear but suggestive language in government commitments to civic participation was one of the key findings of this analysis.

The dominance of low-hanging buzzwords such as consultation and collaborative forums, without explicit descriptions of how such processes would function, should give open government enthusiasts pause. Studies demonstrating the powerful influence that institutional context exercises on open government agendas (Goëta \&

\footnotetext{
${ }^{24}$ Though this document is authored by an independent researcher and described as "third party recommendations to the OGP community", it is published together with OGP resources, and treated here as a component of OGP's norm promotion and policy dissemination.
} 
Davies, 2016; Janssen, Charalabidis, \& Zuiderwijk, 2012; Kornberger, Meyer, \& Höllerer, 2017) would suggest that activities without specific programmatic detail are likely to revert to the status quo of national political contexts (24).

Not only are the quality metrics proposed above largely absent from action plan commitments, commitments' fuzzy articulation generally fails to articulate the kind of metalevel design principles that Fung would expect to target any democratic outcomes. Generally speaking, the norms and policies represented by intermediate outputs in the OGP results chain should not be expected to contribute to more responsive and accountable government.

\subsubsection{Policy adoption and institutionalization}

Regarding norms that are adopted and institutionalized, this dissertation has considered two data sets: a broad range of institutionalization and policy outcomes within a single country case, and the adoption of e-participation policy across multiple countries. Lack of contextual data prevents the application of these quality metrics to e-participation outcomes tracked in Article 2. The sub-indicator of collaborative e-decision-making would likely reflect comparable characteristics of participant control and reciprocity, however, and OGP's more pronounced effect on this indicator is noteworthy.

Norwegian policy outcomes traced in Article 1 do not fare much better than national action plans when considered against the quality metrics of reciprocity, participant control and governance context. Within-case analysis identified three informal policy outcomes and three formal policy outcomes associated with OGP promotion of civic participation in Norway. Informal outcomes consisted of processes of institutionalization, whereby institutional practices and cultures developed towards increased alignment with civic participation norms, and were evidenced by changes in activities, rhetoric, and formal incentives. While Norwegian informal outcomes recall notions of socialization articulated by OGP's theory of change and Lemieux et al.'s (2015) description of third order outcomes, none of these outcomes explicitly referenced design characteristics of reciprocity, participant control, or situation in a governance context. The three formal instances of institutionalized participation policy in Norway included expanding the scope of public consultations in the national government's Instructions for Official Studies, an official 
declaration by the Ministry of Culture on government interaction with civil society organizations, and digital consultations held by the Ministry of Health with stakeholders. None of these formal policy outcomes included explicit language dictating that participation include reciprocity, participant control or situation in a governance context either.

In summary, the norms and policies assessed in this dissertation only very rarely incorporated the quality measures described above as civic participation design characteristics, and never included all of them. OGP's promotion of civic participation were by this measure most meaningful when providing guidance on national consultations, which is also the normative venue that might most contribute to the socialization of civic participation norms through repetition. Following Fung's approach to associating high level design characteristics with specific democratic outputs, it is reasonable to expect that the collaborative guidance on action plan development might contribute to more responsive and accountable government in member countries when that guidance is received and implemented. Viewed as norm promotion, however, it is not certain that those norms will be adopted in member countries, and the near absolute lack of these measures in countries open government commitments offers little cause for optimism.

Neither did the policy outcomes traced to OGP in the Norwegian case incorporate any of these quality metrics, though that case should not be treated as representative of the informal outcomes that might be evidenced in other countries. Nor is it possible to determine the degree to which the e-participation activities associated with OGP membership include reciprocity, participant control and situation in a governance context, though the slight emphasis of OGP's influence on collaborative e-decision-making provides the single instance in which OGP's norm promotion might be contributing to the adoption of civic participation that is meaningful in the context of responsive and accountable government.

This is a generally bleak verdict. It should be noted, however, that while this analysis suggests that the norms and policies promoted and adopted in an OGP context are unlikely to contribute to responsive and accountable government, this does exclude other means through which OGP might do so. The most important lesson to draw from this dissertation may well be that the influence of public governance MSIs like the OGP is a subtle and slippery affair. Individuals engage with MSI norms deliberately across institutions and 
discursive structures. Subtle processes of learning and socialization can interact with multiple causal mechanisms in complicated ways. This can give rise to a host of different outcomes, with varying degrees of formality, and not always clearly tied to the processes and fora associated with MSI results chains.

The complicated ways in which individuals contribute to the national translation of global norms suggests that even when adopted in national policy or practice, OGP norms might not look the same as when they started out. "Weak" norms aren't a final indictment of OGP's impact in this sense. There are a host of contextual variables and causal mechanisms associated with public governance MSIs, and it is entirely plausible that the promotion and adoption of weak norms by these quality metrics might contribute to policy outputs that are more explicitly and consistently aligned with those metrics. Future research is necessary to develop a theoretical basis for predicting when this might occur. At this point, it is safe only to say that OGP's policy influence is exercised through subtle and complex processes, and may have surprising effects outside of OGP-specific policy areas. If OGP does contribute to more responsive and accountable governance, however, it is likely not due to the quality of the civic participation norms and policies it promotes.

\section{Contributions, limitations, and opportunities for further}

\section{research}

This cover chapter closes by considering the contributions made to theory and policy of MSI norm promotion, and how the findings presented here should be considered and advanced. The first sub-section presents contributions to theory on the promotion and diffusion of norms and policies, followed by a sub-section describing practical contributions to the design and strategy of public governance MSIs. The third and final sub-section presents the most prominent limitations to this research, and suggests future avenues for study.

\subsection{Theoretical contributions}

This dissertation's most immediate theoretical contribution regards the theorization of public governance MSIs' influence on national policy. This has not been significantly treated in the grey literature on public governance MSIs, which notes that even MSIs' own theories of change tend towards abstraction when considering how their influence is exerted, and 
that some "remain agnostic" to how they might impact the domestic policy and practice of participating countries (Brockmyer \& Fox, 2015, p. 19). Reviewing the research and commentary surrounding public governance MSIs suggested that causal mechanisms related to persuasion and socialization might be at play. These were elaborated according to theoretical frameworks from international relations scholarship on global norm promotion and policy studies research on processes of diffusion, transfer, translation, and learning. Doing so provided a theoretically detailed articulation of two specific mechanisms that might drive public governance MSIs policy influence. This included an exploration of whether Risse's conceptualization of argumentative and discursive mechanisms apply in MSI contexts, and a detailed articulation and validation of a mechanism related to knowledge transfer and policy learning.

The analytical framework for knowledge transfer and policy learning connects insights from policy transfer scholarship with Heikkila \& Gerlak's (2013) conceptual model for policy learning, and was validated through process tracing OGP norm promotion in Norway. Doing so provided several important insights regarding the role of individuals and the scope of policy outcomes in national MSI processes. Firstly, assessments of global norms by civil servants and policy makers was identified as a key site where those norms are either blocked, or diffused across institutions to facilitate policy outcomes. This directly challenges an IR theoretical approach to the diffusion of global norms which emphasizes the salience and appropriateness of global norms primarily in terms of aggregate national culture and politics (Cortell \& Davis, 2002), and suggests that contemporary research on identity and state action in international relations (Bucher \& Jasper, 2017) should more directly engage with the roles of individuals.

Secondly, this analysis emphasized how individual assessments were exercised according to the multiple logics (moral, consequential, and specification) anticipated by BenJosef Hirsch (2014) and subjected to multiple levels of contextual influence (national, institutional and individual) in line with the levels of policy change articulated by Kay \& Baker (2015). Granular attention to these dynamics challenges IR theoretical emphasis on the role of political elites when considering the role of individuals (see Cortell \& Davis, 2005, pp. 67), and fills a gap in policy studies literature, where discursive theory has attended to a much 
broader scope of individual's roles and actions, but has not explored how individuals are influenced by international factors (Erikson, 2015; Leipold \& Winkel, 2017).

Tracing these dynamics adds theoretical specificity to several loosely articulated theories of influence in the literature surrounding public governance MSIs. For example, the elaboration of gatekeeping as individual processes of translation and assessment in the context of policy learning helps to explain the "blocking" function that has been attributed to civil servants in the context of open government transformative processes (Chadwick, 2011; Goëta \& Davies, 2016; Wirtz et al., 2016). This also adds theoretical precision and explanatory power to OGP's ambitions to facilitate "norm shifts" and socialization of participation norms across government agencies in member countries (Open Government Partnership, 2014b, pp. 14, 6).

The conceptualization of a continuum for "soft" and "hard" policy outcomes in the context of MSI norm promotion also indicates what those "norm shifts" might look like, and provides theoretical justification for studies that have suggested the importance of establishing institutional cultures for open government and citizen engagement before related programs and activities can be effectively implemented (Chadwick, 2011; Freeman, 2013; Goëta \& Davies, 2016; Wirtz et al., 2016). This provides analytical clarity to notions of institutional culture which have featured in much research on open government and norm diffusion (Cortell \& Davis, 2002; Freeman \& Quirke, 2013; Wirtz et al., 2016), and helps to explain why formal open government policy has not contributed to informal policy outcomes such as institutional culture change (Villeneuve, 2014). Lastly, the validation of epistemic gobetweens as a driver of norm diffusion suggests that a comparable theoretical model might be usefully applied in other open government and accountability contexts, where specific norms and practices appear to "spill over" into tangential policy arenas (Fox \& Aceron, 2015, p. 11; Lemieux et al., 2015; Porto de Oliveira, 2017; World Bank Group, 2016, p. 15).

Attention to how multiple logics and contextual levels operate in individual assessments also has implications for causal theory. Specifically, the complex interaction of logics and levels provides conceptual space in which to theorize the interaction of causal mechanisms, and an analytical framework that is theoretically rigorous enough to trace such processes in complex policy contexts. Doing so significantly advances the degree of theoretical granularity with which high order interaction effects and multifinality are currently conceptualized in policy contexts (Falleti \& Lynch, 2009; Kay \& Baker, 2015; Lyall, 
2015). By providing multiple axes on which to assess individuals' engagement with global norms, this framework may even strengthen Bayesian-inspired counterfactual reasoning as a means of testing the validity of causal claims, an effort often hampered by a lack of evidence (Kay \& Baker, 2015, p. 19).

In addition to these insights, this research has provided the foundation for developing a middle range theory for the national influence of global MSIs. As the name implies, middle range theory occupies a middle range between the highly predictive but case-specific theory that fails to provide "contingent generalizations on the conditions under which [it] is actualized and under which it is overridden by other circumstances," and "highly general theories that attempt to generate broad covering laws [but] tend to have quite limited predictive and explanatory powers" (George \& Bennett, 2005, pp. 266, 8).

Middle-range theories, on the other hand, are deliberately limited in their scope; they attempt to explain different subclasses of general phenomena. Middle-range theories attempt to formulate well-specified conditional generalizations of more limited scope. These features make mem more useful for policymaking (George \& Bennett, 2005, p. 266)

The development of middle range theory may be pursued through a "building-block" approach, iterating the articulation and testing of theoretical propositions about subclasses of phenomena, with definitions about the scope conditions to which they apply. A deviant and data rich case such as Norway is particularly well-suited to initiating such an effort, as is described in section 3.4 .

Article 1 offered two theoretical propositions with which to begin developing middlerange theory:

i. In countries where abstract governance norms are a "good fit" with national cultures and structures, norm promotion by public governance MSIs will lead to policy outcomes through mechanisms of policy learning, only when those norms are framed as specific policies and in light of institutional logics of consequences and specification.

ii. Norm promotion by public governance MSIs will lead to policy outcomes through mechanisms of policy learning to a greater degree when policy 
learning is framed according to logics of consequence and specification at the level of institutions and individuals.

These propositions lay the groundwork for elaborating a middle-range theory of how MSIs influence national policy through policy learning. This would start by testing the propositions on a set of cases that are differentiated according to the characteristics of abstract norm alignment and policy specification, as indicated in the two propositions. Use of such a "contrast typology" enables definition of the scope conditions under which that theory would apply (George and Bennett 2005, 233-262). In the current case, it would test the waters for external validity of this dissertation's findings, by determining if they apply only to countries with strong pre-existing national traditions for the norms promoted by public governance MSIs, or to a wider population of cases.

Though not as clearly defined or validated in the Norwegian case, this dissertation also theorized a casual mechanism of MSI influence related to argumentation and persuasion, drawn from International Relations scholarship on global norm promotion. Doing so makes a well-established theoretical framework available to the study of how public governance MSIs influence member countries, while questioning some of the assumptions built into that framework. This was primarily noted in regard to the antagonistic context of human rights promotion in Risse-Kappen, Ropp, \& Sikkink's case studies (1999). As with the national characteristics referenced in regard to policy learning in the Norwegian case, this distinction might inform a testing of scope conditions for a middle range theory about public governance MSIs' argumentative influence. This could be tested through application of theoretical propositions to a contrast typology defined by degrees of antagonism. That project has not been explicitly pursued in this dissertation.

Considered together with the validation of policy learning mechanisms, however, this dissertation's treatment of argumentative and socialization mechanisms in the IR literature adds detail and clarity to the notions of persuasion, legitimacy, political space, public disclosure and participation that are regularly articulated in MSI theories of change (Brockmyer \& Fox, 2015, pp. 18, 24, 31, 35, 41). Application of this theory in the MSI context also suggests avenues for research across disciplinary traditions. The study of public 
governance MSIs is conspicuously absent in policy studies' treatment of international policy intermediaries (Stone, 2012, pp. 491-496) as well as International Relations treatment of international organizations as norm entrepreneurs (Finnemore, 1993). This dissertation demonstrates that public governance MSIs are a useful site for integrating and strengthening the analytical capacity of both those research traditions.

In summary, this dissertation's most important theoretical contribution has been the identification and validation of a causal mechanism for MSI influence related knowledge dissemination and policy learning. This allowed the articulation of theoretical propositions that can be used to begin developing a predictive theory of MSI influence through policy learning. The theorization of this mechanism in tandem with mechanisms of argumentation and persuasion adds clarity and precision to the theories of change with which public governance MSIs conceptualize their influence, particularly in regard to the role of individuals and the spectrum of policy outcomes they hope to achieve. This process has also introduced public governance MSIs as an important and overlooked object of study in international relations scholarship and the study of policy diffusion, and suggests several opportunities to further integrate theoretical frameworks from those two strains of research.

\subsection{Policy relevance}

The findings presented in this dissertation can be reduced to fairly commonsensical truisms. MSI influence is a complex and nuanced affair that can lead to surprising outcomes. The norms that public governance MSIs promote are not always as advanced as some might like, but nor are they the only way in which MSIs hope to influence the quality of governance in member countries. None of this should surprise thoughtful advocates of multistakeholderism. There are, nevertheless, at least three specific insights that can usefully inform the design and implementation of public governance MSIs like the OGP.

Firstly, the spectrum of policy outcomes resulting from norm promotion in this dissertation is significantly more varied than what is commonly discussed in relation to public governance MSIs. Evaluations of these initiatives tend to emphasize compliance with MSI procedures and processes (Brockmyer \& Fox, 2015, p. 67; Jackson School Task Force, 2012; Turianskyi \& Chisiza, 2018), and policy outcomes are considered primarily within the 
context of MSI-specific policy fora (Brockmyer \& Fox, 2015), either in OGP action plans (Foti, 2014, pp. 9-10), EITI reporting (C. Corrigan, 2014), or highly specific policy arenas such as construction procurement (Brockmyer \& Fox, 2015, p. 31).

The variety of policy outcomes attributed to the OGP in this analysis directly challenges this narrow view. Not only is it reasonable to expect that public governance MSIs can contribute to informal policy outcomes such as the institutionalization of open government culture in government institutions, but these processes can be empirically identified, and they can contribute to policy outcomes at a distance from the processes explicitly associated with MSIs. This suggests that public governance MSI would do well to anticipate the potential for such outcomes, and how they might be facilitated by deliberate knowledge dissemination and learning activities.

The highly contingent and fragile nature of policy learning in an MSI context also suggests that strategies to facilitate this mechanism should identify key individuals in government likely to facilitate processes of policy learning, and more rigorously account for their role in gatekeeping or diffusing norms and policy frames. Though individuals have long been recognized to play an important role in open government and citizen participation activities' design (Goëta \& Davies, 2016; Lundgren, 2017; Vogt \& Haas, 2015; T.-M. Yang \& Wu, 2016), implementation (Chadwick, 2011; Wirtz et al., 2016), and diffusion (Porto de Oliveira, 2017), this research has elaborated a detailed processes through which that role can be manifest. It suggests that MSI strategies to facilitate policy learning and socialization should account for this dynamic by anticipating the sometimes competing and contradictory logics and levels of context that influence how key individuals engage with MSI norms.

Secondly, this research has demonstrated that OGP's effect on e-participation is doubly differential. OGP had a slightly more pronounced effect on countries' implementation of collaborative e-decision-making, compared to the more general practice of e-participation, which includes the one-way provision of government information, and the one-way receipt of citizen preferences in e-consultations. OGP also had a significantly more pronounced effect on e-participation in countries where the national political, administrative and legal structures were already aligned with norms for civic participation.

This dissertation has argued that these findings can be attributed to policy learning and socialization dynamics described above, and may be generalized to other public governance norms promoted by the OGP. As such, these findings provide a useful 
counterpoint to criticisms that the OGP is only facilitating country progress on "low hanging fruit" such as the creation of open data portals (Hasan, 2016, p. 9). They also challenge assertions that the initiative will be most effective in autocratic environments (Gruzd et al., 2018), and have concrete implications for the ongoing debate about OGP membership criteria and the advantages of engaging with countries that do not meet basic benchmarks for democratic practice (Open Government Partnership, 2017b). These findings should be used to inform the cost-benefit analyses that underpin strategic advocacy decisions and decisions relating to country engagement. Put bluntly, policy learning and socialization strategies are likely to be most effective with encouraging democracies to adopt progressive open government norms and policies. Encouraging more fundamental reforms in less democratic countries may be better served by different strategies.

Lastly and cumulatively, the findings presented in this dissertation serve to productively complicate what is otherwise a largely categorical debate on the impact of public governance MSIs. Notwithstanding the absence of evidence for these initiatives' longterm impact (Brockmyer \& Fox, 2015; Gruzd et al., 2018), this dissertation demonstrates the viability of three methods for testing whether public governance MSIs are influencing national governments and progressing towards their end objectives. By elaborating the mechanisms through which public governance MSIs exert national influence, it is possible to test whether those mechanisms are active in the context of specific MSI processes. By conceptualizing the ways in which MSIs can contribute to the institutionalization of public governance norms and policy spill-over into non-related policy arenas, it is possible to test for the influence of public governance MSIs using substantively related data sets. By elaborating detailed metrics for the alignment of specific norms and policies with the overall objectives pursued by public governance MSIs, it is possible to test whether the norms and policies promoted and adopted in an MSI context are likely to contribute to the initiative's objectives.

These three strategies for testing the influence and effectiveness of public governance MSIs are not perfect. They do provide useful insights, however, and should add nuance and rigor to the current policy discourse. 


\subsection{Limitations and avenues for further research}

This dissertation should be read in light of several limitations, derived both from the analytical focus employed, and limitations imposed by available data and measurements.

The measures and data employed in these analyses limit how the findings should be interpreted in at least two ways. Firstly, as is widely commented, OGP is still in early days. While it is not too early to identify mechanisms of influence and test whether those mechanisms are active in specific countries, it may well be that those mechanisms and their effects are changing as the OGP develops. The OGP is very much a living initiative, adapting in real time to its experiences and learnings from country engagement, as evidenced by the recent overhaul of the initiative's strategy (Open Government Partnership, 2016b). Analysis of influence and policy outcomes in this dissertation may be out of date before it is read. This requires sustained attention.

Secondly, the validity of data sources used in this analysis could be questioned. Action plan data curated by the OGP IRM is only loosely maintained, and generated through a process that lacks significant controls for internal validity. Individual researchers for each member country code the IRM data for action plan commitments, with only minimal guidance and quality control by IRM staff, and the resulting data is not subjected to coder reliability tests. Analysis in Article 4 suggested that data on commitment relevance to the value of civic participation contained a number of false positives. There is no reason to expect that this would be different for other aspects of IRM-coded data, or that there would not be false negatives as well.

In a similar vein, several methodological weaknesses attach to the UN's EParticipation Index. Most fundamentally, basing dichotomous indicators on surveys that report the existence of specific types of participatory mechanisms does not get to the heart of what those mechanisms are, or how they work. As Berntzen (2013) notes in another context, "the problem with this "checklist" approach is that it neither quantifies the amount of user involvement, nor the quality of the involvement" (p. 135). The UN Index also appears to privilege participatory engagement with executive branches of government, and might thus underrepresent interaction with parliaments in countries based on indirect democracy (Lasse Berntzen \& Olsen, 2009, p. 81). The EPI methodology is, moreover, less than completely transparent, and the index has been criticized for longitudinal consistency and 
poor concept validity (Curtin, 2006; Potnis, 2010). The EPI is not unique in this regard, and several other prominent comparative indices focused on aspects of national governance have been subjected to similar criticism (Gisselquist, 2014).

These critiques and concerns are valid, and yet data from the OGP IRM and the UN's E-Participation Index remain the best comparative data available on the implementation of e-participation and OGP. Like democracy, they represent the worst option, except for all the others. ${ }^{25}$ That said, this dissertation has heeded the caution of critics like Curtin, who argue that EPI scores "should be used and interpreted with great caution," "to illustrate broad trends and practices in promoting e-participation and e-inclusion" rather than to examine specific country progress or practice (p. 10-11). This approach is reflected in the application of these data to the dissertation's second and third research questions.

Several limitations also derive from the frame of analysis employed in this dissertation, focusing on specific mechanisms, domestic factors, and cases. Five such limitations are considered below.

Firstly, there may well be other mechanisms for MSIs influence on national policy aside from those discussed here. Indeed, analysis of in-country OGP processes often describe multiple "pathways to change", including the catalyzation of domestic reform movements, the stimulation of deep participation, and the trickle down of institutional practice from high level leadership (Elgin-Cossart et al., 2016, p. 5; Guerzovich \& Moses, 2016, p. 4). Each of these might imply additional mechanisms of influence.

Similarly, this dissertation attended to the national factors that are highlighted in social constructivist literature on norm global promotion. This focus necessarily ignores a near-infinite list of other national factors which might play a definitive role in how public governance MSIs are understood and adapted nationally, including factors related to the diffusion and accessibility of internet and mobile technologies. All that can be said about the potential for additional mechanisms or influential national factors is that they merit further study, and the current analysis should not be treated as exhaustive.

\footnotetext{
${ }^{25}$ See https://winstonchurchill.org/resources/quotes/the-worst-form-of-government/, accessed 17 March 2019.
} 
Thirdly, empirical analysis in this dissertation focused explicitly on civic participation norms and policies that relied on the use of digital media. This was justified by the prominence of digital media in the discourse surrounding OGP and global policy discourse more generally (see sections 1.23 and 2.2). Because technological tools and techniques are such a prominent frame within which civic participation is conceptualized and adopted, it is a useful site at which to study the influence of global norms on national policy. As discussed in section 2.4 , this does not imply a normative assumption regarding the use of technology in civic participation.

It is nevertheless the case that causal mechanisms underpinning MSIs' policy influence might operate differently in regard to norms of civic participation that do not explicitly rely on digital technology, and empirical analysis in this dissertation would not be able to fully account for that difference. With the exception of Article 2, however, whose analysis relied entirely on e-participation data, this dissertation has been careful to track distinctions between civic participation online and offline, and how they are conceptualized by different actors in the MSI context. Empirically, this was captured in the Norwegian case through close attention to how participation and dialogue have traditionally been conceptualized in the Norwegian governance context, and how this has contrasted with the emergent policy dialogues surrounding government modernization, digitization and open government. Thus, while the findings of this dissertation cannot be applied categorically to civic participation in a non-digital information environment, they can be applied with some caution. It is in any case not clear that there still exist any information and advocacy environments where enthusiasm for technology does not play a meaningful role. The findings and causal mechanisms outlined here can help explain how that enthusiasm is manifest, and how distinctions between online and offline participation are formed and disseminated.

The fourth limitation outlined here has to do with this dissertation's choice not to directly assess processes of action plan development. This omission is noteworthy, insofar as the collaborative and consultative processes through which member countries are encouraged to develop their national action plans were shown to be the most promising site for socializing participation norms, and the focus of OGP's most explicit, detailed and progressive promotion of civic participation norms. This process is, however, already the focus of the large majority of OGP research, as discussed in section 1.24. This dissertation 
chose instead to pursue alternative assessment strategies. None of these strategies or their associated research questions targeted processes of action plan development exclusively. Action plan development processes were nevertheless included in analyses. They represent a key discursive mechanism in the theoretical definition of a policy learning mechanism (see section 5.1) and featured in one of three registers considered in the third assessment strategy (see section 5.3.2).

Lastly, this analysis must account for its reliance on a single case study, and the limits that this poses on the external validity of findings. Norway was selected for this analysis by virtue of its deviant and data-rich character, which makes it an excellent site for the development of causal theory, as discussed in section 3.4. The theoretical findings in this case are thus analytically generalizable across cases, but not representative. The causal mechanism of knowledge transfer and policy learning validates OGP ambitions towards the socialization of participation norms, and also provides an explanation for the causal effect of that OGP membership was demonstrated to exercise on e-participation in Article 2. It does not follow, however, that those processes are necessarily at play in other countries, or that comparable outcomes related to the informal institutionalization of civic participation norms would be manifest in other countries.

This analysis does not claim that Norway is representative of other countries in which public governance MSIs operate, or that similar outcomes can be expected in other countries. It does, however, provide analytical generalizations with which to posit the mechanisms that might be at play if those outcomes are manifest. It also sets the stage for theoretical work to define the scope conditions for a theory that could predict when such outcomes would be produced and when they would not.

This is one of several areas in which additional research would advance the insights presented in this dissertation. Causal analysis should assess the operation of similar mechanisms in countries that differ significantly from Norway according to key characteristics, such as the national factors assessed here and the level of civil society engagement, constituting what George and Bennett call a contrast typology (2005, pp. 233262). In addition to an explicit focus on causal mechanisms related to knowledge transfer and policy learning, within-case research should further define and test for the operation of causal mechanisms related to argumentation and persuasion, as understood in IR theory, and consistently implied by commentary on public governance MSIs. An emphasis on 
distinguishing the influence of antagonism in deliberative processes would provide useful insights on the costs and benefits of voluntary approaches to governance challenges. Other research suggested by this dissertation would target a wider scope national factors influencing the promotion and adoption of norms in a MSI context. In addition to national level alignment of norms and structures with promoted norms, factors such as technology diffusion and political trust merit further study in the context of civic participation.

Each of these efforts would complicate and extend the findings asserted in this dissertation, contributing significantly to understanding how and under what conditions MSIs can be expected to influence national policy. The most important thing, perhaps, is that the emerging research community interested in public governance MSIs does not sit on its hands waiting for evidence of long-term impact. Too much money and effort is being spent. Too much research is conducted on processes too closely analogous to the efforts of public governance MSIs.

The ambitions and aspirations of public governance MSIs are as important as the cynicism they have provoked. This dissertation, and the additional research it suggests, offer a way to leverage both of those towards a more nuanced understanding over how these actors are influencing the behavior of countries, and what that means for the global policy discourse surrounding open, responsive, and accountable governance. 


\section{Reference list}

Aaronson, S. A. (2011). Limited Partnership: business, government, civil society, and the public in the Extractive Industries Transparency Initiative (EITI). Public Administration and Development, 31, 50-63. https://doi.org/10.1002/pad.588aut

Acharya, A. (2004). How Ideas Spread: Whose Norms Matter? Norm Localization and Institutional Change in Asian Regionalism. International Organization, 58(1), 239-275.

Arias, R., Gomez, S., Rivera, T. P., \& Fernandez, E. V. (2016). Opening Government?: the Case of Costa Rica in the Open Government Partnership. Retrieved January 1, 2019, from https://www.globalintegrity.org/resource/log-costarica/

Arnstein, S. R. (1969). A Ladder Of Citizen Participation. Journal of the American Institute of Planners, 35(4), 216-224. https://doi.org/10.1080/01944366908977225

Asbed, G., Gordon, J., \& Hubbell, S. (2005). The Problem With Multi-Stakeholder Initiatives. Open Society Foundations. Retrieved from https://www.opensocietyfoundations.org/events/problem-multi-stakeholder-initiatives

Åström, J., Karlsson, M., Linde, J., \& Pirannejad, A. (2012). Understanding the rise of eparticipation in non-democracies: Domestic and international factors. Government Information Quarterly, 29(2), 142-150. https://doi.org/10.1016/j.giq.2011.09.008

Bäckstrand, K. (2006). Multi-Stakeholder Partnerships for Sustainable Development :

Rethinking and Effectiveness. European Environment, 16, 290-306.

https://doi.org/10.1002/eet.425

Bahl, A. (2012). So What's In Those OGP Action Plans, Anyway? Retrieved April 4, 2017, from http://www.globalintegrity.org/2012/07/whats-in-ogp-action-plans/

Becker, H. S. . (1958). Problems of Inference and Proof in Participant Observation. American Sociological Review, 23(6), 652-660.

Ben-Aaron, J., Denny, M., Desmarais, B., \& Wallach, H. (2016). Transparency by Conformity: A Field Experiment Evaluating Openness in Local Governments. Public Administration Review, (February). https://doi.org/10.1111/puar.12596 
Ben-Josef Hirsch, M. (2014). Ideational change and the emergence of the international norm of truth and reconciliation commissions. European Journal of International Relations, 20(3), 810-833. https://doi.org/10.1177/1354066113484344

Bennett, A. (2002). Where the Model Frequently Meets the Road: Combining Statistical, Formal, and Case Study Methods. American Political Science Association Conference.

Bennett, A., \& Checkel, J. T. (2014). Process tracing: From philosophical roots to best practices. In A. Bennett \& J. T. Checkel (Eds.), Process Tracing: From Metaphor to Analytic Tool (pp. 3-38). Cambridge: Cambridge University Press.

Bennett, A., \& Checkel, J. T. (Eds.). (2015). Process Tracing: From Metaphor to Analytic Tool. Cambridge: Cambridge University Press.

Bennett, A., \& Elman, C. (2006). Complex causal relations and case study methods: The example of path dependence. Political Analysis, 14(3), 250-267. https://doi.org/10.1093/pan/mpj020

Berliner, D. (2015). Ambition and Realities in OGP Commitments: Analysis of Commitment Completion Across Countries Using Hierarchical Models. Advancing Open Government and Evaluating its Impact: Research Papers by the Winners of the OGP IDRC Research Grant. Retrieved from https://www.opengovpartnership.org/stories/ambitions-andrealities-ogp-commitments-analysis-of-commitment-completion-across-countries

Berliner, D., \& Erlich, A. (2015). Competing for Transparency: Political Competition and Institutional Reform in Mexican States. American Political Science Review, 109(01), 110128. https://doi.org/10.1017/s0003055414000616

Berntzen, L. (2013). Citizen-centric eGovernment Services. In CENTRIC 2013 : The Sixth International Conference on Advances in Human-oriented and Personalized Mechanisms, Technologies, and Services (pp. 132-136). Retrieved from http://www.thinkmind.org/index.php?view=article\&articleid=centric_2013_6_50_3050 0

Berntzen, L., \& Olsen, M. G. (2009). Benchmarking e-government: A comparative review of three international benchmarking studies. In Proceedings of the 3rd International Conference on Digital Society, ICDS 2009 (pp. 77-82). 
https://doi.org/10.1109/ICDS.2009.55

Bertot, J. C., Jaeger, P. T., \& Grimes, J. M. (2010). Using ICTs to create a culture of transparency: E-government and social media as openness and anti-corruption tools for societies. Government Information Quarterly, 27(3), 264-271.

https://doi.org/10.1016/j.giq.2010.03.001

Bezanson, K. A., \& Isenman, P. (2012). Governance of New Global Partnerships Challenges, Weaknesses, and Lessons (CGD Policy Paper No. 014). Washington D.C. Retrieved from https://www.cgdev.org/publication/governance-new-global-partnerships-challengesweaknesses-and-lessons

Björnehed, E., \& Erikson, J. (2018). Making the most of the frame: developing the analytical potential of frame analysis. Policy Studies, 39(2), 109-126. https://doi.org/10.1080/01442872.2018.1434874

Boscarino, J. E. (2016). Setting the Record Straight: Frame Contestation as an Advocacy Tactic. Policy Studies Journal, 44(3), 280-308. https://doi.org/10.1111/psj.12121

Bovens, M. (2007). Analysing and Assessing Accountability: A Conceptual Framework. European Law Journal, 13(4), 447-468. https://doi.org/10.1111/j.14680386.2007.00378.x

Bovens, M., Shillemans, T., \& Goodin, R. E. (2014). Public Accountability. In M. Bovens, T. Shillemans, \& R. E. Goodin (Eds.), The Oxford Handbook of Political Accountability (1st ed.). Oxford, UK: Oxford University Press.

Brockmyer, B., \& Fox, J. (2015). Assessing the Evidence: The Effectiveness and Impact of Public Governance-Oriented Multi-Stakeholder Initiatives. Retrieved from http://www.transparency-initiative.org/uncategorized/429/assessing-the-evidence-theeffectiveness-and-impact-of-public-governance-oriented-multi-stakeholder-initiatives/

Brunnée, J., \& Toope, S. J. (2010). Legitimacy and Legality in International Law: an international account. Cambridge: Cambridge University Press.

Bryer, T. A. (2011). Online Public Engagement in the Obama Administration: Building a Democracy Bubble? Policy and Internet, 3(4), 1-22. https://doi.org/10.2202/1944- 
2866.1135

Bryman, A. (2015). Social research methods (5th ed.). Oxford: Oxford University Press. Retrieved from https://books.google.no/books?hl=en\&lr=\&id=N2zQCgAAQBAJ\&oi=fnd\&pg=PP1\&dq=S ocial+Research+Methods\&ots=doMrDYMbrj\&sig=Nxdm9epd0MfJcaSqt_Kuu6fDW_s\&re

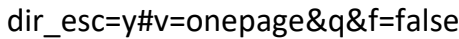

Bucher, B., \& Jasper, U. (2017). Revisiting 'identity' in International Relations: From identity as substance to identifications in action. European Journal of International Relations, 23(2), 391-415. https://doi.org/10.1177/1354066116644035

Cañares, M. P. (2016). Enhancing Citizen Engagement with Open Government Data : The Case of Local Governments in the Philippines. Journal of Community Informatics', 12(2), 69-98.

Carolan, L. (2016). Open data, transparency and accountability: Topic Guide (GSDRC Topic Guides). Birmingham, UK. Retrieved from http://www.gsdrc.org/topic-guides/opendata-transparency-and-accountability/

Chadwick, A. (2011). Explaining the Failure of an Online Citizen Engagement Initiative: The Role of Internal Institutional Variables. Journal of Information Technology \& Politics, 8(1), 21-40. https://doi.org/10.1080/19331681.2010.507999

Chatfield, A. T., \& Reddick, C. G. (2016). Open Data Policy Innovation Diffusion : An Analysis of Australian Federal and State Governments. In Proceedings of the 17th International Digital Government Research Conference on Digital Government Research (pp. 155163).

Checkel, J. T. (1997). International Norms and Domestic Politics: Bridging the RationalistConstructivist Divide. European Journal of International Relations1, 3(4), 473-495.

Collier, D. (2011a). Teaching Process Tracing: Examples and Exercises. Unpublished Manuscript. Retrieved from https://papers.ssrn.com/sol3/papers.cfm?abstract_id=1944646

Collier, D. (2011b). Understanding Process Tracing. Politics, 44(4), 823-830. 
https://doi.org/10.1017/S1049096511001429

Common, R. (2013). When Policy Diffusion does not lead to Policy Transfer: explaining resistance to international learning in public management reform. In P. Carroll \& R. Common (Eds.), Policy Transfer and Learning in Public Policy and Management: International contexts, content and development (Vol. 1, pp. 13-29). New York: Routledge. https://doi.org/10.4324/9780203749395

Cornwall, A., \& Coelho, V. S. P. (2007). Spaces for change?: the politics of citizen participation in new democratic arenas. In A. Cornwall \& V. S. P. Coelho (Eds.), Spaces for change?: the politics of citizen participation in new democratic arenas (pp. 1-29). London and New York: Zed Books. Retrieved from http://libproxy.mit.edu/login?url=http://search.ebscohost.com/login.aspx?direct=true $\& d b=$ cat00916a\&AN=mit.001420894\&site=eds-live \&scope $=$ cite

Corrigan, C. (2014). Breaking the resource curse: Transparency in the natural resource sector and the extractive industries transparency initiative. Resources Policy, 40(1), 17-30. https://doi.org/10.1016/j.resourpol.2013.10.003

Corrigan, T., \& Gruzd, S. (2018). Civil Society Participation in the Open Government Partnership (OGP). Retrieved from https://saiia.org.za/research/learning-lessons-frommulti-stakeholder-initiatives/

Cortell, A. P., \& Davis, J. W. (2002). Understanding the Domestic Impact of International Norms: A Research Agenda. International Studies Review, 2(1), 65-87. https://doi.org/10.1111/1521-9488.00184

Cortell, A. P., \& Davis, J. W. (2005). When norms clash: International norms, domestic practices, and Japan's internalisation of the GATT/WTO. Review of International Studies, 31(1), 3-25. https://doi.org/10.1017/S0260210505006273

Curtin, G. G. (2006). Issues and Challenges - Global E-Government/E-Participation Models, Measurement and Methodology. In Workshop on E-Participation and E-government: Understanding the Present and Creating the Future (р. 33).

Dahlberg, L. (2011). Re-constructing digital democracy: An outline of four "positions." New Media \& Society, 13(February), 855-872. https://doi.org/10.1177/1461444810389569 
Dahlgren, P. (2016). Civic Engagement. In G. Maxxoleni, K. G. Barnhurst, K. Ikeda, R. C. M. Maia, \& H. Wessler (Eds.), The International Encyclopedia of Political Communication. Chichester: Wiley Blackwell.

Damnjanović, I. (2019). Democratic innovations in Serbia: a misplaced trust in technology. Contemporary Politics, 25(1), 111-127. https://doi.org/10.1080/13569775.2018.1544028

David-Barrett, E., \& Okamura, K. (2016). Norm Diffusion and Reputation: The Rise of the Extractive Industries Transparency Initiative. Governance, 29(2), 227-246. https://doi.org/10.1111/gove.12163

Davies, T., \& Bawa, Z. A. (2012). The Promises and Perils of Open Government Data (OGD) _ Davies_ The Journal of Community Informatics. Journal of Community Informatics, 8(2).

Dixon, J. M. (2017). Rhetorical Adaptation and Resistance to International Norms. Perspectives on Politics, 15(1), 83-99. https://doi.org/10.1017/S153759271600414X

Dobbin, F., Simmons, B., \& Garret, G. (2007). The Global Diffusion of Public Policies: Social Construction, Coercion, Competition, or Learning? Annual Review of Sociology, 33, 44972. https://doi.org/10.1146/annurev.soc.33.090106.142507

Dolowitz, D., \& Marsh, D. (2000). Learning from Abroad: The Role of Policy Transfer in Contemporary Policy-Making. Governance, 13(1), 5. https://doi.org/10.1111/09521895.00121

Douglas, J. W., Raudla, R., \& Hartley, R. E. (2015). Shifting Constellations of Actors and Their Influence on Policy Diffusion: A Study of the Diffusion of Drug Courts. Policy Studies Journal, 43(4), 484-511. https://doi.org/10.1111/psj.12113

Drury, J., \& Stott, C. (2001). Bias as a Research Strategy in Participant Observation: The Case of Intergroup Conflict. Field Methods, 13(1), 47-67. https://doi.org/10.1177/1525822X0101300103

Dunia, F. G. (1997). Explaining legal implementation in the European Union. International Journal of the Sociology of Law, 25, 155-179.

Ekman, J., \& Amnå, E. (2012). Political participation and civic engagement: Towards a new 
typology. Human Affairs, 22, 283-300. https://doi.org/10.2478/s13374-012-0024-1

Elgin-Cossart, M., Sutton, T., \& Sachs, K. (2016). Let the Sunshine In: An Assessment of the Open Government Partnership. Retrieved from https://www.americanprogress.org/issues/security/reports/2016/03/17/133584/letthe-sunshine-in/

Erickson, J. L. (2014). Saving Face, Looking Good, and Building International Reputation in East and West. In L. W. Pauly \& B. W. Jentleson (Eds.), Power in a Complex Global System (pp. 180-193). London: Routledge.

Erikson, J. (2015). Ideas and actors in policy processes: where is the interaction? Policy Studies, 36(5), 451-467. https://doi.org/10.1080/01442872.2015.1091067

Evans, M., \& Davies, J. (1999). Understanding Policy Transfer : A multi-disciplinary perspective. Public Administration, 77(2), 361-385. https://doi.org/10.1111/14679299.00158

Falla, R. (2018). Why OGP Commitments Fall Behind (Open Government Partnership, Independent Reporting Mechanism).

Falleti, T. G. (2006). Theory-Guided Process-Tracing in Comparative Politics: Something Old, Something New. Newsletter of the Organized Section in Comparative Politics of the American Political Science Association, 17(1), 9-14.

Falleti, T. G., \& Lynch, J. F. (2009). Context and Causal Mechanisms in Political Analysis. Comparative Political Studies, 42(9), 1143-1166. https://doi.org/10.1177/0010414009331724

Faria, C., \& Rehbein, M. (2016). Open parliament policy applied to the Brazilian Chamber of Deputies. Journal of Legislative Studies, 22(4), 559-578. https://doi.org/10.1080/13572334.2016.1235333

Ferber, P., Foltz, F., \& Pugliese, R. (2007). Cyberdemocracy and Online Politics: A New Model of Interactivity. Bulletin of Science, Technology \& Society, 27(5), 391-400. https://doi.org/10.1177/0270467607304559

Finnemore, M. (1993). International Organizations as Teachers of Norms: The United Nations 
Educational, Scientific, and Cutural Organization and Science Policy. International Organization, 47(4), 565-597.

Finnemore, M., \& Sikkink, K. (1998). International Norm Dynamics and Political Change. International Organization, 53(2), 887-917.

Foti, J. (2014). Independent Reporting Mechanism:Technical Paper 1 (IRM Technical Papers No. 2). Retrieved from http://www.opengovpartnership.org/sites/default/files/attachments/Technical paper 1_final.pdf

Foti, J. (2016). Beyond the Basics - OGP Action Plans 2012 - 2015 (IRM Technical Papers No.

2). Retrieved from http://www.opengovpartnership.org/sites/default/files/IRMReport_Technical-Paper_20161130_web.pdf

Fox, J. (2007). The uncertain relationship between transparency and accountability.

Development in Practice, 17(4-5), 663-671.

https://doi.org/10.1080/09614520701469955

Fox, J., \& Aceron, J. (2015). Doing accountability differently: A proposal for the vertical integration of civil society monitoring and advocacy (U4 Issue).

Francoli, M., \& Clarke, A. (2014). What's in a name? A comparison of 'open government' definitions across seven Open Government Partnership members. JeDEM - EJournal of EDemocracy and Open Government, 6(3), 248-266. Retrieved from https://jedem.org/index.php/jedem/article/view/227

Francoli, M., \& Höchtl, J. (2017). Editorial. EJournal of EDemocracy \& Open Government, 9(1), i-iii.

Francoli, M., Ostling, A., \& Steibel, F. (2015). From Informing to Empowering: Best Practices and Recommendations for Improving Government Civil Society Interactions within OGP. Retrieved from http://www.opengovpartnership.org/sites/default/files/FromInformingToEmpowering_ FullReport.pdf

Fransen, L. W., \& Kolk, A. (2007). Global rule-setting for business: A critical analysis of multi- 
stakeholder standards. Organization, 14(5), 667-684.

https://doi.org/10.1177/1350508407080305

Fraundorfer, M. (2017). The Open Government Partnership: Mere Smokescreen or New Paradigm? Globalizations, 14(4), 611-626.

https://doi.org/10.1080/14747731.2016.1236463

Freeman, J. (2013). E-government in the context of monitory democracy: Public participation and democratic reform. Media Asia, 40(4).

https://doi.org/10.1080/01296612.2013.11689988

Freeman, J., \& Quirke, S. (2013). Understanding E-Democracy. Journal of E-Democracy and Open Government, 5(2), 141-154.

Fung, A. (2006). Varieties of Participation in Complex Governance. Public Administration Review, 66, 66-75. https://doi.org/10.1111/j.1540-6210.2006.00667.x

Fung, A., Russon Gilman, H., \& Shkabatur, J. (2013). Six models for the internet + politics. International Studies Review, 15(1), 30-47. https://doi.org/10.1111/misr.12028

Gallagher, M. (2013). Capturing Meaning and Confronting Measurement. In L. Mosely (Ed.), Interview Research in Political Science (pp. 181-195). Ithica: Cornell University Press.

Gaventa, J. (2004). Towards Participatory Local Governance: Assessing the Transformative Possibilities. In S. Hickey \& G. Mohan (Eds.), Participation: from tyranny to transformation?: exploring new approaches to participation in development. New York: Zed Books. https://doi.org/10.1007/s13398-014-0173-7.2

Gawel, E., \& Bernsen, K. (2011). Virtuelles Wasser - Chancen und Probleme eines Wasserfußabdrucks. Wirtschaftsdienst, 91(8), 558-564. Retrieved from https://www.wzb.eu/en/research/international-politics-and-law/globalgovernance/publications

Geissel, B., \& Newton, K. (2012). Evaluating democratic innovations: Curing the democratic malaise? Evaluating Democratic Innovations: Curing the Democratic Malaise? https://doi.org/10.4324/9780203155196

George, A., \& Bennett, A. (2005). Case Studies and Theory Development. In Case Studies and 
Theory Development in the Social Sciences (Vol. 36, pp. 3-36). Cambridge, MA: MIT Press. https://doi.org/10.1017/S0022381607080231

Gerring, J. (2008). The mechanismic worldview: Thinking inside the box. British Journal of Political Science, 38(1), 161-179. https://doi.org/10.1017/S0007123408000082

Gerson, P., \& Nieto, F. (2016). Opening Government? The Case of Mexico in the Open Government Patnership. Washington D.C. Retrieved from https://www.globalintegrity.org/resource/log-mexico/

Gerven, M. Van, Vanhercke, B., \& Gürocak, S. (2014). Policy Learning, Aid Conditionality or Domestic Politics? The Europeanization of Dutch and Spanish Activation Policies Through the European Social Fund. Journal of European Public Policy, 21(July), 509-527. https://doi.org/10.1080/13501763.2013.862175

Gigler, B.-S., \& Bailur, S. (Eds.). (2014). Closing the Feedback Loop: Can Technolog Bridge the Accountability Gap? the World Bank. Washington D.C.: Directions in Development. https://doi.org/10.1596/978-1-4648-0191-4

Gisselquist, R. M. (2014). Developing and evaluating governance indexes: 10 questions. Policy Studies, 35(5), 513-531. https://doi.org/10.1080/01442872.2014.946484

Goertz, G. (2012). Social science concepts: A user's guide. Social Science Concepts: A User's Guide (2nd ed.). Princeton, New Jersey: Princeton University Press.

Goëta, S., \& Davies, T. (2016). The daily shaping of state transparency: Standards, machinereadability and the configuration of open government data policies. Science and Technology Studies, 29(4), 10-30.

Goldstein, J., \& Weinstein, J. (2012). The Benefits of a Big Tent: Opening Up Government in Developing Countries. UCLA Law Review Discourse, 178(2012), 178-208.

Gonzalez-Zapata, F., \& Heeks, R. (2014). The multiple meanings of open government data: Understanding different stakeholders and their perspectives. Government Information Quarterly, 32(4), 441-452. https://doi.org/10.1016/j.giq.2015.09.001

Graham, E., Shipan, C., \& Volden, C. (2013). The Diffusion of Policy Diffusion Research. British Journal of Political Science, 43(3), 673-701. 
Grönlund, Å. (2009). ICT Is Not Participation Is Not Democracy - eParticipation Development Models Revisited. In A. Macintosh \& E. Tambouris (Eds.), Electronic Participation First International Conference, ePart 2009 Linz, Austria, September 1-3, 2009 Proceedings (pp. 12-23). Lecture Notes in Computer Science.

Gruzd, S., Turianskyi, Y., Grobbelaar, N., \& Mizrahi, Y. (2018). Multi-stakeholder Initiatives: Lessons Learned. Retrieved from https://saiia.org.za/research/learning-lessons-frommulti-stakeholder-initiatives/

Guerzovich, F., \& Moses, M. (2016). Learning How to Open Government: Findings and reflections on how the Open Government Partnership is playing out, in practice, in five countries. Retrieved from https://www.opengovpartnership.org/resources/learningopen-government-findings-and-reflections-on-how-ogp-playing-out-practice-five

Gurumurthy, A., Bharthur, D., \& Chami, N. (2017). Voice or chatter? Making ICTs work for transformative citizen engagement democracy (Making All Voices Count). Brighton: Institute of Development Studies.

Hale, S. A., John, P., Margetts, H., \& Yasseri, T. (2018). How digital design shapes political participation: A natural experiment with social information. PLOS ONE, 13(4), 1-20. https://doi.org/10.1371/journal.pone.0196068

Halloran, B. (2015). From Openness to Real Accountability: The Role of MSIs (TALEARN). Retrieved from https://www.transparency-initiative.org/blog/405/from-openness-toreal-accountability-the-role-of-msis/

Hansen, S. T. (2016). Taking ambiguity seriously: Explaining the indeterminacy of the European Union conventional arms export control regime. European Journal of International Relations, 22(1), 192-216. https://doi.org/10.1177/1354066115584086

Haro-de-Rosario, A., Saez-Martin, A., \& del Carmen Caba-Perez, M. (2016). Using social media to enhance citizen engagement with local government: Twitter or Facebook? New Media \& Society. https://doi.org/10.1177/1461444816645652

Harrison, T. (2013). The "audience" as participative, idea generating, decision making citizens: will they transform government? Participations. Journal of Audience \& Reception Studies, 10(1), 395-399. 
Hasan, M. (2016). OGP Internal Research Synthesis Paper (No. on file with author).

Haufler, V. (2010). Disclosure as Governance: The Extractive Industries Transparency Initiative and Resource Management in the. Global Environmental Politics, 10(August), $53-73$.

Hayes, A. F. (2013). Introduction to mediation, moderation, and conditional process analysis: a regression-based approach (2nd ed.). New York: The Guilford Press.

Heikkila, T., \& Gerlak, A. (2013). Building a conceptual approach to collective learning: lessons for public policy scholars. Policy Studies Journal, 41(3), 484-512.

Herrero, A. (2015). Access to Information Commitments in OGP Action Plans: A Report on the Progress of Reforms Worldwide (World Bank).

Hintz, A., \& Milan, S. (2014). In Multistakeholderism We Trust: on the limits of the multistakeholder debate. Retrieved March 28, 2019, from https://global.asc.upenn.edu/in-multistakeholderism-we-trust-on-the-limits-of-themultistakeholder-debate/

Honig, D., \& Weaver, C. (2018). A Race to the Top?: The Aid Transparency Index and the Normative Power of Global Performance Assessments. International Organization, (Forthcoming).

Institute for Human Rights and Business. (2017). How Home Governments Can Incentivise Responsible Business Conduct of Extractive Companies Operating Abroad: MultiStakeholder Initiatives.

Irvin, R. a., \& Stansbury, J. (2004). Citizen Participation in Decision Making: Is It Worth the Effort? Public Administration Review, 64(1), 55-65. https://doi.org/10.1111/j.1540$6210.2004 .00346 . x$

Jackson School Task Force. (2012). Review of Best Practices for Multi-Stakeholder Initiatives: Recommendations for GIFT. Henry M. Jackson School of International Studies.

Jacobs, A. M. (2014). Process tracing the effects of ideas. In A. Bennett \& J. T. Checkel (Eds.), Process Tracing: From Metaphor to Analytic Tool (pp. 41-73). Cambridge: Cambridge University Press. https://doi.org/10.1007/9781139858472.005 
James, O., \& Lodge, M. (2003). The Limitations of "Policy Transfer" and "Lesson Drawing" for Public Policy Research. Political Studies Review, 1(2), 179-193.

https://doi.org/10.1111/1478-9299.t01-1-00003

Janssen, M., Charalabidis, Y., \& Zuiderwijk, A. (2012). Benefits, Adoption Barriers and Myths of Open Data and Open Government. Information Systems Management, 29(4), 258268. https://doi.org/10.1080/10580530.2012.716740

Janssen, M., \& Helbig, N. (2015). Innovating and changing the policy-cycle: Policy-makers be prepared! Government Information Quarterly, 7-13.

https://doi.org/10.1016/j.giq.2015.11.009

Jeff Gulati, G. J., Williams, C. B., \& Yates, D. J. (2014). Predictors of on-line services and eparticipation: A cross-national comparison. Government Information Quarterly, 31(4), 526-533. https://doi.org/10.1016/j.giq.2014.07.005

Johnson, B., \& Hagström, B. (2005). The Translation Perspective as an Alternative to the Policy Diffusion Paradigm: The Case of the Swedish Methadone Maintenance Treatment. Journal of Social Policy, 34(3), 365-388.

https://doi.org/10.1017/S0047279405008822

Jörgens, H. (2009). Cross-National Imitation And Learning. The Handbook of Rational and Social Choice, 1(9), 271-298.

https://doi.org/10.1093/acprof:oso/9780199290420.003.0012

José María Marín. (2016). Evidence of citizen engagement impact in promoting good governance and anti-corruption efforts » U4. Retrieved from http://www.u4.no/publications/evidence-of-citizen-engagement-impact-in-promotinggood-governance-and-anti-corruption-efforts/

Jun, K. N., \& Weare, C. (2011). Institutional motivations in the adoption of innovations: The case of e-government. Journal of Public Administration Research and Theory, 21(3), 495-519. https://doi.org/10.1093/jopart/muq020

Kassen, M. (2014). Globalization of e-government: open government as a global agenda; benefits, limitations and ways forward. Information Development, 30(1), 51-58. https://doi.org/10.1177/0266666912473620 
Katz, J., \& Halpern, D. (2013). Political and Developmental Correlates of Social Media Participation in Government: A Global Survey of National Leadership Websites. International Journal of Public Administration, 36(1), 1-15. https://doi.org/10.1080/01900692.2012.713286

Katzenstein, P., \& Okawara, N. (2001). Japan, Asian-Pacific Security, and the Case for Analytical Eclecticism. International Security, 26(3), 153-185.

Kaufmann, D., Kraay, A., \& Mastruzzi, M. (2011). The worldwide governance indicators: Methodology and analytical issues. Hague Journal on the Rule of Law, 3(2), 220-246. https://doi.org/10.1017/S1876404511200046

Kay, A., \& Baker, P. (2015). What can causal process tracing offer to policy studies? A review of the literature. Policy Studies Journal, 43(1), 1-21. https://doi.org/10.1111/psj.12092

Khan, S., \& Foti, J. (2015). Aligning Supply and Demand for Better Governance: Open Data in the Open Government Partnership (Open Government Partnership, Independent Reporting Mechanism). Retrieved from https://drive.google.com/file/d/OB471ujVfgLNMWINKdEVyMXZQaVE/view

Khwaja, A. I. (2004). Is increasing community participation always a good thing? Journal of the European Economic Association, 2(2-3), 427-436. Retrieved from http://onlinelibrary.wiley.com/doi/10.1162/154247604323068113/abstract\%5Cnhttp:/ /www.hks.harvard.edu/fs/akhwaja/papers/JEEAfinal.pdf

King, C. S., Feltey, K. M., \& O'Neill Susel, B. (1998). The Question of Participation : Toward Authentic Public Participation in Public Administration. Public Administration Review, 58(4), 317-326.

Kornberger, M., Meyer, R. E., \& Höllerer, M. A. (2017). When Bureaucracy Meets the Crowd : Studying "Open Government " in the Vienna City Administration. Organization Studies, 1-22. https://doi.org/10.1177/0170840616655496

Krishnan, S., \& Teo, T. S. H. (2009). Moderating Effects of Governance on Information Infrastructure and E-Government Development. Communications in Information Literacy, 3(2), 80-90. 
Krishnan, S., Teo, T. S. H., \& Lymm, J. (2017). Determinants of electronic participation and electronic government maturity: Insights from cross-country data. International Journal of Information Management, 37(4), 297-312. https://doi.org/10.1016/j.ijinfomgt.2017.03.002

Lee, A. C., Chang, K., Berry, F. S., Lee, C., \& Berry, F. S. (2017). Testing the Development and Diffusion of E-Government and E-Democracy: A Global Perspective. Public Administration Review, 71(3), 444-454.

Leipold, S., \& Winkel, G. (2017). Discursive Agency: (Re-)Conceptualizing Actors and Practices in the Analysis of Discursive Policymaking. Policy Studies Journal, 45(3), 510-534. https://doi.org/10.1111/psj.12172

Lemieux, V. L., Trapnell, S. E., Worker, J., \& Excell, C. (2015). Transparency and Open Government: Reporting on the Disclosure of Information. JeDEM - EJournal of EDemocracy and Open Government, 7(2), 155-167. Retrieved from http://www.donauuni.ac.at/en/department/gpa/telematik/edemocracyconference/edem/vid/20773/index.php?URL=/en/department/gpa/telematik/edemocr acy-conference/20773\&cursor $=6$

Liden, G. (2016). Inequality in Local Digital Politics : How Different Preconditions for Citizen Engagement Can Be Explained. Policy and Internet, 8(3), 270-291. https://doi.org/doi.org/10.1002/poi3.122

Lindberg, S. I. (2013). Mapping accountability: core concept and subtypes. International Review of Administrative Sciences, 79(2), 202-226. https://doi.org/10.1177/0020852313477761

Linden, R. H. (Ed.). (2002). Norms and nannies : the impact of international organizations on the central and east European states. Lanham, Maryland: Rowman \& Littlefield Publishers.

Linders, D. (2012). From e-government to we-government: Defining a typology for citizen coproduction in the age of social media. Government Information Quarterly, 29(4), 446454. https://doi.org/10.1016/j.giq.2012.06.003

Liu, H. K. (2016). Exploring Online Engagement in Public Policy Consultation: The Crowd or 
the Few? Australian Journal of Public Administration, 00(0), 1-15.

https://doi.org/10.1111/1467-8500.12209

Loureiro, M., Cassim, A., Darko, T., And, L. K., \& Salome, N. (2016). When does the state listen? IDS Bulletin, 47(1), 55-68.

Lucke, J. von, \& Große, K. (2014). Open Government Collaboration. In M. Gascó-Hernández (Ed.), Opportunities and Challenges for Public Governance (pp. 189-204). New York: Springer.

Luna-reyes, L. F., \& Harrison, T. M. (2016). Open Data and Open Government : From Abstract Principles to Institutionalized Practices. In Proceedings of the 17th International Digital Government Research Conference on Digital Government Research (pp. 76-85).

Lundgren, A. (2017). The Openness Buzz: A Study of Openness in Planning, Politics, and Political Decision-Making in Sweden from an Institutional Perspective. KTH Royal Institute of Technology.

Lyall, J. (2015). Process tracing, causal inference, and civil war. In A. Bennett \& A. George (Eds.), Process Tracing: From Metaphor to Analytic Tool (pp. 186-208). Cambridge, Mass.: Cambridge University Press.

Mabillard, V., \& Zumofen, R. (2016). The complex relationship between transparency and accountability: A synthesis and contribution to existing frameworks. Public Policy and Administration, 32(2), 110-129. https://doi.org/10.1177/0952076716653651

Maggetti, M., \& Gilardi, F. (2016). Problems (and solutions) in the measurement of policy diffusion mechanisms. Journal of Public Policy, 36(01), 87-107. https://doi.org/10.1017/S0143814X1400035X

Mahoney, J., \& Goerts, G. (2006). A tale of two cultures: Contrasting quantitative and qualitative research. Political Analysis, 14(3), 227-249. https://doi.org/10.1093/pan/mpj017

March, J. G., \& Olsen, J. P. (2011). The Logic of Appropriateness. In R. E. Goodin (Ed.), The Oxford Handbook of Political Science (pp. 478-497). Oxford University Press. https://doi.org/10.1093/oxfordhb/9780199604456.013.0024 
Mastenbroek, E., \& Kaeding, M. (2006). Europeanization Beyond the Goodness of Fit: Domestic Politics in the Forefront1. Comparative European Politics, 4(4), 331-354. https://doi.org/10.1057/palgrave.cep.6110078

Mcgee, R., Anderson, C., Hudson, H., \& Feruglio, F. (2018). Appropriating technology for accountability : messages from Making All Voices Count. Brighton.

McGee, R., \& Edwards, D. (2016). Opening Governance. IDS Bulletin, 47(1), 1-22. https://doi.org/10.19088/1968-2016.103

McMillan, S. J. (2002). A four-part model of cyber-interactivity: some cyber-places are more interactive than others. New Media \& Society, 4(2), 271-291.

Meissner, H., Creswell, J., Klassen, A. C., Plano, V., \& Smith, K. C. (2011). Best Practices for Mixed Methods Research in the Health Sciences. Methods, 29, 1-39. https://doi.org/10.1037/e566732013-001

Mena, S., \& Palazzo, G. (2012). Input and Output Legitimacy of Multi-Stakeholder Initiatives. Business Ethics Quarterly, 22(03), 527-556. https://doi.org/10.5840/beq201222333

Mergel, I. (2013). A framework for interpreting social media interactions in the public sector. Government Information Quarterly, 30(4), 327-334. https://doi.org/10.1016/j.giq.2013.05.015

Meseguer, C. (2005). Policy learning, policy diffusion, and the making of a new order. Annals of the American Academy of Political and Social Science, 598(March), 67-82. https://doi.org/10.1177/0002716204272372

Michener, G. (2015). Policy Evaluation via Composite Indexes: Qualitative Lessons from International Transparency Policy Indexes. World Development, 74, 184-196. https://doi.org/10.1016/j.worlddev.2015.04.016

Millard, J., Nielsen, M. M., Warren, R., Smith, S., Macintosh, A., Konstantinos, K., ... Parisoloulos, K. (2009). European eParticipation Summary Report (Information Society and Media DG). https://doi.org/10.1136/bmj.328.7444.845

Miller-Dawkins, M. (2014). How can you tell whether a Multi-Stakeholder Initiative is a total waste of time? Retrieved March 28, 2019, from https://oxfamblogs.org/fp2p/how-can- 
you-tell-whether-a-multi-stakeholder-initiative-is-a-total-waste-of-time/

Mintrom, M. (1997). Policy Entrepreneurs and the Diffusion of Innovation. American Journal of Political Science, 41(3), 738-770. https://doi.org/10.2307/2111674

Mizrahi, S., Vigoda-Gadot, E., \& Cohen, N. (2009). Trust, Participation, and Performance in Public Administration. Public Performance \& Management Review, 33(1), 7-33. https://doi.org/10.2753/PMR1530-9576330101

Montero, A. G. (2015a). Open government and transparency reform in Chile: Balancing leadership, ambition and implementation capacity (U4 Report No. 2). Retrieved from http://www.u4.no/publications/open-government-and-transparency-reform-in-chilebalancing-leadership-ambition-and-implementation-capacity/\#sthash.TfaKkID0.dpuf

Montero, A. G. (2015b). Open government in Uruguay: Strengthening dialogue to make up for institutional challenges (U4 Report No. 1). Retrieved from http://www.u4.no/publications/open-government-in-uruguay-strengthening-dialogueto-make-up-for-institutional-challenges/

Montero, A. G., \& Taxell, N. (2015). Open government reforms The challenge of making public consultations meaningful in Croatia (U4 Report No. 3). Retrieved from http://www.u4.no/publications/open-government-reforms-the-challenge-of-makingpublic-consultations-meaningful-in-croatia/

Moog, S., Spicer, A., \& Böhm, S. (2015). The Politics of Multi-Stakeholder Initiatives: The Crisis of the Forest Stewardship Council. Journal of Business Ethics, 128, 469-493. https://doi.org/10.1007/s10551-013-2033-3

MSI Integrity. (2015). Protecting the Cornerstone: Assessing the Governance of Extractive Industries Transparency Initiative Multi-Stakeholder Groups.

Müller, H. (2004). Arguing, bargaining and all that: Communicative action, rationalist theory and the logic of appropriateness in international relations. European Journal of International Relations, 10(3), 395-435. https://doi.org/10.1177/1354066104045542

Nabatchi, T., Sancino, A., \& Sicilia, M. (2017). Varieties of Participation in Public Services: The Who, When, and What of Coproduction. Public Administration Review. 
https://doi.org/10.1111/puar.12765

Nelimarkka, M., Nonnecke, B., Krishnan, S., Aitamurto, T., Catterson, D., Crittenden, C., ... Goldberg, K. (2014). Comparing Three Online Civic Engagement Platforms using the Spectrum of Public Participation Framework. In Proceedings of the Oxford Internet, Policy, and Politics Conference (IPP) (pp. 25-26).

Nielsen, R. A., \& Simmons, B. A. (2015). Rewards for Ratification: Payoffs for Participating in the International Human Rights Regime? International Studies Quarterly, 59(2), 197208. https://doi.org/10.1111/isqu.12142

Niemann, H., \& Schillinger, H. (2017). Contestation "all the way down"? the grammar of contestation in norm research. Review of International Studies, 43(1), 29-49. https://doi.org/10.1017/S0260210516000188

Noveck, B. S. (2009). Wiki government : how technology can make government better, democracy stronger, and citizens more powerful. Washington D.C.: Brookings Institution Press.

O'Mahoney, J. (2014). Rule tensions and the dynamics of institutional change: From "to the victor go the spoils" to the Stimson Doctrine. European Journal of International Relations, 20(3), 834-857. https://doi.org/10.1177/1354066113483781

Obinger, H., Schmitt, C., \& Starke, P. (2013). Policy Diffusion and Policy Transfer in Comparative Welfare State Research. Social Policy and Administration, 47(1), 111-129. https://doi.org/10.1111/spol.12003

OECD. (2001). Citizens as Partners: OECD Handbook on information, consultation and public participation in policy making. Retrieved from https://www.internationalbudget.org/wp-content/uploads/Citizens-as-Partners-OECDHandbook.pdf.

OGP Independent Reporting Mechanism. (2017). IRM Procedures Manual version 4. OGP Independent Reporting Mechanism. Retrieved from https://www.opengovpartnership.org/documents/irm-procedures-manual Open government Partnership. (2011). Mission and strategy. Retrieved July 3, 2018, from 
https://www.opengovpartnership.org/mission-and-strategy

Open Government Partnership. (2011). Open Government Declaration. Retrieved March 28, 2019, from https://www.opengovpartnership.org/open-government-declaration

Open Government Partnership. (2014a). Guidance for national OGP dialogue (on file with author).

Open Government Partnership. (2014b). Open Government Partnership: Four Year Strategy 2015-2018. Retrieved from https://www.opengovpartnership.org/documents/fouryear-ogp-strategy

Open Government Partnership. (2015a). OGP Values Guidance Note. Retrieved from http://www.opengovpartnership.org/sites/default/files/attachments/OGPvaluesguidan cenote.pdf

Open Government Partnership. (2015b). Open Government Partnership Articles of Governance. Retrieved from https://www.opengovpartnership.org/about/aboutogp/governance/articles-of-governance

Open Government Partnership. (2016a). Government Point of Contact Manual. Retrieved from https://www.opengovpartnership.org/sites/default/files/OGP_POCManual_2017_EN.pdf

Open Government Partnership. (2016b). Strategic Refresh of the Open Government Partnership. Retrieved from https://www.opengovpartnership.org/ogp-strategicrefresh-and-mid-term-review

Open Government Partnership. (2017a). OGP Participation \& Co-Creation Standards. Retrieved January 11, 2019, from https://www.opengovpartnership.org/ogpparticipation-co-creation-standards

Open Government Partnership. (2017b). OGP Steering Committee Meeting Agenda and PrePacket. Retrieved from https://www.opengovpartnership.org/sites/default/files/SCMeeting-Packet_September2017.pdf

Park, C., Lee, J., \& Wilding, M. (2016). Distorted policy transfer? South Korea's adaptation of UK social enterprise policy. Policy Studies, 38(1), 39-58. 
https://doi.org/10.1080/01442872.2016.1188904

Park, C., Wilding, M., \& Chung, C. (2014). The importance of feedback: Policy transfer, translation and the role of communication. Policy Studies, 35(4), 397-412. https://doi.org/10.1080/01442872.2013.875155

Pasquier, M., \& Villeneuve, J. P. (2007). Organizational barriers to transparency: A typology and analysis of organizational behaviour tending to prevent or restrict access to information. International Review of Administrative Sciences, 73(1), 147-162. https://doi.org/10.1177/0020852307075701

Peixoto, T. (2013). The Uncertain Relationship Between Open Data and Accountability: A Response to Yu and Robinson' s The New Ambiguity of "Open Government." UCLA Law Review Discourse, 60(2007), 200-213.

Peixoto, T., Fall, M., \& Sjoberg, F. (2016). Evaluating Digital Citizen Engagement: A Practical Guide. Retrieved from http://hdl.handle.net/10986/23752

Peixoto, T., \& Fox, J. (2016a). When Does ICT-Enabled Citizen Voice Lead to Government Responsiveness? IDS Bulletin, 47(1), 23-40.

Peixoto, T., \& Fox, J. (2016b). When Does ICT-Enabled Citizen Voice Lead to Government Responsiveness? IDS Bulletin, 47(1), 23-40.

Petrie, M. (2015a). Fiscal Transparency in Open Government Partnership Countries, and the Implementation of OGP Commitments : An Analysis (Background Paper prepared by GIFT for the Open Government Partnership Fiscal Openness Working Group: Mexico OGP Summit Mexico City, October 28-30, 2015).

Petrie, M. (2015b). New Zealand and the OGP. Retrieved September 25, 2017, from https://www.opengovpartnership.org/stories/new-zealand-and-ogp

Pieth, M. (2006). Multi-stakeholder initiatives to combat money laundering and bribery. In D. L. Christian Brütsch (Ed.), Law and Legalization in Transnational Relations (1st ed., pp. 81-100). Milton Park: Routledge/Taylor and Francis Group. https://doi.org/10.4324/9780203964422

Piotrowski, S. J. (2007). Governmental Transparency in the Path of Adminstrative Reform. 
New York: Statue University of New York Press.

Piotrowski, S. J. (2017). The “Open Government Reform” Movement: The Case of the Open Government Partnership and U.S. Transparency Policies*. American Review of Public Administration, 47(2), 155-171. https://doi.org/10.1177/0275074016676575

Porto de Oliveira, O. (2017). International Policy Diffusion and Participatory Budgeting. Cham, Switzerland: Palgrave Macmillan.

Potnis, D. D. (2010). Measuring e-Governance as an innovation in the public sector. Government Information Quarterly, 27(1), 41-48. https://doi.org/10.1016/j.giq.2009.08.002

Prince, R. (2012). Policy transfer, consultants and the geographies of governance. Progress in Human Geography, 36(2), 188-203. https://doi.org/10.1177/0309132511417659

Reddick, C. G. (2005). Citizen interaction with e-government: From the streets to servers? Government Information Quarterly, 22(1), 38-57. https://doi.org/10.1016/j.giq.2004.10.003

Risse-Kappen, T., Ropp, S. C., \& Sikkink, K. (Eds.). (1999). The Power of Human Rights: International Norms and Domestic Change. Cambridge: Cambridge University Press.

Risse-Kappen, T., \& Sikkink, K. (1999). The socialization of international human rights norms into domestic practices: introduction. In T. Risse-Kappen, S. C. Ropp, \& K. Sikkink (Eds.), The Power of Human Rights: International Norms and Domestic Change (pp. 1-38). Cambridge: Cambridge University Press.

Risse, T. (1999). International norms and domestic change: Arguing and communicative behavior in the human rights area. Politics \& Society, 27(4), 529-559.

Rogers, E. M. (2003). Diffusion of innovations (5th ed.). New York: Free Press.

Rose, J., Flak, L. S., \& Sæb $\varnothing, \varnothing$. (2018). Stakeholder theory for the E-government context: Framing a value-oriented normative core. Government Information Quarterly, 35(3), 362-374. https://doi.org/10.1016/j.giq.2018.06.005

Roulston, K., \& Shelton, S. A. (2015). Reconceptualizing Bias in Teaching Qualitative Research Methods. Qualitative Inquiry, 21(4), 332-342. 
https://doi.org/10.1177/1077800414563803

Rowe, G., \& Frewer, L. J. (2000). Public Participation Methods: A Framework for Evaluation. Science, Technology \& Human Values, 25(1), 3-29. https://doi.org/10.1177/016224390002500101

Rowe, G., \& Frewer, L. J. (2005). A Typology of Public Engagement Mechanism. Science, Technology, \& Human Values, 30(2), 251-290. https://doi.org/10.1177/0162243904271724

Rumbul, R. (2015). Who benefits from civic technology? (MySociety). Retrieved from https://research.mysociety.org/sites/who-benefits/\#start

Sanders, R. (2016). Norm Proxy War and Resistance Through Outsourcing: The Dynamics of Transnational Human Rights Contestation. Human Rights Review, 17(2), 165-191. https://doi.org/10.1007/s12142-016-0399-1

Sandoval-Almazan, R., \& Gil-Garcia, R. J. (2015). Towards an Integrative Assessment of Open Government: Proposing Conceptual Lenses and Practical Components. Journal of Organizational Computing and Electronic Commerce, 9392(December), 170-192. https://doi.org/10.1080/10919392.2015.1125190

Savard, J., Villeneuve, J., \& Caron, I. (2013). Institutional Policy Coherence: the Case of Swiss Transparency Act. Jahrbuch Der Schweizerischen Verwaltungswissenschaften, 151-162.

Schimmelfennig, F. (2000). International Socialization in the New Europe:: Rational Action in an Institutional Environment. European Journal of International Relations, 6(1), 109139. https://doi.org/10.1177/1354066100006001005

Schmidthuber, L., Antons, D., \& Hilgers, D. (2015). On the bumpy road towards open government: The Not-Invented-Here syndrome as a major pothole. In Academy of Management Proceedings (pp. 201-246). Briarcliff Manor: Academy of Management. https://doi.org/10.2139/ssrn.3203741

Schneider, J. (2015). Bringing Government Data Into the Light: Slovakia's Open Data Initiative, 2011-2015 (Innovations for Successful Societies which). Retrieved from https://successfulsocieties.princeton.edu/publications/bringing-government-data-light- 
slovakias-open-data-initiative-2011-2015

Schwartz, M. S. . S. and C. G. (1955). Problems in Participant Observation. American Journal of Sociology, 60(4), 343-353.

Schwegmann, C. (2013). Open Data in Developing Countries. Retrieved from https://www.europeandataportal.eu/sites/default/files/library/201302_open_data_in_ developing_countries.pdf

Scott, T. A., \& Thomas, C. W. (2017). Unpacking the Collaborative Toolbox: Why and When Do Public Managers Choose Collaborative Governance Strategies? Policy Studies Journal, 45(1), 191-214. https://doi.org/10.1111/psj.12162

Seawright, J., \& Gerring, J. (2008). Case Selection Techniques in Case Study Research. Political Research Quarterly, 61(2), 294-308. https://doi.org/10.1177/1065912907313077

Sexton, R. (n.d.). The Unintended Effects of Bottom-Up Accountability: Evidence from a Field Experiment in Peru. Retrieved from https://www.povertyaction.org/study/accountability-and-transparency-extractive-industries-peru

Simmons, B. (2009). Mobilizing for Human Rights: International law in Domestic Politics. Cambridge, Mass.: Cambridge University Press.

Sjoberg, F. M., Mellon, J., \& Peixoto, T. (2015). The Effect of Government Responsiveness on Future Political Participation (Digital Engagement Evaluation Team No. 1). Retrieved from http://hdl.handle.net/10986/22780

Smith, G. (2009). Democratic Innovation: designing institutions for citizen participation. New york: Cambridge University Press.

Spada, P., \& Ryan, M. (2017). The Failure to Examine Failures in Democratic Innovation. PS Political Science and Politics, 50(3), 772-778. https://doi.org/10.1017/S1049096517000579

Steibel, F., Alves, M., \& Konopacki, M. (2017). Fighting Corruption Alone: Civic Participation in OGP Anti-Corruption Commitments. Revue Internationale Des Gouvernements Ouverts, 6, 1-29. 
Stein, C., Michel, B., Glasze, G., \& Putz, R. (2015). Learning from failed policy mobilities: Contradictions, resistances and unintended outcomes in the transfer of "Business Improvement Districts" to Germany. European Urban and Regional Studies, 24(1), 3549. https://doi.org/10.1177/0969776415596797

Steinberg, P. F. (2003). Understanding Policy Change in Developing Countries: The Spheres of Influence Framework. Global Envionmental Politics, 3(1), 11-32.

Stern, A., Kingston, D., \& Ke, J. (2015). More Than the Sum of Its Parts: Making MultiStakeholder Initiatives Work. Retrieved from https://globaldevincubator.org/wpcontent/uploads/2016/02/Making-MSIs-Work.pdf

Stone, D. (2004). Transfer agents and global networks in the 'transnationalization' of policy. Journal of European Public Policy, 11(3), 545-566. https://doi.org/10.1080/13501760410001694291

Stone, D. (2012). Transfer and translation of policy. Policy Studies, 33(6), 483-499. https://doi.org/10.1080/01442872.2012.695933

Stone, D. (2016). Understanding the transfer of policy failure: bricolage, experimentalism and translation. Policy \& Politics, 45(1), 1-16. https://doi.org/10.1332/030557316X14748914098041

Terman, R., \& Voeten, E. (2017). The relational politics of shame: Evidence from the universal periodic review. Review of International Organizations, 1-23. https://doi.org/10.1007/s11558-016-9264-x

The Economist Intelligence Unit. (2019). Democracy Index 2018: Me Too? London. Retrieved from http://www.eiu.com/Handlers/WhitepaperHandler.ashx?fi=Democracy_Index_2018.pd $\mathrm{f} \&$ mode=wp\&campaignid=Democracy 2018

Thurmond, V. A. (2001). The Point of Triangulation. Journal of Nursing Scholarship, 33(3), 253-258. https://doi.org/10.1111/j.1547-5069.2001.00253.x

Towns, A. E., \& Rumelili, B. (2017). Taking the pressure: Unpacking the relation between norms, social hierarchies, and social pressures on states. European Journal of 
International Relations, 1-24. https://doi.org/10.1177/1354066116682070

Transparency and Accountability Initiative. (2013). Open Government Guide. Retrieved from http://www.transparency-initiative.org/wp-content/uploads/2017/09/opengovernment-guide-cross-cutting-topics-summary-nov-2013.pdf

Treisman, C., Kelley, T. M., \& Johnston, E. W. (2016). Designing Successful Participatory Platforms With a Public Intent: Lessons Learned From Practitioners, Scholars, and Citizen Participants. International Journal of Organization Theory and Behavior, 19(4), 479-513.

Turianskyi, Y., \& Chisiza, M. (2018). Peer Pressure and Learning in Multi-stakeholder Initiatives. Retrieved from https://saiia.org.za/research/learning-lessons-from-multistakeholder-initiatives/

Turianskyi, Y., Corrigan, T., Chisiza, M., \& Benkenstein, A. (2018). Multi-stakeholder Initiatives: What Have We Learned? An Overview and Literature Review. Retrieved from https://saiia.org.za/research/learning-lessons-from-multi-stakeholder-initiatives/

Ulibarri, N. (2015). Tracing Process to Performance of Collaborative Governance: A Comparative Case Study of Federal Hydropower Licensing. Policy Studies Journal, 43(2), 283-308. https://doi.org/10.1111/psj.12096

United Nations Department of Economic and Social Affairs. (2016). UN E-government survey 2016: E-Government in Support of Sustainable Development. https://doi.org/10.1016/S1369-7021(02)00629-6

United Nations Department of Economic and Social Affairs. (2018). UN E-Government Survey 2018: Gearing E-Government to support transformation towards sustainable and resilient societies. New York. Retrieved from https://publicadministration.un.org/egovkb/en-us/Reports/UN-E-Government-Survey2018

Vaismoradi, M., Turunen, H., \& Bondas, T. (2013). Content analysis and thematic analysis: Implications for conducting a qualitative descriptive study. Nursing and Health Sciences, 15(3), 398-405. https://doi.org/10.1111/nhs.12048 
van Deth, J. W. (2016). What is Political Participation? In Oxford Research Encyclopedia of Politics (pp. 207-231). https://doi.org/10.1093/acrefore/9780190228637.013.68

Velasco-Sánchez, E. (2016). Designing and managing an OGP multistakeholder forum: a practical handbook with guidance and ideas. Retrieved from https://www.opengovpartnership.org/multistakeholder-forums

Verhulst, S. G., \& Young, A. (2017). Open Data in Developing Economies Toward Building an Evidence Base on What Works and How. Cape Town: African Minds. Retrieved from www.africanminds.org.za

Villeneuve, J. P. (2014). Transparency of transparency: The pro-active disclosure of the rules governing access to information as a gauge of organisational cultural transformation. The case of the Swiss transparency regime. Government Information Quarterly, 31(4), 556-562. https://doi.org/10.1016/j.giq.2013.10.010

Vogt, S., \& Haas, A. (2015). The future of public participation in Germany: Empirical analyses of administration experts' assessments. Technological Forecasting and Social Change, 98, 157-173. https://doi.org/10.1016/j.techfore.2015.04.013

Voice and Accountability Methodology Description. (n.d.). Retrieved March 10, 2019, from http://info.worldbank.org/governance/wgi/index.aspx\#doc

Vukasovic, M., \& Huisman, J. (2017). Europeanization, Policy Transfer or Domestic Opportunity? Comparison of European Impact in Higher Education Policy. Journal of Comparative Policy Analysis: Research and Practice, 1-19. https://doi.org/10.1080/13876988.2017.1320132

Wagner, S. A., Vogt, S., \& Kabst, R. (2016). How IT and social change facilitates public participation: A stakeholder-oriented approach. Government Information Quarterly. https://doi.org/10.1016/j.giq.2016.07.003

Welch, E. W., \& Fulla, S. (2005). Virtual Interactivity Between Government and Citizens: The Chicago Police Department's Citizen ICAM Application Demonstration Case. Political Communication, 22(2), 215-236. https://doi.org/10.1080/10584600590933205

Whitt, J. P. (2015). Civic Participation in Latin American OGP Commitments. Washington D.C. 
Retrieved from http://www.opengovpartnership.org/sites/default/files/LatAm Participation Web.pdf

Wilson, C. (2017). Norway: 2014-2015 End of Term Report. Retrieved from https://www.opengovpartnership.org/documents/norway-end-of-term-report-20142015

Winston, C. (2017). Norm structure, diffusion, and evolution: A conceptual approach. European Journal of International Relations, 135406611772079. https://doi.org/10.1177/1354066117720794

Wirtz, B. W., \& Birkmeyer, S. (2015). Open Government: Origin, Development, and Conceptual Perspectives. International Journal of Public Administration, 38(April), 381396. https://doi.org/10.1080/01900692.2014.942735

Wirtz, B. W., Piehler, R., Thomas, M. J., \& Daiser, P. (2016). Resistance of Public Personnel to Open Government: A cognitive theory view of implementation barriers towards open government data. Public Management Review, 18(9), 1335-1364. https://doi.org/10.1080/14719037.2015.1103889

World Bank Group. (2016). Open Government Impact and Outcomes: mapping the Landscape of Ongoing Research.

Yang, K. (2012). Theory Building and Testing in Citizen Participation Research: reflection and conjecture. In H. L. Schachter \& K. Yang (Eds.), The State of Citizen Participation in America (pp. 447-464). Charlotte: Information Age Publishing Inc.

Yang, T.-M., \& Wu, Y.-J. (2016). Examining the socio-technical determinants influencing government agencies' open data publication: A study in Taiwan. Government Information Quarterly. https://doi.org/10.1016/j.giq.2016.05.003

Yavuz, N., \& Welch, E. W. (2014). Factors affecting openness of local government websites: Examining the differences across planning, finance and police departments. Government Information Quarterly, 31(4), 574-583. https://doi.org/10.1016/j.giq.2014.07.004

Yin, R. K. (2009). Case study research : design and methods. (Sage, Ed.) (5th ed.). Los Angeles: 
SAGE Publications.

Yu, H., \& Robinson, D. G. (2012). The New Ambiguity of "Open Government." UCLA Law Review Discourse, 59(2012), 178-208. https://doi.org/10.2139/ssrn.2012489

Zhou, R., Su, H., Wang, X., Hu, Y., \& Zhang, F. (2013). The Participatory Cube: A Framework for Analysis of Online Participation Platforms. In S. Geertman, F. Toppen, \& J. Stillwell (Eds.), Planning Support Systems for Sustainable Urban Development (pp. 395-414). Berlin: Springer Berlin Heidelberg. https://doi.org/10.1007/978-3-642-37533-0_23

Zimmermann, L. (2016). Same same or different? Norm diffusion between resistance, compliance, and localization in post-conflict states. International Studies Perspectives, 17(1), 98-115. https://doi.org/10.1111/insp.12080

Zuckerman, E. (2014). New Media, New Civics? Policy and Internet, 6(2), 151-168. https://doi.org/doi.org/10.1002/1944-2866.POI360

Zwingel, S. (2012). How Do Norms Travel? Theorizing International Women's Rights in Transnational Perspective. International Studies Quarterly, 56(1), 115-129. https://doi.org/10.1111/j.1468-2478.2011.00701.x 


\title{
Article 1:
}

\section{Multi-stakeholder policy learning and institutionalization: the surprising failure of open government in Norway}

\begin{abstract}
:
Global multi-stakeholder initiatives (MSIs) promote norms and policy to national governments, and the voluntary model of many such initiatives is criticized for failing to produce formal policy outputs. This article proposes an analytical framework for policy learning and transfer to understand how MSIs can influence the informal institutionalization of policy in sub-national institutions, and formal policy outputs by extension. This framework is applied to Norwegian participation in one such MSI, the Open Government Partnership, and tests for the influence of those processes on the formal and informal institutionalization of policy related to digital dialogue between government and civil society. Results validate policy learning and translations framework for assessing MSI contributions to informal policy outcomes, highlight the important role of institutional context in limiting the influence of this mechanism, and fill an important gap in the literature on policy transfer and policy learning.
\end{abstract}

Accepted by Policy Studies with minor revisions, March 28, 2019. 
Article 2:

\title{
Open Government and E-Participation: assessing the effect of the Open Government Partnership and national political factors
}

\begin{abstract}
:
The Open Government Partnership (OGP) is a prominent international mechanism aiming to institutionalize civic participation and technology for accountability. Research on the initiative's impact has been restricted to OGP-specific outcomes and restrained by a lack of long-term evidence. Noting the close alignment of discourses on open government and e-participation, this analysis considers whether OGP contributes to the global diffusion of e-participation. Comparative analysis of OGP member and non-member countries finds that OGP has a statistically significant causal effect on countries' e-participation. Mediation and moderation analysis suggest that this effect is not solely attributable to national political factors, but that alignment of national traditions and structures with civic participation norms does have a positive moderating effect on OGP's relationship to e-participation. OGP's effect on the more specific variable of collaborative e-decision-making is consistently more pronounced that OGP's effect on e-participation generally.
\end{abstract}

Revisions submitted to Government Information Quarterly Jan 18, 2019. 


\title{
Article 3:
}

\section{Digital Civic Interaction: Identifying, conceptualizing and comparing interactions between governments and}

\author{
publics
}

\begin{abstract}
:
This article proposes the concept of digital civic interaction to assess how relationships between publics and government institutions might be meaningfully impacted by the use of digital communication technologies. This concept draws from scholarly work across a fragmented research literature, identifying the key structural and interactive dynamics at play in such novel phenomena as government social media use, e-participation initiatives, digital policy consultations and the opening and release of government data. Assessing such activities according to their underlying interactive dynamics allows a direct interrogation of digital technology's effects and fills a notable void across multiple literatures. The concept is constructed according to Goertz's 3-layer model for social science concepts, on the basis of communications theory and contemporary practice. The article concludes with an argument that political communications scholars have a particular role to play in advancing a common understanding of digital civic interaction.
\end{abstract}

Submitted to International Journal of Communication, December 12, 2018. 


\title{
Article 4:
}

\section{Look Who's Talking: Assessing Civic Voice and Interaction in OGP Commitments}

\begin{abstract}
:
This article argues that meaningful citizen-state interaction is a core component of the OGP mandate and theory of change. Assessing the frequency and quality of such activities in countries' national action plans can indicate the degree to which OGP is encouraging government to engage meaningfully with their citizens in the pursuit of accountable and responsive governance. A conceptual framework is proposed for identifying and evaluating the quality of civic voice and interaction in OGP commitments. Analysis of commitments from 61 countries finds little evidence of meaningful civic interaction, and proposes implications for open government advocates and campaigners.
\end{abstract}

Published in eJournal of eDemocracy and Open Government special issue on Dec. 2017. 
Article 1: Multi-stakeholder policy learning and institutionalization: the surprising failure of open government in Norway

\section{Introduction and background}

Multi-stakeholder initiatives (MSIs) have become a popular instrument for facilitating the global diffusion of governance policy and reform (Gruzd, Turianskyi, Grobbelaar, \& Mizrahi, 2018; Stern, Kingston, \& Ke, 2015), and are notable in the public administration sector for their reliance on participation, dialogue, and voluntary commitments (Brockmyer \& Fox, 2015; Mena \& Palazzo, 2012). This approach has proved popular, but has also been criticized for failing to achieve tangible impacts in the policy or behaviour of participating governments (Brockmyer \& Fox, 2015; Fraundorfer, 2017; Gruzd et al., 2018; O’Reilly, 2013). Such criticisms tend to implicitly rely on logics of compliance and coercion drawn from scholarship on norm promotion and transnational advocacy (Cortell \& Davis, 2002; Finnemore, 1993; Vasilev, 2015; Zimmermann, 2016), and fail to consider whether the voluntary mechanisms associated with public governance MSI's exert other kinds of influence. The Open Government Partnership (OGP) is exemplative. Focused on "improving government transparency, accountability and responsiveness to citizens" membership in the initiative requires only passable democratic performance according to global indicators, high-level political support for abstract open government norms, and a commitment to collaborate with national civil society organizations in the development and implementation of open government action plans (Frey 2014, 4-13).

The way in which national action plans are developed are left entirely to the discretion of governments, however, as are their content and implementation. Lack of enforcement mechanisms have been blamed for lack of implementation, and produced a proliferation of "compliance"-focused OGP research (Turianskyi et al. 2018, 3) that emphasizes the potential for specific policy and activity outcomes (Berliner, 2015; 
Article 1: Multi-stakeholder policy learning and institutionalization: the surprising failure of open government in Norway

Guerzovich \& Moses, 2016; Manolea \& Cretu, 2013; Petrie, 2015a). Despite an increasing recognition that OGP's greatest contribution to more responsive government might be as "an effective focal point where a transformative culture of openness and transparency can take root" (Basford et al. 2016, 11; Corrigan and Gruzd 2018), and civil society interest in measuring such effects (Christiansen, 2018), there is no established framework for assessing whether and how MSIs like the OGP might influence cultures of public administration through their interaction over time.

Theoretical and empirical insights from the study of policy diffusion, policy transfer and policy learning provide useful starting points for developing such a framework. Attention to the soft social pressures and communicative dynamics between government actors in policy learning contexts (Gilardi, 2015; Heikkila \& Gerlak, 2013), to how global policy knowledge is adapted to national contexts (Johnson \& Hagström, 2005; Stone, 2004), and to the role of international actors in knowledge transmission (Stone, 2012), are particularly relevant to assessing the "soft" influence of public governance MSIs.

To test the feasibility of such a framework, this article traces the process of Norway's participation in the OGP. Widely regarded as a pillar liberal democratic practice, Norway has been ranked the "world's best democracy" by the Economist Intelligence Unit for six years running, and is a founding member of the OGP. Independent evaluations of Norway's OGP implementation have, however, roundly and consistently criticized both the development and implementation of Norway's national action plans, citing a lack of clarity, relevance and ambition (Skedsmo, 2014; Wilson, 2017a; Wilson \& Nahem, 2013). This poor performance runs counter to expectations, and has prompted descriptions of a "Nordic race to the bottom in the OGP" (Petrie, 2015b). Deviance from the presumed positive relationship between democratic practice 
Article 1: Multi-stakeholder policy learning and institutionalization: the surprising failure of open government in Norway

and OGP performance provide a rich context in which to assess how global MSIs

influence national institutional cultures. Norway's role as a founding member of OGP

also provides a rich body of evidence, including documentation of interactions between

multiple subnational agencies during the two years of planning and negotiation that preceded OGP's launch.

The OGP's institutional design and theory of change are also well suited to assess the influence of MSIs' norm promotion on government cultures and practice. OGP leverages three mechanisms to promote more open and responsive governance. Most prominently, governments are required to produce and implement national action plans for open government. The OGP encourages governments to create these national action plans in open collaboration with civil society, in a hope that doing so will provide national reformers with a "framework to advance and institutionalize a more coherent reform agenda across different government agencies” (Frey 2014, 4). Secondly, highlevel political support for open government norms is expected to open political space for reformers, helping civil society to come to the national action plan process on equal footing with government. Lastly, the OGP continually promotes specific policy articulations of these norms through global summits, webinars, policy briefs, case studies, research papers and direct country support, providing raw material for national reform processes (Open Government Partnership, 2014).

Together, these mechanisms aim to facilitate the institutionalization of open government policy through "a shift in norms and culture to ensure open and honest dialogue between governments and society" and anticipate that "as norms shift and governments become more comfortable with transparency, governments will begin introducing more opportunities for dialogue and become more receptive to civil society input and participation" (Frey 2014, pp. 8, 16). Notably, the notions of "responsive 
Article 1: Multi-stakeholder policy learning and institutionalization: the surprising failure of open government in Norway government" and "open and honest dialogue between governments and society" that the OGP hopes to institutionalize are never precisely defined. An emphasis on digitally mediated interaction with civil society and the general public is clearly discernible, however, as a "cluster" of norms (Winston, 2017) rooted in the values of technology for accountability and civic participation (OGP 2011), and referred to here as digital dialogue.

This analysis traces Norway's engagement with OGP to assess whether the initiative's promotion of digital dialogue has influenced national level policy, including informal policy outcomes, and whether the mechanisms of influence underpinning those outcomes differ from mechanisms of influence that lead to formal policy outcomes. To do so, it constructs and applies an analytical framework for policy learning and transfer. This implies two empirical and two theoretical research questions:

(1) To what extent did Norway's participation in the OGP lead to formal or informal institutionalization of open government norms?

(2) Through what mechanisms did this occur, and did it differ for formal and informal outcomes?

(3) What explanatory power does an analytical framework for policy learning and transfer provide for understanding these mechanisms?

(4) What theoretical propositions can be derived to predict MSI influence over policy learning processes? 
Article 1: Multi-stakeholder policy learning and institutionalization: the surprising failure of open government in Norway

\section{Conceptual and theoretical framework}

\section{Policy learning as an analytical framework for the institutionalization of digital dialogue}

Several case studies illustrate how civic participation and e-governance initiatives rely on prior changes to the institutional culture of government bodies (Chadwick, 2011; Freeman \& Quirke, 2013; Head, 2012; Yang \& Wu, 2016; Zuiderwijk \& Janssen, 2014). Changes to institutional culture have not, however, been significantly conceptualized by scholars of government communication and accountability, and Chadwick's (2011) observation regarding the lack of "insider studies" of democratic engagement initiatives appears to hold (23).

In policy studies, changes in institutional culture can be conceptualized as the informal institutionalization of norms, and are often seen as a precursor to the formal institutionalization of norms in policy (Béland \& Waddan, 2015; Björnehed \& Erikson, 2018; Erikson, 2015). Changes to the way in which policy problems are conceptualized and understood within institutions can influence policy outcomes in a variety of ways. Different branches of policy scholarship have emphasized the embedding of narratives about policy appropriateness that facilitate or block specific avenues to formal policy change (Hope \& Raudla, 2012; Leipold \& Winkel, 2017), how ideational frames signal changes of appropriateness within a policy environment (Björnehed \& Erikson, 2018; Erikson, 2015), or the development of structural conditions for policy change within institutions (Bleich, 2006). Many of these approaches also incorporate attention to policy learning, broadly construed as the processes through with individuals in institutions update their policy-relevant knowledge and beliefs (Dunlop \& Radaelli, 2013). 
Article 1: Multi-stakeholder policy learning and institutionalization: the surprising failure of open government in Norway

The conceptual model for individual and collective policy learning advanced by Heikkila and Gerlak (2013) provides a useful frame for assessing whether OGP policy mechanisms lead to institutional learning, and informal policy change by extension. Heikkila and Gerlak emphasize that "learning processes often start with individuals and move up into different levels of subunits of a group" (486), contributing to collective policy learning in institutions. That process is marked by three sequential stages. During acquisition, individuals receive information. Translation involves "interpreting the meaning of new information, or the application of existing information to a new context" through the use of heuristics, mental framing" and "characteristics of the collective group" (490-491). In the final stage of dissemination, learning products and policy knowledge are shared with others. This sequence has the potential to produce collective learning products, including "changes in collective behaviours or actions [that] can range from new or enhanced informal routines and strategies, to new or expanded programs and plans that structure group behaviour, or highly formalized rules or sets of institutional arrangements and policies” (491-492). Applying Heikkila and Gerlak's model to OGP allows for a close look at how individuals interact with institutions in an open government policy context, and also allows for a useful distinction between formal and informal institutionalization of digital dialogue policy.

\section{Setting policy learning within a causal model of policy translation}

Models of policy learning also align well with theories of policy transfer and translation (Meseguer 2005; Stone 2012; Berry and Berry 2014, cited in Dunlop and Radaelli 2018). The policy translation perspective emphasizes how communicative processes influence perceptions about the appropriateness of global norms and policies, reshaping them during the process of policy adoption (Johnson \& Hagström, 2005; Park, Wilding, 
Article 1: Multi-stakeholder policy learning and institutionalization: the surprising failure of open government in Norway

\& Chung, 2014; Stone, 2016). This approach explicitly avoids mechanistic conceptions of transfer from international norm entrepreneurs to national policy makers, and emphasizes "the messy processes of hybrid policies emerging from multiple exemplars, and the messy interpretative processes where importing countries translate and amend transferred policies" (Stone 2016, 55). Stone has noted the important contributions that international actors can make to policy learning in such processes, functioning as epistemic communities or policy intermediaries (2012, 491-496).

Setting Heikkila and Gerlak's model for collective policy learning within a causal process of policy translation has two importance consequences. Firstly, it helps to explain the observation that the soft transfer of ideas and information to national policy makers is much more common than instances where ideas structure governance and become institutionalised (Stone 2012, 496). The spread of ideas precedes and justifies the transfer of specific polices into national contexts (Stone 2016, 62), and policy learning provides a framework for understanding how it does so.

Secondly, the policy learning model emphasizes individuals' gatekeeping roles in translation processes, particularly at the translation stage of learning cycles. Here, global policy information is processed contextually and becomes policy knowledge. Heikkila and Gerlak (2013) note that this process often involves a "subconscious or unintentional mechanism that people use in translating information" and that these conceptualizations can be significantly influenced by the social and formal characteristics of institutions and social groups (489-490). This recalls ideas of "congruence" and "cultural match" in norms research, which are used to assess the "fit" between global norms and the cultural context of national institutions (Acharya 2004, 243), but situates logics of appropriateness at the level of the individual rather than national culture. This implies attitudinal processes and questions of credibility required 
Article 1: Multi-stakeholder policy learning and institutionalization: the surprising failure of open government in Norway

for recognizing the presence of a policy problem to be addressed (Oxley, Vedlitz, \& Wood, 2014), and may involve assessments of appropriateness at multiple levels. BenJosef Hirsch (2014) distinguishes, for example, between logics of morality, consequences, and specification ("relations with similar or alternative practices") that drive changes in how norms and policies are understood in national contexts (812). Each of these logics could conceivably result in different assessments of appropriateness by different individuals assessing any given global norm.

This emphasis on individuals' agency resonates with studies of civic participation and open government that demonstrate how individual perceptions of institutional cultures can block or facilitate the adoption and implementation of policy (Head, 2012; Mizrahi, Vigoda-Gadot, \& Cohen, 2009; Vigoda, 2002; Wirtz, Piehler, Thomas, \& Daiser, 2016). Individuals also play a key role in dissemination phases, and integrating these frameworks allows for insights from the diffusion literature on how individuals move ideas within and across institutional boundaries, and facilitate the flow of information between micro and macro policy environments (Douglas, Raudla, \& Hartley, 2015).

Viewed together and applied to the current case, this suggests an analytical framework that is sequential and initiated with the dissemination of knowledge and promotion of norms by global MSIs like the OGP. Knowledge transfer and the first phase of policy learning coincide when individual policy makers and civil servants are exposed to that information. Individuals then assess information in light of their national and institutional contexts, and if deemed appropriate, disseminate that knowledge in the third phase of policy learning, contributing to collective learning processes within institutions. Collective learning processes may then contribute to the informal institutionalization of policy in institutional culture, which may in turn support the 
Article 1: Multi-stakeholder policy learning and institutionalization: the surprising failure of open government in Norway

formal institutionalization of norms in policy, law or administrative rules. This sequence is represented in Figure 1.

\section{Methodology}

\section{Research scope and evidentiary sources}

This analysis traces processes of MSI policy influence from the Norwegian MFA's first OGP discussions with representatives of the US National Security Council in 2010, through to the completion of Norway's second action plan in 2015. The analysis focuses on the promotion and institutionalization of norms and policy related to digital dialogue in eight institutional agencies and ministerial divisions (hereafter "agencies"). These agencies are selected on the basis of their involvement in the OGP process and the relevance of digital dialogue to their policy mandate, and are displayed in Table 1. 
Article 1: Multi-stakeholder policy learning and institutionalization: the surprising failure of open government in Norway

Table 1: Overview of agencies assessed

\begin{tabular}{|c|c|c|c|}
\hline $\begin{array}{l}\text { Norwegian agency } \\
\text { (and Norwegian acronym) }\end{array}$ & $\begin{array}{l}\text { Commitments in 1st ( }\left(^{*} \text { and 2nd National Action Plans }\right. \\
\text { (numbered) }\end{array}$ & Other roles and responsibilities & Short name \\
\hline $\begin{array}{l}\text { Section for ICTs, Modemization and Innovation } \\
\text { in the Ministry of Local Government and } \\
\text { Modernization (KMD) }\end{array}$ & $\begin{array}{l}\text { *: Open Public Sector and Inclusive Government } \\
\text { 1: Public review and public consultation } \\
\text { 2: A better overview of committees, boards and councils [...] } \\
\text { 3: "Simplifiy" "Enkelt og greil") } \\
\text { 5: Re-use of public sector information } \\
\text { 19: Reducing confilicts of interests } \\
\text { 21: Modernizing Public Governance }\end{array}$ & $\begin{array}{l}\text { Responsible for national } \\
\text { coordination of OGP from } 2013 .\end{array}$ & $\begin{array}{l}\text { ICTs and } \\
\text { Modernization } \\
\text { team }\end{array}$ \\
\hline $\begin{array}{l}\text { Various divisions in the Norwegian Minisitry of } \\
\text { Foreign Affairs (MFA) }\end{array}$ & $\begin{array}{l}\text { *: Transparency in the management of oil and gas revenues, [...] } \\
\text { 22: Transparency in the management of oll and gas revenues } \\
\text { 24: Transparency and anti-corrupition efforts }\end{array}$ & $\begin{array}{l}\text { Led planning and development of } \\
\text { OGP, responsible for national } \\
\text { coordination from } 2010 \text { - } 2012 \text {. }\end{array}$ & MFA \\
\hline $\begin{array}{l}\text { Agency for Public Management and } \\
\text { eGovernment (DIFI) }\end{array}$ & $\begin{array}{l}\text { 4: Electronic Public Records (OEP) } \\
\text { 10: Registering and preserving digital documentation [...] } \\
\text { 11: The Norweglan Citizen Survey } \\
\text { 15: eGovernment with an end } \\
\text { 16: Plain Legal Language }\end{array}$ & $\begin{array}{l}\text { Responsible for implementing and } \\
\text { coordinating Norwegian policy on } \\
\text { e-govermment and modemization. }\end{array}$ & $\begin{array}{l}\text { eGovernment } \\
\text { Agency }\end{array}$ \\
\hline $\begin{array}{l}\text { Department of Civil Society and the Voluntary } \\
\text { Sector in Minisisty of Government Administration, } \\
\text { Reform and Church Affarirs (KUD) }\end{array}$ & $\begin{array}{l}\text { 8- Interaction with NGOS } \\
\text { 9- Digital adminisistration of arrangements for NGOS } \\
\text { 10- Digital documentation }\end{array}$ & & $\begin{array}{l}\text { Department } \\
\text { of Civil } \\
\text { Society }\end{array}$ \\
\hline Legistation Department in the Ministry of Jusice & $\begin{array}{l}\text { 13-Strengthening the transparency of public authorities [...] } \\
\text { 14- Strenghthened information exchange for [... crime prevention }\end{array}$ & & $\begin{array}{l}\text { Legislation } \\
\text { Department }\end{array}$ \\
\hline $\begin{array}{l}\text { Directorate of Health in the Minisistry of Health } \\
\text { and Care Services }\end{array}$ & 6: Access to health data & & $\begin{array}{l}\text { Directorate of } \\
\text { Health }\end{array}$ \\
\hline $\begin{array}{l}\text { Department for Economic and Administrative } \\
\text { Affairs in Ministry of Petroleum \& Energy }\end{array}$ & $\begin{array}{l}\text { *: Transparency in the management of oil and gas revenues [...] } \\
\text { 22: Transparency in the managaement of oll and gas revenues }\end{array}$ & & $\begin{array}{l}\text { Ministry of } \\
\text { Energy }\end{array}$ \\
\hline $\begin{array}{l}\text { Department of Consumer Affairs and Equality in } \\
\text { the Ministry of Children and Equality }\end{array}$ & $\begin{array}{l}\text { *: Measures to promote gender equality and women's full } \\
\text { participation in civic life [...] }\end{array}$ & & $\begin{array}{l}\text { Ministry of } \\
\text { Equality }\end{array}$ \\
\hline
\end{tabular}


Article 1: Multi-stakeholder policy learning and institutionalization: the surprising failure of open government in Norway

Evidentiary sources considered in this research include official documents produced by Norwegian government agencies and the OGP, as well as complementary policy documents and evaluations. Several documents were also secured from the Norwegian IRM research team responsible for evaluating the Norway's first two national action plans, including 25 internal self-assessment reports prepared by OGP commitment focal points in Norwegian government agencies, minutes from public consultations, and records of 58 IRM interviews with civil servants and stakeholders. Consent was retroactively secured from those individuals whose information appears in documents not publicly available. The author also actively participated in policy debate and IRM evaluations of OGP in Norway while working as [redacted to preserve anonymity]. ${ }^{1}$

In addition to documentation, twenty-seven in-depth and semi-structured interviews were conducted with twenty-three individuals, either in person or over phone or VOIP, lasting between 45 and 90 minutes. Interviews were recorded, transcribed, translated, and subjected to categorical and axial coding (Bryman 2016, 574-589). Subject codes for referencing interviews in this article are presented in Table 2, together with interviewees roles and the institutions they represent.

\footnotetext{
${ }^{1}$ These experiences took place prior to data collection for the current analysis and introduce additional risks of bias. This prior experience also increases access to data, however, and strengthens contextual understanding in analysis. These experiences are conceptualized as ex post facto participant observation, in order to identify appropriate measures to for mitigating socio-cultural and confirmation bias, as described in the following section.
} 
Article 1: Multi-stakeholder policy learning and institutionalization: the surprising failure of open government in Norway

Table 2: Overview of interview subjects

\begin{tabular}{lcll}
\hline Role & $\#$ & Respondent interview codes & Agencies / Institutions \\
\hline Agency commitment & 12 & NO182*, NO183, NO185, NO186, NO187, & KMD, UD, DIFI, KUD, \\
focal point & & NO188, NO189, NO190, NO193, NO194 & JD, HD, OED, BLD \\
National OGP & 8 & NO182*, NO184, NO191, NO195, NO199, & KMD, UD, SMK \\
coordination & & NO203* \\
$\begin{array}{l}\text { Civil society } \\
\text { stakeholder/counterpart }\end{array}$ & 9 & NO192, NO196, NO197*, NO197*, & OGP Council, national \\
*= repeat interviews with & NO198*, NO200*, NO201*, NO202 & NGOs, OGP Secretariat \\
\hline
\end{tabular}

\section{Methods and validity}

Causal process tracing is used to assess the mechanisms through which OGP norm promotion contributed to the Norwegian institutionalization of digital dialogue. Process tracing's inherent orientation towards "multiple causality, feedback loops, path dependencies, tipping points, and complex interaction effects" (Falleti 2006, 7) is well suited to the messy environment of policy translation, and when applied robustly, offers "singular advantages for [...] understanding causality from within-case accounts of policy change" (Kay and Baker 2015, 2).

Noting the analytical risks posed by complex policy environments, the ambiguous character of norms, and the author's early involvement in OGP processes, this analysis adheres to the three part methodological standard asserted by Bennett and Checkel (2015), in which process tracing methods are meta-theoretically grounded, contextually attuned to discursive structures, and methodologically attentive to challenges of multiple causal explanations (20-25). This latter standard implies the use of Bayesianinspired tests for assessing the veracity of multiple causal explanations as they arise, and is strengthened by the diversity of evidentiary sources described above (Bennett \& Checkel, 2015, pp. 292-293; Yin, 2009, pp. 68, 120-121). 
Article 1: Multi-stakeholder policy learning and institutionalization: the surprising failure of open government in Norway

Rigorous application of this standard, and in particular, the use of evidentiary tests to assess the veracity of causal explanations, helps to identify and mitigate instances of respondent and interviewer bias (Bennett and Checkel 2015, 24-25). Analysis of the current case took place over an 18-month period, during which multiple explanations were tested, rejected, and refined, new evidentiary sources were identified, and hypotheses revised. This processes, what Yin calls adaptive research design (2009, pp. 65-67) is closely analogous to the "soaking and poking" phase in process tracing, whereby a researcher "immerses oneself in the details of the case and tries out protohypotheses that may either quickly prove to be dead ends or become plausible and worthy of more rigorous testing (Bennett \& Checkel, 2014, p. 18).

\section{Theory building}

This analysis should be considered a heuristic case study, aiming to identify new variables and relationships, in an effort to develop middle range theory with predictive capacity (George and Bennett 2005, 75). This effort capitalizes on the deeply contextual character of theory-driven process tracing (Bennett \& Checkel, 2015; Collier, 2011; Falleti \& Lynch, 2009; Kay \& Baker, 2015), as well as the case's deviance from a presumed correlation between strong democratic governance and strong OGP performance (Bennett et al., 2015, 269-272). The primary objective is to develop theoretical propositions on the basis of causal analysis, which can be tested in other cases in order to establish the structure and scope conditions of a middle level theory for the national policy influence of multi-stakeholder initiatives (George \& Bennett, 2005, pp. 235-266).

It is important to distinguish this theoretical ambition from the analytical framework elaborated in the previous section. Analytical frameworks are in essence the collection and simplification of ontological assumptions about the world. Structuring 
Article 1: Multi-stakeholder policy learning and institutionalization: the surprising failure of open government in Norway

assumptions for their application to empirical cases, they help to identify and understand complex phenomena across different contexts. Theory, on the other hand, explains the relationships between complex phenomena, and aspires to predict those relationships across contexts (George and Bennett 2005, 115-117). The analytical framework described above is thus applied to the Norwegian case in order to develop theoretical propositions, which can be leveraged in a more extended theory building effort.

\section{Findings}

\section{Evidence of formal and informal institutionalization of digital dialogue policy}

There is little evidence of digital dialogue being formally institutionalized in Norwegian policy as a result of OGP implementation. The eight agencies assessed here were responsible for a total of 20 open government commitments over the first two action plans. According to the OGP's independent review mechanism (IRM), less than half of these (8) were completed and none significantly contributed to a more open government. The IRM did find that six commitments associated with the agencies under study resulted in "marginal" improvements, and the IRM's descriptions of these commitments' impact describes three outputs that might be considered formal institutionalization of digital dialogue (Wilson, 2017b).

Commitment 6 (Access to health data) led to online consultations with stakeholders regarding the design and functionality of the national health portal. Commitment 8 (Interaction with NGOs) led to the consultation with civil society regarding a Declaration of Principles for Interaction and Dialogue with NGOs, and the eventual publication of that declaration. Commitment 1 (Public review and public consultation) resulted in substantive changes to official Instructions for Official Studies 
Article 1: Multi-stakeholder policy learning and institutionalization: the surprising failure of open government in Norway

of Central Government Measures, mandating that all government agencies consider specific consultation and participation mechanisms when considering reforms, rule changes or investments.

Interviews and review of self-assessment reports provide evidence of informal institutionalization associated with three agencies. In the Legislation Department, interviews suggested that implementation of commitments to improve coordination and freedom of information legislation led to increased formal and informal interaction with external actors, including both international government counterparts participating in OGP, and national civil society counterparts. The focal point for these commitments suggested that this was motivated by internal institutional concerns, but facilitated by OGP participation, which in the Legislation Department, was understood as a mechanism to facilitate internal debate about policy modalities (NO183).

Informal institutionalization was more widespread and readily apparent in the eGovernment Agency and the ICTs and Modernization team, which each noted in internal self-assessment reports that commitment activities had influenced policy discourse externally. The ICTs and Modernization team noted that a report on the availability of geo-spatial data was used in multiple external policy processes, including proposals to revise Norway's freedom of information legislation (Self-assessment regarding Re-use of public sector information, on file with author). The eGovernment Agency noted that workshops and publications regarding the clarity and accessibility of legal language prompted increased demand from civil society actors (Self-assessment regarding Plain Legal Language, on file with author). Respondents also noted an increased internal salience of open government rhetoric in both agencies, which drew attention to digital dialogue in the discussion of institutional processes (NO 184, 189, 194). In some cases, this made it easier to secure political support or financial resources 
Article 1: Multi-stakeholder policy learning and institutionalization: the surprising failure of open government in Norway

for activities with a digital dialogue component. (NO192, 193, 194). Table 3

summarizes examples of informal and formal policy outcomes associated with each agency.

Table 3: Overview of institutionalization outcomes by agency

\begin{tabular}{lll}
\hline \multicolumn{1}{c}{ Agency } & \multicolumn{1}{c}{ Evidence of informal institutionalization } & \multicolumn{1}{c}{ Evidence of formal institutionalization } \\
\hline $\begin{array}{l}\text { ICTs and } \\
\begin{array}{l}\text { Modernization } \\
\text { team }\end{array}\end{array}$ & $\begin{array}{l}\text { Internal salience and external uptake of } \\
\text { eGources (public sector data use) }\end{array}$ & $\begin{array}{l}\text { Expanded scope of public consultations in } \\
\text { Instructions for Official Studies. }\end{array}$ \\
$\begin{array}{l}\text { Agency } \\
\text { Legislation }\end{array}$ & $\begin{array}{l}\text { Internal salience and external demand for } \\
\text { learning outputs (clear legal language) }\end{array}$ & None \\
$\begin{array}{l}\text { Department } \\
\text { stakeholders }\end{array}$ & None \\
$\begin{array}{l}\text { Department of None } \\
\text { Civil Society }\end{array}$ & \\
$\begin{array}{l}\text { Directorate of } \\
\text { Health }\end{array}$ & Official declaration on government \\
MFA & None & interaction with civil society organizations \\
Ministry of & None & Digital consultations with stakeholders \\
Energy & & None \\
Ministry of & None & None \\
Equality & & None \\
\hline
\end{tabular}

\section{Policy learning and translation as causal mechanisms}

Several respondents described OGP processes as having no influence over digital dialogue policy in Norway, and even enthusiasts were cautious in their attributions, noting that "there has been very little enthusiasm or excitement around [the OGP]. And what has come out on the other end that would not have come anyway, that I'm very unsure of" (NO196). Two aspects of institutional culture were particularly prominent in this regard.

Respondents regularly referenced the Nordic model of consensual policymaking, sometimes described as a natural driver of digital dialogue. Others noted that the Nordic model, insofar as it prioritizes the representation of organized interest groups 
Article 1: Multi-stakeholder policy learning and institutionalization: the surprising failure of open government in Norway

at the beginning of policy-making processes and does not engage the general public or representative civil society organizations (Arter 2016, 196-198; Haugsvær 2003, 7), is fundamentally in opposition to contemporary notions of digital dialogue, and even suggested that any advances in digital dialogue policy would "over time be overshadowed by the ponderous Norwegian way of doing things" (NO184).

Notions of government efficiency were also regularly described as driving institutional interest in digital dialogue, which corresponds with articulations in Norwegian policy documents (På nett med innbyggerne: Regjeringens digitaliseringsprogram, 2012) and reviews of Norwegian e-government by the OECD (OECD 2017, 48; OECD 2005, 161-163). Some respondents also noted that the ICTs and Modernization team explicitly framed the OGP as a component of the government's modernization agenda, though this was not consistently reflected in how other agency respondents described the initiative.

Indeed, knowledge transfer from OGP to the agencies studied here was remarkably uneven. In the Norwegian model for OGP coordination, a single agency engages with the international OGP secretariat and community, then disseminates information to Norwegian counterparts and focal points. The MFA initially performed this role, which was assumed by the ICTs and Modernization team shortly after the launch of the first national action plan in 2013. As a result, individuals in these agencies were much more familiar with OGP norms related to digital dialogue than other respondents, whose familiarity appears to be significantly influenced the regularity of their interaction with national coordinators. Several respondents were completely unfamiliar with the initiative or how it functioned. Others were uncertain when asked about their familiarity, noting that they "understand the idea, but just the buzzwords; if you ask me about any specifics I'm going to have a hard time." The exception to this 
Article 1: Multi-stakeholder policy learning and institutionalization: the surprising failure of open government in Norway

was the eGovernment Agency, where civil servants had significant exposure to

knowledge from the OGP, independent of Norway`s participation in the OGP, due to the agency's mandate to develop and implement Norway's open data policy.

Interviews suggest that the intermediary role of national coordinators had a significant influence on how OGP was understood in agencies. Respondents described a gradual process in the MFA and the ICTs and Modernization team during which the domestic applicability of OGP was increasingly recognized, and noted that early conceptualizations of OGP by the MFA framed the initiative as a mechanism for promoting a Norwegian model of open government internationally rather than influencing domestic policy. Individuals working in agencies primarily involved in Norway's first action plan (the MFA, the Ministry of Energy, the Ministry of Equality) repeated this conceptualization in interviews, and these were also the agencies that were not associated with any informal or formal institutionalization of digital dialogue. This supports the assertion that knowledge dissemination, in this case regarding the domestic applicability of digital dialogue norms, is the first step in a causal sequence of policy learning towards institutionalization.

In policy learning cycles, acquisition of information is followed by a translation phase, in which individuals evaluate the appropriateness of norms and policies. Respondent statements about the relevance of OGP and digital dialogue to their work paints a messy picture of how appropriateness is conceptualized. When describing why OGP did not lead to more significant policy outcomes in Norway, some respondents described common presumption that Norwegian governance was already sufficiently open.

That Norway was challenged on openness, that demands a little time to accept and understand and to make it useful. There was a completely uniform reaction from 
Article 1: Multi-stakeholder policy learning and institutionalization: the surprising failure of open government in Norway

everyone, regardless of where in the system they were, they made it very clear [det var smurt tjukt utenpå], "why should we be pressured on this, we who are so open?" (NO184).

Others suggested that OGP values were already thoroughly integrated into the daily work of institutions (NO185). Several respondents also noted personal factors inhibiting the uptake of OGP policy ideas, including concerns about increasing individuals' own workload (NO184, 192), or a "what's in it for me mentality" (NO193) and the career ambitions of individuals in key positions for translating and disseminating OGP norms and policies (NO186, 196).

Institutional structures and incentives were prominent in how respondents discussed OGP's limitations. Some respondents objected to the idea that open government and digital dialogue norms should be formalized, describing OGP as a "conceptual match" but an "administrative mismatch," because "trust is informal in Norway, and does not require institutionalization" (NO195). Others noted that broad norms of open government are rarely translated into practice, and argued that more specific prescriptions from OGP would have provoked a defensive attitude among civil servants (NO183). Systemic factors, such as the predominance of political priorities (NO198) and competition with comparable initiatives for resources (NO186,187) were also referenced. Several respondents specifically noted that digital dialogue was inherently foreign to a Norwegian context, either suggesting that the Nordic model of consensual policy-making in parliamentary processes was superior (NO182) or equivalent (NO185) to digital dialogue, or lamenting a widespread institutional reluctance to engage in meaningful interaction and participatory activities with civil society (NO193).

Despite this messy account, there is evidence that translation processes significantly impacted the positions and beliefs of individuals working in some agencies 
Article 1: Multi-stakeholder policy learning and institutionalization: the surprising failure of open government in Norway

(the Legislation Department, the Department of Civil Society, the MFA), and led to dissemination of policy knowledge in others. In the eGovernment Agency and the ICTs and Modernization team, processes of translation appear to have seeped into institutional policy dialogues, focusing attention on policy issues relevant to digital dialogue. This was likely facilitated by characteristics that these agencies share, and which distinguish them from other agencies at study. Firstly, respondents note that open government policy is easily associated with modernization policy, with which both agencies are mandated. Secondly, both agencies are formally located within the Ministry of Localization and Modernization, and enjoy the internal support of political leadership from a State Secretary deeply engaged in OGP policy. In the words of one respondent, "[the State Secretary] got it. He wrote blogs [about OGP]. That definitely helped to change the culture" (NO193). Both the eGovernment Agency and the ICTs and Modernization team also enjoyed a direct engagement with OGP knowledge products and international discourse which was not accessed by individuals in other agencies.

In the eGovernment Agency, knowledge about OGP norms were accessed and translated independent of national OGP processes. OGP processes nevertheless lent a legitimacy to the rhetoric of open government and digital dialogue, and respondents consistently credited this to the legitimacy conveyed by OGP's international character. This rhetorical legitimacy enabled individuals to raise awareness with decision-makers and to secure political and financial support for related projects (NO193, 194). There is no evidence, however, that this led to specific formal digital dialogue policy outcomes.

The ICTs and Modernization team is the only agency studied here where informal institutionalization of digital dialogue is directly associated with formal institutionalization, through the expansion of digital dialogue in the Instructions for 
Article 1: Multi-stakeholder policy learning and institutionalization: the surprising failure of open government in Norway

Official Studies. Most notably, earlier instructions to consult with "affected groups" in policy evaluation was expanded to instruct government bodies to include "everyone" in such consultations (chapter 3.3). This adjustment is both vague and modest (several exceptions are allowed), but likely meaningful, insofar as it applies to the development of all central government policy. Respondents attributed this change directly to a heightened attention to digital dialogue among a small group of case workers who actively lobbied in informal and ad hoc meetings for including a wider notion of consultation enabled by digital technologies.

The ICTs and Modernization team's unique role in the OGP process likely contributed to this outcome. As the national coordinators of OGP, the ICTs and Modernization team was responsible for engaging with international events and dialogues, liaising between international and national actors, and the implementation of specific commitments. This likely heightened the salience of open government rhetoric in the ICTs and Modernization team generally, but also in how the agency understood the commitments with which they were mandated, including the commitment to improve public review and public consultation. Other factors in the Norwegian policy environment may also have contributed to this outcome, such as comparable policy promotion by organizations such as the EU and OECD, or tendencies towards inclusion in the broader digitization agenda. This is not, however, reflected in contemporaneous policy outputs, such as the 2016 Digitalization Memorandum produced by other agencies within the same ministry, or rhetoric employed by OECD and EU recommendations on open government. The assertion that informal institutionalization of OGP contributed to this formal outcome is further strengthened by respondent assertions that language in the final document was significantly tempered by concerns 
Article 1: Multi-stakeholder policy learning and institutionalization: the surprising failure of open government in Norway

that a more explicit description of digital dialogue would impose undue bureaucratic burdens on government bodies.

\section{Other contributions to formal outcomes}

The two other instances of formal institutionalization documented here were not preceded by informal institutionalization in agencies. The implementation of digital consultations by the Directorate of Health appears to be completely decoupled from the influence of OGP. The agency focal point described those consultations as enabled by changes in technological and political environments that simultaneously made it easier to meet the expectations of OGP, but argued that the norms and values of OGP were thoroughly integrated into the day to day work of civil servants in the Directorate of Health long before the OGP was initiated (NO185).

The Department of Civil Society's Declaration of principles for interaction and dialogue with NGOs may well have been influenced by OGP, but there is no evidence suggesting that this was driven by mechanisms of policy learning. The Declaration was firmly rooted in political processes that significantly preceded the OGP, and the agency focal point for this work describes OGP as having no influence on the implementation of the commitment. Notes from IRM evaluations of Norwegian action plans include an interview with the national association of civil society organizations, however, which suggests that political leverage associated with OGP may contributed to producing the declaration.

The government signs up for lots of random stuff, which means that civil society can use it as an arena for improvements. This is also the case for OGP. This might be part of why we actually got the declaration, even though it was the former government that set it in motion. (interview notes on file with author). 
Article 1: Multi-stakeholder policy learning and institutionalization: the surprising failure of open government in Norway

This description aligns well with theories of political pressure and rhetorical persuasion in research on norm entrepreneurship (Finnemore \& Sikkink, 1998; RisseKappen, Ropp, \& Sikkink, 1999), and lends credibility to the claim that MSIs like the OGP provide credibility and open political space for reform efforts, independent of policy learning processes. This reinforces an understanding of policy learning as one of many mechanisms through which MSIs might hope to facilitate the institutionalization of policy in national contexts.

\section{Discussion}

\section{Differences between mechanisms and processes}

The above analysis traced the effect OGP norm promotion on institutionalization of digital dialogue in eight Norwegian agencies, and demonstrated the explanatory power of a policy learning and transfer framework in doing so. This revealed significant variation in the influence of MSIs across agencies, displayed in Table 4.

Table 4: Overview of institutionalization outcomes and causal mechanisms by agency

\begin{tabular}{|c|c|c|c|}
\hline Agency & $\begin{array}{l}\text { Evidence of informal } \\
\text { institutionalization }\end{array}$ & $\begin{array}{l}\text { Evidence of formal } \\
\text { institutionalization }\end{array}$ & Casual mechanism \\
\hline $\begin{array}{l}\text { ICTs and } \\
\text { Modernization } \\
\text { team }\end{array}$ & $\begin{array}{l}\text { Internal salience and } \\
\text { external uptake of policy } \\
\text { resources (public sector } \\
\text { data use) }\end{array}$ & $\begin{array}{l}\text { Expanded scope of public } \\
\text { consultations in Instructions } \\
\text { for Official Studies. }\end{array}$ & $\begin{array}{l}\text { Knowledge transfer and } \\
\text { translation led to policy } \\
\text { learning and informal } \\
\text { institutionalization, which } \\
\text { contributed directly to formal } \\
\text { institutionalization. }\end{array}$ \\
\hline $\begin{array}{l}\text { eGovernment } \\
\text { Agency }\end{array}$ & $\begin{array}{l}\text { Internal salience and } \\
\text { external demand for } \\
\text { learning outputs (clear } \\
\text { legal language) }\end{array}$ & None & $\begin{array}{l}\text { Knowledge transfer and } \\
\text { translation led to policy } \\
\text { learning and combined with } \\
\text { mechanisms of persuasion to } \\
\text { support informal } \\
\text { institutionalization. }\end{array}$ \\
\hline $\begin{array}{l}\text { Legislation } \\
\text { Department }\end{array}$ & $\begin{array}{l}\text { Increased interaction } \\
\text { with civil society } \\
\text { stakeholders }\end{array}$ & None & $\begin{array}{l}\text { Knowledge transfer and } \\
\text { translation led to policy } \\
\text { learning and informal } \\
\text { institutionalization. }\end{array}$ \\
\hline
\end{tabular}


Article 1: Multi-stakeholder policy learning and institutionalization: the surprising failure of open government in Norway

\begin{tabular}{|c|c|c|c|}
\hline $\begin{array}{l}\text { Department of } \\
\text { Civil Society }\end{array}$ & None & $\begin{array}{l}\text { Official declaration on } \\
\text { government interaction with } \\
\text { civil society organizations }\end{array}$ & $\begin{array}{l}\text { Visible engagement witl } \\
\text { introduced political leve } \\
\text { which contributed to for } \\
\text { institutionalization. }\end{array}$ \\
\hline $\begin{array}{l}\text { Directorate of } \\
\text { Health }\end{array}$ & None & $\begin{array}{l}\text { Digital consultations with } \\
\text { stakeholders }\end{array}$ & No causal relationship. \\
\hline MFA & None & None & None \\
\hline $\begin{array}{l}\text { Ministry of } \\
\text { Energy }\end{array}$ & None & None & None \\
\hline $\begin{array}{l}\text { Ministry of } \\
\text { Equality }\end{array}$ & None & None & None \\
\hline
\end{tabular}

These differences highlight the contingency of policy learning and transfer as a mechanism for formal policy institutionalization. Not only can this process be inhibited or derailed at any stage of the sequence, it can interact with other causal mechanisms in complicated ways, as suggested regarding the production of the Official declaration on government interaction with civil society organizations. The way in which eGovernment Agency respondents deliberately leveraged the presumed international attention of OGP to secure resources and political support for digital dialogue is likely an example of this interaction within a specific institutionalization process.

The messy interplay of causal mechanisms driving policy outcomes is widely recognized (Kay \& Baker, 2015). These distinctions further validate the analytical framework of policy learning and transfer to assess such interactions, and serve as a useful reminder to practitioners about the "disturbances [that] can occur in the spaces between the 'creation', the 'transmission' and the 'interpretation' or 'reception' of policy meanings' (Lendvai and Stubbs 2007, cited in Stone 2012, 487).

\section{Individuals' processes of translation}

This analysis highlights a variety of logics and frameworks with which individuals assess the appropriateness of global policy information. The emphasis on 
Article 1: Multi-stakeholder policy learning and institutionalization: the surprising failure of open government in Norway

individual incentives, personal convictions, and bureaucratic processes suggests that individuals distinguish between personal, institutional and national appropriateness of policy, in keeping with hierarchical understandings of policy beliefs, but also recalling Ben-Josef Hirsch's (2014) distinctions between logics of consequence, morality and specification. These distinctions nuanced and further complicated by respondents", consistent reference to the differences between abstract norms and specific policies that they are expected to support.

Translation processes of policy learning in this account are messier than first proposed, adding depth and complexity to a mechanistic notion of "soft" policy transfer laying the groundwork for "hard" policy transfer (Stone, 2012), and to theoretical accounts of norm scholarship, which tend to situate logics of appropriateness in the context of national political and cultural norms (Cortell \& Davis, 2005). Most importantly, perhaps, this suggests that the sequence of policy learning and transfer can be blocked or disrupted by any number of assessments of appropriateness. Policy learning and transfer is a fragile mechanism, prone to disruption at the weakest link in individual processes of translation.

\section{Theoretical propositions and implications}

Some distinctions are notable, however, and suggest two theoretical propositions that could be tested on additional cases. Firstly, widespread attention to the "good fit" of abstract norms at the macro level and across all three logics of assessment appears in several instances to have inhibited the acquisition and translation of information on more specific policies. This seems directly linked to the degree and regularity of agencies' exposure to the global discourses in which abstract digital dialogue norms were articulated as specific policies. Simply put, the abstract norms of open government were such a good fit for Norway, many respondents failed to recognize a policy 
Article 1: Multi-stakeholder policy learning and institutionalization: the surprising failure of open government in Norway

problem for which digital dialogue could be relevant. Several respondents articulated some version of the conviction that "Norway is open enough already." The attitudinal process underpinning policy problem recognition is here shaped not only by the persuasiveness of policy messaging (Oxley et al., 2014), but by a more broad understanding of relevance. Theoretically, this suggests that in countries where abstract governance norms are a "good fit" with national cultures and structures, MSI contributions to policy outcomes through policy learning will be unsuccessful unless those norms are framed as specific policies and in light of institutional logics of consequences and specification.

Secondly, this analysis suggests that considerations of specific policies according to logics of consequences and specification can be a powerful inhibitor, not only of translation in policy learning, but even at advanced stages in the analytical framework applied here, as evidenced by the strategic use of open government rhetoric in the eGovernment Agency and the conservative description of digital dialogue in the Instructions for Government Studies. Theoretically, this suggests that mechanisms of policy learning will contribute to formal and informal policy outcomes to a greater degree when policy learning is framed according to logics of consequence and specification at the level of institutions and individuals. In the Norwegian context, this would likely have involved a stronger application of the frame of government efficiency that has driven Norway's digitization agenda.

Lastly, and though not analytically generalizable on the basis of this study, it is worth noting the absence of civil society engagement in the Norwegian OGP process. IRM assessments consistently cite this lack of engagement in explaining the lack of meaningful OGP outcomes (Skedsmo, 2014; Wilson, 2017b; Wilson \& Nahem, 2013), recalling the notion that national civil society actors play an important role in 
Article 1: Multi-stakeholder policy learning and institutionalization: the surprising failure of open government in Norway

mechanisms of persuasion and political pressure in policy translation processes

(Johnson \& Hagström, 2005; Park et al., 2014; Stone, 2004). This perspective was also

articulated by several respondents, who noted that "OGP failed to connect with national watchdogs."

The above analysis complicates this notion by providing evidence of OGP's policy learning influence independent of national civil society engagement. It also raises the question of how more meaningful engagement might have influenced policy learning processes and their outcomes. In particular, the importance of mediation in knowledge transfer suggests that national civil society actors already linked to international open government and participation discourses could have played an important role connecting agencies with those discourses. In doing so, they could be expected to function as policy "go-betweens", contributing to the uptake of policy by facilitating access to information in the macro policy environment (Douglas et al., 2015). This dynamic has been ignored in previous accounts of non-state actors in policy learning and diffusion processes (Stone 2012, 491-496), and merits further study.

\section{Conclusions}

This exercise identified three formal and three informal instances of policy institutionalization associated with OGP, and traced the causal mechanisms underpinning each. This provides several case-level insights about how Norwegian institutional legacies and path dependencies are inhibiting the adoption of more progressive policy for digital dialogue and participation. It also suggests a number of practical implications for MSI influence on governance norms and policies. Most importantly, it suggests that should MSIs actively consider the ways in which the governance norms they promote are framed - not only in the context of national 
Article 1: Multi-stakeholder policy learning and institutionalization: the surprising failure of open government in Norway

politics, but in relation to the institutional and individual incentives embedded in the most relevant sub-national institutions. This in turn implies a role for national civil society actors beyond simple participation in national policy fora or the application of political pressure and persuasion vis-à-vis government actors. National civil society can also play a key role as "go-betweens" between micro and macro level policy environments, facilitating the effective dissemination of knowledge that is framed as nationally, institutionally and individually appropriate to the civil servants and policy makers on whom policy learning relies.

Conceptually, this exercise also validated the explanatory power of an analytical framework for MSI influence on policy learning and translation, and demonstrated one instance in which that mechanism contributed sequentially to informal and then formal policy outcomes. As an explanatory framework, this highlighted the contingency of policy learning mechanisms, suggesting two theoretical propositions that should be tested in developing a generalizable theory of MSI influence through policy learning.

While these propositions are distinct to countries whose national political and cultural norms strongly align with abstract norms promoted by MSIs, within-case analysis should also be applied to OGP processes with other characteristics. In particular, a contrast typology (George and Bennett 2005, 233-262) should be composed of cases that include larger sets of policy outcomes, demonstrate less developed institutional infrastructure, and entail different levels of participation by national civil society actors. This would support the development of middle range theory capable of predicting the combination of factors that facilitate successful contributions of MSIs to the institutionalization of policy in national contexts.

This analysis explored the curious case of failed OGP implementation in Norway in order to make theoretical contributions to understanding the national policy 
Article 1: Multi-stakeholder policy learning and institutionalization: the surprising failure of open government in Norway

influence of public sector MSIs. Doing so fills a notable gap in the literature on policy transfer and policy learning, which had not yet considered the role of MSIs that bridge national political discourses with global policy communities, and the ways in which this can co-occur with mechanisms of persuasion and political pressure. It also suggests important design considerations for how public governance MSIs frame the norms and policies they promote against the context of national governments. It's contributions to both theory and practice are thus preliminary, but potentially significant.

\section{References}

Acharya, A. (2004). How Ideas Spread: Whose Norms Matter? Norm Localization and Institutional Change in Asian Regionalism. International Organization, 58(1), 239-275.

Arter, D. (2016). Scandinavian politics today (3rd ed.). Manchester: Manchester University Press.

Basford, M., Webster, N., Williamson, A., \& Zacharzewski, A. (2016). Developing a model for open government in the EU. Retrieved from https://www.opengovpartnership.org/resources/developing-model-opengovernment-eu

Béland, D., \& Waddan, A. (2015). Breaking down ideas and institutions: the politics of tax policy in the USA and the UK. Policy Studies, 36(2), 176-195. https://doi.org/10.1080/01442872.2014.1000845

Ben-Josef Hirsch, M. (2014). Ideational change and the emergence of the international norm of truth and reconciliation commissions. European Journal of International Relations, 20(3), 810-833. https://doi.org/10.1177/1354066113484344

Bennett, A., \& Checkel, J. T. (2014). Process tracing: From philosophical roots to best practices. In A. Bennett \& J. T. Checkel (Eds.), Process Tracing: From Metaphor to Analytic Tool (pp. 3-38). Cambridge: Cambridge University Press.

Bennett, A., \& Checkel, J. T. (Eds.). (2015). Process Tracing: From Metaphor to Analytic Tool. Cambridge: Cambridge University Press. 
Article 1: Multi-stakeholder policy learning and institutionalization: the surprising failure of open government in Norway

Berliner, D. (2015). Ambition and Realities in OGP Commitments: Analysis of Commitment Completion Across Countries Using Hierarchical Models. Advancing Open Government and Evaluating its Impact: Research Papers by the Winners of the OGP IDRC Research Grant. Retrieved from https://www.opengovpartnership.org/stories/ambitions-and-realities-ogpcommitments-analysis-of-commitment-completion-across-countries

Björnehed, E., \& Erikson, J. (2018). Making the most of the frame: developing the analytical potential of frame analysis. Policy Studies, 39(2), 109-126. https://doi.org/10.1080/01442872.2018.1434874

Bleich, E. (2006). Institutional continuity and change: Norms, lesson-drawing, and the introduction of race-conscious measures in the 1976 British Race Relations Act. Policy Studies, 27(3), 219-234. https://doi.org/10.1080/01442870600885990

Brockmyer, B., \& Fox, J. (2015). Assessing the Evidence: The Effectiveness and Impact of Public Governance-Oriented Multi-Stakeholder Initiatives. Retrieved from http://www.transparency-initiative.org/uncategorized/429/assessing-the-evidencethe-effectiveness-and-impact-of-public-governance-oriented-multi-stakeholderinitiatives/

Bryman, A. (2015). Social research methods (5th ed.). Oxford: Oxford University Press. Retrieved from https://books.google.no/books?hl=en\&lr=\&id=N2zQCgAAQBAJ\&oi=fnd\&pg=PP $1 \& d q=$ Social + Research + Methods\&ots $=$ doMrDYMbrj\&sig=Nxdm9epd0MfJcaSqt _Kuu6fDW_s\&redir_esc $=\mathrm{y} \# \mathrm{v}=$ onepage $\& \mathrm{q} \& \mathrm{f}=$ false

Chadwick, A. (2011). Explaining the Failure of an Online Citizen Engagement Initiative: The Role of Internal Institutional Variables. Journal of Information Technology \& Politics, 8(1), 21-40. https://doi.org/10.1080/19331681.2010.507999

Christiansen, J. (2018). Developing an impact framework for cultural change in government. Retrieved September 13, 2018, from https://www.nesta.org.uk/blog/developing-impact-framework-cultural-changegovernment/

Collier, D. (2011). Understanding Process Tracing. Politics, 44(4), 823-830. 
Article 1: Multi-stakeholder policy learning and institutionalization: the surprising failure of open government in Norway

https://doi.org/10.1017/S1049096511001429

Corrigan, T., \& Gruzd, S. (2018). Civil Society Participation in the Open Government Partnership (OGP). Retrieved from https://saiia.org.za/research/learning-lessonsfrom-multi-stakeholder-initiatives/

Cortell, A. P., \& Davis, J. W. (2002). Understanding the Domestic Impact of International Norms: A Research Agenda. International Studies Review, 2(1), 6587. https://doi.org/10.1111/1521-9488.00184

Cortell, A. P., \& Davis, J. W. (2005). When norms clash: International norms, domestic practices, and Japan's internalisation of the GATT/WTO. Review of International Studies, 31(1), 3-25. https://doi.org/10.1017/S0260210505006273

Douglas, J. W., Raudla, R., \& Hartley, R. E. (2015). Shifting Constellations of Actors and Their Influence on Policy Diffusion: A Study of the Diffusion of Drug Courts. Policy Studies Journal, 43(4), 484-511. https://doi.org/10.1111/psj.12113

Dunlop, C. A., \& Radaelli, C. M. (2013). Systematising Policy Learning: From Monolith to Dimensions. Political Studies, 61(3), 599-619. https://doi.org/10.1111/j.1467-9248.2012.00982.x

Dunlop, C. A., \& Radaelli, C. M. (2018). Does Policy Learning Meet the Standards of an Analytical Framework of the Policy Process? Policy Studies Journal, 46, S48S68. https://doi.org/10.1111/psj.12250

Erikson, J. (2015). Ideas and actors in policy processes: where is the interaction? Policy Studies, 36(5), 451-467. https://doi.org/10.1080/01442872.2015.1091067

Falleti, T. G. (2006). Theory-Guided Process-Tracing in Comparative Politics: Something Old, Something New. Newsletter of the Organized Section in Comparative Politics of the American Political Science Association, 17(1), 9-14.

Falleti, T. G., \& Lynch, J. F. (2009). Context and Causal Mechanisms in Political Analysis. Comparative Political Studies, 42(9), 1143-1166. https://doi.org/10.1177/0010414009331724

Finnemore, M. (1993). International Organizations as Teachers of Norms: The United Nations Educational, Scientific, and Cultural Organization and Science Policy. International Organization, 47(4), 565-597. 
Article 1: Multi-stakeholder policy learning and institutionalization: the surprising failure of open government in Norway

Finnemore, M., \& Sikkink, K. (1998). International Norm Dynamics and Political Change. International Organization, 53(2), 887-917.

Fraundorfer, M. (2017). The Open Government Partnership: Mere Smokescreen or New Paradigm? Globalizations, 14(4), 611-626. https://doi.org/10.1080/14747731.2016.1236463

Freeman, J., \& Quirke, S. (2013). Understanding E-Democracy. Journal of EDemocracy and Open Government, 5(2), 141-154.

George, A., \& Bennett, A. (2005). Case Studies and Theory Development. In Case Studies and Theory Development in the Social Sciences (Vol. 36, pp. 3-36). Cambridge, MA: MIT Press. https://doi.org/10.1017/S0022381607080231

Gilardi, F. (2015). Who Learns from What in Policy Diffusion Processes? American Journal of Political Science, 54(3), 650-666.

Gruzd, S., Turianskyi, Y., Grobbelaar, N., \& Mizrahi, Y. (2018). Multi-stakeholder Initiatives: Lessons Learned. Retrieved from https://saiia.org.za/research/learninglessons-from-multi-stakeholder-initiatives/

Guerzovich, F., \& Moses, M. (2016). Learning How to Open Government: Findings and reflections on how the Open Government Partnership is playing out, in practice, in five countries. Retrieved from https://www.opengovpartnership.org/resources/learning-open-governmentfindings-and-reflections-on-how-ogp-playing-out-practice-five

Haugsvær, S. (2003). The Norwegian Study on Power and Democracy. Retrieved from https://www.oecd.org/norway/33800474.pdf

Head, B. W. (2012). The contribution of integrity agencies to good governance. Policy Studies, 33(1), 7-20. https://doi.org/10.1080/01442872.2011.601200

Heikkila, T., \& Gerlak, A. (2013). Building a conceptual approach to collective learning: lessons for public policy scholars. Policy Studies Journal, 41(3), 484512.

Hope, M., \& Raudla, R. (2012). Discursive institutionalism and policy stasis in simple and compound polities: The cases of Estonian fiscal policy and United States climate change policy. Policy Studies, 33(5), 399-418. https://doi.org/10.1080/01442872.2012.722286 
Article 1: Multi-stakeholder policy learning and institutionalization: the surprising failure of open government in Norway

Johnson, B., \& Hagström, B. (2005). The Translation Perspective as an Alternative to the Policy Diffusion Paradigm: The Case of the Swedish Methadone Maintenance Treatment. Journal of Social Policy, 34(3), 365-388.

https://doi.org/10.1017/S0047279405008822

Kay, A., \& Baker, P. (2015). What can causal process tracing offer to policy studies? A review of the literature. Policy Studies Journal, 43(1), 1-21. https://doi.org/10.1111/psj.12092

Leipold, S., \& Winkel, G. (2017). Discursive Agency: (Re-)Conceptualizing Actors and Practices in the Analysis of Discursive Policymaking. Policy Studies Journal, 45(3), 510-534. https://doi.org/10.1111/psj.12172

Manolea, B., \& Cretu, V. (2013). The influence of the Open Government Partnership (OGP) on the Open Data discussions.

Mena, S., \& Palazzo, G. (2012). Input and Output Legitimacy of Multi-Stakeholder Initiatives. Business Ethics Quarterly, 22(03), 527-556. https://doi.org/10.5840/beq201222333

Meseguer, C. (2005). Policy learning, policy diffusion, and the making of a new order. Annals of the American Academy of Political and Social Science, 598(March), 6782. https://doi.org/10.1177/0002716204272372

Mizrahi, S., Vigoda-Gadot, E., \& Cohen, N. (2009). Trust, Participation, and Performance in Public Administration. Public Performance \& Management Review, 33(1), 7-33. https://doi.org/10.2753/PMR1530-9576330101

O’Reilly, M. (2013). Open Government Partnership Open Government Partnership What Difference Does It Make? Retrieved February 15, 2018, from https://indigotrust.org.uk/2013/11/08/open-government-partnership-whatdifference-does-it-make-2/

OECD. (2017). Digital Government Review of Norway. Paris: OECD. https://doi.org/10.1787/9789264279742-en

OECD Publishing. (2005). OECD e-Government Studies: Norway 2005 (OECD EGovernment Studies). Paris. https://doi.org/10.1787/9789264010680-en Open Government Partnership. (2011). Open Government Declaration. Retrieved March 28, 2019, from https:/www.opengovpartnership.org/open-government- 
Article 1: Multi-stakeholder policy learning and institutionalization: the surprising failure of open government in Norway

declaration

Open Government Partnership. (2014). Open Government Partnership: Four Year

Strategy 2015-2018. Retrieved from

https://www.opengovpartnership.org/documents/four-year-ogp-strategy

Oxley, D. R., Vedlitz, A., \& Wood, B. D. (2014). The effect of persuasive messages on policy problem recognition. Policy Studies Journal, 42(2), 252-268. https://doi.org/10.1111/psj.12058

På nett med innbyggerne: Regjeringens digitaliseringsprogram. (2012). (No. April). Digital agenda Norge. Oslo. Retrieved from www.publikasjoner.dep.no

Park, C., Wilding, M., \& Chung, C. (2014). The importance of feedback: Policy transfer, translation and the role of communication. Policy Studies, 35(4), 397-412. https://doi.org/10.1080/01442872.2013.875155

Petrie, M. (2015a). Fiscal Transparency in Open Government Partnership Countries, and the Implementation of OGP Commitments: An Analysis (Background Paper prepared by GIFT for the Open Government Partnership Fiscal Openness Working Group: Mexico OGP Summit Mexico City, October 28-30, 2015).

Petrie, M. (2015b). New Zealand and the OGP. Retrieved September 25, 2017, from https://www.opengovpartnership.org/stories/new-zealand-and-ogp

Risse-Kappen, T., Ropp, S. C., \& Sikkink, K. (Eds.). (1999). The Power of Human Rights: International Norms and Domestic Change. Cambridge: Cambridge University Press.

Skedsmo, P. W. (2014). Independent Reporting Mechanism (IRM): Norway Progress Report 2016-2018. Retrieved from https://www.opengovpartnership.org/documents/norway-mid-term-report-20162018

Stern, A., Kingston, D., \& Ke, J. (2015). More Than the Sum of Its Parts: Making Multi-Stakeholder Initiatives Work. Retrieved from https://globaldevincubator.org/wp-content/uploads/2016/02/Making-MSIsWork.pdf

Stone, D. (2004). Transfer agents and global networks in the 'transnationalization' of policy. Journal of European Public Policy, 11(3), 545-566. 
Article 1: Multi-stakeholder policy learning and institutionalization: the surprising failure of open government in Norway

https://doi.org/10.1080/13501760410001694291

Stone, D. (2012). Transfer and translation of policy. Policy Studies, 33(6), 483-499. https://doi.org/10.1080/01442872.2012.695933

Stone, D. (2016). Understanding the transfer of policy failure: bricolage, experimentalism and translation. Policy \& Politics, 45(1), 1-16. https://doi.org/10.1332/030557316X14748914098041

Turianskyi, Y., Corrigan, T., Chisiza, M., \& Benkenstein, A. (2018). Multi-stakeholder Initiatives: What Have We Learned? An Overview and Literature Review. Retrieved from https://saiia.org.za/research/learning-lessons-from-multistakeholder-initiatives/

Vasilev, G. (2015). Minority rights activism beyond borders: the synergies between deliberation and strategic action. Policy Studies, 36(3), 329-344. https://doi.org/10.1080/01442872.2015.1065964

Vigoda, E. (2002). From Responsiveness to Collaboration: Governance, Citizens, and the Next Generation of Public Administration. Public Administration Review, 62(5), 527-540. https://doi.org/10.1111/1540-6210.00235

Wilson, C. (2017a). Norway: 2014-2015 End of Term Report. Retrieved from https:/www.opengovpartnership.org/documents/norway-end-of-term-report-20142015

Wilson, C. (2017b). Norway: 2014-2015 End of Term Report. Retrieved from https://www.opengovpartnership.org/documents/norway-end-of-term-report-20142015-english

Wilson, C., \& Nahem, J. (2013). Norway: Independent Reporting Mechanism (IRM) Progress Report 2011-2013. Retrieved from http://www.opengovpartnership.org/sites/default/files/172755568-Norway-IRMReport.pdf

Winston, C. (2017). Norm structure, diffusion, and evolution: A conceptual approach. European Journal of International Relations, 135406611772079. https://doi.org/10.1177/1354066117720794

Wirtz, B. W., Piehler, R., Thomas, M. J., \& Daiser, P. (2016). Resistance of Public Personnel to Open Government: A cognitive theory view of implementation 
Article 1: Multi-stakeholder policy learning and institutionalization: the surprising failure of open government in Norway

barriers towards open government data. Public Management Review, 18(9), 13351364. https://doi.org/10.1080/14719037.2015.1103889

Yang, T.-M., \& Wu, Y.-J. (2016). Examining the socio-technical determinants influencing government agencies' open data publication: A study in Taiwan. Government Information Quarterly. https://doi.org/10.1016/j.giq.2016.05.003

Yin, R. K. (2009). Case Study Research: design and methods. (Sage, Ed.) (5th ed.). Los Angeles: SAGE Publications.

Zimmermann, L. (2016). Same same or different? Norm diffusion between resistance, compliance, and localization in post-conflict states. International Studies Perspectives, 17(1), 98-115. https://doi.org/10.1111/insp.12080

Zuiderwijk, A., \& Janssen, M. (2014). Open data policies, their implementation and impact: A framework for comparison. Government Information Quarterly, 31(1), 17-29. https://doi.org/10.1016/j.giq.2013.04.003 


\title{
Look Who's Talking: Assessing Civic Voice and Interaction in OGP Commitments
}

\section{Christopher Wilson}

University of Oslo, christbw@media.uio.no

\begin{abstract}
This article argues that meaningful citizen-state interaction is a core component of the OGP mandate and theory of change. Assessing the frequency and quality of such activities in countries' national action plans can indicate the degree to which OGP is encouraging government to engage meaningfully with their citizens in the pursuit of accountable and responsive governance. A conceptual framework is proposed for identifying and evaluating the quality of civic voice and interaction in OGP commitments. Analysis of commitments from 61 countries finds little evidence of meaningful civic interaction, and proposes implications for open government advocates and campaigners.
\end{abstract}

Keywords: OGP, open government, civic voice, interaction, accountability 


\section{Introduction}

The explicit objectives of the Open Government Partnership (OGP) are to improve government transparency, accountability and responsiveness to citizens (Frey, 2014: 4). This has proved to be a popular rallying cry for countries and civil society organizations alike, and a combination of conceptual ambiguity and technological enthusiasm has no doubt contributed significantly to the Partnership's prominence. There is, however, little evidence to date regarding the OGP's impact in national political contexts, and the mechanisms through which the Partnership is expected to achieve its objectives would benefit from closer interrogation.

Specifically, this article argues that the OGP's objectives are fundamentally relational, leveraging the power of international norms and new technologies to change how governments and their citizens interact. The importance of citizen-state interaction is widely recognized by scholarship on democracy and e-participation, but has received little treatment as a distinct phenomenon in the transparency and accountability literature. In OGP policy discourse, citizenstate interaction is referenced obliquely through a number of conceptual principles, but addressed operationally almost exclusively in terms of the consultation and co-production processes through which national action plans are developed. These processes are important, but they represent a single step on the theory of change according to which the OGP is expected to make governments more open and responsive to citizens.

Questioning government intentions to pursue citizen-state interaction beyond action plan consultations is an important first step towards understanding how the OGP is influencing government practice. Because action plans are the result of consultations, and cover a longer time span than consultations (two years for most), they are arguably a better indicator of OGP outcomes than consultative processes. Treating action plan commitments as outcomes requires assuming, however, that commitments represent the actual intentions of governments, which might not always be the case. Action plan commitments to interact with citizens should thus be considered a necessary but insufficient condition for citizen-state interaction as an outcome of OGP processes.

This article draws on the scholarly literature surrounding the OGP, as well as conceptual advances in e-participation, accountability and communication theory scholarship, to propose a framework for identifying and evaluating the quality of citizen-state interaction in governments' OGP commitments. An assessment of the most relevant English language commitments in 61 countries' 2011-2014 action plans finds a surprising lack of citizen-state interaction, and that when such interaction is present, it only rarely describes interaction that is clearly meaningful in the context of transparent, accountable and responsive governance. Nor does technology appear to play the driving and connecting role in OGP commitments that many open government advocates might have hoped.

This article proceeds as follows. Section 2 sketches the contours of contemporary research on citizen-state interaction and open government. Drawing on OGP policy and research from several disciplines, it proposes a framework for identifying and evaluating the quality of civic interaction in OGP commitments, and posits three research questions for this analysis. Section 3 describes the OGP commitment data set and analytical methods. Section 4 discusses findings and their 
implications, according to each of the three research questions. The final section proposes broad conclusions to be drawn, as well as limitations to the current analysis and potential avenues for further research.

\section{Background Literature and Theory}

\subsection{Civic Voice and Interaction in Open Government}

This analysis builds on a simple presumption that OGP's stated objectives of accountability, transparency and responsiveness are all fundamentally relational concepts, which can only be understood as interaction between two parties, in this case: governments and citizens. This interactional dynamic is implicitly central to OGP policy and discourse and referenced consistently as both a policy objective and an instrumental mechanism through which to pursue change.

As an objective, citizen-state interaction looms large in guidance for OGP government focal points, which is riddled with references to co-production, input and feedback. "Civic participation" constitutes one of the four key values of the OGP and to which commitments are to be classified (Government Point of Contact Manual, 2016), ${ }^{1}$ whereby " governments seek to mobilize citizens to engage in public debate, provide input, and make contributions that lead to more responsive, innovative and effective governance" ("OGP IRM Data Guide v 2.5," 2015: 15). The instrumental value of civic interaction is central to the OGP's theory of change, as highlighted in recent synthesis of five in-depth country case studies organized by the non-profit organization Global Integrity (Guerzovich and Moses, 2016), which emphasizes communication between governments and nongovernment actors in each of the "pathways to change" it enumerates.

Despite this centrality, attention to citizen-state interactions in OGP policy and discourse tend to revert consistently to the consultation processes intended to inform development and implementation of national action plans, and do not address citizen-state interaction as an outcome of action plans. Francoli, Ostling and Steibel's (2015) commissioned report on "Government Civil Society Interactions within OGP" is an excellent example. The report aims to assess interaction "within the framework of the OGP" (1), which leads naturally to an emphasis on consultative processes attendant to action plan development and implementation, as these represent the "policy spaces" which OGP aims to open in domestic political contexts.

These consultation processes are indeed important. They can set the terms and course of countries' OGP implementation, can help to establish permanent mechanisms for interaction, and may provide unique leverage for civil society to assert issues and track implementation (though the evidence on this is mixed, see Arias, Gomez, Rivera, \& Fernandez, 2016; Montero, 2015b).

${ }^{1}$ The other three OGP values are access to information, public accountability, and technology and innovation for openness and accountability. For further details, see also the OGP Values Guidance Note, available from http://www.opengovpartnership.org/sites/default/files/ogp_2016_poc_manual.pdf. 
Consultations for action plan development represent the very first input on the OGP theory of chain, however, and allow interaction with limited scope. The action plans that they produce and monitor cover larger spans of time and represent mid-level inputs towards the eventual outputs of action plan implementation. In these early stages of OGP, when little output level data on action plan implementation is yet available for comparative analysis, government commitments arguably offer the best indicator for assessing what types of government action the OGP is successfully facilitating. It remains, however, unclear what citizen-state interaction looks like in OGP commitments, or how it would be identified.

The Francoli et al report treats consultative processes across 9 national case studies, which are complemented by third party contextual indicators on the quality of citizen engagement across countries. Discussion of interaction in action plan commitments are restricted to a discussion of whether commitment are coded by the OGP IRM as relevant to "civic participation" (5-6). This use of civic participation as a proxy for citizen-state interaction is also employed in other research on OGP commitments (Whitt, 2015). Civic participation is not a well-defined or operationalized concept, however, and is not easily equated with the kind of interaction implied by OGP's mandate. Can you imagine political participation without responsive government? Maybe. It's hard to say.

This analysis is motivated by these two concerns, the importance of OGP commitments as output indicators and the lack of conceptual clarity regarding citizen-state interaction outside of consultations. To move towards an operational, the rest of this subsection will review the types of activities that might be relevant in an open government context.

Briefly surveying OGP commitments reveals a wide variety of relevant activities. Online complaint platforms, websites to facilitate public discussion on budgets, the release of performance assessment results, open data portals, online competitions for policy innovation, the appointment of thematic contact points and social media initiatives to promote public awareness are just some examples. Each of these represents a decidedly different mode of interaction, and the scholarly literature addressing such interaction is equally varied, from established fields such as public administration, e-government and e-participation studies, to more emergent disciplines such as policy informatics (Johnston, 2015). Much contemporary scholarship tends to focus on specific types of interaction, such as government crowdsourcing of expertise or input (Leicht et al., 2016; Liu, 2016; Noveck, 2009), online consultations (Åström et al, 2016; Balla \& Zhou, 2013), participatory policy-making (Janssen and Helbig, 2015; Johnston, 2015; Sørensen, 2016), or interactivity in government websites (Ferber et al., 2007; Liden, 2016; Norris, 2003; van Noort et al., 2016; Yavuz and Welch, 2014).

Attempts to categorize the breadth of this field of practice are also diverse, as demonstrated in the literature on transparency and accountability. Research published by the World Bank distinguishes types of "government feedback loops" according to the basic communicative functions they perform (Wittemyer et al, 2014, in Gigler \& Bialur, 2014: 47-50) and curates taxonomies of digital citizen engagement organized according to variables such as spectrums of participation, directions of engagement and initiating parties (Peixoto, Fall, \& Sjoberg, 2016: 18-19). Similarly, Kosack \& Fung's (2014) review of 16 experimental evaluations leads them to propose 
typologies distinguished by the types of actors and interactions they encompass, while Loureiro et al (2016) draw distinctions by the degree to which government actors listen to the people they consult, or engage directly with them in collaborative processes.

In order to operationalize the types of interaction described in OGP commitments, this analysis focuses instead on the degrees of back and forth communication present in any interaction between government actors and non-government actors. It proposes the concept of Civic Interaction to capture this dynamic, wherein communication may be synchronous or asynchronous and may or may not be substantively or explicitly political. This concept is operationalized by drawing on Arnstein's seminal (1969) ladder of participation, and particularly the notion of cumulative degrees. Adapting Arnstein's ladder to the context of open government suggests six distinct modes of interactivity, described in Table 1.

Table 1: Modes of civic interaction in an open government context

\begin{tabular}{|l|l|}
\hline Publish & $\begin{array}{l}\text { Government takes steps to make information available to citizens, either } \\
\text { through publishing information actively, or through removing restrictions to } \\
\text { information. }\end{array}$ \\
\hline Enable & $\begin{array}{l}\text { Government takes steps to facilitate communication on government } \\
\text { information by non-governmental groups, including citizens, civil society and } \\
\text { business, without necessarily or explicitly engaging in that interaction }\end{array}$ \\
\hline Receive & $\begin{array}{l}\text { Government receives information from non-governmental actors, such as } \\
\text { citizen or civil society reports on incidents or perspectives on policy issues, } \\
\text { without any explicit mechanism for government follow up. }\end{array}$ \\
\hline React & $\begin{array}{l}\text { Government takes measures in response to communication from non- } \\
\text { government actors, but those measures are identified, designed and } \\
\text { implemented in a forum that is removed from that communication, and } \\
\text { without the influence of non-governmental actors. }\end{array}$ \\
\hline Respond & $\begin{array}{l}\text { Government responds to communications from citizens, civil society or } \\
\text { business communications in a way that explicitly acknowledges those } \\
\text { communications. }\end{array}$ \\
\hline Dialogue & $\begin{array}{l}\text { Communication between government and non-governmental actors is } \\
\text { structured to facilitate sustained interaction, in which there is more than one } \\
\text { back and forth (more than } 1 \text { degree of message dependency). This may } \\
\text { include communication that takes place asynchronously, through specific } \\
\text { structures that facilitate the communication of related messages over time } \\
\text { (such as a citizen feedback platform that mandates a specific set of responses) } \\
\text { or synchronous communication, such as conversations and debates in real life, } \\
\text { or chats online. Synchronous communication may include activities } \\
\text { characterized as discussion or collaboration. }\end{array}$ \\
\hline
\end{tabular}

An advocate of accountable and responsive governance might be quick to question whether the less interactive modes of Publish and Enable really "count" as civic interaction. This is a reasonable concern, and the OGP has been criticized for its emphasis on open data (Bahl, 2012; Schwegmann, 2013), whose contributions to accountability and government responsiveness are not always clear (Davies \& Bawa, 2012; Meng, 2014; Worthy, 2015). One might also raise this concern in terms of citizen voice, which is here understood as an instance of expression or communication by non- 
government actors in the course civic interaction. ${ }^{2}$ Though popular reference is often made to oneway communication (you can talk at someone, you don't have to talk with them), one-way communication does not resonate well in the context of civic interaction. One would like civic interaction to refer to modes that include a component of civic voice. Simply put, government cannot be responsive if it has nothing to respond to.

In the above operationalization of civic interaction, civic voice is only clearly present in the modes of Receive through Dialogue. The "less interactive" modes of Publish and Enable are not excluded, however, because they represent common activities in OGP action plans, and because there is an ongoing discussion about the degree to which releasing information to the public or enabling public discourse facilitates government accountability (Reggi and Dawes, 2016; van Schalkwyk et al., 2015).

This analysis is, moreover, exploratory and descriptive. Identifying less interactive modes in OGP commitments will contribute to understanding the frequency of civic interaction as OGP outputs per se. Operationalized through theses six modes of interaction, the first research question for this analysis can be formulated is: how frequent are different modes of civic interaction in government's OGP commitments?

\subsection{Technology and Civic Interaction}

Modern technology is inextricably bound up in contemporary ideas about civic interaction and open government. Francoli \& Clark's (2014) review of open government understandings in the OGP context notes that "many of today's definitions see a vital role for digital technology in the fulfillment of open government" (251), and technology is clearly positioned as one of the four OGP values according to which countries are encouraged to develop commitments (Government Point of Contact Manual, 2016).

Though concerns have been raised regarding the conceptual ambiguity surrounding open data technology and open government policy (Yu and Robinson, 2012), there is a widely recognized causal relationship between the two. Not only do new technologies actually enable greater openness and communication at scale, the open government community increasingly recognizes

" openness as facilitating new modes of production, enabling more efficient delivery of services, or as supporting the role of competitive market forces in the operation of government services" (T. G.

Davies \& Bawa, 2012).

At its best, the open government assertion of government responsiveness recognizes this subtle interplay to pursue a more nuanced understanding of technology's role in governance. As Linders et al (2013) articulate their argument for open government as a vehicle for government transformation:

2 Scholarship on transparency and accountability often treats instances of citizen feedback, monitorial democracy and public service reporting as examples of citizen voice; this operationalization of civic voice also includes communications by private sector and professional actors and organizations 
"If government is to transform through ICTs, it will likely be the interaction between people and the technology that creates something new and valuable, not the technology itself (Scholl, 2005). Likewise, open government is not so much an end in itself as a means to fundamentally evolve the relationship between governments and their citizens toward a collaborative partnership. [...] With ICT's enabling 'many more people to work together,' it is possible that 'we can redesign our institutions' around more collaborative problem-solving and thereby deliver a 'new kind of democratic legitimacy'" (12).

The interplay between communication, policy and technology described here suggests a potentially profound role for technology to facilitate a wide variety of civic interaction activities in OGP commitments.

This potential is widely recognized in the context of the Publishing mode. Digital and internet technologies enable the sharing of information to degrees and at scales that would have been unimaginable a few decades ago. Similarly, technology's contribution to modes of Reception through Dialogue are apparent in the wide variety of platforms available for online collaboration and policy discussion (Janssen and Helbig, 2015; Lucke and Große, 2014), and the United Nations 2016 E-Government Survey (2016) notes that "public consultations on policy options and documents have become both the backbone and driver of e-participation" (71).

Given the above, one would expect technology to play a consistently prominent role in governments' OGP commitments, often directly enabling or supporting communication and engagement with non-government actors. This leads to the second research question of this analysis: how frequently is technology being used to facilitate different modes of civic interaction in OGP commitments?

\subsection{When are Civic Voice and Interaction Meaningful in an Open Government Context?}

The literature reviewed so far has suggested that civic interaction will feature significantly in OGP commitments, and will be significantly facilitated by the use of technology. It is important to also ask to what degree such activities are meaningful in the context of transparent, accountable and responsive governance. This cannot be derived directly from the six modes of interaction posited above. Less interactive modes might be more meaningful than more interactive modes, insofar as an initiative to publish municipal budget data would be significantly more meaningful for government accountability than an online chat forum where political figures answer questions about their favorite cupcake recipes. Cupcake-driven interaction might have a positive impact on relationships of governance over time, by virtue of continued exposure and engagement, but to consider the quality of civic interaction in OGP commitments, a more transactional approach is necessary.

\subsubsection{Interaction}

Evaluating the quality of civic interaction in an open government context requires considering both the quality of the interaction and the context in which it occurs. The open government and 
accountability literature offers several contextual indicators, which will be discussed below, but not to assess the quality of civic interaction as interaction.

A handful of relevant frameworks for evaluating interaction may be found in literature on eparticipation and public administration. Medaglia (2012) proposes that e-participation may be evaluated according to the quantity of participatory communications, the demographics of participants and the "tone and style in the online activities" (353). Zhou et al's (2013) participatory cube framework emphasizes the degree of decision-making power allocated to participants, the degree to which spaces for participation are openly accessible, and the degree to which of interactivity in communication (defined as symmetry in the number of communicators, i.e.: whether communication is one-to-one, one-to-many or all-to-all) (402). Welch \& Fulla's (2005) framework for cyber interactivity between citizens and government is based on content sophistication, feedback opportunity, dialogue complexity, and response commitment (233).

From a public administration perspective, Vigoda (2002) emphasizes both the active participation and the coercive power of citizens in such interaction, and goes so far as to distinguish between governance responsiveness, which may be assessed by the "speed and accuracy with which a service provider responds to a request for action or information," and government collaboration with citizens as partners (529). Vigoda employs this distinction to sketch a continuum along which public administration proceeds from a primarily coercive function over citizens, through increased responsiveness and collaboration, towards a state in which government institutions' behavior is coerced by citizens (531).

Decision-making power, access to communication, the capacity to coerce other parties and the symmetry and precision of response are key elements here, and together suggest that the reciprocal nature of communication combined with the ability of non-governmental actors to influence communication are fundamental inflection points. These dynamics also correspond with established measures of interactivity in traditional communications theory, where they are described as message dependency and participant control. These two measures are briefly described below and operationalized in the context of civic interaction.

The concept of message dependency was introduced by Rafaeli, who defined it as "the extent to which messages in a sequence relate to each other, and especially the extent to which later messages recount the relatedness of earlier messages" ( Rafaeli and Sudweeks, 1997, cited in Kiousis, 2002: 360). This understanding has been adopted and operationalized in a political context by several scholars (Hacker, 1996; Williams, 1988, cited in Kiousis, 2002; Stromer-Galley, 2000) (Hacker, 1996: 224-226; Strom-Galley, 2000: 117; Williams, 1988: cited in Kiousis, 2002: 359). Kiousis (2002) articulates message dependency in terms of a specific threshold, which he describes as third-order dependency.

A third-order dependent message interaction in a computer chatroom might read like the following:

User 1: Five minutes ago, you said that you wanted to go to the movies tonight, why have you changed your mind?

User 2: I didn't change my mind. Two minutes ago, I thought you said you wanted to go to the movies tomorrow? 
From this dialogue, we notice that both participants refer to prior transmissions, prompting a third-order dependency (359).

This degree of message dependency is quite rare in open government activities. Rejecting or responding to a freedom of information request would exemplify a single degree of message dependency, while allowing appeals when a freedom of information request is rejected would exhibit two degrees of message dependency. Publishing open data that has not been specifically requested by citizens implies no message dependency. Nor does the "two-sided dialogue, but onesided action" described by Loureiro et al, since there is follow-up action taken but no follow-up communication back to citizens.

Participant control has a strong pedigree in the conceptualization of interactivity, where it has often been understood as the capacity of platform users to modify "the form and content of a mediated environment," but has increasingly been understood of relationships between communicating parties (Downes \& McMillan, 2016: 158-161). This concept has been applied to contexts of cyber-interactivity and politics, but without clear definition (Ferber, 2005; McMillan, 2002), necessitating a return to the criteria posed in more general communications literature. This body of work suggests a number communicative components over which participants might exercise control, including communication's content, timing, and roles (Kiousis, 2002: 359-360). In the context of OGP, participant control can be best demonstrated through the simple capacity of non-government actors to influence the timing and regularity of interaction with government, or to dictate the specific topic of interaction. Together, participant control and message dependency provide two metrics for the quality of communication that can be used to assess civic interaction in OGP commitments.

\subsubsection{Context}

An alternative approach to assessing the quality of civic interaction in OGP commitments focuses on the context in which interaction occurs. The infinite variation in context makes such an approach challenging, but the open government, transparency and accountability scholarship provides at least three useful starting points, distinguished by modes of civic interaction.

For publishing activities, there is wide recognition that open government data does not automatically lead to improved service delivery and government accountability (Davies and Bawa, 2012; Reggi and Dawes, 2016; Van Schalkwyk et al., 2015; Worthy, 2015). In a digital environment, intermediation through civil society and professional organizations is often necessary to contextualize published information and create the insights and tools that citizens can use to make demands of governments (Al-Sobhi et al., 2010; Cañares, 2016; Davies, 2010; Reggi and Dawes, 2016; van Schalkwyk et al., 2015). Activities in the mode of publishing are likely to be much more meaningful for government responsiveness and accountability when they explicitly anticipate the role of intermediaries in regard to published information.

Civic interaction using technology to facilitate the expression of citizen voice is particularly prone to challenges of to access and representation (UN E-government survey 2016: E-Government in Support of Sustainable Development, 2016: 78), and tendencies towards elite-overrepresentation 
(Liu, 2016). Such dynamics have led open government scholars and stakeholders to encourage governments to move beyond technological solutions and towards more fundamental and institutional reforms (Montero, 2015b: 24), or to combine online and offline consultations, in order to ensure appropriate access and representation (de Zuniga, Copeland, \& Bimber, 2014; Francoli et al., 2015: 41; Montero \& Taxell, 2015: 33; Mossberger \& Tolbert, 2010; UN E-government survey 2016: E-Government in Support of Sustainable Development, 2016: 70). It is in this vein that the OGP Participation and Co-creation standards encourage consultation methodologies that are an "appropriate combination of open meetings and online engagement for the country context." Citizen voice activities in OGP commitments are likely to be more meaningful in an accountability context when they acknowledge the limits of technological platforms and accommodate the incorporation and combination of offline solutions.

In the most comprehensive empirical assessment of citizen voice and government accountability to date, Peixoto \& Fox (2016b) review 23 ICT-enabled platforms "to solicit and collect feedback on public service delivery" in 17 countries (5). The study assesses correlations between citizen voice and government responsiveness, defined as "a clearly identifiable action taken by government/service providers, following individual or collective input by citizens" (10), but not necessarily responding to it. Government response is in this sense disconnected from citizen voice once that voice is expressed. According to the modes of interaction operationalized in this analysis, it represents a mode of React, but not Respond, because citizens have no further influence on the nature or context of government reaction, and those reactions do not explicitly engender further interaction. The study's findings suggest a number of compelling variables to inform the design of "successful" voice and accountability initiatives. The most relevant for modes of Receive and React is the publication of citizen voice.

"...feedback systems aggregate data - by asking citizens to share their assessments of service provision - but if the resulting information is not made public, then it cannot inform citizen action. In these systems, if users' input is going to influence service provision, voice must activate 'teeth' through a process other than public transparency - such as the use of data dashboards that inform senior managers' discretionary application of administrative discipline" (5).

Government descriptions of civic interaction that explicitly anticipate the public visibility of civic voice are likely to be more meaningful in the context of transparency, accountable and responsive governance (Peixoto and Fox, 2016: 5).

Drawing on the above literature, this article proposes two types of quality metrics with which to assess civic interaction in OGP commitments. The quality of communication can be assessed by the degree of message dependency and participant control exhibited in civic interaction. The contextual indicators of whether government commitments explicitly anticipate intermediation, the combination of online/offline voice platforms, and the public visibility of civic voice can also be used to assess the quality of civic interaction. These metrics are used to pursue the third research question in this analysis: how meaningful are OGP commitments to civic interaction in the context of accountable, transparent and responsive governance? 


\subsection{Summary of Research Questions}

This article explores whether the OGP is facilitating meaningful government-initiated civic voice and interaction. This is approached by assessing governments' OGP commitments, to determine what kinds of civic interaction they pursue, whether it is facilitated by technology, and whether it is meaningful in the context of transparent, accountable and responsive governance.

This is operationalized through the following three research questions:

RQ 1: How common are different modes of civic interaction in government's OGP commitments?

RQ 2: Is technology being used to facilitate civic interaction in OGP commitments?

RQ 3: How meaningful are OGP commitments to civic interaction in the context of accountable, transparent and responsive governance?

\section{Methods and Data}

\subsection{The OGP Commitments Data Set}

Countries' implementation of OGP National Action Plans are evaluated by the OGP's International Review Mechanism (IRM), which employs national researchers to determine whether commitments were implemented and whether they had any significant impact on open government in the country. In December of 2016, the IRM released an updated data set of government commitments, culled from the National Action Plans of 61 countries over a four year period, and corresponding IRM reports. ${ }^{3}$ This data set contains 2,015 commitments, ${ }^{4}$ coded according to substantive variables such as thematic focus, institutional variables (such as the time period for activities and responsible government agency), and evaluation variables (such as whether the commitment was completed and whether it had any impact on opening government in the country).

Of the full data set, 1498 commitments were written in English, of which 494 had been reviewed and coded as relevant to civic participation by the IRM. This subset of commitments was further filtered to include only those 386 commitments which used variations of word stems relevant to citizen state interaction (assess, collaborate, consider, contribute, cooperate, debate, deliberate, dialogue, discuss, engage, feedback, feedback, input, recommend, respond, review).

\section{${ }^{3}$ Available at http://www.opengovpartnership.org/explorer/landing.}

${ }^{4}$ Data records in the OGP data set include commitments and benchmarks, where individual commitments contained multiple benchmarks and were split into corresponding data records by the IRM. These records are here referred to collectively as commitments. 
A unique identifier was applied to all commitments in this data subset, and when commitments referenced distinct activities relevant to civic interaction, they were divided into individual data records for each activity before coding. Activities in this data subset were then evaluated for interactivity, and 20 of the activities were presented with wording so vague or imprecisely formulated that it was impossible to determine what they actually meant, even after consulting the full text of national action plans and IRM reports. These activities were removed from the data set.

The remaining data set, analyzed below, is thus composed of the 422 English language activities most likely to anticipate some degree of civic interaction.

\subsection{Methods and Analysis}

Content analysis was conducted on the commitment data set and the following variables were coded according to each research question.

1) RQ 1: How common are different modes of civic interaction in government's OGP commitments?

a) Variable: Modes of interaction. Each distinct activity in an OGP commitment was categorized as one of the six modes of interaction described in Table 1.

i) Values: No interaction, modes 1-6, unclear.

b) Variable: Second Order Interaction. Some commitments did not describe activities that would lead directly to civic interaction, but did describe activities that might result in civic interaction in the future. For example, commitments to consider amendments to freedom of information legislation, or to allocate budget for developing guidelines for municipal participatory budgeting will not result in citizen state interaction when implemented, but can reasonably be expected to lead to interaction as an extended consequence. These types of second order interactions were categorized as one of the six modes of interaction described in Table 1.

i) Values: No interaction, modes 1-6, unclear

2) RQ 2: Is technology being used to facilitate civic interaction in OGP commitments?

c) Variable: Technology dependency. When commitments described activities that were explicitly dependent on the use of technology, including the internet, mobile phones or other digital media.

i) Values: yes/no

3) RQ 3: How meaningful are OGP commitments to civic interaction in the context of accountable, transparent and responsive governance?

d) Variable: Message dependency. Activities were coded as to whether they explicitly described one or more degrees of message dependency, or whether message dependency was suggested by the structure of interaction, (live conversation or live chats online) or the wording of the activity (words such as collaborate, partner with). 
i) Values: No explicit message dependency, suggestive language, single degree, more than one degree.

e) Participant control Activities were coded as to whether non-government actors were explicitly allocated control over interactive components including the topics or timing of discussions, or whether participant control was suggested by the structure of interaction, (live conversation or live chats online) or the wording of the activity (words such as collaborate, partner with).

i) Values: No explicit participant control, suggestive language, explicit participant control over any aspect of interaction.

f) Interaction targets: Activities were coded on the basis of the types of actors interaction targeted, distinguishing between civil society or stakeholder organizations that might function as intermediaries with citizens, and interactions targeting individuals or the general public directly.

i) Values: No interaction, organized civil society or professional groups, individuals or the general public.

After a full coding of the data set according to the above variables, a random selection of $20 \%$ of the data records were re-coded by a second researcher in order to confirm data validity, as recommended by Cresswell (2008) in cases where qualitative data is coded by a single coder. Vaismoradi et al (2013) note that such a "peer checking" approach is appropriate for improving reliability and confirmability of single coder data, but cannot establish the objectivity of coding in a strict sense. The quality of interactive processes is inherently a subjective evaluation, so this is considered appropriate for the current analysis and code set.

The ReCal2 web service was used to test the reliability of the peer checked data (Freelon, 2010), using percent agreement and Scott's Pi measures, which are the most appropriate for nominal data coded by two coders (Krippendorff, 2004). The values of these two tests are displayed in Table 2 and demonstrate acceptable reliability scores for most variables. The quality metrics for message dependency and participant control received significantly lower scores than the other indicators, however. This is likely due to in part to the lack of precision in OGP commitment data, which necessitated the use of a "suggestive language" value for these variables. Implications for interpreting these variables, and for their use in other research and assessments, are discussed in the section on findings and in the conclusion of this article.

Table 2: Inter-coder reliability test scores

\begin{tabular}{|l|c|c|}
\hline & $\begin{array}{c}\text { Percent } \\
\text { Agreement }\end{array}$ & Scott's Pi \\
\hline _interactivity_ & 89,3 & 0,84 \\
\hline _2nd_order_ & 90,5 & 0,81 \\
\hline msg_dep & 85,7 & 0,67 \\
\hline part_control & 86,9 & 0,69 \\
\hline tech_dep & 95,2 & 0,89 \\
\hline
\end{tabular}




\begin{tabular}{|l|c|c|}
\hline interact_with & 92,9 & 0,87 \\
\hline
\end{tabular}

Coded data were subjected to descriptive statistical analysis, whereby frequency statistics and cross tabulation were used to assess the degree and quality of civic interaction in OGP commitments, according to the variables listed above. Subsets of data identified through these analyses were then subjected to secondary analysis, evaluating whether commitments explicitly described the contextual quality indicators for the public visibility of civic voice and the use of online/offline strategies in civic interaction. This secondary analysis on specific subsets of commitments used binary values, and was not subjected to inter-coder reliability testing.

\section{Findings and Discussion}

\subsection{Frequency of Civic Interaction by Modes}

The frequency of civic interaction in OGP commitments was assessed by assigning a mode of interaction to each activity in the commitment data set. Additionally, second order activities, that might or might not result in the future were also identified and categorized according to the same set of six modes. This allows for some preliminary comments on how interactive OGP commitments are, and the quality of interaction is treated more fully at the end of this section.

Surprisingly, nearly half (194/422) of activities in the filtered data set did not clearly propose any interaction with non-government actors, as shown in Table 3. These activities were dominated by policy and administrative initiatives, often in the area of anti-corruption or democratic representation, but did not describe any specific action that could be understood as civic interaction, broadly construed as any of the six modes proposed above. More than two thirds of the activities in OGP commitments data $(290,68.7 \%)$ did not anticipate any degree of citizen voice (No Interaction, modes of Publish and Enable). 16 of the activities seemed to imply some kind of interaction, but the commitment language was too vague to determine what kind of interaction it actually was. At first glance, these are disappointing numbers, which seem to suggest that the OGP commitments most likely to anticipate civic interaction are not very interactive at all.

Table 3: Frequency of Modes of Interaction

\begin{tabular}{|l|l|l|l|l|l|}
\hline \multicolumn{2}{|c|}{} & Frequency & Percent & $\begin{array}{l}\text { Valid } \\
\text { Percent }\end{array}$ & $\begin{array}{l}\text { Cumulative } \\
\text { Percent }\end{array}$ \\
\hline $\begin{array}{l}\text { Modes of } \\
\text { Interaction }\end{array}$ & $\begin{array}{l}\text { No } \\
\text { Interaction }\end{array}$ & 194 & 46,0 & 46,0 & 46,0 \\
\cline { 2 - 6 } & Publish & 89 & 21,1 & 21,1 & 67,1 \\
\cline { 2 - 7 } & Enable & 7 & 1,7 & 1,7 & 68,7 \\
\cline { 2 - 7 } & Receive & 51 & 12,1 & 12,1 & 80,8 \\
\cline { 2 - 7 } & React & 3 &, 7 &, 7 & 81,5 \\
\hline
\end{tabular}




\begin{tabular}{|l|l|l|l|l|l|}
\hline & Respond & 7 & 1,7 & 1,7 & 83,2 \\
\cline { 2 - 6 } & Dialogue & 55 & 13,0 & 13,0 & 96,2 \\
\cline { 2 - 6 } & Unclear & 16 & 3,8 & 3,8 & 100,0 \\
\hline \multicolumn{2}{|l|}{ Total } & 422 & 100,0 & 100,0 & \\
\hline
\end{tabular}

For those activities that did imply some degree of civic interaction, Publishing was the most common mode, representing $21 \%$ of activities. Government activities coded as Publish did not include explicit mechanisms by which non-government actors could respond to the information that was published. The dominance of this mode is consistent with popular critiques that the OGP overemphasizes open data strategies at the expense of meaningful reform and accountability (Bahl, 2012; Schwegmann, 2013).

$12 \%$ of activities (51) were coded as Receive. This mode indicates a government commitment to receive information from non-government actors, without any explicit commitment to react to that information. A significant portion of these activities (19) represented consultation processes in a traditional sense, without explicit follow ups, what Loureiro et al (2016) would call hearing but not listening. A narrow majority of activities (29) sought non-governmental feedback on specific policy objects or public services (as coded according to message dependency), while a handful of activities established mechanisms for citizen input without specific topic limitations. The Receive mode represents a tipping point in the continuum for civic interactivity proposed here. It is the first mode in which citizen voice is present, but does not explicitly anticipate response to that voice or sustained interaction.

$13 \%$ of activities (55) were coded as Dialogue in the OGP data set. It is worth re-emphasizing that this mode should not be confused with the concept of dialogue employed in Public Relations studies or scholarship on deliberative democracy. The term dialogue is used exclusively in this analysis to refer to activities which explicitly imply synchronous or asynchronous exchanges of information between governmental actors, which are sustained over some period of time and include at least one degree of message dependency. In the OGP commitments data set, this included a variety of disparate activities, from elaborate networking aiming to engage with the scientific community, to community forums and collaborative policy development mechanisms.

A common thread throughout these activities was vague and imprecise language. Though a problem throughout the data set, this style was particularly prominent in Dialogue mode, where categorization would often rely on a single word. Thus an activity reading "Conduct a public discussion about the financial statements of all companies of special state interest" would be categorized as the Dialogue mode by virtue of the "public discussion," with very little clarity about how that discussion would be implemented or the degree of interactivity it would entail.

Questions surrounding the quality of activities in this mode will be explored below. For now it can simply be noted that though Dialogue made a significant showing in the data, there are reasons to doubt how interactive these activities are actually intended to be. 
Lastly, it's worth noting that several activities in this data set (90 of 244) described activities that might lead to interaction in the future. Reviews of institutional guidelines for policy consultation processes, evaluations of FOIA legislation and task forces to consider transparency regulations all fit this bill. Like first order interactions, publishing information was the most common mode of secondary interactions ( $40 \%$ compared to $21.1 \%$ ). Unlike first order interactions, the Dialogue mode was not significantly represented, though a significant number of second order interactions (39) were coded as unclear, due to ambiguous descriptions of future activities.

Table 4: Cross tabulation of first and second order interaction

\begin{tabular}{|c|c|c|c|c|c|c|c|}
\hline & & \multicolumn{5}{|c|}{ Second Order Interaction } & \multirow{2}{*}{$\mathrm{tal}^{\mathrm{To}}$} \\
\hline & & $\mathrm{b}^{\prime} \mathrm{Pu}$ & $\begin{array}{l}\text { Rece } \\
\text { ive }\end{array}$ & $\begin{array}{l}\mathrm{Re} \\
\text { act }\end{array}$ & $\begin{array}{l}\text { Dialo } \\
\text { gue }\end{array}$ & $\begin{array}{l}\text { n- } \\
\text { clear }\end{array}$ & \\
\hline \multirow{6}{*}{$\begin{array}{l}\quad \text { Modes } \\
\text { of } \\
\text { Interaction }\end{array}$} & $\begin{array}{l}\text { No } \\
\text { Interaction }\end{array}$ & 35 & 6 & 2 & 1 & 29 & 73 \\
\hline & Publish & 0 & 0 & 0 & 0 & 3 & 3 \\
\hline & Receive & 1 & 1 & 0 & 0 & 1 & 3 \\
\hline & Respond & 1 & 0 & 0 & 0 & 0 & 1 \\
\hline & Dialogue & 3 & 1 & 0 & 0 & 3 & 7 \\
\hline & Unclear & 0 & 0 & 0 & 0 & 3 & 3 \\
\hline \multicolumn{2}{|l|}{ Total } & 40 & 8 & 2 & 1 & 39 & 90 \\
\hline
\end{tabular}

As shown in Table 4, the majority of second order interactions (73 of 90) occurred in activities that did not directly anticipate civic interaction. There are at least two ways to read this. One might argue that when activities were not interactive, governments are at least laying the early groundwork for future civic interaction. It is early days after all, and the majority of government commitments in this data set are drawn from countries' first or second national action plans. Another way to read this data is that $81.1 \%$ of the activities through which governments prepare to initiate civic interaction, those activities did not themselves anticipate a role for citizen voice. It does not appear that governments are consulting on how to consult.

\subsection{Technology and civic interaction}

Of the 422 activities categorized with a mode of civic interaction in this data set, only a minority $(24.9 \%)$ explicitly relied on the use of technology. It is impossible to draw immediate conclusions from this. Not relying on technology for civic engagement may well reflect government restraint that is entirely appropriate in the context of civic inclusion and representation. It is, however, surprising, given the prominence of technology in open government rhetoric. 
Table 5: Technology Dependency by Mode of Interaction

\begin{tabular}{|c|l|l|l|l|}
\hline \multicolumn{2}{|c|}{} & None & $\begin{array}{l}\text { Explicit } \\
\text { dependence }\end{array}$ & $\begin{array}{l}\text { Explicit } \\
\text { (Percent) }\end{array}$ \\
\hline $\begin{array}{l}\text { Modes of } \\
\text { Interaction }\end{array}$ & Publish & 36 & 53 & 59,6 \\
\cline { 2 - 5 } & Enable & 3 & 4 & 57,1 \\
\cline { 2 - 5 } & Receive & 23 & 28 & 54,9 \\
\cline { 2 - 5 } & React & 0 & 3 & 100,0 \\
\cline { 2 - 5 } & Respond & 2 & 5 & 71,4 \\
\cline { 2 - 5 } & Dialogue & 45 & 10 & 18,2 \\
\cline { 2 - 5 } & Unclear & 14 & 2 & 12,5 \\
\hline Total & 317 & 105 & 24,9 \\
\hline
\end{tabular}

As shown in Table 5, reliance on technology was most common in interactive modes of Publish and Receive, as anticipated by literature on open government and e-participation. Activities in the mode of Dialogue were least likely to rely on the use of technology. This might be due to the vague language in which more interactive commitments were framed, or it might reflect a lack of nuance in the way that technology is expected to facilitate dialogue in a political context.

\subsection{Quality of Civic Interaction in OGP Commitments}

\subsubsection{Communication Metrics}

The framework for this analysis proposed participant control and message dependency as two communication metrics by which to assess the quality of civic interaction and the degree to which it is meaningful in an accountability context. It was proposed that these variables could function independently, which makes a certain intuitive sense. It's easy to imagine a conversation that is responsive but where one participant sets the rules, or a conversation where both parties have control of the timing and content of their discussion, but one party simply refuses to respond. In everyday discourse about how people interact, such dynamics might be more reminiscent of an abusive relationship than a healthy partnership. The type of healthy relationship we would like to analogize to progressive open government and civic interaction would seem to imply both equal controls of communication and dialogue that follows a logical substantive progression, predictable and free of non-sequiturs. Positive scores for both participant control and message dependency represent higher quality civic interaction than a positive score for one of the metrics alone.

Quality metrics did not clearly demonstrate a strong relationship within the data set, however. Though samples size prevented the use of Pearson Chi-Square to test for independence $(41,7 \%$ of cells demonstrated an expected count of less than 5), 76\% of activities demonstrating explicit message dependency did not demonstrate or suggest participant control, and $53 \%$ of those that demonstrated explicit participant control did not demonstrate or suggest message dependency. Re-tabulating quality variables only for those activities which were categorized as a mode of civic interaction (228) demonstrates some striking frequencies however (Table 6). The most frequent instances are seen when the two quality variables co-occur in the same activity, either by their mutual absence (120) or by their mutual implication through suggestive but unclear language (54). 
Table 6: Cross tabulation of Suggested and Explicit Communication Metrics

\begin{tabular}{|c|c|c|c|c|c|}
\hline & & \multicolumn{3}{|c|}{ Participant control } & \multirow[t]{2}{*}{ Total } \\
\hline & & None & $\begin{array}{l}\text { Suggestive } \\
\text { language }\end{array}$ & Explicit & \\
\hline \multirow{3}{*}{$\begin{array}{l}\text { Message } \\
\text { dependency }\end{array}$} & None & 120 & 1 & 9 & 130 \\
\hline & Suggestive language & 0 & 54 & 3 & 57 \\
\hline & 1 Explicit & 41 & 5 & 5 & 41 \\
\hline \multicolumn{2}{|l|}{ Total } & 151 & 60 & 17 & 228 \\
\hline
\end{tabular}

Quality variables were coded with liberal thresholds, participant control scoring positively when non-governmental control over either content or timing was explicit, and message dependency in the case of a single degree. The vague language employed by government OGP commitments nevertheless made it difficult to code for these variables, and a value was introduced for suggestive language. This value was applied when government commitments described a synchronous interaction whereby basic social mores would dictate some degree of message dependency and participant control. Thus when activities described conversations in person or in online chats, or when they used descriptive words such as "collaborate" or "partner with," they were coded for suggestive language on the two quality metrics.

These codes were assigned to a minority of activities (26\% with participant control and 25\% with message dependency), which appeared primarily together. Only 1 activity in this data set received a suggestive language code for one of the quality variables, but not for the other. More notably, suggestive language clusters profoundly around the Dialogue mode, as shown in Table 7.

Table 7: Suggestive Language Frequencies by Mode of Interaction

\begin{tabular}{|l|l|l|l|}
\hline \multirow{7}{*}{} & & $\begin{array}{l}\text { Participant } \\
\text { Control }= \\
\text { Suggestive } \\
\text { Language }\end{array}$ & $\begin{array}{l}\text { Message } \\
\text { Dependency }= \\
\text { Suggestive } \\
\text { Language }\end{array}$ \\
\hline \multirow{4}{*}{$\begin{array}{l}\text { Interactive } \\
\text { mode }\end{array}$} & Publish & 0 & 0 \\
\cline { 2 - 4 } & Enable & 1 & 1 \\
\cline { 2 - 4 } & Receive & 4 & 0 \\
\cline { 2 - 4 } & React & 0 & 1 \\
\cline { 2 - 4 } & Respond & 0 & 0 \\
\cline { 2 - 4 } & Dialogue & 52 & 53 \\
\cline { 2 - 4 } & Unclear & 3 & 2 \\
\hline Total & 60 &
\end{tabular}

The frequency of suggestive language highlights a significant limitation of the OGP commitment data set. More importantly, it emphasizes a significant shortcoming in how governments are articulating open government commitments. Only 3 activities coded as Dialogue 
explicitly described participant control, only 2 explicitly described at least one degree of message dependency.

This lack of precision in the most interactive of open government commitments is inherently problematic. The coding structure underpinning this analysis has assumed that language suggesting live communication implies some degree of message dependency and participant control, because basic social mores dictate that when people speak face to face, they respond to what is said and both parties control the timing and content of conversation. This assumption supports an argument that governments will facilitate high quality interactions with citizens and civil society even when they don't explicitly plan them. This assumption might not be valid, however. As Loureiro et al (2016) note, governments can be quite good at receiving feedback and yet to do precisely what they have already determined they are going to do. Actual listening and concertive action might not follow directly from a government reference to "dialogue."

Suggestive values for the quality variables should thus be taken with a grain of salt. They are almost exclusively present in the OGP commitment data set by virtue of descriptive language. To what extent the interactions here described will actually exhibit participant control and message dependency will depend entirely on the nature of implementation, and by extension, on the power relationships and social norms governing citizen-state interaction more generally in each country context. Perhaps more importantly, the virtual absence of explicit participant control and message dependency in the OGP commitment data set suggests that, in general, commitments are not being articulated with an anticipation of high quality civic interaction.

\subsubsection{Contextual variables}

Three contextual variables were identified to further consider the quality of specific modes of civic interaction. For Publishing activities, the importance of intermediaries to actualize the accountability potential of public information is widely recognized, and by this logic, one might expect that government commitments to open and publish data would facilitate civic interaction by targeting intermediaries. It is impossible to determine to what extent this actually occurs on the basis of this data set, but such dynamics are not anticipated by government commitments.

Only one of the 89 publishing activities in this data explicitly targeted civil society or business organizations in the language of their OGP commitment. The overwhelming majority simply describe publishing or releasing information to "the public." This might imply a lack of awareness regarding the roles of intermediaries in creating ecosystems of open government data and accountability, or even that a kind of magical thinking persists in many governments, whereby the opening and publishing of government data is expected to lead automatically into improved governance outcomes. This is speculative. What can be said with certainty is that governments are not framing their OGP commitments to open data within the broadly recognized conceptual frameworks of open data and accountability articulated in OGP policy documents (Frey, 2014). The most frequent mode of interactivity in this data set of government activities is best conceptualized as the unilateral broadcast of information without any follow up, and is not particularly interactive. 
The use of technology in civic voice activities is expected to convey a number of advantages in terms of scale and access. While the adoption of web platforms, mobile phones and crowdsourcing methodologies were common in OGP commitments with a civic voice component, these activities scored poorly on quality metrics. Reception activities dependent on technology were less likely to imply any degree of message dependency and only one explicitly implied any degree of participant control. In the entire set of 422 activities, only three activities described efforts to combine online and offline interaction, all of which were consultative processes (formal consultation processes in Mongolia, South Korea and USA).

For activities anticipating the expression and reception of civic voice, the public visibility of civic voice and the combination of online/offline tactics were both identified as important contextual indicators. The overwhelming majority of activities described in governments' OGP commitments did not describe the public visibility of citizen voice. In many instances of online and offline consultations, citizen feedback might be visible to other participants in consultations, and 6 activities described online platforms for e-petitions of competitions where citizen inputs would likely be visible to the general public. Explicit intentions were much less common, however. Two activities described web platforms which would allow for public commenting on policy, and two activities described explicit policies to publish citizen feedback.

In a data set of over two thousand government commitments, 422 of which are expected to be relevant to civic interaction, four examples of governments intending to endow citizen voice with the "teeth" of public visibility might be disheartening to the advocate of government accountability. One might also argue that this is least surprising finding of the current analysis. Recalling the truism that accountability is all about power, and that powerful actors rarely surrender their power voluntarily, it is not surprising to find few examples of "teeth" in voluntary commitments by governments.

\section{Conclusions and Potential for Further Research}

This article bears a facetious title. It asks who is talking in OGP commitments, with the conviction that talk matters, and the degree to which that talk is reciprocal and sustained matters a great deal in the context of responsive and accountable governance. The 422 English language 2011-2014 OGP commitment activities deemed most relevant to civic interaction were assessed, and the vast majority described government actors either talking amongst themselves or broadcasting information unilaterally into the public sphere, without specific mechanisms to facilitate any kind of response or further interaction. The answer to the question, put bluntly, seems to be that it is mostly governments doing the talking.

This finding reinforces concerns regarding the dominance and ambiguity of data publication in the open government agenda (Schwegmann, 2013; Yu and Robinson, 2012), and that government participation in OGP has not led to specific plans for interacting with civil society and citizens 
outside of action plan consultations. The findings further emphasize that OGP commitments consistently fail to anticipate the mechanisms by which less interactive activities are expected to lead to accountable and responsive governance, such as the mobilization of open data intermediaries, (Davies and Bawa, 2012; Sorrentino and Niehaves, 2010; Van Schalkwyk et al., 2015) the public visibility of citizen voice (Peixoto and Fox, 2016), or the combination of online and offline consultation mechanisms to solicit civic voice (de Zúñiga, Veenstra, Vraga, \& Shah, 2010; Francoli et al., 2015: 41; Montero \& Taxell, 2015: 33; UN E-government survey 2016: E-Government in Support of Sustainable Development, 2016: 70).

The omission of such programmatic details might suggest that the authors of government commitments are either not familiar with, or not committed to, such progressive mechanisms. More concerning is the overly broad and imprecise language through which commitments are formulated. This type of language made it difficult to assess the quality of civic interaction for many activities, particularly those that were coded as representing the most interactive mode of Dialogue. The dominance of low-hanging buzzwords such as consultation and collaborative forums, without explicit descriptions of how such processes would function, should give open government enthusiasts pause. Studies demonstrating the powerful influence that institutional context exercises on open government agendas (Goëta and Davies, 2016; Janssen et al., 2012; Kornberger et al., 2017) would suggest that activities without specific programmatic detail are likely to revert to the status quo of national political contexts. While this will vary infinitely across country contexts, the default status of civic engagement is rarely ideal (Francoli et al., 2015), and this finding suggests that as currently formulated, OGP action plans are doing little to advance government intentions in terms of civic interaction.

Equally important is the finding that the civic interaction activities described by OGP commitments do not explicitly allocate non-governmental actors control over either the content or process of civic interaction, nor do they expressly anticipate reciprocal and sustained interaction over time. The consistent negative scores for these two quality metrics raise questions about the degree to which planned activities will be interactive in more than name, and to the capacity of government actors to design and plan meaningful civic engagement. This is precisely the type of thing OGP is designed to facilitate.

These findings do not reflect on the actual practice of governments in the context of OGP, but only on governments' expressed intentions. Failing to motivate more ambitious government intentions matters, however, especially in the area of civic interaction, which is so central to the OGP mandate as both an outcome and an instrument. This analysis suggests that outside formal OGP consultation processes, and at least in the early iterations of OGP action plans, the international partnership has not produced significant government intentions towards civic interaction and civic voice.

These findings should reinvigorate a discussion about the relative merits of voluntary mechanisms for improving governance within countries. The dominance of non-interaction, oneway communication and wooly rhetoric in the OGP commitments most relevant to interaction should also reinvigorate concerns about the inherent conceptual ambiguity of open government, 
and how easily it lends itself to open washing. As the editors of a recent special issue on opening governance noted:

"The ambiguity around the 'open' in governance today might be helpful in that its very breadth brings into the fold actors who would otherwise be unlikely adherents, and they end up committing themselves beyond what they initially envisaged. But if the fuzzier idea of 'open government' or the low-hanging allure of 'open data' displace the Herculean task of clear transparency, hard accountability (Fox 2007) and fairer distribution of power as what this is all about, then what started as an inspired movement of governance visionaries may end up merely putting a more open face on an unjust and unaccountable status quo"(McGee E Edwards, 2016: 18).

This analysis also posed a number of methodological implications for the study and evaluation of civic interaction and open government. To the extent that civic interaction is accepted as desirable policy outcome, the framework hopes to make a significant contribution. The six modes of interactivity and two metrics for communication quality offer a much higher degree of precision than frameworks commonly applied to open government participation and consultation, such as the IAP2 spectrum currently in use by the OGP IRM (Francoli et al., 2015: 63-68). They also avoid the conflation of civic interaction with technological sophistication that is common in eparticipation frameworks (Grönlund, 2009). Perhaps most importantly, the plain language categories of this framework lend themselves to policy advocacy in a way that frameworks like the participatory cube do not. It is in many respects easier to tell a government that it is reacting when it should be responding, than it is to present a radar chart. ${ }^{5}$ While the quality metrics of message dependency and participant control proved challenging to apply to the OGP commitment data set, they should be clear and easily employed in contexts with more data, are directly relevant to open government policy development, and likely useful to assess the quality of OGP consultations.

Lastly, it is important to acknowledge a number of limitations accompanying this analysis. By their very nature, government commitments are a limited data source. They represent institutional intentions at best and the arbitrary formulations of individuals at worst. The tendency towards diffuse language frustrates clear analysis, and invites criticism that such an analysis does not engage enough with actual policy or program implementation. Empirical research on actual government outcomes would inevitably add significant value to the current analysis, but at base, this assessment of OGP commitments is useful for the remarkable room for improvement it demonstrates. Secondly, this analysis has considered the corpus of OGP commitments from 20112014 as a whole, and has not distinguished between the 61 countries in references, or the institutional and cultural contexts in which commitments were produced. Doing so might provide useful insights into the conditions that facilitate government intentions towards civic interaction. Lastly, it must be noted that the OGP is still in early days. Anecdotal evidence suggests that countries' OGP action plans are improving with subsequent iterations, and the commitment data deployed here is time stamped by nearly half a decade. This limitation should motivate assessment

\footnotetext{
${ }^{5}$ Several evaluation frameworks including the participatory cube and the civic society index use Radar Charts to demonstrate results. These graphs present scores for individual indicators along "spokes" extending from a common hub, and lines connecting them in what resembles a spider web.
} 
of contemporary commitments in individual countries, and inform strategic thinking about how to frame new membership in voluntary initiatives such as the OGP.

\section{References}

Al-Sobhi F, Weerakkody V and Kamal MM (2010) An exploratory study on the role of intermediaries in delivering public services in Madinah City: Case of Saudi Arabia. Transforming Government: People, Process and Policy 4(1): 14-36. Available from: http://dx.doi.org/10.1108/17506161011028786.

Arias R, Gomez S, Rivera TP, et al. (2016) Opening Government?: the Case of Costa Rica in the Open Government Partnership. Available from: http://www.transparency-initiative.org/reports/openinggovernment.

Arnstein SR (1969) A Ladder Of Citizen Participation. Journal of the American Institute of Planners 35(4): 216-224. Available from: http://www.tandfonline.com/doi/abs/10.1080/01944366908977225.

Bahl A (2012) So What's In Those OGP Action Plans, Anyway? Global Integrity Blog. Available from: http://www.globalintegrity.org/2012/07/whats-in-ogp-action-plans/ (accessed 4 April 2017).

Cañares MP (2016) Enhancing Citizen Engagement with Open Government Data : The Case of Local Governments in the Philippines. Journal of Community Informatics' 12 (2 (Special issue on Open Data for Social Change and Sustainable Development)): 69-98.

Davies T (2010) Open data, democracy and public sector. Interface: 1-47. Available from: http://practicalparticipation.co.uk/odi/report/wp-content/uploads/2010/08/How-is-open-governmentdata-being-used-in-practice.pdf.

Davies T and Bawa ZA (2012) The Promises and Perils of Open Government Data (OGD) _ Davies _ The Journal of Community Informatics. Journal of Community Informatics 8(2).

de Zuniga HG, Copeland L and Bimber B (2014) Political consumerism: Civic engagement and the social media connection. New Media \& Society 16(3): 488-506. Available from: http://nms.sagepub.com/cgi/doi/10.1177/1461444813487960.

de Zúñiga HG, Veenstra A, Vraga E, et al. (2010) Digital Democracy: Reimagining Pathways to Political Participation. Journal of Information Technology \& Politics 7(1): 36-51. Available from: 10.1080/19331680903316742\%5Cnhttp:/ / zuezproxy.zulib.de/login?url=http:/ / search.ebscohost.com/login. aspx?direct=true\&AuthType $=\mathrm{ip}$, cookie, $\mathrm{uid} \& \mathrm{db}=$ poh\&AN=47906551\&lang=de\&site=eds-live.

Downes EJ and McMillan SJ (2016) Defining Interactivity: a qualitative identification of key dimensions. New Media \& Society 2(2): 157-179. Available from: http://nms.sagepub.com/cgi/doi/10.1177/14614440022225751 (accessed 19 September 2016).

Ferber P (2005) The Internet and Public Participation: State Legislature Web Sites and the Many Definitions of Interactivity. Bulletin of Science, Technology \& Society 25(1): 85-93.

Ferber P, Foltz F and Pugliese R (2007) Cyberdemocracy and Online Politics: A New Model of Interactivity. Bulletin of Science, Technology \& Society 27(5): 391-400. Available from: http://bst.sagepub.com/cgi/content/abstract/27/5/391. 
Francoli M and Clarke A (2014) What's in a name? A comparison of 'open government' definitions across seven Open Government Partnership members. JeDEM - eJournal of eDemocracy and Open Government 6(3): 248-266. Available from: http://www.jedem.org/article/view/227.

Francoli M, Ostling A and Steibel F (2015) From Informing to Empowering: Best Practices and Recommendations for Improving Government Civil Society Interactions within OGP. Available from: http://www.opengovpartnership.org/sites/default/files/FromInformingToEmpowering_FullReport.pdf.

Freelon DG (2010) ReCal : Intercoder Reliability Calculation as a Web Service. International Journal of Internet Science 5(1): 20-33.

Frey L (2014) Open Government Partnership: Four Year Strategy 2015-2018.

Gigler B-S and Bialur S (2014) Closing the Feedback Loop: Can Technolog Bridget the Accountability Gap? the World Bank.

Goëta S and Davies T (2016) The daily shaping of state transparency: Standards, machine-readability and the configuration of open government data policies. Science and Technology Studies 29(4): 10-30.

Government Point of Contact Manual (2016). Available from:

http://www.opengovpartnership.org/sites/default/files/ogp_2016_poc_manual.pdf.

Grönlund Å (2009) ICT Is Not Participation Is Not Democracy - eParticipation Development Models Revisited. In: Macintosh A and Tambouris E (eds), Electronic Participation First International Conference, ePart 2009 Linz, Austria, September 1-3, 2009 Proceedings, Lecture Notes in Computer Science, pp. 12-23. Available from: http://www.ulb.tu-darmstadt.de/tocs/59142804.pdf.

Guerzovich F and Moses M (2016) Learning How to Open Government: Findings and reflections on how the Open Government.

Hacker KL (1996) Missing links in the evolution of electronic democratization. Media, Culture \& Society 18(2): 213-232. Available from: http://mcs.sagepub.com/cgi/doi/10.1177/016344396018002003 (accessed 19 September 2016).

Janssen M and Helbig N (2015) Innovating and changing the policy-cycle: Policy-makers be prepared! Government Information Quarterly, Elsevier Inc.: 7-13. Available from: http://dx.doi.org/10.1016/j.giq.2015.11.009.

Janssen M, Charalabidis Y and Zuiderwijk A (2012) Benefits, Adoption Barriers and Myths of Open Data and Open Government. Information Systems Management 29(4): 258-268.

Johnston EW (2015) Conceptualizing Policy Informatics. In: Johnston EW (ed.), Governance in the Inofrmation Era: theory and practice of policy informatics, New York: Routledge, pp. 3-22.

Kiousis S (2002) Interactivity: a concept explication. New Media \& Society 4(3): 355-383.

Kornberger M, Meyer RE and Höllerer MA (2017) When Bureaucracy Meets the Crowd : Studying ' Open Government ' in the Vienna City Administration. Organization Studies: 1-22.

Kosack S and Fung A (2014) Does Transparency Improve Governance? Annual Review of Political Science 17(1): 65-87. Available from: http://www.annualreviews.org/doi/abs/10.1146/annurev-polisci032210-144356. 
Krippendorff K (2004) Reliability in Content Analysis Some Common Misconceptions and Recommendations. Human Communication Research 30(3): 411-433.

Leicht N, Durward D, Haas P, et al. (2016) An Empirical Taxonomy of Crowdsourcing Intermediaries t A nn ua $1 \mathrm{M}$ tin. In: 2016 Academy of Mamagement Meeting.

Liden G (2016) Inequality in Local Digital Politics : How Different Preconditions for Citizen Engagement Can Be Explained. Policy \& Internet $\mathrm{n} / \mathrm{a}(\mathrm{n} / \mathrm{a})$.

Linders D, Wilson S and Bertot JC (2013) Open Government as a Vehicle for Government Transformation. 1st ed. In: Weerakkod V and Reddick CG (eds), Public Sector Transformation through E-Government: Experiences from Europe and North America, London: Routledge.

Liu HK (2016) Exploring Online Engagement in Public Policy Consultation: The Crowd or the Few? Australian Journal of Public Administration 0(0): 1-15. Available from: http://doi.wiley.com/10.1111/14678500.12209.

Loureiro M, Cassim A, Darko T, et al. (2016) When does the state listen? IDS Bulletin 47(1): 55-68.

Lucke J von and Große K (2014) Open Government Collaboration. In: Gascó-Hernández M (ed.), Opportunities and Challenges for Public Governance, New York: Springer, pp. 189-204.

McGee R and Edwards D (2016) Opening Governance. IDS Bulletin Continuity and Conceptual AmbiguityOpening Governance' IDS Bulletin 47(1): 1-22.

McMillan SJ (2002) A four-part model of cyber-interactivity: Some cyber-places are more interactive than others. New Media \& Society 4(2): 271-291. Available from:

http://nms.sagepub.com/cgi/doi/10.1177/14614440222226370.

Medaglia R (2012) eParticipation research: Moving characterization forward (2006-2011). Government Information Quarterly, Elsevier Inc. 29(3): 346-360. Available from:

http://dx.doi.org/10.1016/j.giq.2012.02.010.

Meng A (2014) Investigating the Roots of Open Data' s Social Impact. JeDEM - eJournal of eDemocracy and Open Government 6(1): 1-13.

Montero AG (2015) Open government and transparency reform in Chile: Balancing leadership, ambition and implementation capacity. U4 Report. Available from: http://www.u4.no/publications/opengovernment-and-transparency-reform-in-chile-balancing-leadership-ambition-and-implementationcapacity/\#sthash.TfaKklD0.dpuf.

Montero AG and Taxell N (2015) Open government reforms The challenge of making public consultations meaningful in Croatia. U4 Report. Available from: http://www.u4.no/publications/opengovernment-reforms-the-challenge-of-making-public-consultations-meaningful-in-croatia/.

Mossberger K and Tolbert CJ (2010) Digital Democracy: How Politics Online is Changing Electoral Participation. The Oxford Handbook of American Elections and Political Behavior (November): 1-22.

Norris P (2003) Preaching to the Converted?: Pluralism, Participation and Party Websites. Party Politics 9(1): 21-45. 
Noveck BS (2009) Wiki government : how technology can make government better, democracy stronger, and citizens more powerful. Brookings Institution Press. Available from: https:/ / books.google.no/books?hl=no\&lr=\&id=bmSmcDo3kPoC\&oi=fnd\&pg=PP1\&dq=wiki+government +noveck\&ots=lxxoZV_KOo\&sig=hiLPTFNNDyTowKr-RnyjO8rZVAo\&redir_esc $=y \# v=$ onepage\&q=wiki government noveck\&f=false (accessed 3 April 2017).

OGP IRM Data Guide v 2.5 (2015) Open Government Partnership Independent Review Mechanisms. Available from: https://docs.google.com/document/d/10bRRkjyRXG0u8HjUQkwBL6Zo79VHVfBKMXSZCllqoDA/edit.

Peixoto T and Fox J (2016) When Does ICT-Enabled Citizen Voice Lead to Government Responsiveness? 2016 World Development Report Background Paper, Washington DC. Available from: https://openknowledge.worldbank.org/handle/10986/23650 License: CC BY 3.0 IGO.?

Peixoto T, Fall M and Sjoberg F (2016) Evaluating Digital Citizen Engagement: A Practical Guide. Available from: http://hdl.handle.net/10986/23752.

Reggi L and Dawes S (2016) Open Government Data Ecosystems: Linking Transparency for Innovation with Transparency for Participation and Accountability. In: Scholl JH, Glassey O, Janssen M, et al. (eds), Electronic Government: 15th IFIP WG 8.5 International Conference, EGOV 2016, Guimarães, Portugal, September 5-8, 2016, Proceedings, Cham: Springer International Publishing, pp. 74-86. Available from: http://dx.doi.org/10.1007/978-3-319-44421-5_6.

Schwegmann C (2013) Open Data in Developing Countries European Public Sector Information Platform Open Data in Developing Countries. Available from:

https://www.europeandataportal.eu/sites/default/files/library/201302_open_data_in_developing_countr ies.pdf (accessed 23 March 2017).

Sorrentino M and Niehaves B (2010) Intermediaries in E-inclusion: A literature review. Proceedings of the Annual Hawaii International Conference on System Sciences: 1-10.

Stromer-Galley J (2000) On-line interaction and why candidates avoid it. Journal of Communication 50(4): 111-132. Available from: http://doi.wiley.com/10.1111/j.1460-2466.2000.tb02865.x.

Sørensen E (2016) Political innovations: innovations in political institutions, processes and outputs. Public Management Review 9037(August): 1-19. Available from:

http://www.tandfonline.com/doi/full/10.1080/14719037.2016.1200661.

UN E-government survey 2016: E-Government in Support of Sustainable Development (2016). Available from: http://workspace.unpan.org/sites/Internet/Documents/UNPAN96407.pdf.

Vaismoradi M, Turunen H and Bondas T (2013) Content analysis and thematic analysis: Implications for conducting a qualitative descriptive study. Nursing and Health Sciences 15(3): 398-405.

van Noort G, Vliegenthart R and Kruikemeier S (2016) Return on interactivity? The characteristics and effectiveness of Web sites during the 2010 Dutch local elections. Journal of Information Technology \& Politics, Routledge 0(0): 1-13. Available from: https://www.tandfonline.com/doi/full/10.1080/19331681.2016.1230921.

van Schalkwyk F, Willmers M and McNaughton M (2015) Viscous Open Data: The roles of intermediaries in an open data ecosystem. Journal of Information Technologies for Development 1102(Special Issue). 
Van Schalkwyk F, Caňares M, Chattapadhyay S, et al. (2015) Open Data Intermediaries in Developing Countries. Journal of Community Informatics 12(2 (Special Issue on Open Data for Social Change and Sustainable Development)): 9-25. Available from: www.steupconsultants.com.

Vigoda E (2002) From Responsiveness to Collaboration: Governance, Citizens, and the Next Generation of Public Administration. Public Administration Review 62(5): 527-540. Available from:

http:/ / search.ebscohost.com/login.aspx?direct=true\&db=bth\&AN=12862475\&site=ehost-live.

Welch EW and Fulla S (2005) Virtual Interactivity Between Government and Citizens: The Chicago Police Department's Citizen ICAM Application Demonstration Case. Political Communication 22(2): 215-236.

Whitt JP (2015) Civic Participation in Latin American Ogp Commitments.: 1-22. Available from: http://www.opengovpartnership.org/blog/j-preston-whitt/2015/03/04/new-irm-analysis-civicparticipation-commitments-latin-america.

Worthy B (2015) The impact of open data in the UK: Complex, unpredictable, and political. Public Administration 93(3): 788-805.

Yavuz N and Welch EW (2014) Factors affecting openness of local government websites: Examining the differences across planning, finance and police departments. Government Information Quarterly, Elsevier Inc. 31(4): 574-583. Available from: http://dx.doi.org/10.1016/j.giq.2014.07.004.

Yu H and Robinson DG (2012) The New Ambiguity of \&quot;Open Government\&quot; UCLA Law Review Discourse 59(2012): 178-208. Available from: http://www.uclalawreview.org/pdf/discourse/5911.pdf.

Zhou R, Su H, Wang X, et al. (2013) The Participatory Cube: A Framework for Analysis of Online Participation Platforms. In: Geertman S, Toppen F, and Stillwell J (eds), Planning Support Systems for Sustainable Urban Development, Berlin: Springer Berlin Heidelberg, pp. 395-414. Available from: http://link.springer.com/chapter/10.1007/978-3-642-37533-0_7/fulltext.html.

\section{About the Author}

\section{Christopher Wilson}

Christopher is a research fellow at the Institute for Media and Communication, University of Oslo, and Visiting Fellow at Georgetown University's Beeck Center for Policy Innovation and Social Impact. His research focuses on the institutional conditions that facilitate open government and digital civic interaction between institutions and publics. He previously co-founded The Engine Room (https://theengineroom.org), and provided support to civil society organizations in the UNDP and through the International Freedom of Expression network, IFEX. He currently advises advocacy organizations on research design and organizational growth on a pro bono basis, and blogs about methodological issues related to civic technology research at https: / / methodicalsnark.org. 